\title{
Modelagem matemática e simulação numérica do transporte de metano em reservatórios de hidrelétricas
}

\author{
Eliandro Rodrigues Cirilo
}




\title{
Modelagem matemática e simulação numérica do transporte de metano em reservatórios de hidrelétricas
}

\author{
Eliandro Rodrigues Cirilo
}

Orientador: Prof. Dr. Antonio Castelo Filho

Tese apresentada ao Instituto de Ciências Matemáticas e de Computação - ICMC-USP, como parte dos requisitos para obtenção do título de Doutor em Ciências - Ciências de Computação e Matemática Computacional. VERSÃO REVISADA. 
Ficha catalográfica elaborada pela Biblioteca Prof. Achille Bassi e Seção Técnica de Informática, ICMC/USP, com os dados fornecidos pelo(a) autor(a)

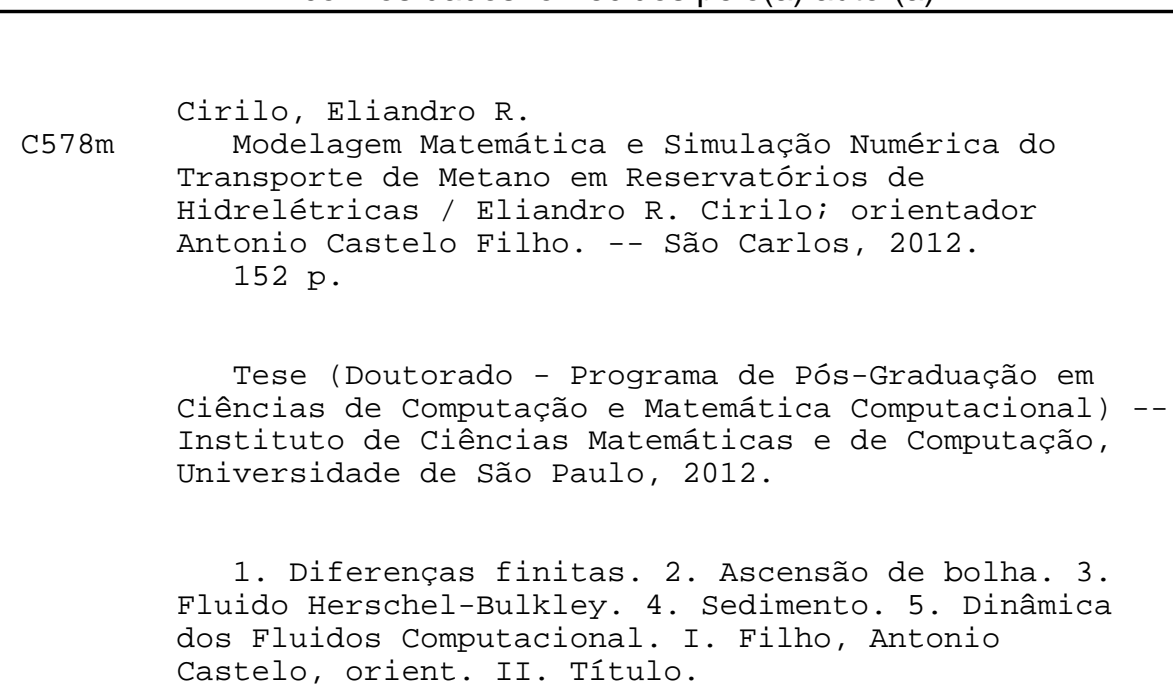

1. Diferenças finitas. 2. Ascensão de bolha. 3. Fluido Herschel-Bulkley. 4. Sedimento. 5. Dinâmica dos Fluidos Computacional. I. Filho, Antonio Castelo, orient. II. Título. 
"Se, porém, algum de vós necessita de sabedoria, peça-a a Deus, que a todos dá liberalmente e nada lhes impropera; e ser-lhe-a concedida."

Bíblia Sagrada - Tiago 1:5

Em fim depois de muita transpiração e alguma inspiração, dedico este trabalho às pessoas mais importantes e que mais amo na vida,

à minha família. 
Meu sincero agradecimento:

- primeiramente a Deus por me fazer acreditar neste projeto de doutoramento e dar força para desenvolvê-lo;

- aos meus pais que direcionaram, apoiaram e incentivaram os meus estudos;

- a minha esposa Marcia B. Oliveira, que enxergou o mesmo que eu enxerguei, acreditou no que acreditei e me auxiliou em todos os momentos;

- aos meus filhos que souberam me compreender nas muitas ausências ocorridas e aos meus irmãos que supriram-me em algumas das ausências;

- a Universidade Estadual de Londrina - departamento de Matemática, por aprovar e permitir a minha saída para capacitação;

- aos meus grandes amigos e colegas de trabalho Dr. Paulo Natti e Dra. Neyva M. L. Romeiro por auxiliar no desenvolvimento de doutoramento;

- a Universidade de São Paulo, São Carlos - Instituto de Ciências Matemáticas e de Computação - Programa de Ciências de Computação e Matemática Computacional, por acolher e permitir a execução do trabalho de tese;

- ao meu grande amigo e orientador, Dr. Antonio Castelo Filho por sua valorosa sabedoria e paciência no direcionamento do meu trabalho;

- aos meus professores e amigos - Valdemir G. Ferreira, Sergio R. Fontes, Gustavo C. Buscaglia, Leandro F. de Souza pela disponibilidade nos ensinamentos;

- aos doutores Irineu Bianchini Jr e Rosario E. S. Bretas, da Universidade Federal de São Carlos, por permitirem que os resultados experimentais do trabalho de tese pudessem ser obtidos;

- aos meus amigos do lcad que sempre estiveram a meu lado auxiliando quando possível, em particular meu agradecimento ao Alysson A. Naves Silva e a Giseli A. B. Lima;

- ao meu amigo Leonardo Martinussi que sempre foi prestativo em solucionar algumas dificuldades da área computacional;

- a banca examinadora constituída pelos doutores: Murilo F. Tomé, Irineu B. Jr, Norberto Mangiavacchi e Gilmar M. M. da Cruz, que lapdaram com suas sugestões o trabalho de tese;

- ao CNPq que financiou uma grande parte deste projeto. 


\title{
Resumo
}

É notório que a degradação ambiental vem ao longo do tempo posicionando-se como um dos principais problemas do mundo moderno. Dentre as várias questões do interesse ambiental podemos destacar a ascensão da bolha de metano, em reservatórios hidrelétricos, desde o sedimento anóxico no fundo do reservatório até a interface água atmosfera. Neste contexto, a presente tese vêm propor uma nova modelagem matemática para a ascensão da bolha axissimétrica em fluidos newtonianos/nãonewtonianos e mostrar resultados numéricos simulados. Desta forma, o estado da arte estaria elevado a posição de permitir, via Matemática e Simulação Numérica-Computacional, a análise do transporte de metano em reservatórios de hidrelétricas através da bolha.

Palavras chave: Diferenças Finitas, Ascensão de Bolha, Fluido Herschel-Bulkley, Sedimento, Dinâmica dos Fluidos Computacional.

\begin{abstract}
It is well-known that environmental degradation has come along the time positioning as one of the main problems from modern world. Among several questions of the environmental interest may emphasize the methane bubble rise in hydroelectric reservoirs from the anoxic sediment in the bottom of reservoir until water interface atmosphere. In this context, the current thesis has come to propose a new mathematic modeling to the rise of the axisymmetric bubble in the newtonian/non-newtonian fluids and display numerical results simulated. Therefore, the state of art would be ascended to a position to permit, via Mathematics and Computing-Numeric Simulation, the analysis of transport of methane in hydroelectric reservoirs through of bubble.
\end{abstract}

Keywords: Finite Diference, Rise of the Bubble, Herschel-Bulkley Fluid, Sediment, Computational Fluid Dynamics. 


\section{Sumário}

1 Introdução 1

1.1 Considerações Iniciais $\ldots \ldots \ldots \ldots \ldots \ldots$

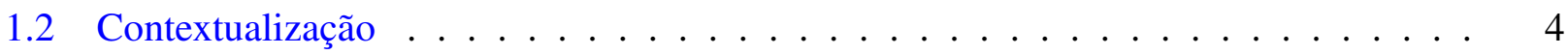

1.3 Organização da Tese . . . . . . . . . . . . . . . . 7

2 Problemática dos Reservatórios $\quad 8$

2.1 Demanda Energética . . . . . . . . . . . . . . . . . . 8

2.2 Características dos Lagos . . . . . . . . . . . . . . . . 13

2.3 Produção-Emissão de Metano em Sedimentos . . . . . . . . . . . . . . . . 15

3 Equações Governantes $\quad 24$

3.1 Conceitos Básicos . . . . . . . . . . . . . . . . . . . . . . . 24

3.2 Equações da Mecânica dos Fluidos . . . . . . . . . . . . . . . . . 31

3.3 Equações de Ascensão da Bolha . . . . . . . . . . . . . . . . . . 38

4 Equações Adicionais para o Fluido Sedimentar e Geometria da Bolha 41

4.1 Modelagem da Viscosidade Via Dados Experimentais . . . . . . . . . . . . . . . . 41

4.2 Modelagem Geométrica para Bolha em Ascensão . . . . . . . . . . . . . . . . 52

5 Modelo Matemático $\quad 59$

5.1 Formulação do Modelo Axissimétrico . . . . . . . . . . . . . . . . . 59

5.2 Condições Auxiliares . . . . . . . . . . . . . . . . . . . . 63

5.3 Adimensionalização . . . . . . . . . . . . . . . . . . . . . . 68 
6 Metodologia Numérica $\quad 71$

6.1 Método GENSMAC $\ldots \ldots \ldots \ldots \ldots \ldots$

6.2 Aproximações Numéricas . . . . . . . . . . . . . . . . . . . . . . 74

6.3 Atualizações Realizadas no FREEFLOW-AXI . . . . . . . . . . . . . . . . . . . . 84

7 Resultados Numéricos $\quad 87$

7.1 Validação . . . . . . . . . . . . . . . . . . . . . . . . 89

7.2 Aplicação em Reservatórios Hidráulicos ～. . . . . . . . . . . . . . . . . 120

8 Considerações Finais $\quad 129$

8.1 Conclusões . . . . . . . . . . . . . . . . . . . . . 129

8.2 Trabalhos Futuros . . . . . . . . . . . . . . . . . . . 131

$\begin{array}{ll}\text { Referências Bibliográficas } & 145\end{array}$

$\begin{array}{llr}\text { A Teoremas } & 146\end{array}$

B Reologia $\quad 147$ 


\section{Lista de Figuras}

2.1 Potencial tecnicamente aproveitável para a geração de energia hidrelétrica no mundo

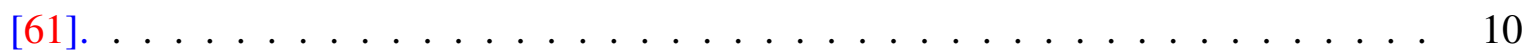

2.2 Evolução da concentração de usinas hidrelétricas no Brasil [61] . . . . . . . . . . . . 12

2.3 Formação e liberação de Metano e Gás Carbônico em reservatórios [122]. . . . . . 18

2.4 Caminhos da Emissão de Metano em Lagos [10]. . . . . . . . . . . . . . . . . . . . 21

2.5 Fluxo de $\mathrm{CH}_{4}$ em função da área dos lagos. (A) fluxo difusivo, (B) fluxo ebulitivo e (C) armazenamento na coluna d'água $[10] \ldots \ldots \ldots \ldots$. . . . . . . . . . 22

2.6 Contribuição dos tipos de Emissão de Metano em Lagos [10]. . . . . . . . . . . . . 23

3.1 Escoamento entre duas placas paralelas ilustrando a tensão de cisalhamento . . . . . 25

3.2 Ilustração da força atrativa de coesão . . . . . . . . . . . . . . . . . . . . 28

3.3 Configuração inicial da bolha $b_{1}=b_{2}=a \ldots \ldots \ldots$. . . . . . . . . 29

3.4 Ilustração das forças de Tensão agindo sobre as faces de um volume . . . . . . . . . 33

3.5 Fluxo total através das faces de um volume infinitesimal . . . . . . . . . . . . . 38

3.6 Esquema de configuração das forças atuantes sobre a bolha. . . . . . . . . . . . . 39

4.1 Localização da Estação Ecológica de Jataí (EEJ) (esquerda), ecossistemas aquáticos da estação (direita) [13]. . . . . . . . . . . . . . . . . . . . . . . . 42

4.2 Core vazio (esquerda), com sedimento (direita) . . . . . . . . . . . . . . 43

4.3 Lagoa do Óleo (esquerda) aparelho Core Sample Model Phleger acoplado ao core vazio (centro) e preenchido de sedimento (direita) . . . . . . . . . . . . . . . 43

4.4 Grupos de frascos A e B respectivamente (esquerda), mufla (centro) balança de precisão (direita) . . . . . . . . . . . . . . . . . . . . . . . . . . . 43 
4.5 Sedimento no core (esquerda), grupos A e B respectivamente (centro) e pesagem da amostra (direita). . . . . . . . . . . . . . . . . . . 44

4.6 Disposição e rotulação das amostras. Core II (esquerda) e core III (direita). . . . . 44

4.7 Reômetro Rheometric Scientific modelo ARES (esquerda) e conjunto de cilindros coaxiais Couette-Box (direita). . . . . . . . . . . . . . . . . . . 46

4.8 Dados medidos no reômetro Rheometric Scientific para as amostras do core II. . . . . 46

4.9 Dados medidos no reômetro Rheometric Scientific para as amostras do core III. . . 46

4.10 Gráficos das tensões $\dot{\gamma} \times \tau_{\lambda} \ldots \ldots \ldots$. . . . . . . . . . . . . 49

4.11 Gráfico da concentração em função das cotas. . . . . . . . . . . . . . . 50

4.12 Gráfico da lei geral para a tensão de cisalhamento. . . . . . . . . . . . . . 51

4.13 Velocidade terminal de bolha (na água) em função do diâmetro equivalente [29]. . . . 53

4.14 Forma variável com $a$ sendo o raio e $b_{1}, b_{2}$ os semi-eixos maior e menor [15]. . . . . 53

4.15 Mapa do formato de bolhas quando $\frac{\rho_{c}}{\rho_{d}}=1000$ e de viscosidade $\frac{\mu_{c}}{\mu_{d}}=100$ [54]. . . 54

4.16 Formatos: calota elipsoidal oblato (esquerda), calota esférica (centro) e com bordo de fuga cúspide (direita) [58] . . . . . . . . . . . . . . . . 55

4.17 Formatos: Formas para volume abaixo (esquerda) e acima (direita) do crítico [50]. . . 55

4.18 Geometrias de interesse. . . . . . . . . . . . . . . . . 56

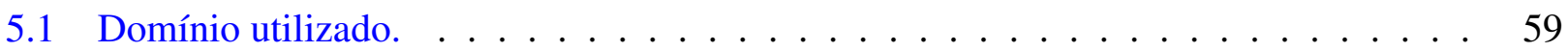

5.2 Configuração de celulas no domínio (esquerda) e localização da velocidade e pressão na célula (direita). . . . . . . . . . . . . . . . . . . . 63

5.3 Mudança de forma (esquerda) e esquema de cálculo da condição de contorno para a bolha (direita). . . . . . . . . . . . . . . . . . . . 66

6.1 Localização das variáveis (esquerda) e rótulos da célula (direita). . . . . . . . . . . . 74

6.2 Esquema SDPUS-C1 no ponto $A=(i+1 / 2, j)$ para $v_{i+1 / 2, j+1 / 2} \ldots \ldots \ldots$

6.3 Esquema SDPUS-C1 no ponto $A=(i+1 / 2, j)$ para $v_{i+1 / 2, j-1 / 2} \ldots \ldots \ldots 77$

6.4 Esquema SDPUS-C1 no ponto $A=(i, j)$ para $u_{i+1 / 2, j} \ldots \ldots \ldots \ldots$

6.5 Esquema SDPUS-C1 no ponto $A=(i, j)$ para $u_{i-1 / 2, j} \ldots \ldots \ldots \ldots$

6.6 Caso 1 para célula $(\mathbf{b}) \ldots \ldots \ldots \ldots \ldots \ldots \ldots$

6.7 Caso 2 para célula $(\mathbf{b}) . \ldots \ldots \ldots \ldots \ldots$. . . . . . . . . . . . . 82

6.8 Caso 3 para célula $(\mathbf{b}) . \ldots \ldots \ldots \ldots \ldots \ldots$. . . . . . . . . . . . . 82

6.9 Caso 4 para célula $(\mathbf{b}) . \ldots \ldots \ldots \ldots \ldots$. . . . . . . . . . . . . 82

6.10 Caso 5 para célula $(\mathbf{b}) . \ldots \ldots \ldots \ldots \ldots$ 
6.11 Caso 6 para célula $(\mathbf{b}) \ldots \ldots \ldots \ldots \ldots$

6.12 Caso 7 para célula $(\mathbf{b}) . \ldots \ldots \ldots \ldots \ldots$

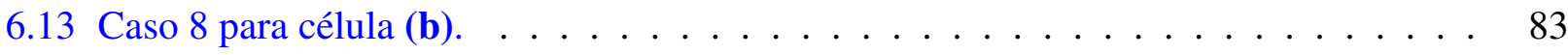

7.1 Forma de bolhas de ar ascendendo em água [30]. . . . . . . . . . . . . . . 88

7.2 Presença de bolhas no core. . . . . . . . . . . . . . . . . . 88

7.3 Resultados quanto a convergência para S-1 nas malhas $M_{1}: 45 \times 150, M_{2}: 60 \times 200$, $M_{3}: 90 \times 300$ e $M_{4}: 105 \times 350 \ldots \ldots \ldots \ldots \ldots$

7.4 Perfis de velocidade e posição do centro de massa da bolha para S-1, nas malhas $M_{1}: 45 \times 150, M_{2}: 60 \times 200, M_{3}: 90 \times 300$ e $M_{4}: 105 \times 350 \ldots \ldots \ldots 1$

7.5 Indicativo de convergência via velocidade terminal da bolha no tempo $t=0.1 \mathrm{~s} . \ldots 91$

7.6 Perfis de velocidade do centro de massa da bolha para S-1, nos domínios $R \stackrel{1}{\times} h$,

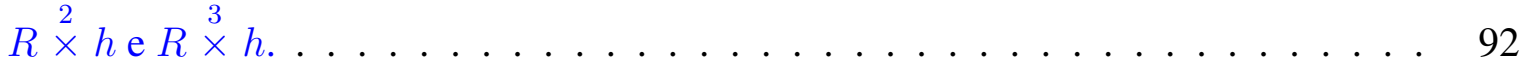

7.7 Número de Reynolds para bolhas nos casos S-1, S-2, S-3 e S-4 . . . . . . . . . . . . 93

7.8 Velocidade do centro de massa da bolha com $L=0.001 \mathrm{~m}$ (esquerda) e posição em função do tempo (direita). . . . . . . . . . . . . . . . . . . . . . . . . 94

7.9 Representação do campo de pressão no inicio da simulação. . . . . . . . . . . . 95

7.10 Representação das componentes $u$ (esquerda) e $v$ (direita) do vetor velocidade. . . . 96

7.11 Representação do campo de pressão (superior) e das componentes $u$ (esquerda-inferior) e $v$ (direita-inferior) do vetor velocidade no tempo $t=0.1 \mathrm{~s} . \ldots \ldots$. . . . . . 97

7.12 Evolução de $d t$ no caso da bolha esférica com $L=1.5$ milímetros de diâmetro. . . . 98

7.13 Velocidade do centro de massa da bolha com $L=1.5$ milímetros (esquerda) e Posição em função do tempo (direita) . . . . . . . . . . . . . . . . . . . . . . . . 99

7.14 Representação do campo de pressão (superior) e das componentes $u$ (esquerda-inferior) e $v$ (direita-inferior) do vetor velocidade no tempo $t=0.1 \mathrm{~s} \ldots \ldots \ldots$. . . . . 99

7.15 Velocidade do centro de massa para uma pequena bolha de nitrogênio na glicerina (esquerda) e posição em função do tempo (direita) . . . . . . . . . . . . . . . . 101

7.16 Número de Tadaki (esquerda) e razão de aspecto/fator de distorção (direita) calculados para uma pequena bolha de nitrogênio ascendendo em glicerina ${ }_{1}$

7.17 Evolução dos valores $b_{1}, b_{2}$ e $a$ para uma pequena bolha de nitrogênio ascendendo em

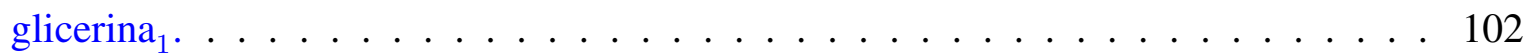

7.18 Representação das componentes $u$ (esquerda) e $v$ (direita) do vetor velocidade. . . . 105 
7.19 Representação do campo de pressão (superior) e das componentes $u$ (esquerda-inferior) e $v$ (direita-inferior) do vetor velocidade no tempo $t=0.45 \mathrm{~s} \ldots \ldots \ldots \ldots$

7.20 Visualização do nosso resultado (esquerda) e formato encontrado por Melo, F. R. G. [77] (direita), da forma final para uma pequena bolha de nitrogênio ascendendo em

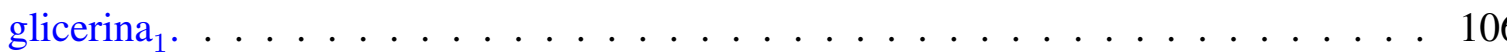

7.21 Velocidade do centro de massa para uma grande bolha de nitrogênio na glicerina ${ }_{1}$ (esquerda) e posição em função do tempo (direita) . . . . . . . . . . . . . . . . . . 107

7.22 Número de Tadaki (esquerda) e razão de aspecto/fator de distorção (direita) calculados para uma grande bolha de nitrogênio ascendendo em glicerina ${ }_{1}$.

7.23 Evolução dos valores $b_{1}, b_{2}$ e $a$ para uma grande bolha de nitrogênio ascendendo em

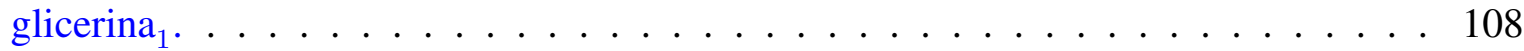

7.24 Representação das componentes $u$ (esquerda) e $v$ (direita) do vetor velocidade. . . . 111

7.25 Representação do campo de pressão (superior) e das componentes $u$ (esquerda-inferior) e $v$ (direita-inferior) do vetor velocidade no tempo $t=1.0 \mathrm{~s} \ldots \ldots \ldots \ldots \ldots$

7.26 Visualização do nosso resultado (esquerda) e formato encontrado por Melo, F. R. G. [77] (direita), da forma final para uma grande bolha de nitrogênio ascendendo em

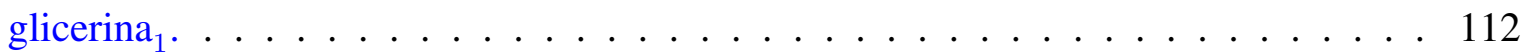

7.27 Core II com extensão. . . . . . . . . . . . . . . . . . . . . . . . . . 113

7.28 Campo de viscosidade. . . . . . . . . . . . . . . . . . . . . 114

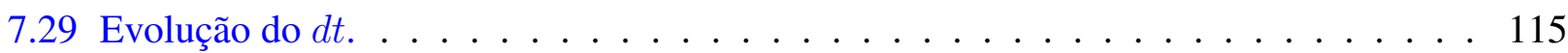

7.30 Velocidade do centro de massa para uma bolha de nitrogênio no sedimento (esquerda) e posição em função do tempo (direita) . . . . . . . . . . . . . . . . . . . . 116

7.31 Evolução dos valores $b_{1}, b_{2}$ e $a$ para uma bolha de nitrogênio ascendendo no sedimento. 116

7.32 Representação das componentes $u$ (esquerda) e $v$ (direita) do vetor velocidade. . . . 117

7.33 Representação das componentes $u$ (esquerda) e $v$ (direita) do vetor velocidade no

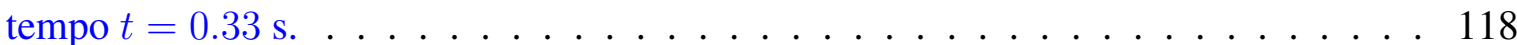

7.34 Representação do campo de concentração nos tempos $t=0.1 \mathrm{~s}$ (esquerda) e $t=0.2$

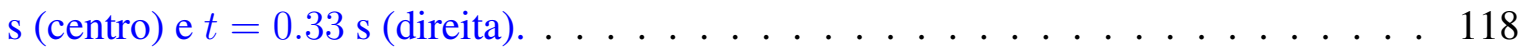

7.35 Representação do campo de viscosidade nos tempos $t=0.1 \mathrm{~s}$ (esquerda) e $t=0.2 \mathrm{~s}$ (centro) e $t=0.33 \mathrm{~s}$ (direta) . . . . . . . . . . . . . . . . 119

7.36 Comparação qualitativa caso V (esquerda) e Annaland, M. V. S. et al. [8] (direita). 119

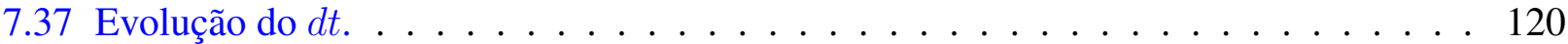


7.38 Velocidade do centro de massa para a bolha de metano e de nitrogênio no sedimento (esquerda) e posição em função do tempo (direita) . . . . . . . . . . . . . . . . . . . 121

7.39 Evolução dos valores $b_{1}, b_{2}$ e $a$ para bolhas de metano (símbolos fechados) e nitrogênio (símbolos abertos) ascendendo no sedimento. . . . . . . . . . . . . . . 121

7.40 Representação das componentes $u$ (superior) e $v$ (inferior) do vetor velocidade no

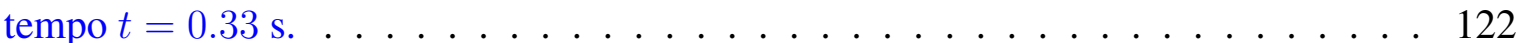

7.41 Representação do campo de concentração no tempo $t=0.33 \mathrm{~s}$ das bolhas de metano (esquerda) e nitrogênio (direta). . . . . . . . . . . . . . . . . . . . 123

7.42 Representação do campo de viscosidade no tempo $t=0.33 \mathrm{~s}$ das bolhas de metano (esquerda) e nitrogênio (direta). . . . . . . . . . . . . . . . . . 123

7.43 Representação da velocidade e posição no tempo em três momentos distintos para bolhas de metano nos diâmetros $L=0.03$ e $L=0.05 \ldots \ldots \ldots$. . . . . . . . . 124

7.44 Representação das componentes $u$ e $v$ (superior-esquerda/direita) e dos campos de concentração e viscosidade (inferior-esquerda/direita) no tempo $t=0.4 \mathrm{~s} . \ldots .$. . 126

7.45 Taxa de cisalhamento das bolhas nos diâmetros $L=0.03$ (esquerda) e $L=0.05$ (direita). . . . . . . . . . . . . . . . . . . 126

7.46 Velocidade do centro de massa da bolha com $L=1.0$ milímetro (esquerda) e Posição em função do tempo (direita). . . . . . . . . . . . . . . . . . . . . . . . . 127

7.47 Representação do campo de pressão (superior) e das componentes $u$ (esquerda-inferior) e $v$ (direita-inferior) do vetor velocidade no tempo $t=0.1 \mathrm{~s} . \ldots \ldots \ldots \ldots$

B.1 Diagrama de classificação reológico, adaptado de [14] . . . . . . . . . . . . . . 148 


\section{Lista de Tabelas}

2.1 Tabela de Potencial hidrelétrico brasileiro - Março de 2003 [61] . . . . . . . . . . 11

2.2 Tabela de Fluxos Difusivo e Ebulitivo. Adaptado de [122] . . . . . . . . . . . . 21

3.1 Tabela de variações de propriedades da água . . . . . . . . . . . . . . . . 27

4.1 Tabela de dados experimentais do core II. . . . . . . . . . . . . . . . . 45

4.2 Tabela de valores das constantes $\tau_{0_{\lambda}}, K_{\lambda}$ e $n_{\lambda}$ obtidas por mínimos quadrados. . . . 48

4.3 Tabela de cotas versus concentração de sedimento. . . . . . . . . . . . . . . . 49

4.4 Tabela geral de tendência para a tensão. . . . . . . . . . . . . . . . 51

4.5 Tabela de valores para os modelos. . . . . . . . . . . . . . . 56

7.1 Tabela de parâmetros de entrada do primeiro conjunto de simulações. . . . . . . . . . 89

7.2 Tabela de parâmetros de entrada do segundo conjunto de simulações. . . . . . . . . 100

7.3 Tabela de parâmetros de entrada do terceiro conjunto $(\mathrm{S}-8) \ldots \ldots$. . . . . . . . . 114

7.4 Tabela de parâmetros de entrada do quarto conjunto de simulações. . . . . . . . . . . 120

B.1 Tabela de comportamento reológico em função dos parâmetros. . . . . . . . . . . . 151 


\section{Lista de Símbolos}

$\begin{array}{ll}g_{0} & \text { Aceleração gravitacional de Escala } \\ L & \text { Comprimento de Escala } \\ u & \text { Componente radial da velocidade na célula } \\ v & \text { Componente longitudinal da velocidade na célula } \\ c & \text { Concentração } \\ c_{0} & \text { Concentração de Escala } \\ d_{e q} & \text { Diâmetro Equivalente } \\ D^{m} & \text { Difusividade Massica de Escala } \\ R & \text { Dimensão Horizontal do Domínio } \\ h & \text { Dimensão Vertical do Domínio } \\ H & \text { Dimensão Vertical Inicial da região de Fluido no Domínio } \\ d r, d z & \text { Dimensões de uma Típica Célula do Domínio } \\ \gamma & \text { Fator de Distorção } \\ N_{a} & \text { Fluxo Advectivo } \\ N_{d} & \text { Fluxo Difusivo } \\ F V_{z} & \text { Força Viscosa na direção longitudinal } \\ F V_{L} & \text { Força Viscosa Local } \\ W_{h} & \text { Função Núcleo Gaussiana } \\ n & \text { Índice de Escoamento } \\ M_{k} & \text { K-esima Malha } \\ \left(r_{c m}, z_{c m}\right) & \text { Localização do Centro de Massa } \\ R \times h & \text { L-ésimo Domínio } \\ l & \end{array}$




\begin{tabular}{|c|c|}
\hline$\rho$ & Massa Específica \\
\hline$\rho_{A p}$ & Massa Específica Aparente \\
\hline$\rho_{m}$ & Massa Específica Média \\
\hline$\rho_{c}$ & Massa Específica no Meio Contínuo \\
\hline$\rho_{d}$ & Massa Específica no Meio Disperso \\
\hline$m_{b}$ & Massa da Bolha \\
\hline$n b$ & Número Total de Células que contém o Contorno da Bolha \\
\hline$n i$ & Número Total de Pontos na Direção Radial \\
\hline$n j$ & Número Total de Pontos na Direção Longitudinal \\
\hline$\lambda$ & Numeração de Amostras \\
\hline$P, p$ & Pressão \\
\hline$E$ & Razão de Aspecto \\
\hline$b_{1}$ & Semi-eixo Vertical Inferior \\
\hline$b_{2}$ & Semi-eixo Vertical Superior \\
\hline$a$ & Semi-eixo Horizontal \\
\hline$s c$ & Superfície de Controle \\
\hline$\dot{\gamma}$ & Taxa de Cisalhamento \\
\hline$D$ & Taxa de Deformação por Cisalhamento \\
\hline$t$ & Tempo \\
\hline$T$ & Temperatura \\
\hline$\tau$ & Tensão de Cisalhamento \\
\hline$\tau_{\lambda}$ & Tensão de Cisalhamento da Amostra $\lambda$ \\
\hline$\tau_{0}$ & Tensão Crítica \\
\hline$\tau_{0_{\lambda}}$ & Tensão Crítica da Amostra $\lambda$ \\
\hline$\sigma$ & Tensão Superficial \\
\hline$\Delta i$ & Variação na direção i \\
\hline$\phi$ & Variável Convectada \\
\hline$V_{k}^{T}$ & Velocidade Terminal da Bolha na K-ésima Malha \\
\hline$U$ & Velocidade de Escala \\
\hline$\nu$ & Viscosidade Cinemática \\
\hline$\nu_{c}$ & Viscosidade Cinemática no Meio Contínuo \\
\hline$\nu_{d}$ & Viscosidade Cinemática no Meio Discreto \\
\hline$\mu$ & Viscosidade Dinâmica \\
\hline
\end{tabular}




$\begin{array}{ll}\eta & \text { Viscosidade Aparente } \\ \kappa & \text { Viscosidade Plástica } \\ \kappa_{\lambda} & \text { Viscosidade Plástica da Amostra } \lambda \\ \nu_{0} & \text { Viscosidade de Escala } \\ v c & \text { Volume de Controle } \\ v o l & \text { Volume da Bolha } \\ & \\ \delta_{i, j} & \text { Delta de Kronecker } \\ V e r & \text { Matriz de Informação dos Vértices } \\ \boldsymbol{\sigma} & \text { Tensor Tensão } \\ D_{i, j} & \text { Tensor Taxa de Deformação por Cisalhamento em notação indicial } \\ \mathbf{v} & \text { Vetor velocidade } \\ \mathbf{x} & \text { Vetor Posição } \\ \mathbf{n} & \text { Vetor Unitário Normal Exterior à Superfície Livre } \\ \mathbf{m} & \text { Vetor Unitário Tangente à Superfície Livre } \\ \mathbf{E} & \text { Vetor Força de Empuxo } \\ \mathbf{P} & \text { Vetor Força Peso } \\ \mathbf{F V} & \text { Vetor Força Viscosa } \\ \mathbf{v b} & \text { Vetor Velocidade do Centro de Massa da Bolha } \\ & \end{array}$




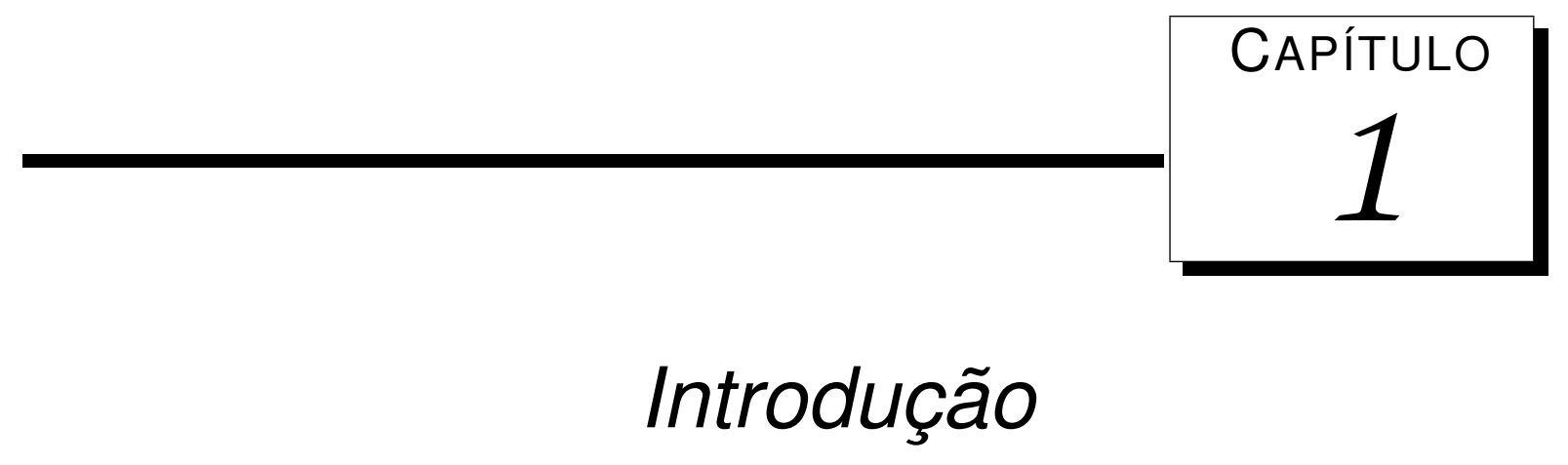

\subsection{Considerações Iniciais}

Como bem expressa o matemático Davis [32], a natureza com um escasso respeito pelos desejos dos matemáticos, algumas vezes, delicia-se em formular seus mistérios em termos de sistemas nãolineares de equações. Tais equações originam-se de muitas maneiras distintas quando da modelagem matemática dos fenômenos naturais. Assim, por exemplo, as teorias da elasticidade e hidrodinâmica são especialmente ricas em tais sistemas. Outros exemplos ocorrem na teoria dos sistemas ópticos, na mecânica de partículas através das equações de Euler e Lagrange, na dinâmica dos fluidos, etc. Quase sempre, encontrar soluções de tais sistemas de equações, nos quais possam ser expressados em termos de funções elementares, é uma tarefa bastante difícil e em alguns casos impossível.

No campo da ciência Matemática existem várias técnicas como: expressões integrais, sistemas de equações algébricas, equações diferenciais, transformadas integrais e outros, que podem ser utilizadas na construção do modelo dos fenômenos naturais. A resolução desse modelo vem tentar explicar e descrever os detalhes das mudanças nas variáveis de interesse [28]. Em particular vários modelos na área da dinâmica dos fluidos computacional são atrelados aos fenômenos da natureza via equações diferenciais parciais. E o estado da arte fica elevado a posição de permitir, via Matemática e Simulação Numérica-Computacional a análise daqueles fenômenos.

Nas questões inerentes aos fenômenos da natureza, particularmente, é notório que a degradação ambiental vem ao longo do tempo posicionando-se como um dos principais problemas no mundo 
moderno. Nos vários problemas na área ambiental, podemos destacar as questões: da mudança climática, da dispersão de poluentes em corpos d'água, do desmatamento de florestas e aterro de mangues, do impacto ambiental (local e ao de redor) do enchimento de reservatórios para produção de energia elétrica, entre outros.

Das mudanças climáticas no passado recente, o professor Kenitiro Suguio [119] aborda em seu livro que a Pequena Idade do Gelo (quando a temperatura média era inferior à atual) se estendeu de 1540 até 1890 . Neste período o agravamento do frio ocorreu em três momentos e acredita-se que a temperatura média durante a Pequena Idade do Gelo tenha chegado a ser 2 graus centígrados menor que a atual. Em contra partida, nos dias de hoje, o dióxido de carbono e outros gases-estufa (como o metano) exalados por atividades industriais, como possíveis gases causadores do aquecimento global através do efeito-estufa, transformou-se num grande problema.

Segundo Castro et al. [22], a caracterização do efeito estufa natural relaciona-se com a constatação de que os gases da atmosfera terrestre comportam-se como campânulas que bloqueiam as radiações calóricas refletidas, retendo parte do calor solar e induzindo a refletâncias. Esse efeito estufa produz uma elevação média de $30^{\circ} \mathrm{C}$ na temperatura da troposfera global, que atinge a média de $16^{\circ} \mathrm{C}$. Logo, o efeito estufa natural, ao manter grandes porções de água da hidrosfera em estado líquido, tornou possível o desenvolvimento da vida na Terra. O desastre misto, como afirma o autor, relaciona-se com uma hipótese de intensificação do efeito estufa em decorrência da crescente liberação dos chamados gases de estufa em consequência de atividades humanas, e que estariam promovendo uma tendência para o aquecimento global.

Dentre as atividades humanas, as hidrelétricas vêm sendo estudadas como uma possível fonte em potencial de liberação de gases de estufa. Estes gases produzidos seriam: o dióxido de carbono, metano e o óxido nitroso, gases de origem biogênica que comprovadamente interagem com a radiação infravermelha na atmosfera causando intensificação do efeito estufa natural [106]. Durante a década de 90 as hidrelétricas passaram a ser alvo de especulações a respeito de que seus reservatórios estariam contribuindo para a intensificação do efeito estufa, através da liberação de gases como produto da decomposição de material orgânico em sua bacia de acumulação. Porém, ainda não está sacramentado que de fato as hidrelétricas são de fato fontes importantes de liberação de gases estufa.

Ednaldo O. dos Santos [104], propôs-se a estudar gases de efeito estufa de ambientes naturais e de reservatórios de hidrelétricas, para uma ampla quantidade de dados de fluxos de dióxido de carbono e metano de diversas partes do mundo. Em seu estudo, os resultados obtidos sinalizam que rios e lagos naturais são fontes significativas de dióxido de carbono, ao passo que áreas de turfa, áreas alagadas e savanas seriam fontes significativas de metano. Além disto, ele constata que os reservatórios 
hidrelétricos emitem menos (gases estufa) ou de forma similar aos ecossitemas naturais alagados. E ressalta que ainda não há como mensurar o impacto final da alteração gerada pelo reservatório em termos de suas emissões. E que algumas perguntas tais como: quais são as rotas do ciclo do carbono no reservatório e os fatores ambientais envolvidos, ou como são estabelecidas corretamente as questões ligadas à extrapolação de dados inter e intra-reservatórios; não estão completamente respondidas.

No Brasil foi realizado um inventário sobre as emissões de dióxido de carbono e metano pelos reservatórios hidrelétricos brasileiros de Miranda (MG), Três Marias (MG), Barra Bonita (SP), Segredo (PR), Xingó (AL,BA,SE), Samuel (RO), Tucuruí(PA), Itaipu (PR) e Serra da Mesa (GO). Foi constatado que no caso do metano este gás sempre é emitido, seja por bolhas ou por difusão molecular. E que em termos gerais pode-se dizer que o risco de emissões de gases de efeito estufa podem ser reduzidos: evitando a baixa densidade de potência na escolha dos reservatórios $\left(\mathrm{W} / \mathrm{m}^{2}\right)$ e desmatando o reservatório antes da inundação (deve-se observar que esta medida tem que ser analisada sob o ponto de vista econômico). Concluiu-se no estudo discriminado no inventário que a energia hidrelétrica não é uma fonte isenta de emissões atmosféricas, o reservatório de uma hidrelétrica emite gases de origem biogênica [102].

Diante do escopo, em particular, a emissão do gás biogênico metano pode ser através de bolhas desprendidas do sedimento do fundo de lagos e isto será detalhadamente explicado no momento oportuno. Por hora é importante salientar que o processo físico do movimento das bolhas é um dos temas de interesse para a construção de modelos matemáticos.

Desvendar os segredos do movimento e forma geométrica de uma bolha em meio a um fluido é deveras interessante, este fato reside nas questões mais importantes ligadas a ciência, então fazemos menção de alguns trabalhos e suas técnicas.

Em seu artigo [121], Mário A. R. Talaia (usando água, glycerol e ar) aplica a análise dimensional para determinar os grupos adimensionais que influenciam a subida de bolhas numa coluna líquida, e registros experimentais de velocidade terminal das bolhas. Ele esclarece em seus resultados forte dependência dos efeitos dinâmicos e da viscosidade quando da velocidade terminal de subida da bolha. Verificou que bolhas maiores apresentavam velocidades terminais maiores para os sistemas ar-água e ar-glycerol. Confrontou seu modelo teórico com os dados experimentais e com outros trabalhos, ilustrando uma concordância aceitável entre eles para prever a velocidade terminal da subida de uma única bolha para vários números de Reynolds. Durante a pesquisa os dados experimentais foram obtidos com as hipóteses de temperatura constante e sem tensão superficial. Neste caso, o trato do movimento da bolha é focado na acurácia de resultados sobre a velocidade teminal da bolha em líquidos de viscosidades distintas, substânciado em registros experimentais e grupos adimensionais. 
Um modelo Físico-Químico para descrever a emissão de metano e outros gases (por difusão, bolhas e plantas) do fundo de lagos foi desenvolvido pelos pesquisadores G.A. Makhov e N.M. Bazhin [74]. Foi mostrado no artigo que a oxidação de metano não influencia muito o fluxo de metano para a atmosfera para muitas situações observadas experimentalmente. Em seu trabalho o modelo é constituído por um sistema de cinco equações algébricas não lineares. Lá eles mostraram a variação da taxa molar de metano em função da profundidade e o fluxo de metano, por bolhas e difusão, na dependência da taxa molar de metano. O fluxo ebulitivo foi comparado entre teoria, modelo e dados experimentais; mostrando concordância expressiva entre resultados. Em fim, no modelo deles o interesse foi avaliar o fluxo ebulitivo do metano na coluna d'água de lagos.

De grande valia no estudo do movimento das bolhas é a sua forma geométrica. No artigo de Mingming Wu e Morteza Gharib eles avaliam a forma e o caminho de bolhas de ar (com diâmetro variando entre $0.1-0.2 \mathrm{~cm}$ ) subindo na água limpa [140]. Eles constataram que as bolhas naqueles diâmetros tem duas formas constantes, a esférica e a elipsoidal, dependendo do tamanho do tubo capilar do qual elas são separadas. Foi observado experimentalmente que as bolhas esféricas movem-se significativamente mais devagar que as elipsoidais para volumes equivalentes. Bolhas com diâmetro menor que $0.15 \mathrm{~cm}$ sobem retilineamente. As grandes bolhas esféricas seguem caminhos em zigzag enquanto que as grandes bolhas elipsoidais seguem caminhos espirais. Para finalizar, no livro Bubbles, Drops, and Particles [30] há uma ampla quantidade de informações e tratamento matemático sobre as bolhas, gotas e partículas quanto: a simetria, fatores de forma, esfericidade, circularidade entre outros.

Como ilustrado até aqui, o estudo das bolhas pode aparecer em meio a vários campos do saber humano e da natureza. Em particular, nos problemas relacionados a lagos de resevatórios hidrelétricos. Objetivando contribuir com mais informações sobre o transporte de metano, este trabalho de tese se concentrará agora em: descrever, modelar, qualificar e quantificar a movimentação de alguns tipos de bolhas num contexto Matemático-Numérico não trivial. Antes porém, fazemos uma breve contextualização das técnicas numéricas usadas no cálculo da ascensão de bolhas, finalizando o texto estabelecendo o estado da arte no qual nosso trabalho se inserirá.

\subsection{Contextualização}

É de consenso na comunidade acadêmica que a matéria pode se apresentar na fase sólida, líquida ou gasosa. Dizemos então que um escoamento é dito multifásico quando o mesmo ocorre na presença de mais de uma fase. O caso mais comum é aquele nomeado por bifásico, como exemplo temos escoamentos no sistema gás/sólido (partículas sólidas transportadas pelo vento), sólido/líquido (sedi- 
mentação de partículas em um rio) e gás/líquido (bolhas de gás ascendendo num líquido). Mas não são raros os escoamentos trifásicos sólido/líquido/gás como por exemplo na exploração de reservatórios petrolíferos onde ocorre o escoamento do óleo, gás, água e ocasionalmente areia. A modelagem e simulação de escoamentos multifásicos não é simples e demanda formalísmo Matemático, Numérico e Computacional.

Com o advento de computadores com grande capacidade de processamento-armazenamentomemória, muitos problemas multifásicos puderam ser modelados e simulados sob condições iniciais diversas. A ponto de proporcionar soluções em vários segmentos, como por exemplo na área médica (ver [79]) ou elucidar questões físicas básicas (ver [44]). De todos os problemas multifásicos permissíveis de serem discutidos, nos atentaremos em alguns daqueles que reportam técnicas numéricas computacionais para o movimento de uma porção de matéria que flui em um meio que permita fluidez.

O método Front-Tracking foi proposto por Unverdi, S. O. e Tryggvason, G. [133] para simular escoamentos multifásicos. Neste trabalho eles descrevem a acentuada interface de separação entre os fluidos incompressíveis de diferentes densidades e viscosidades. A idéia foi discretizar o campo de escoamento por aproximações em diferenças finitas conservativa sobre um grid estacionário, com a interface explicitamente representada mostrando a separação entre os fluidos. Então a interface se move continuamente através do grid estacionário se deformando conforme a interação entre os fluidos. Resumindo, neste trabalho os autores apresentam seus resultados de ascensão de bolhas em duas e três dimensões para uma faixa de valores de Eötvös e Morton.

Também fundamentado na formulação das diferenças finitas, um método numérico para escoamento multifásico (gás-líquido) com grid fixo foi desenvolvido por Yue Hao e Andrea Prosperetti [48]. A idéia deles foi combinar os métodos Front-Tracking e Ghost Fluid com uma técnica numérica de extrapolação da velocidade próxima a interface. Com essa metodologia eles resolveram escoamentos com superfície livre tridimensionais de líquidos incompressíveis e gás compressível. Seus resultados foram comparados com a solução da equação de Rayleigh-Plesset para a oscilação livre de uma bolha de gás, entre outros.

Na linha de uso das técnicas Front-Tracking/Front-Capturing Souza, F. S. et al. [116], simularam diversos problemas de escoamentos multifluidos tridimensionais com superfícies livres. Neste trabalho eles consideraram escoamentos com fluidos incompressíveis, imiscíveis, newtonianos, com a interface de separação entre os fluidos de diferentes densidade e viscosidade. As equações de NavierStokes são resolvidas tomando por base o esquema GENSMAC-3D cuja formulação é em diferenças finitas. A superfície livre e a interface são representadas por um grid Lagrangeano que se move por outro grid Euleriano. A técnica se mostrou robusta e capaz de simular vários casos, entre seus 
resultados eles apresentaram a ascensão de bolhas a baixo e moderado número de Reynolds.

Como na área numérica são amplamente utilizadas as técnicas de discretização em: diferenças finitas, volumes finitos e elementos finitos, muitos trabalhos foram desenvolvidos em diferenças finitas e outros em volumes e elementos finitos. Por exemplo, Fabrício S. de Souza [115] desenvolveu um método numérico em elementos finitos para simular escoamentos multifásicos em malhas dinâmicas não estruturadas em seu trabalho de doutorado. Ele considerou em seu esquema que a interface é discretizada pelos próprios elementos computacionais da malha de elementos finitos. Entre seus resultados ele simulou a ascensão de bolha com razão de densidades $\rho_{c} / \rho_{d}=100$.

Millena Martins Villar fez em seu trabalho de doutorado [136] uma análise numérica de escoamentos multifásicos bidimensionais. Ela partiu de uma metodologia híbrida formada com as técnicas Front-Tracking e Front-Capturing que permite a separação do problema em dois domínios distintos, gás-líquido e líquido-líquido. Utilizou malhas bloco estruturada com refinamento local que se adaptavam dinamicamente nas regiões de interesse do escoamento. Neste trabalho ela avaliou a eficiência e a robustez da sua implementação, formulada em diferenças finitas, via análise de convergência e apresentou resultados para ascensão de bolhas.

Para finalizar nossas citações, utilizando o método de captura de interface VOF (Volume of Fluid) Georg, I. C. et al. [43] estudaram numericamente o escoamento de uma bolha de gás em um meio líquido. Calcularam as forças interfaciais, velocidade terminal, arrasto entre outros. Na comparação de seus resultados com dados experimentais, eles concluiram que a técnica como apresentada mostrou-se adequada sem apresentar difusão.

Em meio às técnicas de resolução de problemas multifásicos consagradamente já estabelecidas no meio acadêmico, como algumas daquelas mencionadas acima, e deparando-nos com o problema de transporte de metano no sedimento anóxico, nos propusemos a desenvolver uma metodologia inédita para resolver o nosso problema de transporte de metano.

Uma vez que a ascensão de uma bolha através da interface sedimento/água ocorre num sistema multifluido de três fases (gás-sólido-água), e que o mesmo é por nós considerado de complexidade Matemática-Numérica-Computacional relevante, simplificamos o problema de três fases em uma única fase (fluido).

A nossa idéia foi estabelecer um grid móvel (bolha), isento de fluido, imerso num domínio composto por fluido na fase contínua, tal que a ascensão da bolha move o fluido circundante simulando o procedimento físico de ascensão. A nossa técnica se dá através de dois conjuntos de equações: o primeiro composto pelas equações da continuidade e Navier-Stokes para a fase contínua e o segundo composto pela segunda lei de Newton para a movimentação do centro de massa da bolha. Desta 
forma, nossa estratégia simplifica o problema multifásico em monofásico. Porquê a mecânica dos fluidos é calculada externamente à bolha, na bolha usamos a segunda lei de Newton. O acoplamento entre os conjuntos de equações se faz através da força viscosa de interação entre a bolha e o meio externo a mesma. Para resolvermos numericamente a movimentação da bolha no meio fluido utilizamos o método de diferenças finitas para a discretização das equações. Escrevemos as equações de NavierStokes na forma não-newtoniana e a viscosidade via o modelo newtoniano generalizado, fazendo uso da relação Herschel-Bulkley para a lei da viscosidade. Com esta idéia modelamos o sedimento que é não-newtoniano e não homogêneo. Para a bolha calculamos os parâmetros de forma: razão de aspecto e fator de distorção que possibilitaram a deformação.

\subsection{Organização da Tese}

Este trabalho de tese foi organizado da seguinte forma:

- No capítulo 2 comentamos a problemática dos reservatórios e descrevemos como ocorre a produção e a emissão de metano.

- No capítulo 3 iniciamos com conceitos básicos que julgamos necessários para o entendimento dos desenvolvimentos, após detalhamos as equações governantes na sua forma mais geral.

- No capítulo 4 abordamos a modelagem da viscosidade para o sedimento desde os aspectos experimentais até o estabelecimento da lei geral da viscosidade. Em seguida tratamos dos parâmetros de forma em conjunto com a teoria das Cônicas.

- No capítulo 5 estabelecemos o nosso modelo matemático em coordenadas cilídricas axissimétrica e em seguida adimensionalizamos o modelo, porquê o código base de onde construímos a nossa versão é adimensional.

- No capítulo 6 mostramos como o método GENSMAC é adaptado para a movimentação de containeres (bolha) e dissertamos sobre as discretizações empregadas. Ao final, esclarecemos a nossa atualização sobre o código FREEFLOW-AXI, originando o FREEFLOW-AXI:N/Non.

- No capítulo 7 exibimos a validação necessária do nosso método e apresentamos nossos resultados para bolhas de metano.

- No capítulo 8 fazemos as considerações finais. Finalizamos o nosso trabalho com a bibliografia autilizada e teoremas/apêndices. 


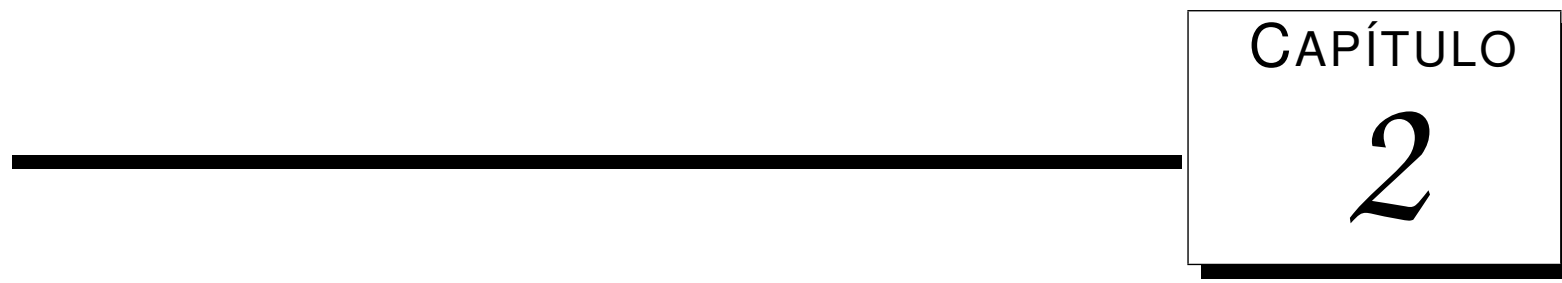

\section{Problemática dos Reservatórios}

\subsection{Demanda Energética}

O desenvolvimento agrícola ocorrido a partir do século XVI e sua política de domínio sobre a terra, deu como consequência a migração de camponeses para áreas urbanas. Os investimentos feitos por proprietários de terras em experiências, pesquisa e novos métodos de cultivo garantiu melhorias na qualidade da alimentação, possibilitando aumento do índice demográfico pela queda na taxa de mortalidade. O crescimento da população no mundo antes do século XVIII deu como consequência o aumento da demanda por bens duráveis, não duráveis e serviços. Isso fez com que o processo produtivo de bens e serviços mudasse radicalmente para atender à crescente demanda [90].

Os artesãos em seus nichos produtivos e comerciais começaram a se organizar no intuito de atender a essa demanda, dessa organização nasceu a automatização dos processos de produção. A crescente demanda fez também com que aumentassem a necessidade e quantidade de matéria-prima. A matéria-prima, por sua vez, teve seus preços elevados e então da organização dos nichos foi possível a aquisição de matéria prima a preços não proibitivos. Com mais bens sendo produzidos, seus valores foram levados a patamares que permitiam maior consumo o que alimentou mais produção, esta retro-alimentação desencadeiou a Revolução Industrial.

A certa altura da década de 1780 , e pela primeira vez na história da humanidade, foram retirados os grilhões do poder produtivo das sociedades humanas, que daí por diante se tornaram capazes de multiplicação rápida, constante, e até o presente ilimitada, de homens, mercadorias, e serviços. 
Além disso, a industrialização foi um momento decisivo na História da humanidade. Em cerca de 150 anos, transformou sociedades de camponeses e artesãos, trabalhadores manuais, em sociedades de maquinistas e guarda-livros (cargo de uma pessoa que desempenha as funções de contabilista e escrivão nas empresas mais antigas) [52].

A Revolução Industrial foi um dos marcos com maior impacto sobre a humanidade, ela iníciou por volta do século XVIII na Inglaterra e expandiu-se para todo o mundo após o século XIX, onde um dos pontos chave da Revolução Industrial foi a automatização. Para que a automatização dos processos fosse otimizada necessitou-se de ciência, foi no período da Revolução Industrial que a ciência se multiplicou muitas vezes. Mediante a todo esse procedimento ocorrido, novos produtos, novas necessidades e mais ciência foram criados e descobertos. A revolução industrial foi vista como à transformação da sociedade, à produção de bens manufaturados em grandes quantidades e em escala maior do que nunca, com base na reunião de um grande número de operários e o uso de máquinas a motor em número crescente [99].

Novas máquinas exigiam nova força, em 1801 o consumo de energia se elevou a um índice sem precedentes. Outras fontes de energia também se tornaram disponíveis. Com a descoberta de que a eletricidade podia ser gerada, o princípio do dínamo foi descoberto por Faraday em 1831, a demanda pelo carvão (para mover geradores) aumentaria de novo, mas uma nova forma de usar a água corrente em projetos hidroelétricos também se tornou disponível, e com eles uma maior expansão dos recursos energéticos [99].

A partir de 1870 a energia elétrica passou a ser diretamente aplicada no setor produtivo, que alavancou o desenvolvimento tecnológico [90], mas também era aplicada no setor de transporte e iluminação residencial e industrial. Por exemplo, em 1879 o americano Thomas Edison inventou a lâmpada incandescente e logo depois projetou e construiu uma central de energia elétrica com sistema de distribuição na cidade de Nova York, ele conseguiu acender aproximadamente 7200 lâmpadas e iluminar um bairro inteiro. Mas a eletricidade já tinha aplicações, por exemplo em comunicações como o telégrafo e o telefone. Esses e outros fatos, amplamente disseminados na História, atestam a crescente necessidade por energia elétrica.

Essa necessidade levou a seguinte questão: Qual seria a maneira mais viável de gerar energia elétrica em grande quantidade a um custo baixo? Essa pergunta está sendo respondida até o tempo moderno por Usinas Hidrelétricas. Atualmente os Estados Unidos, Canadá e Brasil são os maiores produtores de energia elétrica através de Usinas Hidrelétricas. A crescente demanda por energia elétrica e a opção por fontes hidrológicas para a sua produção têm resultado na construção de grande número de reservatórios, com consequentes mudanças no regime hidríco dos cursos de água [3]. 
Já está sacramentado que a energia elétrica é um dos vetores propulsores do desenvolvimento humano mundial. Conant (uma autoridade em geopolítica energética) e Gold (estudioso e profissional de grande experiência na indústria internacional do petróleo) [31], atestam que o consumo de energia elétrica per capita pode ser um bom índice para o estágio de desenvolvimento de um país. O conforto a serviço da humanidade, na forma como conhecemos nos dias atuais, é assegurado em função do uso de máquinas e sistemas alimentados por energia elétrica. Esse conforto faz crescer a demanda energética anualmente.

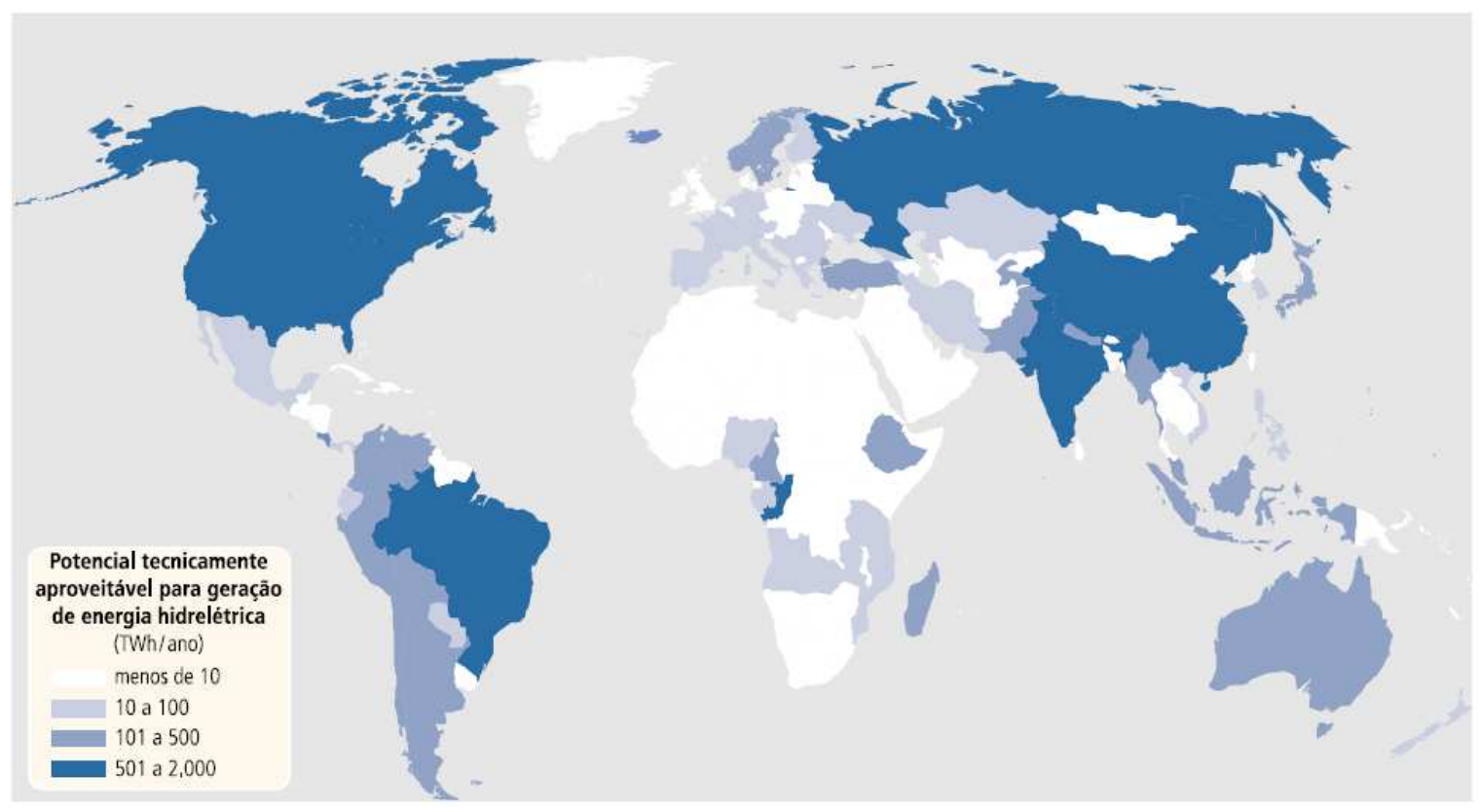

Figura 2.1: Potencial tecnicamente aproveitável para a geração de energia hidrelétrica no mundo [61].

Num aspecto amplo, a energia hidráulica disponível na terra é de aproximadamente 50.000 TWh por ano, que equivale a quatro vezes a quantidade de energia elétrica gerada no mundo anualmente [61]. O potencial tecnicamente aproveitável para a geração de energia hidrelétrica pode ser observado na figura 2.1. Note que América do norte, Ásia, Índia e Brasil possuem os maiores potenciais, enquanto que a África é de baixo potencial. Esse potencial técnico é um dos fatores necessários ao desenvolvimento social e econômico, mas não é suficiente.

Agora num aspecto particular, como observado na figura 2.1, o potencial brasileiro é significativo, em função deste fato muitos projetos de usinas vêm sendo executados no país, o que atrai investimentos externos alavancando o desenvolvimento desta região. O projeto de maior impacto executado até o momento no Brasil foi a usina de Itaipu. Para exemplificar, no ano de 2008 Itaipu (PR) gerou 94.684.781 megawatts-hora, isto é suficiente para suprir a demanda de todo o mundo por 2 dias. Mas para que a geração de energia elétrica por hidrelétricas seja feita é necessário o barramento de águas, 
ou seja a formação de uma bacia de acumulação de água. A geração de eletricidade por Itaipu demanda uma área de aproximadamente $1350 \mathrm{~km}^{2}$, com uma extensão de aproximadamente $170 \mathrm{~km}$ e largura média de $7 \mathrm{~km}$ [78]. Um outro exemplo, de menor envergadura, mas de grande importância na contabilidade energética do país é a usina de segredo (PR). Seu reservatório alaga uma área de 82,5 $\mathrm{km}^{2}$ e gera em média 1260 megawatts [3].

O potencial hidrelétrico brasileiro evolui na medida em que as informações são mais acuradas sobre as características diversas das bacias hidrográficas [6]. O potencial hidrelétrico total do Brasil está resumido na tabela 2.1, ele é o resultado da soma dos potenciais estimado e inventariado. O potencial estimado é formado dos estudos: de potencial remanescente e individualizado. E o inventariado é resultante dos aproveitamentos: apenas em inventário, com estudo de viabilidade, com projeto básico, em construção, em operação [61]. O potencial hidrelétrico brasileiro situa-se próximo de $260 \mathrm{GW}$ tabela 2.1, mas aproximadamente $68 \%$ desse potencial foi inventariado (177435.57). Entre as bacias com maior potencial destacam-se as do rio Amazonas e do rio Paraná. Se elas fossem inventariadas a porcentagem subiria para algo próximo de $96 \%$ que seria um excelente aproveitamento, mas a um custo importante de ser discutido e detalhado sobre o aspecto do impacto ambiental.

\begin{tabular}{|l|c|c|c|}
\hline Bacia & $\begin{array}{c}\text { Estimado } \\
\text { MW }\end{array}$ & $\begin{array}{c}\text { Inventário } \\
\text { MW }\end{array}$ & $\begin{array}{c}\text { Total } \\
\text { MW }\end{array}$ \\
\hline \hline Bacia do Rio Amazonas & 64164.49 & 40883.07 & 105047.56 \\
\hline Bacia do Rio Tocantins & 2018.80 & 24620.65 & 26639.45 \\
\hline Bacia do Atlântico Norte/Nordeste & 1070.50 & 2127.85 & 3198.35 \\
\hline Bacia do Rio São Francisco & 1917.28 & 24299.84 & 26217.12 \\
\hline Bacia do Atlântico Leste & 1779.20 & 12759.81 & 14539.01 \\
\hline Bacia do Rio Paraná & 7119.29 & 53783.42 & 60902.71 \\
\hline Bacia do Rio Uruguai & 1151.70 & 11664.16 & 12815.86 \\
\hline Bacia do Atlântico Sudeste & 2169.16 & 7296.77 & 9465.93 \\
\hline Total & 81390.42 & 177435.57 & 258825.99 \\
\hline
\end{tabular}

Tabela 2.1: Tabela de Potencial hidrelétrico brasileiro - Março de 2003 [61].

Voltando a História, em 1950 o Brasil vivia uma situação política de regime presidencialista tendo como presidente da república o Marechal Eurico Gaspar Dutra. De perfil em busca total do desenvolvimento, Dutra deu prioridade a quatro áreas: Saúde, Alimentação, Transporte e Energia (cujas iniciais formam a sigla SALTE objeto de campanha na eleição presidencial). Naquele ano o mapa brasileiro de usinas mostrava que a máxima concentração delas estava no litoral atlântico nas imedi- 
ações dos estados de São Paulo, Rio de Janeiro e Minas Gerais. E alta/média no Paraná, São Paulo, Rio de Janeiro. Quase todo o estado: do Espírito Santo, Minas Gerais, Goiás, Mato Grosso do Sul e Santa Catarina, figura 2.2. Justificando a concentração da população brasileira, de indústrias e do capital, este era o cenário em 1950!
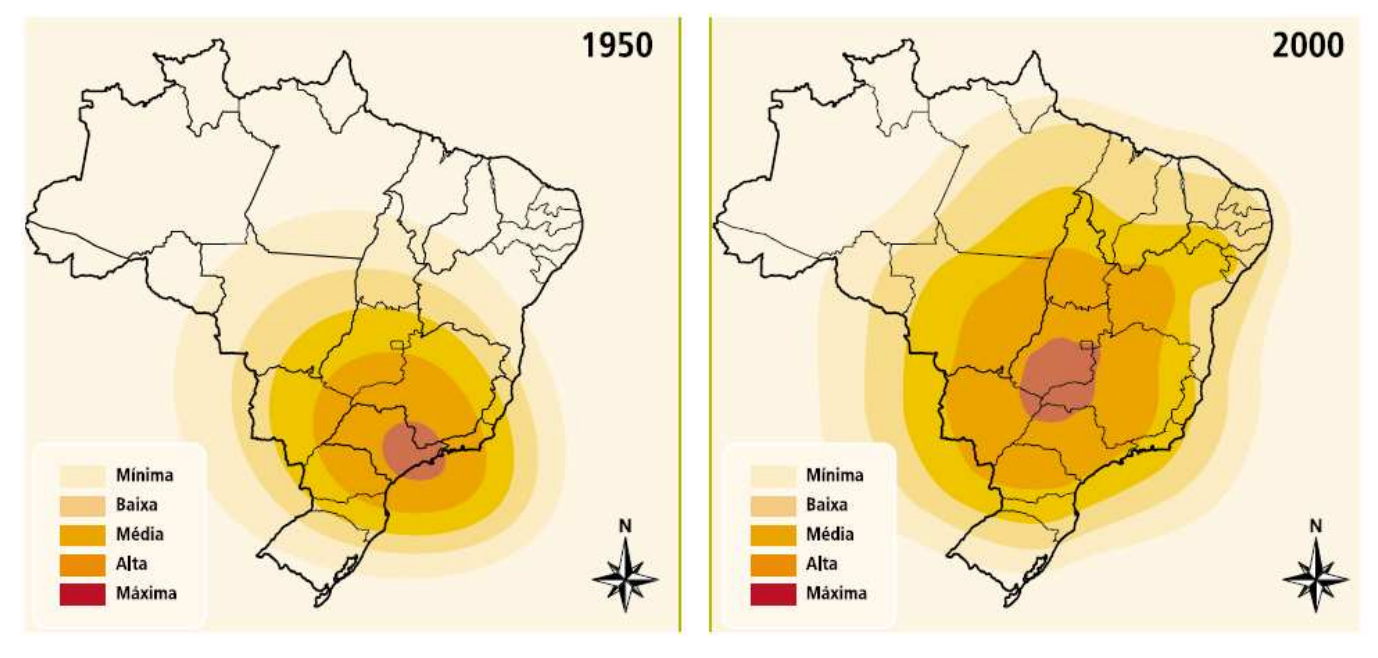

Figura 2.2: Evolução da concentração de usinas hidrelétricas no Brasil [61].

Já no ano de 2000, com o mundo numa economia globalizada capitalista e neoliberalista, onde não existem fronteiras para as grandes indústrias e para o comércio, observamos na figura 2.2 que a concentração das usinas encontra-se no centro com tendência para o norte/nordeste do país. Entre 1970 e meados dos anos 1980 espalharam-se por diversas regiões do País, graças ao aprimoramento de tecnologias de transmissão de energia elétrica em grandes blocos e distâncias [61]. Nesse mesmo período, verificamos também uma forte concentração de projetos na zona de transição entre as regiões Sudeste e Centro-Oeste, onde estão duas importantes sub-bacias do Paraná (Grande e Paranaíba). Mais recentemente, têm-se destacado as regiões Norte e Centro-Oeste, principalmente o Estado de Mato Grosso. Ou seja, o mapa mostra a tendência da ocorrência do inventário, num breve futuro, das bacias do rio Amazonas e do rio Paraná objetivando os $96 \%$ de aproveitamento do potencial hidrelétrico total do Brasil.

Diante dos fatos expostos acima, em conjunto com a exemplificação do caso brasileiro, acreditamos que as análises sobre a viabilidade de projetos de usinas tornam-se cada vez mais elaboradas e criteriosas. A necessidade do inventário é fato, mas o custo ambiental é determinante e um dos pontos de análise é a formação do lago (ou bacia de acumulação) e sua dinâmica de interação com o meio ambiente local e global ao longo do tempo. Logo, o conhecimento de sua dinâmica é fator importante de ser determinado. 


\subsection{Características dos Lagos}

Como observado anteriormente, um reservatório de uma Hidrelétrica é uma bacia de acumulação de água cuja mesma é utilizada para a geração de energia elétrica. Dependendo da topografia do terreno que sofrerá inundação, pode ocorrer a formação de mais de uma bacia de acumulação. Mas em geral os projetos hidrelétricos tendem a viabilizar a formação de apenas uma grande bacia. As questões referentes a dinâmica ambiental na bacia de acumulação antropogênica e nos rios naturais são bem distintas umas das outras.

Quando uma barragem é construída o tempo de residência da água é aumentado, a partir deste fato ocorrem alterações: quanto ao comportamento térmico da coluna d'água, nos padrões de sedimentação e circulação das massas de água, na dinâmica dos gases, na ciclagem de nutrientes e estruturas aquáticas [3].

Nos rios a velocidade do escoamento, na maioria das vezes turbulenta em todo o corpo d'água, é maior que nos reservatórios. Nos rios o transporte de massa é significativo no sentido da corrente fluida, com menor influência nas direções transversal e vertical. Sendo assim, a modelagem matemática dos fenômenos inerentes a rios são diferentes dos modelos para lagos. Num reservatório a velocidade do escoamento é lenta, geralmente eles são de profundidade considerável [132] e os principais processos químicos, físicos e biológicos ocorrem no sentido vertical.

São relevantes as mudanças locais ocorridas quando da formação de reservatórios hidrelétricos. Podemos destacar como impactos positivos: a produção de energia elétrica; a reserva local de água; a criação da possibilidade de abastecimento doméstico após tratamento simplificado; recreação de contato primário; a irrigação de áreas cultiváveis ao derredor do reservatório; navegação; produção via aquicultura entre outros [101]. Num outro extremo podemos destacar como pontos negativos: a inundação de áreas cultiváveis; a perda de fauna e flora; mudanças hidrológicas e geofísicas; a relocação compulsória de populações; perda de heranças históricas e culturais; problemas de saúde pública devido a deterioração ambiental e outros. No planeta existem aproximadamente 40 mil grandes reservatórios de hidrelétricas destinados a produção de energia elétrica [62].

Um outro fator a ponderar é que, ocorrida a formação do reservatório temos um espelho d'água de área considerável, a incidência do sol sobre o espelho d'água produz movimento de calor no sentido vertical, que se equilibra com o empuxo da massa de água. Sobre essa grande área o vento produz turbulência na camada superior da água, disto pode ocorrer a estratificação da temperatura e da densidade, que por sua vez, pode influenciar a estratificação de outros parâmetros, como por exemplo o oxigênio dissolvido [132]. 
Da estratificação da temperatura nos lagos, temos que o corpo d'água fica delineado por camadas com propriedades distintas. As camadas são definidas por Epilímnio, Metalímnio e Hipolímnio. O Epilímnio é uma camada superior, mais quente e com temperatura praticamente uniforme, luminosa e menos densa. Já a camada intermediária Metalímnio é a faixa onde a temperatura decresce rapidamente com a profundidade, o gradiente de temperatura é denominado Termoclina. A Termoclina está presente em regiões temperadas e tropicais, mas está ausente em regiões polares. É na faixa Metalímnia que as ações temporais externas ao reservatório se equilibram. E finalmente a camada inferior hipolímnio é mais fria, mais densa, o gradiente de temperatura é uniforme e as ações temporais externas ao reservatório não há afetam significativamente.

A disposição térmica de reservatórios de hidrelétricas os padrões de circulação e transporte de material são também resultantes da interação com os influxos de água e da operação da barragem. $\mathrm{O}$ fenômeno da estratificação térmica pode implicar numa profunda estratificação química que afeta a distribuição e sobrevivência de vários organismos aquáticos [3].

No ecossistema terrestre a fonte principal de carbono é o dióxido de carbono atmosférico. O dióxido de carbono é fixado pelas plantas durante a fotossíntese para a produção primária de matéria orgânica. Quando os reservatórios estão em processo de enchimento (ou cheios) tem-se o acúmulo de matéria orgânica/sedimentos em seu leito, esses sedimentos são materiais sólidos ou semi-fluidos, depositados no leito do reservatório. Para lagos, três designações tem sido usadas quanto a quantidade de nutrientes do sedimento: Oligotrófico - baixa quantidade de nutrientes -, Mesotrófico - que contém uma quantidade moderada de nutrientes - e finalmente, Eutrófico - aquele que contém uma quantidade elevada de nutrientes [123].

A estabilidade térmica dos lagos Mesotróficos e especialmente os Eutróficos faz com que eles fiquem estratificados, assim o fundo destes lagos se torna anóxico, a região anóxica propicia o metabolismo das Archaea metanogênicas [17]. As Archaea metanogênicas são microorganismos que têm diferenças estruturais das bactérias, de forma que desde 1970 recebem outra classificação. As Archaea metanogênicas (Methanococcus, Methanobacterium, Methanobacillus e Methanosarcina) são microorganismos que realizam a metanogênese.

A metanogênese é o procedimento final da degradação da matéria orgânica em metano $\left(\mathrm{CH}_{4}\right)$ e gás carbônico $\left(\mathrm{CO}_{2}\right)$, a bioquímica da formação de metano é encontrada apenas nas Archaea metanogênicas [87] [134]. Estes microorganismos são importantes no ciclo do carbono, pois promovem um meio para que o carbono não se acumule em depósitos anaeróbicos e retorne a atmosfera, como dióxido de carbono ou metano. Seu metabolismo retira energia para sua sobrevivência dos materiais orgânicos que os circundam transferindo elétrons para o carbono, produzindo assim metano. 
Disto temos consequências ambientais no efeito estufa e aquecimento global, já comentado anteriormente na página 2.

O efeito estufa por sua vez, é um processo que ocorre quando uma parte da radiação solar, refletida pela superfície terrestre, é absorvida por determinados gases presentes na atmosfera. Como consequência disso, o calor fica retido na região em que vivemos, não sendo liberado ao espaço. O efeito estufa dentro de uma determinada faixa é de vital importância pois, sem ele, a vida como conhecemos não seria possível de existir. Mas o que se pode tornar catastrófico é a ocorrência da desestabilização do efeito estufa, neste sentido o desequilíbrio térmico no planeta origina um fenômeno conhecido como aquecimento global. Aquecimento global refere-se ao aumento da temperatura média dos oceanos e do ar perto da superfície da Terra, ele tem sido verificado nas décadas mais recentes e a sua continuação durante o corrente século. O IPCC (Intergovernmental Panel on Climate Change), estabelecido pelas Nações Unidas e pela Organização Meteorológica Mundial em 1988, diz em seu relatório [139] que a maior parte do aquecimento, observado durante os últimos 50 anos, se deve muito provavelmente a um aumento dos gases do efeito estufa. Os gases de estufa $\mathrm{CO}_{2}, \mathrm{CH}_{4}$, $\mathrm{N}_{2} \mathrm{O}, C F C^{\prime} s$ absorvem alguma radiação infravermelha emitida pela superfície terrestre e radiam, por sua vez, parte da energia absorvida de volta para a superfície terrestre. Como resultado desta dinâmica, a superfície recebe quase o dobro de energia da atmosfera do que a que recebe do Sol, então a superfície fica mais quente.

Muitos pesquisadores realizam estudos qualitativos e quantitativos sobre o fluxo de metano a partir de lagos dos reservatórios justamente para qualificar a contribuição (ou não) destes no aumento do aquecimento global. Ainda não se tem uma resposta conclusiva sobre isto como podemos observar nos trabalhos [37], [21], [35], [47], [60].

As hidrelétricas emitem dióxido de carbono e metano por diversos caminhos, esta emissão ocorre a partir do espelho d'água e pelas águas que passam pelas turbinas e vertedouro, sendo a maior parte do metano emitida por este último. Portanto tratamos, no capítulo subsequente, de esclarecer o processo de formação do metano e os caminhos que o leva a contribuir (ou não) no aquecimento global.

\subsection{Produção-Emissão de Metano em Sedimentos}

$\mathrm{O} \mathrm{CH}_{4}$ (metano), $\mathrm{CO}_{2}$ (gás carbônico), $\mathrm{N}_{2} \mathrm{O}$ (óxido nitroso), $C F C 11$ e $C F C 12$ (clorofluorcarbonetos), $\mathrm{O}_{3}$ (ozônio) e o $\mathrm{H}_{2} \mathrm{O}$ (água) são os GEEs (gases de efeito estufa) mais conhecidos [107]. A atmosfera terrestre é composta em grande proporção por $N_{2}$ (nitrogênio) e $O_{2}$ (oxigênio), mas 
quantidades significativas de $\mathrm{H}_{2} \mathrm{O}$ e $\mathrm{CO}_{2}$ são também presentes [73].

Dentre os gases de efeito estufa, o metano, a partir dos últimos 200 anos teve sua concentração duplicada na atmosfera, isto equivale no tempo pré-industrial (nos primórdios da revolução industrial) a 700 partes por bilhão no volume (ppbv) e em 1997 foi estimado em 1.730 ppbv. Uma vez que o metano é um dos gases mais agressivo ao meio ambiente, seu GWP (potencial de aquecimento global - sigla em inglês) é 21 [26] e sua contribuição para o efeito estufa é da ordem de 22\%, isto faz com que seja de grande relevância o estudo das fontes de produção e estimativa da emissão do metano [66] [137].

A partir de dados experimentais coletados, vários tipos de estudos têm sido feitos com o objetivo de mensurar a produção e emissão do metano. Entre eles a técnica da modelagem matemática tem sido apresentada nas últimas décadas. Os resultados numéricos obtidos por modelos matemáticos, validados com os dados experimentais, permitiram estabelecer que o processo de emissão de $\mathrm{CH}_{4}$ tem duas fases: a não-metanogênica e a metanogênica.

Uma descrição do caminho metanogênico foi feita pelo Dr. Larry Wackett e complementada por Jian Ma no ano de 2000. As fontes de emissão e as taxas de trocas globais foram descritas por Hu Neue e Roger em 1993. Em seu artigo os pesquisadores Bernadette Walter, Martin Heimann e Elaine Mathews propuseram um modelo para áreas naturais alagadas dependente da coluna d'água, temperatura do solo e da rede primária de produção necessária para emissão de metano [137]. Já os pesquisadores Chakraborty e Bhattacharayab descreveram um modelo matemático, composto por um sistema de equações diferenciais ordinárias não lineares acopladas, para a produção de metano com controle sobre os índices de emissão [26]. Neste modelo eles consideram duas fases, não-metanogênica e metanogênica, para a produção de metano.

Em verdade, é claro que os modelos que vêm sendo propostos por pesquisadores em todo o mundo, não permitem ainda um completo e acurado conhecimento da produção e liberação do gás, mas a construção dos modelos matemáticos determinísticos têm trazido luz sobre o assunto, e muito quanto a formação e emissão de metano ainda há por ser pormenorizado.

Já se sabe que altas taxas de produção de metano são derivadas da riqueza de matéria orgânica presente no sedimento anaeróbio, e que sua emissão ocorre em várias vertentes. A partir desta constatação, um novo campo de estudos sobre a construção de modelos Matemáticos e Numéricos se voltou sobre a sedimentologia, em particular a presente tese tem esta proposta.

A sedimentologia é a ciência que estuda as propriedades dos sedimentos que podem ser transportados por fluidos. E por definição, sedimento é a partícula derivada da fragmentação das rochas por processo físico ou químico que é transportado pela água ou pelo vento do lugar de origem até rios 
e outros locais de deposição [20].

Para exemplificar o quanto o transporte de sedimento num meio fluido é determinante, T. Okabe et al. [84] publicaram um trabalho no qual foi proposto um modelo hidráulico unidimensional que simulava o processo de sedimentação num reservatório tipo garganta. O seu modelo é tal que a rotina do escoamento (baseada nas equações de conservação da massa e energia) é desacoplada da rotina de sedimento (baseada nas equações de transporte de sedimento e conservação da massa). Seu modelo foi resolvido numericamente para reproduzir o processo de sedimentação no reservatório Kominono no Japão, para um período de 20 anos após a sua construção. Os resultados da simulação foram considerados de acordo com o observado, mas eles enfatizaram que melhoras no modelo eram necessárias para resultados mais exatos. Vale ressaltar que um modelo determinístico do processo de sedimentação como o de T. Okabe et al. abre precedente para o estudo de formação de metano do processo sedimentar simulado.

Uma outra constatação é que, com a deposição de sedimentos no fundo de rios e lagos a condição deste local é de solo saturado, e disto todo o espaço poroso encontra-se disponível ao movimento de fluidos, o que por sua vez, propicia a condutividade hidráulica. A Condutividade Hidráulica é o coeficiente de proporcionalidade da equação de Darcy que determina o movimento de fluidos num meio poroso. No solo esse coeficiente expressa a facilidade com o qual a água é transmitida no perfil [64]. O solo saturado conduz água por todos os vazios, enquanto que, o não saturado só através dos filmes de água que envolve suas partículas; logo, no segundo caso, a área útil condutora de água decresce no solo e, consequentemente, a tortuosidade do caminho da água aumenta. A Tortuosidade é uma característica do solo dada pela relação entre o comprimento do fluxo efetivo pelo fluxo tortuoso, resultando então em valores típicos menores que a unidade [111]. Os solos de bacias de acumulação de água constituem-se como saturado, com gradiente crescente de condutividade no sentido da interface sedimento-água e decrecente quanto a tortuosidade.

Quando uma barragem de usina hidrelétrica é construída, obstruindo o escoamento natural de um rio, temos que o mesmo é rigorosamente afetado. Isto provoca queda acentuada do fluxo de água reduzindo a capacidade do transporte de sedimentos no rio, provocando a sedimentação da carga em suspensão e de arrasto, pelo atrito entre o sedimento com o leito, levando ao assoreamento [18]. Em linhas gerais o assoreamento é um processo que leva ao acúmulo de sedimentos no fundo de rios, canais e lagos e isso pode resultar num ambiente propício a metanogênese. Todos os reservatórios, qualquer que seja sua finalidade, destinação, tamanho e características de operação estão fadados a ter a sua capacidade de armazenamento parcial ou totalmente tomados pelos sedimentos, proporcionando o processo de assoreamento [18]. 
Um outro fator é que o tempo de retenção da água no reservatório, e os aportes predominantes a partir da fonte principal resultam em gradiente longitudinal (ao longo do maior eixo do reservatório) das características limnológicas. A região longitudinal está usualmente associada com o aumento da sedimentação de material particulado, incluso nutrientes dissolvidos absorvidos, no sentido rio barragem. Isto implica na formação das zonas: fluvial, intermediária e lacustre. Cada zona apresenta comportamentos diferenciados quanto aos fatores limnológicos: taxa de sedimentação, concentração de nutrientes, importância relativa dos aportes de material inorgânicos e orgânicos (reciclagem ou advecção), fatores limitantes da produção primária e valores da produção primária. O conhecimento das regiões que se formam no reservatório apresentam grande importância prática, pois a identificação destas regiões permitirá o uso adequado para pesca, criação em tanques-redes, recreação e abastecimento de água [3].

Sob outro foco, da mesma forma que se tem a estratificação da temperatura e consequentemente a Termoclina, temos também a estratificação do oxigênio dissolvido. Considerando um corte no sentido logitudinal de um dado reservatório, figura 2.3, podemos dizer que ele é dividido nas regiões óxica (aquela que apresenta quantidade significativa de oxigênio) e anóxica (que apresenta quantidades insignificantes de oxigênio), cuja interface entre estas regiões é denominada de oxiclina (região que apresenta um gradiente na quantidade de oxigênio). A menos que algum fator externo ocorra, o leito dos reservatórios e sua vizinhança se apresentam como anóxico e as camadas superiores, próximo a superfície, como óxica. As evidências mais recentes para os lagos, sugerem que a maioria do metano produzido ocorre em sedimento anóxico [9] [103] [122].

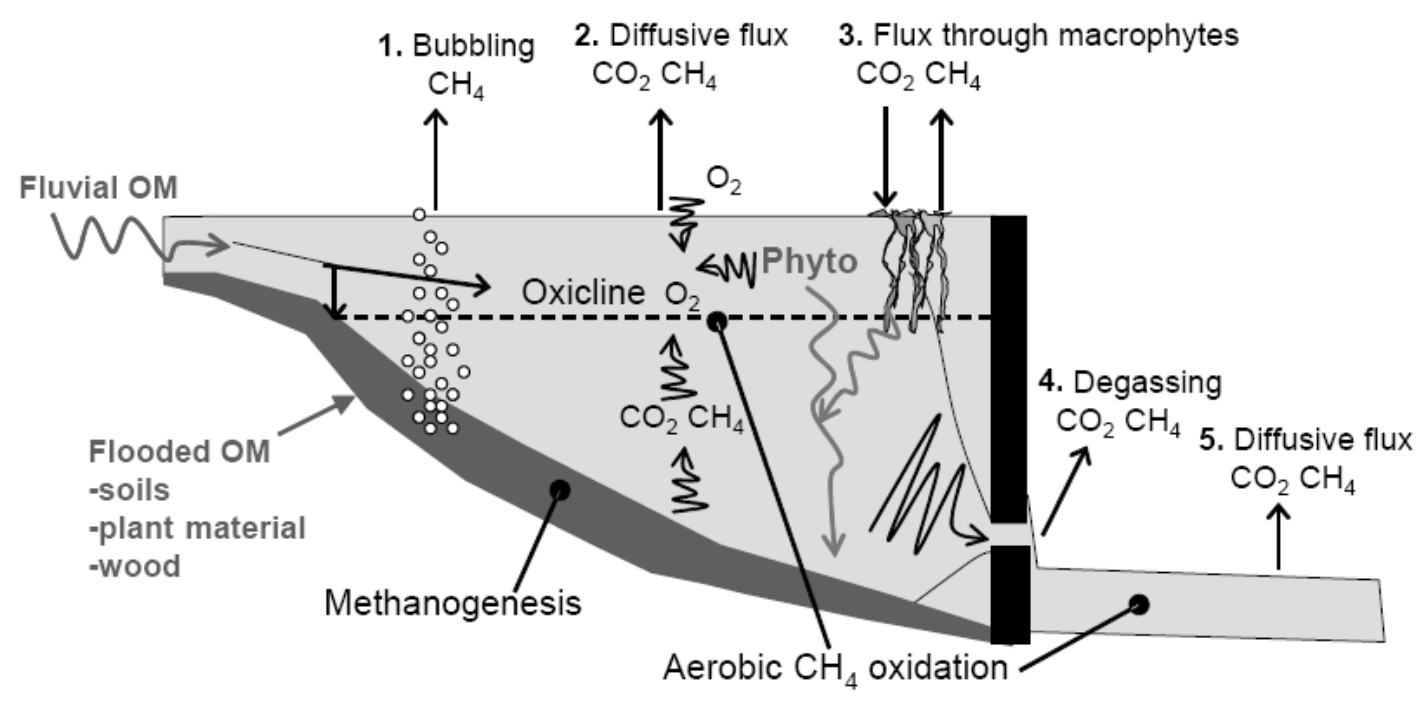

Figura 2.3: Formação e liberação de Metano e Gás Carbônico em reservatórios [122]. 
Com a entrada de matéria orgânica OM no reservatório, figura 2.3, uma parte dela é carregada pelo fluxo convectivo de água e outra parte é depositada no leito. A matéria orgânica depositada no fundo do reservatório passa por decomposição via metanogênese [117] $\left(O M \rightarrow C H_{4}+C_{2}\right)$, ou seja, a produção de metano ocorre na região anóxica [122]. E o metano vai sendo estocado de forma dissolvido na água do reservatório. A taxa de produção depende do substrato disponível e da temperatura do solo [137]. Então o metano produzido pela metanogênese vai entrando na coluna d'água por difusão [1]. O fluxo de metano do solo é resultado da interação de vários processos biológicos e físicos no solo, a produção de metano é um processo microbial, que é predominantemente controlado na falta de oxigênio e da ação de degradação [108].

Acima da oxiclina as condições ambientais são favoráveis para a ocorrência da oxidação aeróbica $\left(\mathrm{CH}_{4}+2 \mathrm{O}_{2} \rightarrow \mathrm{CO}_{2}+2 \mathrm{H}_{2} \mathrm{O}\right)$ pelo grupo de bactérias aeróbias metamórficas [107], pois com a diminuição da profundidade há o aumento da concentração de oxigênio.

Os dados coletados e tratados por Bastviken et al. [11] confirmam as argumentações anteriores. Eles analisaram três pequenos lagos (Illersjön, Mårn e Lillsjön) da região centro sul da Suécia. Verificaram que no verão havia a ocorrência da estratificação da temperatura e da concentração de $\mathrm{O}_{2}$. Com alta concentração de metano no fundo (produzido e estocado) e praticamente inexistência do mesmo nas camadas superiores (oxidado e liberado) próximo a superfície. Em contrapartida, no inverno, observaram pouca estratificação da temperatura com gradiente significativo na concentração de $\mathrm{O}_{2}$. Neste cenário a concentração de metano seguiu a mesma tendência do caso de verão, porém com o perfil de oxidação do metano fortemente alterado devido as condições de temperatura e oxigenação na água.

É verdade também, que para lagos tropicais a dinâmica de formação e liberação de metano ocorre de modo análogo àquele atestado por Bastviken et al. É conhecido que condições ambientais em águas profundas de lagos tropicais favorecem a metanogênese. As concentrações de metano dissolvido aumentam significativamente com a profundidade em reservatórios tropicais [42]. Outros trabalhos que justificam e reforçam a tese de que a produção de metano ocorre em sedimento anóxico, mesmo em regiões com características climáticas bem diferentes, foram os trabalhos de Donato S. Abe et al. em 2005 e J. T. Huttunen et al. em 2006.

Abe et al. [1] avaliaram no reservatório (de clima tropical) Lobo-Broa a concentração de metano no sedimento anóxico do fundo do lago. Da leitura sobre os dados podemos observar que a medida em que se caminha no sentido contrário ao da profundidade as medições indicam uma tendência de aumento na porosidade do sedimento. Isto implica na diminuição da densidade permitindo mais espaço vazio para acúmulo de água nos poros, o que facilita a condutividade hidráulica. A entrada contínua 
de água no reservatório transporta novas quantidades de matéria orgânica que é sedimentada em camadas. Sob este cenário sedimentológico, observamos nos dados do trabalho de Donato S. Abe et al. que há decréscimo na concentração de metano, e isto ocorre porquê há diminuição da tortuosidade. Embora a riqueza da matéria orgânica foi observada ser maior nas camadas superiores das amostras (o que favorece a metanogênese) devemos lembrar que há difusão do metano. A difusividade é por vezes modelada pela lei de Fick [113] [1] [117] por muitos pesquisadores. Abe et al. usando a primeira lei de Fick da difusão $J=-\phi D_{s}\left(d c / d z\right.$ ) (onde $J$ é o fluxo difusivo, $\phi$ é a porosidade, $D_{s}$ é o coeficiente de difusão e $d c / d z$ é a taxa de concentração com a profundidade) em conjunto com a fórmula empírica $D_{s}=D_{0} / \Theta^{2}$, sendo $\Theta$ a tortuosidade do sedimento modelada por $\Theta^{2}=-0.73 \phi+2.17$, obtiveram resultados razoavelmente representativos quanto ao perfil de concentração do metano nas amostras, conforme detalhado em seu artigo [1].

No estudo feito por J. T. Huttunen et al. [57], eles analisaram também a concentração de metano no sedimento dos seguintes lagos boreais Filandeses: Tuusulanjärvi, Postilampi, Soiviojärvi, Takajärvi, Luiminkajärvi, Ranuanjärvi,Lokka e Porttipahta. De uma amostra de sedimento tomada no fundo dos lagos em Julho/Agosto, entre 1994 e 1997, eles observaram que a concentração de metano seguiu tendência de queda até a interface sedimento-água para a maioria dos lagos. Essa tendência também foi observada no trabalho de Abe et al. no lago tropical Lobo-Broa.

Abe et al. conclui em seu trabalho que a maior parte do metano foi produzida via metanogênese no sedimento anóxico. E o caminho principal de transporte de $\mathrm{CH}_{4}$ do sedimento depositado no fundo para a atmosfera foi provavelmente por ebulição, que parece ocorrer somente em águas superficiais onde a baixa pressão hidrostática permite a formação de bolhas no sedimento do fundo [1]. Já J. T. Huttunen et al. observa em seu trabalho que a maior parte de $\mathrm{CH}_{4}$ foi transportado do sedimento principalmente por ebulição para o lago Lokka. Mostrando então que o processo ebulitivo é importante em função das condições limnológicas.

Além disto, no entanto, vale ressaltar que M. B. da Silva pontua em sua tese de doutorado que é comum também a fração do metano liberada por ebulição ser ligeiramente maior do que a que difunde e consegue alcançar a superfície. Mas grande parte deste gás metano que se difunde pela coluna d'água é oxidado quando passa pela zona óxica, podendo variar entre $70 \%$ e $99 \%$ da sua concentração próxima ao sedimento[112]. Diante disto, ponderamos agora a questão da emissão do metano via diversas fontes.

Reportando-nos a figura 2.3, ressaltamos que o metano é liberado difusivamente pelo espelho d'água na interface água-atmosfera (fonte 2) e também através de vegetação em zonas litorâneas e presentes no reservatório [10] (fonte 3). Voltando ao processo metanogênico, quando o leito possui 
matéria orgânica com alta taxa de produção de metano e esta taxa excede a taxa de difusão vertical, na direção da interface sedimento-água, isto resulta na supersaturação do gás na água, por fim a supersaturação dá origem a formação das bolhas de metano. As bolhas são um canal direto de desprendimento de metano do sedimento para a atmosfera, pois elas escapam a oxidação microbial (fonte 1) [72] [112]. Um outro caminho importante a considerar é quanto a influência do movimento das águas no reservatório. Como o movimento das águas é dinâmico, a medida que aquelas águas ricas em metano dissolvido passam pelas turbinas de uma usina hidrelétrica ou pelos vertedouros a pressão hidrostática diminui significativamente, desta forma ocorre o desprendimento do gás para a atmosfera (fonte 4) [36] [71] [62]. Vale ainda destacar que após a barragem ocorre também o fluxo difusivo de metano na interfaçe água-atmosfera (fonte 5). Em resumo, como sugere a figura 2.3, podemos dizer que existem 5 fontes de liberação de metano para a atmosfera. Todas elas submetidas à condições biogeoquímicas diferenciadas no corpo d'água, que necessitam ser modeladas e estimadas com o intuito de esclarecer o peso de contribuição no acúmulo de $\mathrm{CH}_{4}$ na atmosfera.

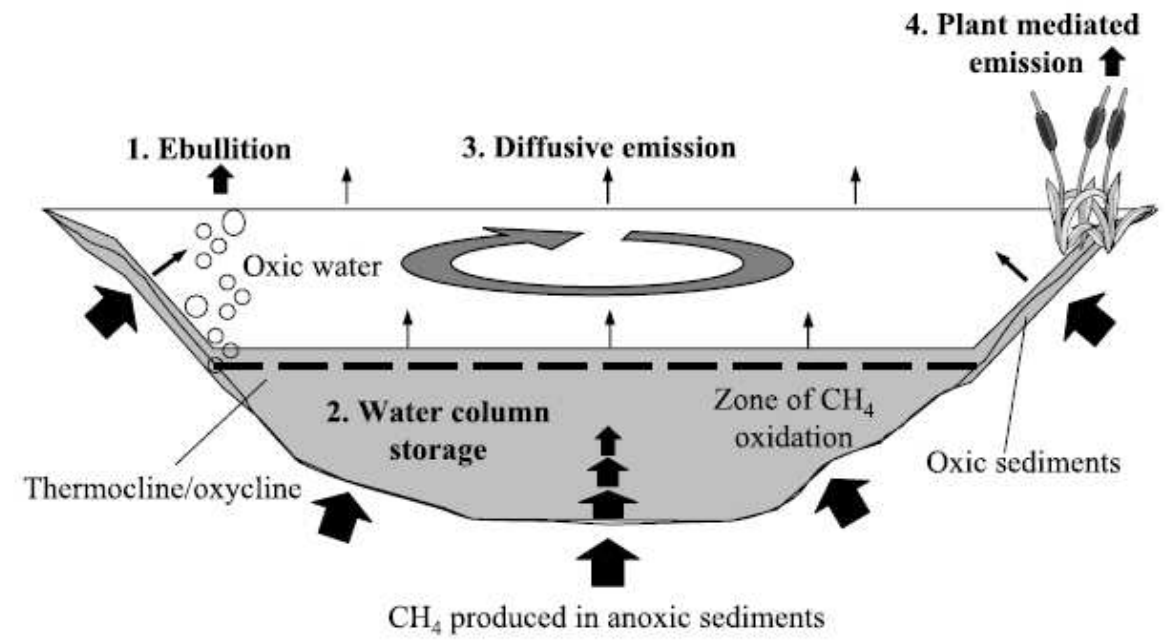

Figura 2.4: Caminhos da Emissão de Metano em Lagos [10].

Estimar a emissão de metano em lagos e reservatórios é difícil, desta forma Bastviken propôs então a existência de pelo menos quatro caminhos de emissão [10], a saber: fluxo por ebulição, fluxo por difusão, fluxo por armazenamento e fluxo por vegetação aquática, figura 2.4.

\begin{tabular}{|c|c|c|}
\hline Caminhos do $\mathrm{CH}_{4}$ em $\frac{\mathrm{mmol}}{\mathrm{m}^{2} . d}$ & Boreal e Temperado & Tropical \\
\hline \hline Fluxo difusivo & $-0.3 \longleftrightarrow 8.0$ & $0.3 \longleftrightarrow 51.0$ \\
\hline Fluxo ebulitivo & $0.0 \longleftrightarrow 18.0$ & $0.0 \longleftrightarrow 88.0$ \\
\hline
\end{tabular}

Tabela 2.2: Tabela de Fluxos Difusivo e Ebulitivo. Adaptado de [122]. 
Dentre os caminhos de emissão os cientistas que se reuniram no Two workshops on the Greenhouse Gas Status of Freshwater Reservoirs em Foz do Iguaçu em Outubro de 2007, chegaram ao consenso de que são significativos os fluxos difusivos e ebulitivos por lagos de reservatórios de hidrelétricas, tabela 2.2 .

Os valores dos fluxos na tabela 2.2 são expressados por faixas devido ao fato de terem sido obtidos por estudos em vários reservatórios. Na representação do fluxo difusivo foram utilizados os dados de 56 reservatórios boreais/temperados e 14 reservatórios de área tropical. De modo análogo, para o fluxo ebulitivo foram analisados 4 reservatórios boreais/temperados e 12 reservatórios tropicais [122]. Observando a tabela podemos dizer que a emissão de metano por reservatórios tropicais é significativa quando comparada a reservatórios boreais/temperados, este fato pôde também ser observado por [72] e [10] em seus trabalhos.
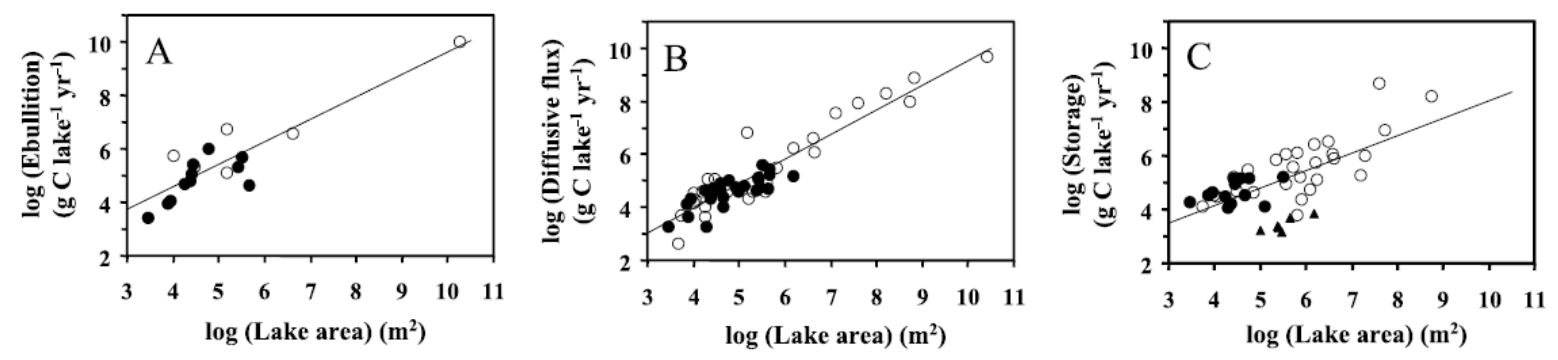

Figura 2.5: Fluxo de $\mathrm{CH}_{4}$ em função da área dos lagos. (A) fluxo difusivo, (B) fluxo ebulitivo e (C) armazenamento na coluna d'água [10].

Um outro dado relevante é quanto a relação de dependência entre a quantidade de metano emitida e a área dos lagos onde ocorre a emissão. Utilizando a escala logarítmica, na figura 2.5 temos que os símbolos sólidos referem-se a lagos da América do Norte e Suécia, as circunferências a outros lagos do artigo de Bastviken et al., e finalmente os triangulos sólidos na figura 2.5C referem-se a lagos sem a parte anóxica da coluna d'água. Observe neste estudo que os fluxos estão correlacionados linearmente com a área dos lagos. Sugerindo que na medida que o espelho d'água aumenta isto proporciona maiores quantidades de produção e emissão de metano.

Mas em particular Bastviken mensura, sobre os mesmos lagos, que a proporção de cada um dos fluxos (ebulitivo, difusivo e por armazenamento) num dado lago não é linear com respeito a área de espelho d'água, figura 2.6. Ele quantificou que o aumento da área faz diminuir a contribuição da componente armazenamento de metano (situação esta que vêm a confirmar o consenso estabelacido em Foz do Iguaçu em Outubro de 2007, seção 2.3 página 22, visto que a componente armazenamento não é referenciada) e crescer as componentes difusão e ebulição. Mas a partir de uma dada área a 
componente difusiva domina sobre a ebulitiva, então temos aumento na difusão e queda na ebulição.

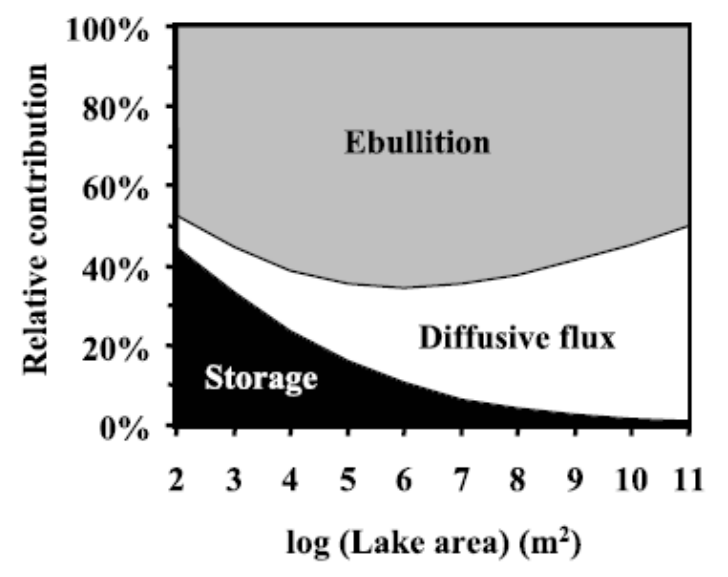

Figura 2.6: Contribuição dos tipos de Emissão de Metano em Lagos [10].

Como tratado anteriormente, as componentes ebulitiva e difusiva têm papel determinante na contabilidade da emissão do metano nos lagos. Essas componentes na verdade são os meios, cuja riqueza de matéria orgânica sedimentada no fundo dos lagos justifica os meios. Reforçamos que o fluxo de metano no solo resulta da interação de vários processos biológicos (como por exemplo a metanogênese) e físicos (por exemplo a porosidade do sedimento) no solo [108].

Ainda, Strayer e Tieje expressam que o transporte de metano do sedimento ocorre pela difusão na coluna de água, mas se a concentração crítica de formação de bolha for atingida então o transporte ocorre na forma ebulitiva. A concentração crítica teórica, no qual as bolhas podem formar-se, é dependente da pressão hidrostática e neste caso da profundidade de água acima do sedimento. Em seu artigo eles também confirmam que para lagos mais profundos, a perda de metano por ebulição pode ser insignificante comparado a perdas de metano por difusão no caso extremo, no qual a pressão hidrostática é bastante grande para impedir a formação de bolhas, nesta circunstância o único caminho do qual o metano pode deixar o sedimento é pela difusão [117]. Porém é comum e possível que o fluxo ebulitivo seja dominante para um lago, isto foi ilustrado no trabalho de J. T. Huttunen et al, mencionado na página 20 deste nosso trabalho. Variáveis ambientais como profundidade e estratificação da coluna d'água mostram ser um fator decisivo na emissão de metano por bolhas.

Portanto, diante da importância do movimento ebulitivo de metano que foi exposto até o momento, a nossa presente proposta de trabalho concentra-se agora em algumas considerações matemáticas da mecânica dos fluidos computacional e da segunda lei de Newton na movimentação do centro de massa, para enfim modelar e simular o transporte de uma bolha de metano no sedimento. 


\section{CAPÍTULO}

\section{Equações Governantes}

\subsection{Conceitos Básicos}

Para expor o transporte de uma bolha de metano no sedimento faz-se necessário a descrição de algumas propriedades do Fluido, da bolha e de alguns números adimensionais, porquê eles serão determinantes na proposição do modelo matemático.

Os pesquisadores W. F. Hughes e J. A. Brighton classificaram a dinâmica dos corpos não rígidos em duas grandes áreas: elasticidade (corpos elásticos sólidos) e mecânica dos fluidos. Para essa última área o conceito de fluido e seus pormenores se fazem necessários para entendimento dos fenômenos caracterizados [56].

Podemos dizer que Fluido é uma substância que não consegue resistir a imposição de uma força de cisalhamento, também denominada tensão de cisalhamento, sem se mover. Ou em outras palavras é a substância que deforma continuamente (escoa) quando submetida a uma tensão de cisalhamento de qualquer valor [80]. Tratando a substância fluida num meio contínuo, e que ela sempre possui o mesmo valor quando observada sob as mesmas condições, então definimos propriedades que caracterizam este fluido.

Se $\delta V$ é um volume infinitesimal em torno de um ponto e a massa da substância distribuída em $\delta V$ é $\delta m$, então a propriedade Massa Específica, indicada por $\rho$, é definida como:

$$
\rho=\frac{\delta m}{\delta V}
$$


cuja unidade pode ser $\mathrm{kg} / \mathrm{m}^{3}$. A massa específica é variável com a temperatura como pode ser visto, por exemplo no caso da água, na tabela 3.1.

Existe também a designação Massa Específica Aparente ou Densidade Aparente, definida por $\rho_{A p}=m_{s} / V$ em que $m_{s}$ é a massa seca da amostra no qual está sendo calculada a $\rho_{A p}$ [86].

A Massa Específica caracteriza a quantidade de massa no volume mas não o comportamento do fluido. Por exemplo, a uma temperatura de $15,6{ }^{\circ} \mathrm{C}$ temos que as massas específicas da água e do óleo SAE 30 são respectivamente $1000 \mathrm{~kg} / \mathrm{m}^{3}$ e $912 \mathrm{~kg} / \mathrm{m}^{3}$, ou seja valores próximos. Porém o comportamento no qual escoam é relevantemente diferente. Um forte indicador dessa diferença é a propriedade viscosidade.

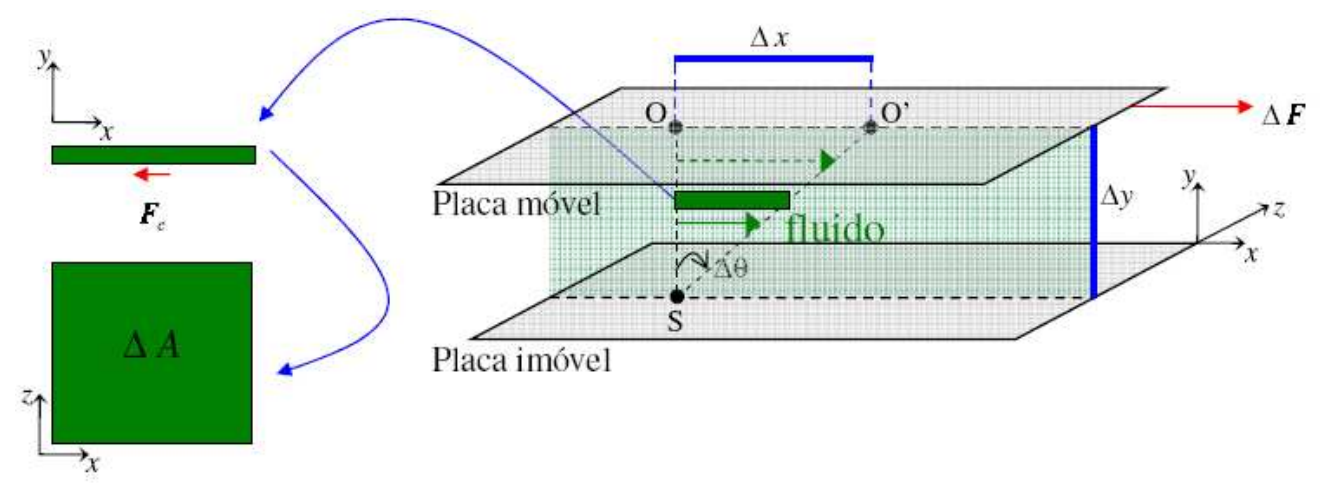

Figura 3.1: Escoamento entre duas placas paralelas ilustrando a tensão de cisalhamento.

A Viscosidade é uma propriedade que descreve a naturalidade de como o fluido escoa, ou ainda uma medida que modela a resistência ao movimento do fluido. Para compreensão da viscosidade considere duas placas paralelas de grande tamanho (figura 3.1), cujo fluido escoa em regime laminar entre elas. A placa inferior encontra-se imóvel e a superior, submetida a uma força de intensidade $\Delta \mathbf{F}$, é posta em movimento uniforme cuja velocidade é $U$. Nesta configuração, como amplamente constatado em experimentos e aceito pela comunidade científica, o fluido adjacente à parede toma a mesma velocidade da parede, então o perfil de velocidade entre as placas, após alcançado o regime estacionário, é do tipo linear [56] [80] conforme está ilustrado na figura 3.1.

Considerando que a velocidade do fluido seja

$$
u(y)=\frac{U}{\Delta y} y
$$

temos que $\frac{d u}{d y}=\frac{U}{\Delta y}$. Ou seja, a taxa de variação da velocidade na direção $y$ é constante.

Se num tempo $t_{0}$ uma porção de fluido está alinhada em $\overline{S O}$, passado um pequeno intervalo de tempo $\Delta t$ temos que esta porção estará alinhada em $\overline{S O^{\prime}}$ descrevendo uma pequena variação de 
ângulo $\Delta \theta$, desta forma:

$$
\tan (\Delta \theta)=\frac{\Delta x}{\Delta y} \quad \text { e } \quad \tan (\Delta \theta) \cong \Delta \theta
$$

como $\Delta x=U . \Delta t$ segue que

$$
\Delta \theta \cong \frac{\Delta x}{\Delta y}=\frac{U \cdot \Delta t}{\Delta y} \quad \Rightarrow \quad \Delta \theta \cong \frac{U \cdot \Delta t}{\Delta y}
$$

Definindo a Taxa de Deformação por Cisalhamento, indicada por $D$, através da relação:

$$
D=\lim _{\Delta t \rightarrow 0} \frac{\Delta \theta}{\Delta t}
$$

então mediante (3.3) podemos escrever

$$
D=\lim _{\Delta t \rightarrow 0} \frac{\Delta \theta}{\Delta t}=\lim _{\Delta t \rightarrow 0} \frac{U \cdot \Delta t / \Delta y}{\Delta t}=\lim _{\Delta t \rightarrow 0} \frac{U}{\Delta y}=\frac{U}{\Delta y}=\frac{d u}{d y}
$$

ou finalmente

$$
D=\frac{d u}{d y}
$$

Por outro lado, na ocorrência do movimento do fluido em regime laminar, o escorregamento de uma camada de fluido sobre a outra produz a Tensão de Cisalhamento, denotada por $\tau$, que é resultado da força cisalhante $\mathbf{F}_{\mathbf{c}}$ na camada de fluido, figura 3.1, de área $\Delta A$, ou seja:

$$
\tau=\frac{\mathbf{F}_{\mathbf{c}}}{\Delta A}
$$

É verificado experimentalmente que a variação da Tensão de Cisalhamento implica na variação da Taxa de Deformação por Cisalhamento [113]. Sendo assim, podemos escrever que

$$
\tau(D) \propto D
$$

Para muitos tipos de fluidos a proporcionalidade acima é bem modelada na forma linear, então podemos escrever $\tau=\mu . D$ ( $\mu$ constante) ou ainda, mediante a equação (3.4)

$$
\tau=\mu \cdot \frac{d u}{d y}
$$

Por exemplo no caso da água e do ar, resultados expressivos tem sido obtidos por várias pesquisas ao longo do tempo com essa relação. A equação (3.7) é conhecidada como a lei de Newton da viscosidade [68], a unidade de $\mu$ pode ser $N . s / m^{2}$.

Fluidos cuja viscosidade é modelada pela relação (3.7) são denominados Fluidos Newtonianos. No entanto, observamos na natureza escoamentos que apresentam características que não podem ser 
modelados pela lei de Newton, por exemplo: fundidos de polímeros, suspensões em misturas, acetado de celulose, sangue, mel, entre outros. Esta impossibilidade de descrever a dinâmica destes fluidos via Lei de Newton pode ser atribuída à influência de alguns fatores na viscosidade, como a dependência com a taxa de deformação, concentração, temperatura, tempo, etc. Quando a viscosidade assume este comportamento, ela passa a ser chamada de Viscosidade Aparente (denotada por $\eta$ ), o escoamento passa a ser denominado escoamento de Fluido Não-Newtoniano [14] .

\begin{tabular}{|c|c|c|c|}
\hline $\begin{array}{c}\text { Temperatura } \\
\left({ }^{\circ} \mathrm{C}\right)\end{array}$ & $\begin{array}{c}\text { Massa Específica } \\
k g / m^{3}\end{array}$ & $\begin{array}{c}\text { Viscosidade Dinâmica } \\
N . s / m^{2}\end{array}$ & $\begin{array}{c}\text { Tensão Superficial } \\
N / m\end{array}$ \\
\hline \hline 00 & 0999.9 & $1.787 \mathrm{e}-3$ & $7.56 \mathrm{e}-2$ \\
\hline 05 & 1000.0 & $1.519 \mathrm{e}-3$ & $7.49 \mathrm{e}-2$ \\
\hline 10 & 0999.7 & $1.307 \mathrm{e}-3$ & $7.42 \mathrm{e}-2$ \\
\hline 20 & 0998.2 & $1.002 \mathrm{e}-3$ & $7.28 \mathrm{e}-2$ \\
\hline 30 & 0995.7 & $7.975 \mathrm{e}-4$ & $7.12 \mathrm{e}-2$ \\
\hline 40 & 0992.2 & $6.529 \mathrm{e}-4$ & $6.96 \mathrm{e}-2$ \\
\hline 50 & 0988.1 & $5.468 \mathrm{e}-4$ & $6.79 \mathrm{e}-2$ \\
\hline 60 & 0983.2 & $4.665 \mathrm{e}-4$ & $6.62 \mathrm{e}-2$ \\
\hline 70 & 0977.8 & $4.042 \mathrm{e}-4$ & $6.44 \mathrm{e}-2$ \\
\hline 80 & 0971.8 & $3.547 \mathrm{e}-4$ & $6.26 \mathrm{e}-2$ \\
\hline 90 & 0965.3 & $3.147 \mathrm{e}-4$ & $6.08 \mathrm{e}-2$ \\
\hline 100 & 0958.4 & $3.818 \mathrm{e}-4$ & $5.89 \mathrm{e}-2$ \\
\hline
\end{tabular}

Tabela 3.1: Tabela de variações de propriedades da água. Adaptado de [80].

A massa específica e viscosidade dos fluidos também dependem da pressão, porém de pequena relevância quando comparada a influência da temperatura na maioria dos problemas de interesse [56]. No caso da água, como pode ser observado na tabela 3.1, elevando a temperatura de $20^{\circ} \mathrm{C}$ para $30^{\circ} \mathrm{C}$, houve uma queda de aproximadamente $0,25 \%$ na massa específica e uma diminuição em mais de $20 \%$ na viscosidade dinâmica. Mostrando desta forma a influência da temperatura de maneira diferenciada nessas propriedades.

Assim como a massa específica caracteriza a quantidade de massa no volume infinitesimal, a viscosidade o comportamento no qual escoa um determinado fluido, a tensão superficial procura explicar como se dá a interação entre um líquido e um gás ou entre líquidos imiscíveis, por exemplo. A tensão superficial é uma outra propriedade utilizada para identificar a atuação de forças superficiais 
em fluidos, onde estas forças levam a superfície a se comportar como uma membrana elástica.

Sejam A e B dois fluidos imiscíveis, onde uma porção de A está imerso em B, figura 3.2. As moléculas situadas no interior de A são atraídas em todas as direções pelas moléculas vizinhas que fazem parte de A (simbolizada pelas flexas em cor laranja), estas forças atrativas de curto alcance são as forças de Van der Waals denominadas Forças Coesivas, por este motivo a resultante das forças que atuam sobre cada molécula no interior é praticamente nula.

Porém, as moléculas situadas na fronteira de A sofrem atração por nem todas as direções, disto a resultante é não nula e dirigida para o interior de $\mathbf{A}$, então as forças coesivas entre as moléculas vizinhas localizadas na fronteira experimentam forças coesivas maiores do que aquelas moléculas no interior de A, o valor destas forças é a Tensão Superficial (simbolizada pelas flexas em cor vermelha figura 3.2), ela faz com que o conjunto das moléculas na fronteira comportem-se como uma película elástica estendida.

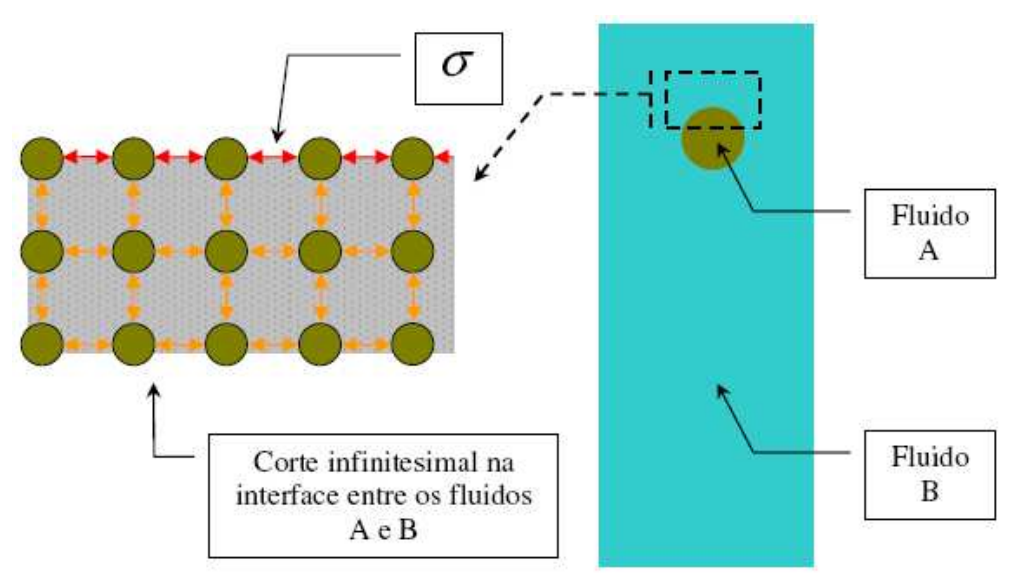

Figura 3.2: Ilustração da força atrativa de coesão.

Denotando a tensão superficial por $\sigma$, então:

$$
\sigma=\frac{\mathbf{F}_{\mathbf{c o e s i v a}}}{L}
$$

onde $\mathbf{F}_{\text {coesiva }}$ é a força intermolecular que atua no plano da superfície e ao longo de qualquer linha, na superfície, cujo comprimento é $L$ [80]. A unidade de $\sigma$ pode ser $N / m$.

A uma temperatura de $20^{\circ}$ centígrados temos para a água que $\sigma=7.28 \times 10^{-2} \mathrm{~N} / \mathrm{m}$, tabela 3.1, isto significa que seria necessária uma força de intensidade de $7.28 \times 10^{-2} \mathrm{~N}$ para corromper um filme superficial de água de comprimento igual a 1 metro. Observe na tabela 3.1 que o aumento da temperatura diminui o valor de $\sigma$. A tensão superficial de uma substância depende fortemente da temperatura, bem como também de outras substâncias em contato com ela própria. Quando se 
aplica o conceito de tensão superficial na fronteira entre duas substâncias, então falamos de Tensão

\section{Interfacial.}

Um outro fato importante na Mecânica dos Fluidos é quanto a Compressibilidade. É entendido pela comunidade científica que a compressibilidade deve ser função apenas da pressão. Porém, de acordo com o uso comum, a compressibilidade de um fluido é definida em termos de sua densidade [113]. Praticamente todos os fluidos são comprimidos se a pressão exercida sobre eles for elevada, desta forma ocorre aumento na massa específica. Um fluido é classificado incompressível quando as variações de densidade com a pressão são insignificantes. Ou também, dizer que um dado fluido é relativamente incompressível quando é necessária uma grande variação de pressão para criar uma variação muito pequena no volume ocupado pelo fluido [80]. Mas vale lembrar também que um fluido pode ser admitido como incompressível ou compressível em função da faixa de operação no qual ele está submetido. Por exemplo, como amplamente estudado pela comunidade científica especializada, o escoamento de ar em certas regiões ao redor de um aerofólio NACA0012 pode ser compressível ou incompressível.

Para gases, se mudanças significativas ocorrem, digamos em $4 \%$, eles devem ser considerados compressíveis. Para pequenas mudanças na densidade, abaixo de $3 \%$, eles podem ser tratados como incompressíveis, isso ocorre para velocidades abaixo de $100 \mathrm{~m} / \mathrm{s}$ [95].

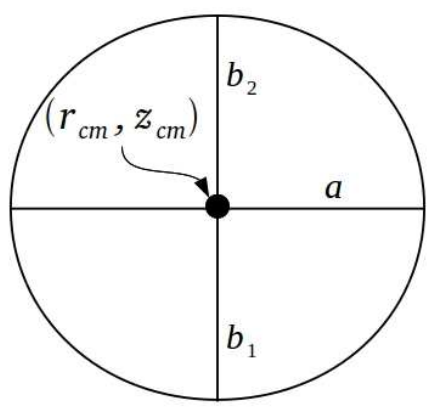

Figura 3.3: Configuração inicial da bolha $b_{1}=b_{2}=a$.

Como neste trabalho tratamos do movimento de ascensão de bolha em meio a fluido viscoso incompressível, então são parâmetros importantes também a Razão de Aspecto $(E)$, o Fator de Distorção $(\gamma)$ [81] e o Diâmetro Equivalente $\left(d_{e q}\right)$ [138], eles são dados por:

$$
E=\frac{b_{1}+b_{2}}{2 a} \quad \gamma=\frac{2 b_{2}}{b_{1}+b_{2}} \quad d_{e q}=\sqrt[3]{4 a^{2}\left(b_{1}+b_{2}\right)}
$$

onde $b_{1}, b_{2}$ e $a$ são respectivamente os semi-eixos verticais (inferior, superior) e horizontal. Além 
disto, temos ainda o termo $\left(r_{c m}, z_{c m}\right)$ como o centro de massa para uma configuração de bolha como ilustrado na figura 3.3.

Com as definições dessas propriedades, passamos agora a descrever alguns números adimensionais de interesse. Os números adimensionais são parâmetros que trazem informações adicionais sobre o fenômeno em estudo, eles permitem ilimitados resultados experimentais que são aplicados em situações envolvendo diferentes dimensões físicas [118], são eles:

- Número de Reynolds:

$$
R e=\frac{L U}{\nu_{0}}
$$

- Número de Froude:

$$
F r=\frac{U^{2}}{L g_{0}}
$$

- Número de Weber:

$$
W e=\frac{\rho L U^{2}}{\sigma}
$$

- Número de Schmidt:

$$
S c=\frac{\nu_{0}}{D^{m}}
$$

- Número de Peclet:

$$
P e=\frac{L U}{D^{m}}
$$

- Número de Eötvös:

$$
E_{o}=\frac{g_{0} L^{2}\left|\rho_{c}-\rho_{d}\right|}{\sigma}
$$

\section{- Número de Bond:}

$$
B o=\frac{g_{0} L^{2} \rho_{c}}{\sigma}
$$

\section{- Número de Morton:}

$$
M o=\frac{g_{0}\left(\nu_{0}\right)^{2} \rho_{c}^{2}\left|\rho_{c}-\rho_{d}\right|}{\sigma^{3}}
$$

onde $L, U$ são valores de referência de comprimento e velocidade, $\nu_{0}$ a viscosidade cinemática de escala, $g_{0}$ é aceleração da gravidade, $D^{m}$ a difusividade mássica e $\rho_{c}, \rho_{d}$ a massa específica dos meios contínuo e disperso respectivamente. 


\subsection{Equações da Mecânica dos Fluidos}

Nesta seção faremos as descrições matemáticas das leis gerais da mecânica dos fluidos e do transporte de matéria. Esta última será utilizada na modelagem da viscosidade. Na seção subsequente, trataremos da aplicação da segunda lei de newton no equacionamento do movimento da bolha.

A notação utilizada neste trabalho será aquela usual em literatura de Mecânica dos Fluidos. Mas sempre que possível o texto não será sobrecarregado com notação funcional.

As equações da mecânica dos fluidos são derivadas dos princípios de conservação: da massa e da quantidade de movimento para fluido incompressível. As variáveis de interesse das equações evolutivas são a massa específica $(\rho)$ e velocidade (v), que por sua vez, podem ter uma dependência funcional da posição $(\mathbf{x})$ e tempo $(t)$.

Existem algumas maneiras de se estabelecer as leis matemáticas que modelam os princípios de conservação. Optamos para este trabalho utilizar a técnica que faz uso de sistemas, volumes e superfícies de controle, cujo vínculo entre eles é dado pelo Teorema do Transporte de Reynolds.

Por definição um sistema é uma certa quantidade de material (substância) composto sempre pelas mesmas partículas, que escoa e interage com o meio. O volume de controle é um volume no espaço através do qual o fluido escoa e a superfície de controle é a face deste volume [80].

Se $N$ é o parâmetro físico (propriedade extensiva) e $n$ é a quantidade deste parâmetro por unidade de massa (propriedade intensiva). E considerando ainda que $m$ é a massa de uma porção analisada ou seja, $N=m . n$, então o Teorema de Transporte de Reynolds é formulado como:

$$
\left.\frac{D N}{D t}\right|_{\text {sistema }}=\frac{\partial}{\partial t} \int_{v c} n \rho d V+\int_{s c} n \rho(\mathbf{v . n}) d A
$$

onde:

- $\left.\frac{D N}{D t}\right|_{\text {sistema }}$ é a taxa de variação temporal da propriedade extensiva no sistema

- $\frac{\partial}{\partial t} \int_{v c} n \rho d V$ é a taxa de variação temporal da propriedade extensiva no volume de controle $v c$

- $\int_{s c} n \rho(\mathbf{v} . \mathbf{n}) d A$ é a vazão líquida da propriedade extensiva através da superfície de controle $s c$ Representando a massa total do sistema na forma $\mathbf{M}_{\text {sistema }}=\int_{\text {sistema }} \rho d V$, em que a integral representa o somatório das massas de todos os volumes elementares do sistema. E se as propriedades extensiva e intensiva são respectivamente $N=\mathrm{M}_{\text {sistema }}$ e $n=1$, então de (3.18) obtemos 


$$
\frac{D}{D t} \int_{\text {sistema }} \rho d V=\frac{\partial}{\partial t} \int_{v c} \rho d V+\int_{s c} \rho(\mathbf{v} \cdot \mathbf{n}) d A
$$

A equação (3.19) descreve que a taxa de variação temporal da massa do sistema é resultado da soma entre a taxa de variação temporal da massa no volume de controle com a vazão líquida da massa através da superfície de controle [80] [41].

Se o princípio de conservação da massa é estabelecido, isto significa então que a taxa de variação temporal da massa do sistema tem de ser nula, logo a equação (3.19) fica

$$
0=\frac{\partial}{\partial t} \int_{v c} \rho d V+\int_{s c} \rho(\mathbf{v . n}) d A
$$

mas aplicando o teorema da divergência A.0.2 na equação anterior e permutando a derivação com a integração, podemos escrever ainda, em notação indicial,

$$
\int_{v c}\left(\frac{\partial \rho}{\partial t}+\frac{\partial}{\partial x_{j}}\left(\rho v_{j}\right)\right)=0
$$

que por sua vez implica em afirmar que

$$
\frac{\partial \rho}{\partial t}+\frac{\partial}{\partial x_{j}}\left(\rho v_{j}\right)=0
$$

que é conhecida como a equação de conservação da massa ou também como equação da continuidade. Em particular, para escoamentos incompressíveis $\rho$ é constante e a equações anterior pode ser simplicada em

$$
\frac{\partial}{\partial x_{j}}\left(v_{j}\right)=0
$$

Se considerarmos uma partícula com massa $\rho d V$ movimentando-se a uma velocidade $\mathbf{v}$, a quantidade de movimento é definida como $\rho d V \mathbf{v}$, logo a quantidade de movimento para um sistema será dada por $\int_{\text {sistema }} \rho \mathbf{v} d V$. Mas sabemos da $2^{a}$ lei de Newton para o sistema que

$$
\sum \mathbf{F}_{\text {sistema }}=m \cdot \mathbf{a}=m \cdot \frac{D \mathbf{v}}{D t}=\frac{D}{D t}(m \cdot \mathbf{v})_{\text {sistema }}=\frac{D}{D t}\left(\int_{\text {sistema }} \rho \mathbf{v} d V\right)
$$

Por outro lado quando o volume de controle é coincidente com o sistema, as forças atuantes no sistema atuam no conteúdo do volume de controle (cvc), assim é verdade também que

$$
\sum \mathbf{F}_{\text {sistema }}=\sum \mathbf{F}_{\mathrm{cvc}}
$$

Agora, se as propriedades extensiva e intensiva são respectivamente $N=\int_{\text {sistema }} \rho \mathbf{v} d V$ e $n=\mathbf{v}$, então de (3.18) obtemos 


$$
\frac{D}{D t} \int_{\text {sistema }} \rho \mathbf{v} d V=\frac{\partial}{\partial t} \int_{v c} \rho \mathbf{v} d V+\int_{s c} \rho \mathbf{v}(\mathbf{v} . \mathbf{n}) d A
$$

onde esta equação descreve que a taxa de variação temporal da quantidade de movimento do sistema é igual a soma entre a taxa de variação temporal da quantidade de movimento do conteúdo no volume de controle e o fluxo líquido de quantidade de movimento através da superfície de controle [80] [41].

Combinando então (3.22), (3.23) e (3.24) a formulação matemática para da $2^{a}$ lei de Newton para volumes será

$$
\begin{aligned}
\sum \mathbf{F}_{\text {sistema }} & =\sum \mathbf{F}_{\mathrm{cvc}} \\
\frac{D}{D t}\left(\int_{\text {sistema }} \rho \mathbf{v} d V\right) & =\sum \mathbf{F}_{\mathrm{cvc}} \\
\frac{\partial}{\partial t} \int_{v c} \rho \mathbf{v} d V+\int_{s c} \rho \mathbf{v}(\mathbf{v} \cdot \mathbf{n}) d A & =\sum \mathbf{F}_{\mathrm{cvc}}
\end{aligned}
$$

que resulta, via A.0.2, na equação

$$
\int_{v c} \frac{\partial}{\partial t}\left(\rho v_{i}\right) d V+\int_{v c} \frac{\partial}{\partial x_{j}}\left(\rho v_{i} v_{j}\right) d V=\sum \mathbf{F}_{\mathrm{cvc}}
$$

mas as forças que agem sobre o conteúdo do volume de controle são tais que $\sum \mathbf{F}_{\mathrm{cvc}}=\mathbf{F}_{s}+\mathbf{F}_{b}$, em que $\mathbf{F}_{s}$ representa a força total de contato (pressão e/ou cisalhamento) e $\mathbf{F}_{b}$ alguma(s) força(s) de campo por unidade de volume, neste caso a gravidade é considerada, então escrevemos ainda

$$
\int_{v c} \frac{\partial}{\partial t}\left(\rho v_{i}\right) d V+\int_{v c} \frac{\partial}{\partial x_{j}}\left(\rho v_{i} v_{j}\right) d V=\mathbf{F}_{s}+\mathbf{F}_{b}
$$

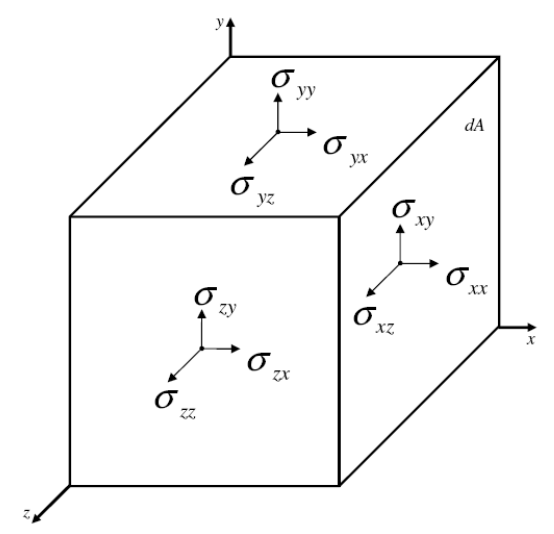

Figura 3.4: Ilustração das forças de Tensão agindo sobre as faces de um volume.

A força de contato que age na superfície de um elemento de área $d A$ é dada por $\boldsymbol{\sigma} \mathbf{n} d A$, figura 3.4, disto a força de contato total que age por toda a superfície de controle resulta em $\int_{s c} \boldsymbol{\sigma} \mathbf{n} d A$; e a força de campo total é dada por $\int_{v c} \rho \mathbf{g} d V$. Desta forma, a equação anterior é escrita por 


$$
\int_{v c} \frac{\partial}{\partial t}\left(\rho v_{i}\right) d V+\int_{v c} \frac{\partial}{\partial x_{j}}\left(\rho v_{i} v_{j}\right) d V=\int_{s c} \boldsymbol{\sigma} \mathbf{n} d A+\int_{v c} \rho \mathbf{g} d V
$$

O termo $\sigma$ é um tensor que traz em si a pressão e a tensão de cisalhamento. A pressão age na intensão de manter a integridade do volume, ela ocorre em sentido contrário ao vetor normal e a tensão cisalhante ocorre na face do mesmo. Denotando os termos de pressão e cisalhamento como $\mathbf{p}$ e $\tau$ respectivamente, o tensor tensão fica

$$
\sigma_{i, j}=\left(\begin{array}{ccc}
\sigma_{11} & \sigma_{12} & \sigma_{13} \\
\sigma_{21} & \sigma_{22} & \sigma_{23} \\
\sigma_{31} & \sigma_{32} & \sigma_{33}
\end{array}\right)=\left(\begin{array}{ccc}
-p & 0 & 0 \\
0 & -p & 0 \\
0 & 0 & -p
\end{array}\right)+\left(\begin{array}{ccc}
\tau_{11} & \tau_{12} & \tau_{13} \\
\tau_{21} & \tau_{22} & \tau_{23} \\
\tau_{31} & \tau_{32} & \tau_{33}
\end{array}\right)
$$

note que agora a tensão de cisalhamento é um tensor de 9 componentes, então sua notação passa a ser na forma $\tau_{i j}$. Se o vetor $\mathbf{g}=g_{i}$, então as integrais do lado direito de (3.25) ficam

$$
\int_{s c} \boldsymbol{\sigma} \cdot \mathbf{n} d A=\int_{v c} \frac{\partial}{\partial x_{j}} \sigma_{i j} d V \quad \text { e } \quad \int_{v c} \rho \mathbf{g} d V=\int_{v c} \rho g_{i} d V
$$

e finalmente (3.25) é escrita por

$$
\int_{v c} \frac{\partial}{\partial t}\left(\rho v_{i}\right) d V+\int_{v c} \frac{\partial}{\partial x_{j}}\left(\rho v_{i} v_{j}\right) d V=\int_{v c} \frac{\partial}{\partial x_{j}} \sigma_{i j} d V+\int_{v c} \rho g_{i} d V
$$

que é a equação de conservação da quantidade de movimento na forma integral.

A equação acima é válida para todo volume de controle, em particular tomando as integrações sobre um volume de controle infinitesimal $v c$ e dividindo toda essa equação por $v c$ obtemos a equação de conservação da quantidade de movimento na forma diferencial, que é expressa por

$$
\frac{\partial}{\partial t}\left(\rho v_{i}\right)+\frac{\partial}{\partial x_{j}}\left(\rho v_{i} v_{j}\right)=\frac{\partial}{\partial x_{j}} \sigma_{i j}+\rho g_{i}
$$

Para o caso da interação entre dois fluidos num escoamento multifásico, como por exemplo o transporte de uma bolha de gás num meio aquoso, a tensão interfacial entre o gás e o meio torna-se importante, ela é uma força de campo. Seu efeito pode ser introduzido no modelo matemático via condições de contorno ou através da adição como termo fonte na equação da quantidade de movimento, estes procedimentos são equivalentes [115]. Se $f_{i}$ é a força vinculada a tensão interfacial, então a equação anterior toma a forma

$$
\frac{\partial}{\partial t}\left(\rho v_{i}\right)+\frac{\partial}{\partial x_{j}}\left(\rho v_{i} v_{j}\right)=\frac{\partial}{\partial x_{j}} \sigma_{i j}+\rho g_{i}+f_{i}
$$

Vários modelos foram propostos com o objetivo de modelar a representação da interface em escoamentos multifásicos, ver detalhes em [115]. Em particular um modelo que faz uso da função de 
Heaviside, utilizada para identificar fluidos imiscíveis, foi utilizado no trabalho de Souza et. al [116], lá uma de suas simulações foi o transporte de duas bolhas num meio líquido com diferentes densidades e viscosidades, constituindo então um problema multifluidos. Já o trabalho de Hua et al. eles utilizaram um modelo para a tensão interfacial dado por uma forma integral (tomada na superfície) sobre o coeficiente de tensão interfacial, curvatura local da superfície e uma função salto. Nesse trabalho eles simularam a ascensão de bolhas de ar na água [55]. Nós não optamos por nenhuma destas técnicas, mas uma terceira opção que será descrita mais a frente na seção 3.3 página 38, portanto suprimimos o termo $f_{i}$ e consideramos em nosso trabalho a equação

$$
\frac{\partial}{\partial t}\left(\rho v_{i}\right)+\frac{\partial}{\partial x_{j}}\left(\rho v_{i} v_{j}\right)=\frac{\partial}{\partial x_{j}} \sigma_{i j}+\rho g_{i}
$$

As relações (3.21) e (3.29) são as equações diferencias parciais não lineares com coeficientes variáveis escritas de forma geral, que podem ser utilizadas para modelar o escoamento tridimensional de fluidos incompressíveis. Para complementar a descrição dessas equações, com o intuito de simular a ascensão de bolha no sedimento, é relevante o tratamento Físico/Matemático do tensor $\sigma_{i j}$.

Observe em (3.26) que o tensor pode ser denotado como $\sigma_{i j}=-p \delta_{i j}+\tau_{i j}$. É sobre este termo que efetuamos a distinção entre fluidos newtonianos e não-newtonianos. O tensor das tensões $\sigma_{i j}$ é composto a partir dos termos de pressão $-p \delta_{i j}$ e cisalhamento $\tau_{i j}$.

O termo de pressão $-p \delta_{i j}$ é definido como a tensão normal ao elemento fluido, ele atua no sentido de efetuar compressão [80].

O termo de cisalhamento caracteriza o fluido que escoa. Na seção 3.1 página 27 foi abordado sucintamente a questão do fluido ser caracterizado como newtoniano ou não-newtoniano, com a taxa de deformação por cisalhamento dada por $D$. No caso geral, essa taxa é um tensor de nove componentes que é denotado como $D_{i j}$

De forma mais específica, podemos dizer que um fluido é newtoniano quando a relação entre $\tau_{i j}$ e $D_{i j}$ é do tipo linear. Se a relação entre $\tau_{i j}$ e $D_{i j}$ é do tipo não linear, então é dito que o fluido é não-newtoniano. Para esse fluido a inclinação da reta tangente num ponto do gráfico de $\tau_{i j}$ é variável, então esta é denominada viscosidade aparente e simbolizada por $\eta$ [80].

Portanto, o comportamento da não linearidade da tensão $\tau_{i j}$ resulta na origem de vários modelos matemáticos, que objetivam descrever as características do escoamento do fluido em questão. Esses modelos são costumeiramente denominados por Modelos Reológicos.

Voltando a modelagem de fluidos, consideremos um elemento cúbico de fluido então o tensor taxa de deformação por cisalhamento sobre o elemento pode ser escrito na forma [126] [125] 


$$
D_{i j}=\left(\frac{\partial v_{i}}{\partial x_{j}}+\frac{\partial v_{j}}{\partial x_{i}}\right)
$$

assim a lei de Newton para a viscosidade $\tau_{i j}=\mu D_{i j}$ é utilizada nas simulações de escoamentos de fluidos newtonianos.

Por outro lado, uma forma de se escrever o tensor $\sigma_{i j}$ é:

$$
\sigma_{i j}=-p \delta_{i j}+\mu(I, I I, I I I) D_{i j}
$$

onde

$$
I=\operatorname{tr}\left(D_{i j}\right) \quad I I=\operatorname{tr}\left(D_{i j}^{2}\right) \quad I I I=\operatorname{tr}\left(D_{i j}^{3}\right)
$$

são funções dos principais invariantes do tensor $D_{i j}$ [92].

Para fluidos incompressíveis $I=0$ e para escoamentos puramente cisalhantes $I I I=0$, então $\mu$

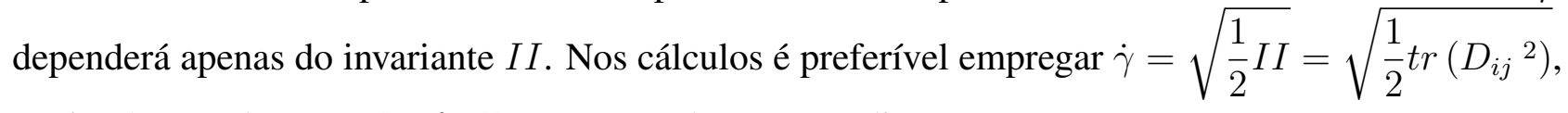
aqui $\dot{\gamma}$ é o escalar taxa de cisalhamento, sob essas condições

$$
\tau_{i j}=\mu D_{i j}
$$

é o modelo newtoniano generalizado.

O modelo newtoniano generalizado pode ser usado para descrever escoamentos cisalhantes de alguns fluidos não newtonianos, pela introdução de uma variação da viscosidade com a taxa de cisalhamento [67]. Ressaltamos ainda, que a viscosidade pode também depender de outras variáveis, ou seja $\mu \equiv \mu(\dot{\gamma}, T, P, c, \ldots)$ onde $T$ é a temperatura, $P$ a pressão, $c$ a concentração [27], entre outros. No Apêndice B página 147, são dadas informações adicionais sobre alguns modelos para a viscosidade. A título de informação adicional, Tomé et al. em seu artigo utilizou uma técnica numérica para resolver o escoamento tridimensional com superfície livre, neste trabalho foi simulado um escoamento newtoniano generalizado em que a viscosidade foi modelada pelo modelo Cross, equação B.2. Os resultados foram apresentados e validados para o escoamento plenamente desenvolvido num tubo, jato sobre uma superfície e de uma esfera de fluido repousando sobre uma superfície plana [128].

Diante então da breve exposição acima, escrevemos a equação de momento com a viscosidade variável tomando por hipótese o modelo newtoniano generalizado para a tensão $\tau_{i j}$.

Levando o termo (3.31) em $\sigma_{i j}=-p \delta_{i j}+\tau_{i j}$, teremos que a equação (3.29) pode ser escrita por 


$$
\begin{aligned}
\frac{\partial}{\partial t}\left(v_{i}\right)+\frac{\partial}{\partial x_{j}}\left(v_{i} v_{j}\right) & =\frac{1}{\rho} \frac{\partial}{\partial x_{j}} \sigma_{i j}+g_{i} \\
& =\frac{1}{\rho} \frac{\partial}{\partial x_{j}}\left[-p \delta_{i j}+\mu D_{i j}\right]+g_{i} \\
& =-\frac{1}{\rho} \frac{\partial p}{\partial x_{j}}+\frac{1}{\rho} \frac{\partial \mu}{\partial x_{j}} D_{i j}+\frac{\mu}{\rho} \frac{\partial D_{i j}}{\partial x_{j}}+g_{i} \\
& =-\frac{1}{\rho} \frac{\partial p}{\partial x_{j}}+\frac{\partial(\mu / \rho)}{\partial x_{j}}\left(\frac{\partial v_{i}}{\partial x_{j}}+\frac{\partial v_{j}}{\partial x_{i}}\right)+\frac{\mu}{\rho}\left[\frac{\partial^{2} v_{i}}{\partial x_{j}^{2}}+\frac{\partial}{\partial x_{i}}\left(\frac{\partial v_{j}}{\partial x_{j}}\right)\right]+g_{i}
\end{aligned}
$$

e como da equação da continuidade $\frac{\partial v_{j}}{\partial x_{j}}=0$, pois admitimos o invariante $I=0$, então a equação acima fica na forma:

$$
\frac{\partial}{\partial t}\left(v_{i}\right)+\frac{\partial}{\partial x_{j}}\left(v_{i} v_{j}\right)=-\frac{1}{\rho} \frac{\partial p}{\partial x_{j}}+\frac{\partial \nu}{\partial x_{j}}\left(\frac{\partial v_{i}}{\partial x_{j}}+\frac{\partial v_{j}}{\partial x_{i}}\right)+\nu \frac{\partial^{2} v_{i}}{\partial x_{j}^{2}}+g_{i}
$$

Abordando agora a questão de transporte, em [132] o autor diz que num sistema hídrico o transporte de uma substância ao longo do tempo e do espaço está sujeito a processos físicos, químicos e biológicos, o transporte ocorre devido à advecção, difusão e dispersão no corpo d'água. Em vista a este fato (como alguma porção de sedimento é transportada decorrente do movimento da bolha, isto será amplamente detalhado mais a frente) e assumindo que não existem flutuações relevantes quanto ao efeito de dispersão, descrevemos agora a equação de transporte advectiva-difusiva sem a parte reativa.

Seja

$$
N=N_{a}+N_{d}
$$

o fluxo total de matéria, onde

$$
N_{a}=v_{j} c \quad \text { e } \quad N_{d}=-D^{m} \frac{\partial c}{\partial x_{j}}
$$

com $v_{j}$ sendo a velocidade do fluido, $c$ a concentração da matéria e $D^{m}$ o coeficiente de difusividade mássica. O fluxo advectivo $N_{a}$ é aquele que transporta a matéria segundo a velocidade do fluido e o fluxo difusivo $N_{d}$ é dado pela lei de Fick.

Supondo que a matéria não pode ser criada ou destruída e desprezando a geração interna, o princípio de conservação diz que [113]:

$$
\left\{\begin{array}{c}
\text { A taxa de matéria } \\
\text { que entra no } \\
\text { volume infinitesimal }
\end{array}\right\}=\left\{\begin{array}{c}
\text { A taxa de matéria } \\
\text { que sai do } \\
\text { volume infinitesimal }
\end{array}\right\}+\left\{\begin{array}{c}
\text { A taxa de matéria } \\
\text { acumulada no } \\
\text { volume infinitesimal }
\end{array}\right\}
$$




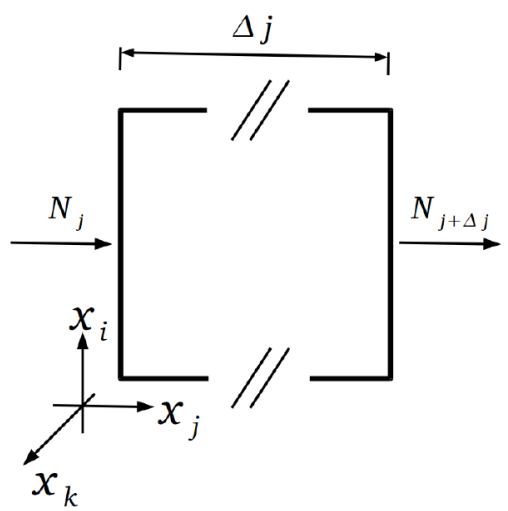

Figura 3.5: Fluxo total através das faces de um volume infinitesimal.

Com o auxílio da figura 3.5, supondo que os fluxos de entrada e saida ocorram através das faces $j$ e $j+\Delta j$ num volume infinitesimal, então a lei de conservação para o fluxo total fica dada por:

$$
N_{j} \Delta j \Delta k=N_{j+\Delta j} \Delta j \Delta k+\frac{\partial c}{\partial t} \Delta i \Delta j \Delta k
$$

que depois de reagrupada e passando o limite reduz-se a $\frac{\partial c}{\partial t}=-\frac{\partial N_{j}}{\partial x_{j}}$. Substituindo o fluxo dado pela equação (3.33) nesta equação obtemos

$$
\frac{\partial c}{\partial t}+\frac{\partial\left(v_{j} c\right)}{\partial x_{j}}=\frac{\partial}{\partial x_{j}}\left(D^{m} \frac{\partial c}{\partial x_{j}}\right)
$$

então, finalmente, a equação (3.35) fica expressa na forma

$$
\frac{\partial c}{\partial t}+\frac{\partial\left(v_{j} c\right)}{\partial x_{j}}=D^{m} \frac{\partial^{2} c}{\partial x_{j}^{2}}
$$

que é a equação de transporte advectiva-difusiva da matéria, cuja concentração no meio é dada por $c$.

\subsection{Equações de Ascensão da Bolha}

A bolha é constituída por um agregado de gás que por sua vez movimenta-se no meio fluido. Em nosso caso o movimento da bolha é modelado com a segunda lei de Newton. Especificamente, aplicamos a lei de Newton pontualmente no centro de massa da bolha. Fazemos o balanço entre as forças de empuxo, peso e a força que o fluido circundante exerce na bolha. Novamente, a nossa idéia é não resolver as equações da mecânica dos fluidos para o gás, mas sim para o fluido externo à bolha.

Considere que:

- a bolha de gás ascenda num fluido viscoso na direção da superfície, sob condições tais que as mudanças de pressão hidrostática com a profundidade não são significativas e não podem ser omitidas; 
- o movimento da bolha promova alterações no campo de velocidade do fluido de tal forma que o escoamento seja do tipo laminar;

- é passível a mudança de forma da bolha (por conta da razão de aspecto e do fator de distorção) e que a mesma seja simétrica em relação ao eixo vertical, mas que o volume seja invariante;

- as únicas forças que atuam no movimento são o empuxo (E) (vertical), peso (P) (vertical) e a resistência ao movimento da bolha (FV) (na fronteira da bolha).

Então a segunda lei de Newton aplicada ao movimento do centro de massa da bolha produz a seguinte equação vetorial

$$
\mathbf{E}-\mathbf{P}+\mathbf{F V}=m_{b} \frac{d}{d t} \mathbf{v b}
$$

onde $m_{b}$ é a massa de gás, $\frac{d}{d t} \mathbf{v b}$ e vb são os vetores aceleração e velocidade do centro de massa da bolha.

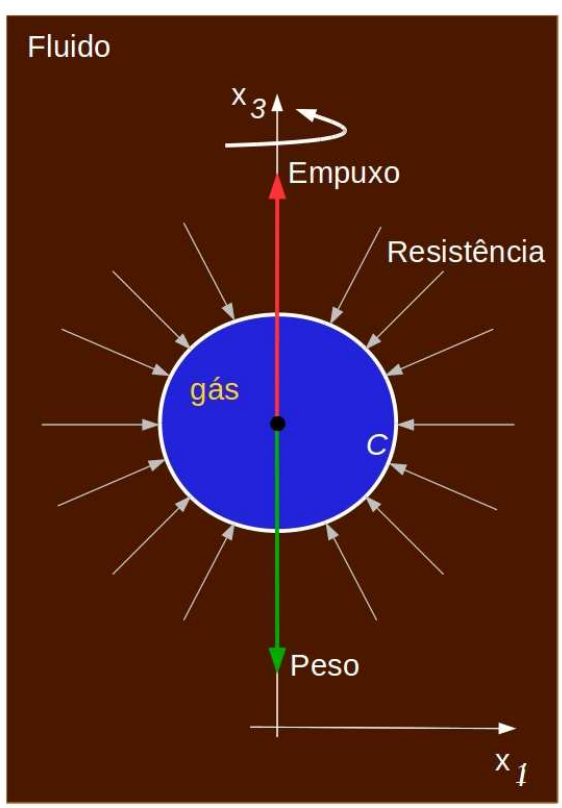

Figura 3.6: Esquema de configuração das forças atuantes sobre a bolha.

Considerando a figura 3.6, o empuxo é de magnitude do peso de fluido deslocado. Age apenas na direção e sentido do eixo vertical e o ponto de aplicação desta força, centro de empuxo, coincide com o centróide do volume da bolha. A componente de interesse do empuxo é calculada mediante a expressão $\rho_{c} g_{0} v o l$ e as outras são nulas. O peso é localizado no centróide da bolha, na mesma direção do empuxo porém em sentido contrário. A componente vertical é $\rho_{d} g_{0} v o l$, as outras são nulas. Nestas 
expressões, os termos $v o l, \rho_{c}, \rho_{d}$ e $g_{0}$ são respectivamente o volume da bolha, as massas específicas do fluido e gás e o valor local da gravidade $9.81 \mathrm{~m} / \mathrm{s}^{2}$.

Na literatura são apresentados alguns modelos para a resistência ao movimento. Nos livros [120], [5] os autores sugerem um modelo dado pela função potência que é ajustada a dados experimentais. Em [135] o autor sugere um modelo tomando como base a viscosidade do fluido, o raio e a profundidade da bolha. Nós levamos em consideração idéias análogas àquelas descritas em [93], equacionamos a força que o fluido exerce sobre a bolha. Então passamos agora a descrever a nossa modelagem matemática.

Considerando o tensor tensão cisalhante, a força que o fluido exerce sobre um elemento de comprimento $d l$ é $\tau_{i j} n_{j} d l$. Desta forma, a resultante ao longo de toda a curva $C$ (ver figura 3.6), rotacionado de $2 \pi r$, é calculada pela integral

$$
F V_{j}=\int_{C} 2 \pi r \tau_{i j} n_{j} d l
$$

ou ainda

$$
F V_{j}=\int_{C} 2 \pi r\left(\mu D_{i j}\right) n_{j} d l
$$

Uma vez que da segunda lei de Newton escrevemos $m_{b} \frac{d}{d t} \mathbf{v b}=\rho_{d} v o l \frac{d}{d t} v b_{j}$, a equação (3.37) do movimento é dada pela lei

$$
E_{j}-P_{j}+\int_{C} 2 \pi r\left(\mu D_{i j}\right) n_{j} d l=\rho_{d} v o l \frac{d}{d t} v b_{j}
$$

Portanto, o movimento de ascensão da bolha é governado pelo sistema de equações diferenciais da forma

$$
\left\{\begin{aligned}
\frac{d}{d t} v b_{j} & =\frac{1}{\rho_{d} v o l}\left[E_{j}-P_{j}+\int_{C} 2 \pi r\left(\mu D_{i j}\right) n_{j} d l\right] \\
\frac{d}{d t} x b_{j} & =v b_{j}
\end{aligned}\right.
$$

aqui o termo $x b_{j}$ representa as coordenadas espaciais de localização do centro de massa.

Observamos que o acoplamento entre as equações do movimento da bolha e da mecânica dos fluidos se dá pela integral, pois o integrando é decorrente da viscosidade e campo de velocidade do fluido que circunda a bolha. 


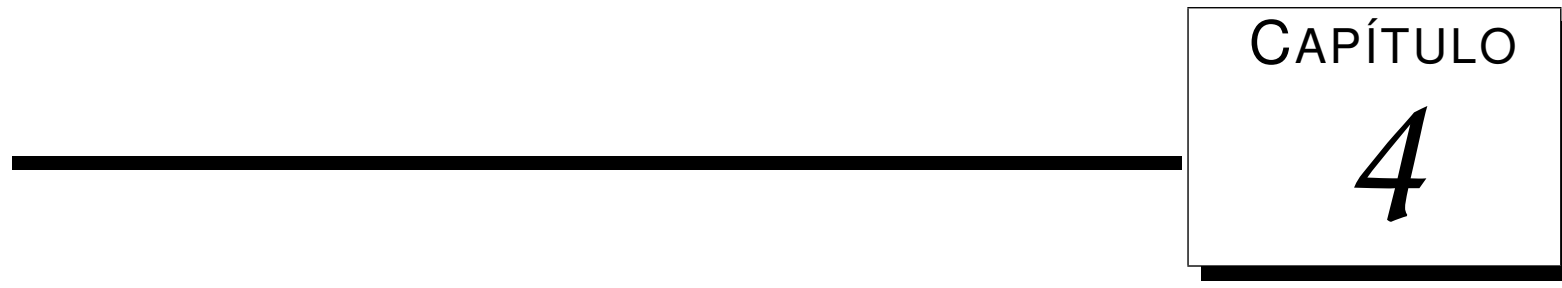

\section{Equações Adicionais para o Fluido}

\section{Sedimentar e Geometria da Bolha}

\subsection{Modelagem da Viscosidade Via Dados Experimentais}

$\mathrm{Na}$ área de estudos reológicos é conhecido que se um fluido newtoniano apresentar uma quantidade não substâncial de material particulado difundido, então a equação constitutiva newtoniana continuará sendo válida. Porém, a medida que a concentração de particulado aumenta, o fluido passa a exibir comportamento não-newtoniano [105]. Diante desse contexto, e sabendo que nosso problema têm variações significativas na concentração de material difundido, consideramos importante investigar as propriedades reológicas do fluido sedimentar.

Os pesquisadores Joyce, J. e Jewell, P. W. [59], afirmam que a observação direta da formação da bolha nos sedimentos não é possível e o borbulhamento é esporádico e dependente de muitos fatores. Neste artigo, eles analisaram o fluxo de metano ebulitivo nos lagos Gatun (Panamá) e Loiza (Porto Rico). Dizem que muito do metano ebulitivo é originário entre $10-20 \mathrm{~cm}$ da parte superior da coluna de sedimento. Esses autores consideraram que o sedimento do fundo dos lagos comportase como um fluido de Bingham e utilizaram o modelo dado em (B.6) com $n=1$ como a lei da tensão de cisalhamento em seus estudos. Motivados por este trabalho, nos propusemos a modelar o fluido sedimentar do nosso problema desde as coletas de amostras do fluido, passando pelas medições reológicas, até a descrição quantitativa da lei da tensão de cisalhamento. 
Escolhemos a Estação Ecológica de Jataí (EEJ), situada no município de Luiz Antônio (SP) (21 ${ }^{o}$ $33^{\prime}$ a $21^{\circ} 37^{\prime} \mathrm{S}$ e $47^{\circ} 45^{\prime}$ a $47^{\circ} 51^{\prime} \mathrm{O}$ ), que possui uma área total de aproximadamente $4500 \mathrm{ha}$, figura 4.1 (esquerda). Esta estação ecológica possui os ecossistemas aquáticos: Rio Mogi-Guaçu; 14 lagoas marginais; córregos Boa Sorte, do Beija-Flor e do Cafundó e ainda a Represa do Beija-Flor.
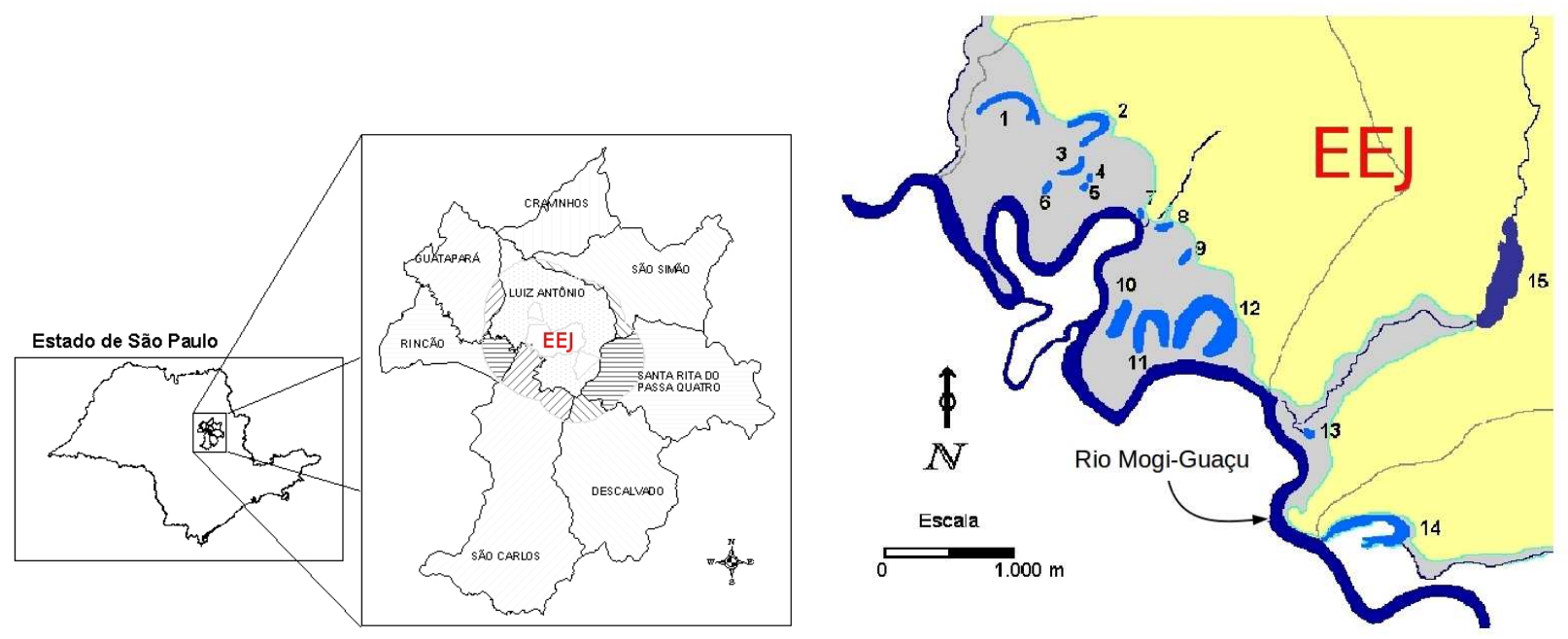

Figura 4.1: Localização da Estação Ecológica de Jataí (EEJ) (esquerda), ecossistemas aquáticos da estação (direita) [13].

Na figura 4.1 (direita) além do rio Mogi-Guaçu estar sendo exibido, temos ainda os lagos: do Óleo (1), do Infernão (2), do inferninho (3), vermelhinha (4), Formiga (5), Gemedeira (6), Mundo Novo (7), Piaba (8), do Campo (9), Quilômetro (10), Sapê (11), dos Patos (12), do Mato (13), do Diogo (14) e finalmente a Represa do Beija-Flor (15).

Dentre as lagoas nomeadas anteriormente selecionamos a lago do Óleo como o local de nosso estudo. A Lagoa do Óleo é localizada a $400 \mathrm{~m}$ do Rio Mogi-Guaçu, numa região de inundação, com uma área em torno de $20000 \mathrm{~m}^{2}$ e apresenta uma profundidade máxima em torno de 5 metros [91].

Com o auxílio do técnico de campo Luis Joaquim da UFSCar, nos deslocamos até a lagoa do Óleo e coletamos 3 cores de sedimentos. O core propriamente dito constitui-se num tubo em acrílico cuja extremidade inferior está agregada a outro tubo cilíndrico de metal (que adentra ao sedimento quando da sua coleta). A extremidade superior é livre para que uma tampa seja rosqueada quando finalizado o procedimento de coleta. O core tem comprimento igual a $20 \mathrm{~cm}$ (medida esta também utilizada por Joyce, J. e Jewell, P. W. [59] em seu artigo), com base circular de raio $5 \mathrm{~cm}$, figura 4.2. 

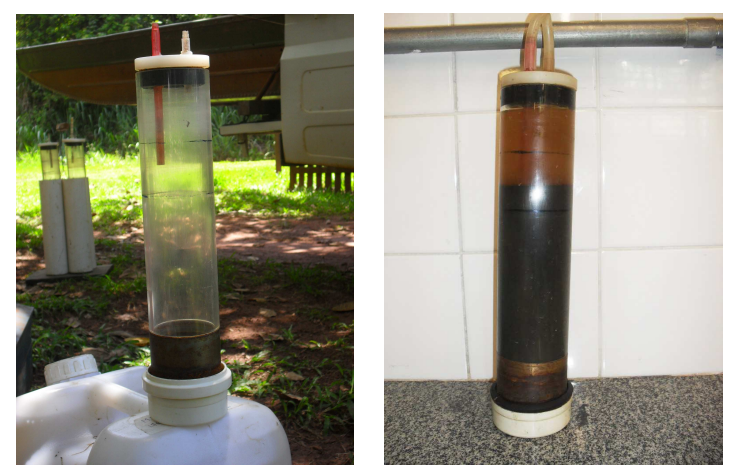

Figura 4.2: Core vazio (esquerda), com sedimento (direita).

A coleta foi realizada com o aparelho Core Sample Model Phleger a $3.30 \mathrm{~m}$ de profundidade. Esta lagoa foi escolhida visto que a mesma apresenta características semelhantes ao lago de reservatórios hidrelétricos, figura 4.3 .
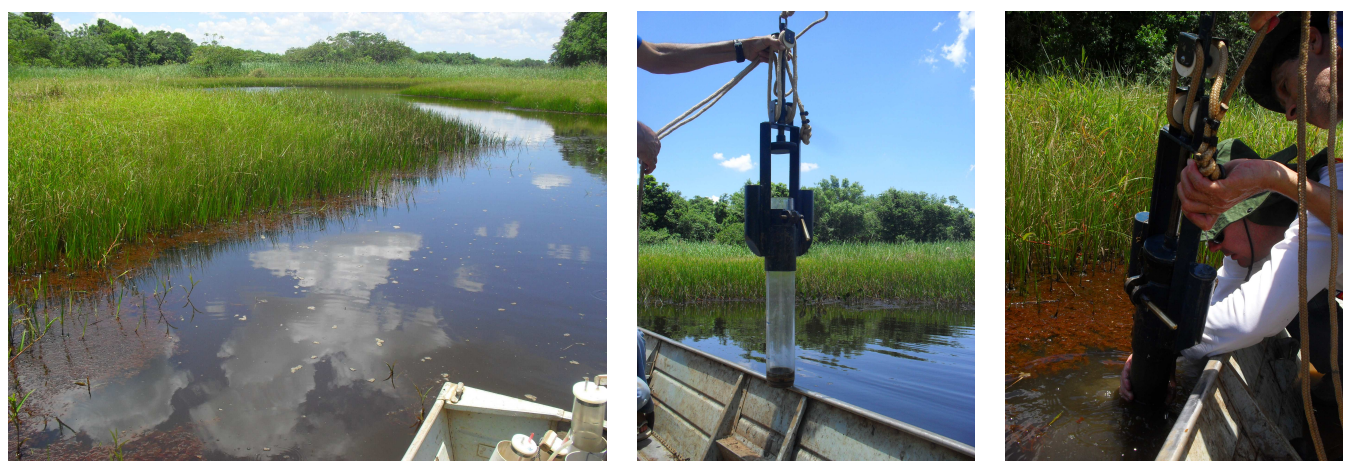

Figura 4.3: Lagoa do Óleo (esquerda) aparelho Core Sample Model Phleger acoplado ao core vazio (centro) e preenchido de sedimento (direita).

Após a coleta, com o auxílio do Prof. Dr Irineu Bianchini Junior, no Laboratório de Bioensaios e Modelagem Matemática da UFSCar, realizamos alguns procedimentos.
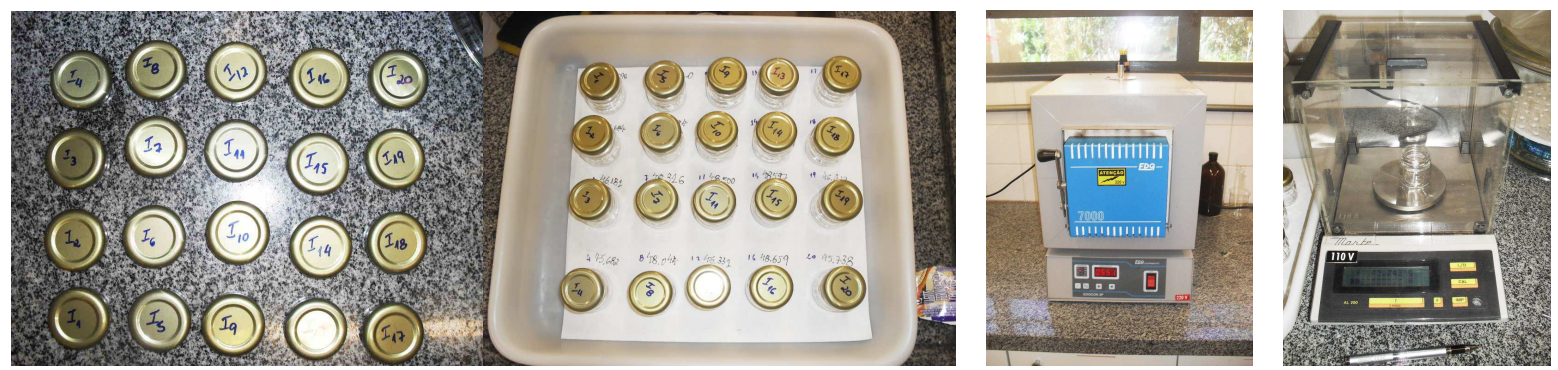

Figura 4.4: Grupos de frascos A e B respectivamente (esquerda), mufla (centro) balança de precisão (direita). 
Primeiramente rotulamos (em dois grupos A e B) e esterilizamos 40 frascos de vidro em uma mufla EDGCON 3P a $551^{\circ} \mathrm{C}$. Após, pesamos os mesmos em uma balança de precisão Maste AL 200, figura 4.4.

Em seguida, para cada core, realizamos o fatiamento do sedimento em camadas. A cada fatia dividimos a mesma em outras duas partes, cujas partes foram levadas aos frascos dos grupos A e B na mesma numeração e finalmente voltamos a balança e pesamos cada uma das amostras, figura 4.5.
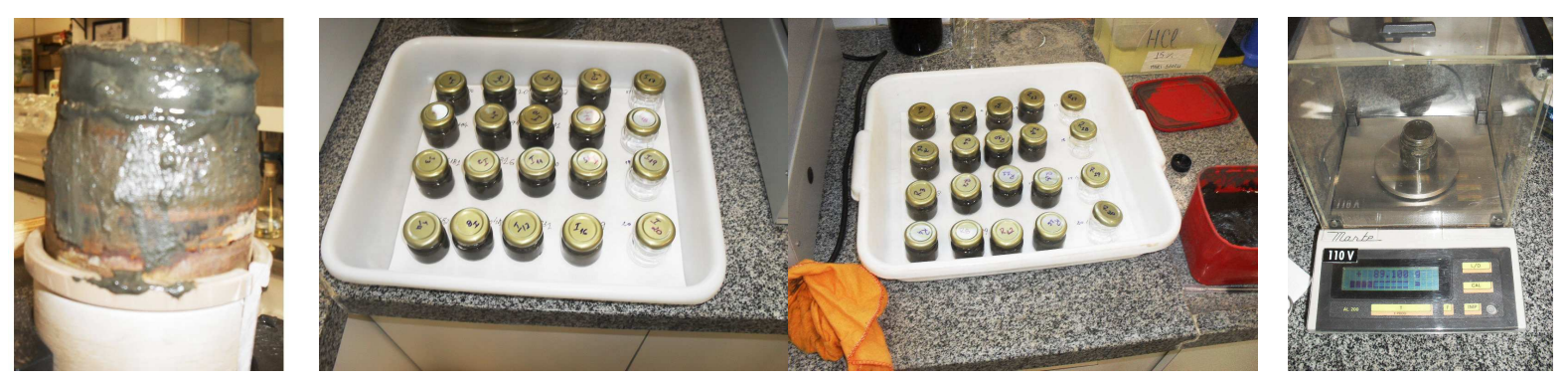

Figura 4.5: Sedimento no core (esquerda), grupos A e B respectivamente (centro) e pesagem da amostra (direita).

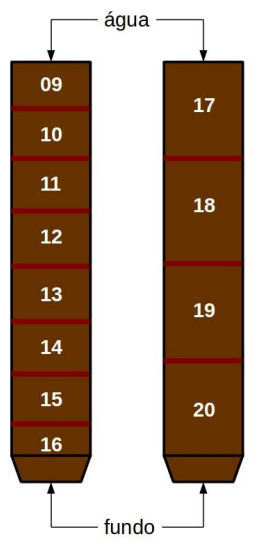

Figura 4.6: Disposição e rotulação das amostras. Core II (esquerda) e core III (direita).

As amostras foram enumeradas de tal forma que a numeração 1 a 8 corresponde ao material sedimentar coletado do core I, as de 9 a 16 do core II e aquelas de 17 a 20 do core III. As medições preliminares mostraram que os dados levantados do core I não esboçaram medidas estatísticas significantes, apresentavam muita dispersão nos dados e portanto foram descartados. A ordem de localização da enumeração foi como está mostrado na figura 4.6. Para o core II apenas a amostra 14 foi suprimida, visto que a mesma apresentou similaridades de medições de concentração e tensão de cisalhamento em relação às amostras 12, 13 e 16. O core III foi utilizado integralmente e serviu-nos apenas para confirmar as tendências observadas no core II. Para o nosso modelo de viscosidade consideramos os 
dados obtidos do core II.

Partindo das amostras de interesse do grupo A montamos a tabela 4.1 de dados experimentais. Para cada amostra calculamos a massa de sedimento via os dados das colunas 3 e 4, em seguida calculamos o volume que este sedimento ocupa (coluna 5). Finalmente obtivemos a massa específica para cada amostra conforme mostrado na coluna 6. Após a secagem de cada amostra, calculamos ainda a massa específica aparente ou conhecida também como concentração do material particulado (coluna 8).

\begin{tabular}{|c|c|c|c|c|c|c|c|}
\hline $\begin{array}{c}\text { rótulo inicial } \\
\text { das amostras }\end{array}$ & $\begin{array}{c}\text { numeração } \\
\text { das amostras }\end{array}$ & $\begin{array}{c}\text { frasco } \\
\text { vazio }\end{array}$ & $\begin{array}{c}\text { frasco } \\
\text { cheio }\end{array}$ & volume & $\begin{array}{c}\text { massa } \\
\text { específica }\end{array}$ & $\begin{array}{c}\text { frasco com } \\
\text { material seco }\end{array}$ & $\begin{array}{c}\text { concentração } \\
\text { do sedimento }\end{array}$ \\
\hline \hline$(n)$ & $(\lambda)$ & $(g)$ & $(g)$ & $\left(m^{3}\right)$ & $\left(K g / m^{3}\right)$ & $(g)$ & $\left(K g / m^{3}\right)$ \\
\hline \hline 09 & 1 & 46.042 & 64.280 & $1.87 \times 10^{-5}$ & 974.82 & 46.616 & 030.68 \\
10 & 2 & 48.131 & 79.703 & $3.16 \times 10^{-5}$ & 1000.53 & 50.205 & 065.72 \\
11 & 3 & 48.500 & 91.118 & $5.34 \times 10^{-5}$ & 798.18 & 55.770 & 136.15 \\
12 & 4 & 46.331 & 90.410 & $5.34 \times 10^{-5}$ & 825.55 & 55.216 & 166.40 \\
13 & 5 & 48.365 & 93.397 & $5.34 \times 10^{-5}$ & 843.39 & 55.961 & 142.26 \\
15 & 6 & 48.597 & 95.751 & $5.34 \times 10^{-5}$ & 883.14 & 63.682 & 282.52 \\
16 & 7 & 48.659 & 83.805 & $3.16 \times 10^{-5}$ & 1113.79 & 56.744 & 256.21 \\
\hline \hline 17 & 1 & 45.731 & 85.028 & $4.82 \times 10^{-5}$ & 814.36 & 46.205 & 009.82 \\
18 & 2 & 48.631 & 91.964 & $5.33 \times 10^{-5}$ & 811.57 & 57.441 & 165.00 \\
19 & 3 & 46.423 & 91.079 & $5.33 \times 10^{-5}$ & 836.35 & 56.463 & 188.03 \\
20 & 4 & 45.738 & 89.105 & $4.82 \times 10^{-5}$ & 898.70 & 54.318 & 177.80 \\
\hline
\end{tabular}

Tabela 4.1: Tabela de dados experimentais do core II.

Finalizando o procedimento experimental, com o grupo B calculamos a reologia pertinente a cada amostra. Sob a orientação da $\operatorname{Prof}^{a}$. $\operatorname{Dr}^{a}$. Rosario E. S. Bretas, no Laboratório de Polímeros da UFSCar, realizamos as etapas descritas a seguir.

Com o reômetro Rheometric Scientific modelo ARES e utilizando um conjunto de cilindros coaxiais Couette-Box, figura 4.7, obtivemos o conjunto de pares ordenados da taxa de cisalhamento versus tensão de cisalhamento para cada amostra $\lambda$.

Os gráficos de pares ordenados de cada amostra, na escala $\log$ - log, para cada core, podem ser observados nas figuras 4.8 e 4.9. O intervalo de medição da taxa de cisalhamento operado no reômetro foi de 0 a $400 s^{-1}$. 

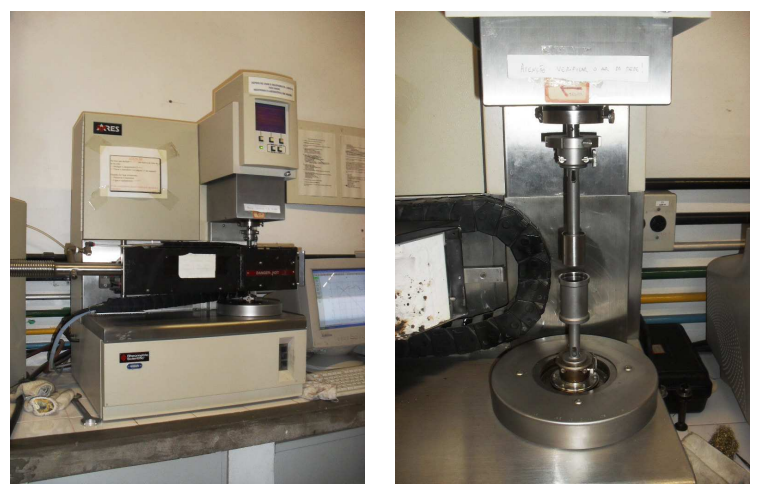

Figura 4.7: Reômetro Rheometric Scientific modelo ARES (esquerda) e conjunto de cilindros coaxiais Couette-Box (direita).

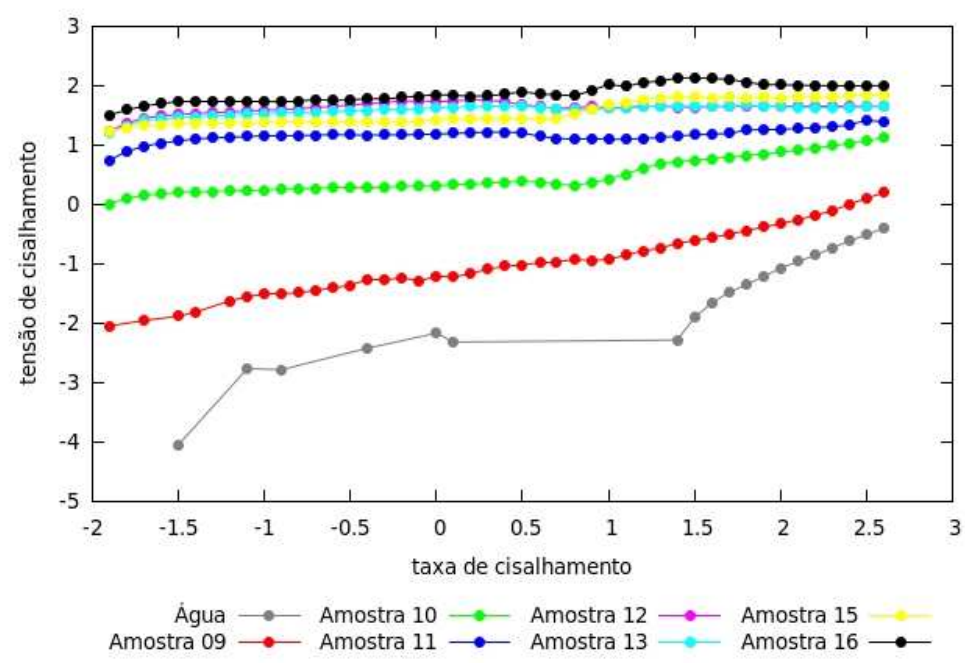

Figura 4.8: Dados medidos no reômetro Rheometric Scientific para as amostras do core II.

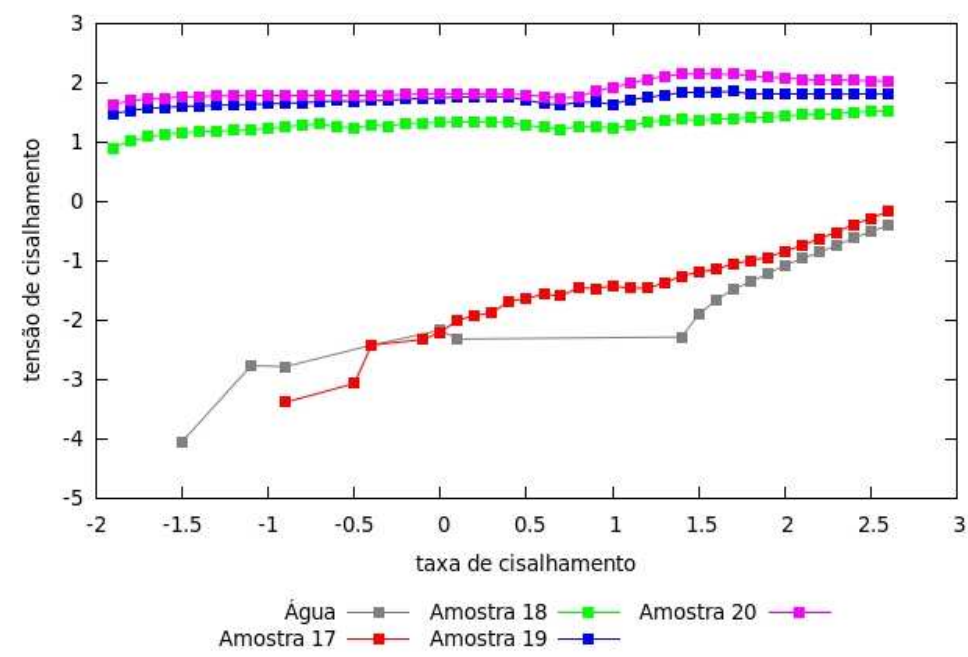

Figura 4.9: Dados medidos no reômetro Rheometric Scientific para as amostras do core III. 
Observamos adicionalmente que mensuramos também a tensão para a água, porquê no movimento de ascensão da bolha a mesma alcança a região com valor desprezível de material particulado. Por este motivo exibimos os valores de tensão para água nas figuras 4.8 e 4.9 .

Na figura 4.8 (4.9) os dados referentes a água são aqueles da parte superior ao core II (III) como mostrado na figura 4.6. Em seguida, os dados referentes a amostra 09 (17) são da região próxima a extremidade superior do core, onde se aplica a tampa rosqueada. As outras amostras são obtidas percorrendo o core até alcançar a parte metálica agregada, onde foi tomada a amostra 16 (20). Observe que os dados esboçados dos dois cores apresentam o mesmo comportamento.

Do ponto de vista da modelagem matemática, descrever leis constitutivas que governam as variações de viscosidade não é uma tarefa fácil, são vários os parâmetros inerentes ao fluido que atuam em diferentes magnitudes na composição da lei. Muitos pesquisadores propuseram uma ampla faixa de leis constitutivas procurando descrever a viscosidade, entre eles podemos destacar os clássicos: Isaac Newton (1687) quando definiu viscosidade em sua obra Principia Mathematica segundo volume, Bingham e Green (1919), Ostwald (1925), Herschel e Bulkley (1926) (ver detalhes na página 151), Casson (1959).

Para este trabalho de tese modelamos a lei da viscosidade como uma generalização sobre o modelo de Herschel-Bulkley. Entendemos que a cada amostra, temos novos valores para os parâmetros do modelo. Isto é consequência das variações de concentração do particulado. Dos dados medidos e exibidos nas figuras 4.8 e 4.9 pudemos observar a existência de uma tensão crítica não nula para o escoamento do fluido presente em cada amostra, além disto observamos que com o aumento da taxa de cisalhamento a tensão de cisalhamento mostrava-se em ascendência e aproximava de um valor constante nas altas taxas. O padrão observado sugeriu que o modelo de Herschel-Bulkley poderia ser ajustado.

Ressaltamos que em cada amostra há diferenças relevantes no valor da concentração de particulado, ver tabela 4.1, acreditamos que a ascensão da bolha no fluido sedimentar é fortemente influenciada pela concentração de material particulado. Podendo ocorrer dificuldades de ascenção, ou até mesmo, não ocorrer a ascensão por conta de que a bolha não conseguiria romper a tensão crítica do fluido. Então, propusemos um modelo de viscosidade variável (tomando por base os dados do core II) em termos do modelo de Herschel-Bulkley, mas levando em consideração as variações de concentração de material particulado agregada ao modelo.

Portanto a nossa idéia para a viscosidade é ajustar primeiramente um modelo Herschel-Bulkley para cada amostra do core. Logo em seguida calculamos a equação de ajuste que julgamos descrever melhor a variação da concentração. Finalmente, correlacionamos o ajuste sobre todos os modelos 
a priori obtidos. Com isto, a lei geral da viscosidade ficará inicialmente estabelecida para todo o domínio de interesse onde faremos nossas simulações. Isto difere de outros trabalhos da modelagem de viscosidade visto que contemplamos adicionalmente o transporte de sedimento. Esta modelagem é detalhada a seguir.

Admitindo os modelos de tensão de cisalhamento para a água e amostras da forma $\tau_{\lambda}=\tau_{0_{\lambda}}+$ $K_{\lambda}(\dot{\gamma})^{n_{\lambda}}, \operatorname{com} \lambda=0, \ldots, 7$. Então o conjunto de equações a ser obtido é:

$$
\begin{array}{ll}
\tau_{0}=\tau_{0_{0}}+K_{0}(\dot{\gamma})^{n_{0}} & \tau_{4}=\tau_{0_{4}}+K_{4}(\dot{\gamma})^{n_{4}} \\
\tau_{1}=\tau_{0_{1}}+K_{1}(\dot{\gamma})^{n_{1}} & \tau_{5}=\tau_{0_{5}}+K_{5}(\dot{\gamma})^{n_{5}} \\
\tau_{2}=\tau_{0_{2}}+K_{2}(\dot{\gamma})^{n_{2}} & \tau_{6}=\tau_{0_{6}}+K_{6}(\dot{\gamma})^{n_{6}} \\
\tau_{3}=\tau_{0_{3}}+K_{3}(\dot{\gamma})^{n_{3}} & \tau_{7}=\tau_{0_{7}}+K_{7}(\dot{\gamma})^{n_{7}}
\end{array}
$$

sendo que as constantes (parâmetros do modelo) $\tau_{0_{\lambda}}, K_{\lambda}$ e $n_{\lambda}$ devem ser determinadas. Para determinarmos as constantes $\tau_{0_{\lambda}}, K_{\lambda}$ e $n_{\lambda}(\lambda=0, \ldots, 7)$ utilizamos o método de ajuste por mínimos quadrados. Lembramos ainda que em particular se $\lambda=0$ sabemos que o termo $\tau_{0_{0}}=0, K_{0}$ é a viscosidade da água e $n_{0}=1$, então a equação constitutiva da tensão newtoniana é recuperada.

\begin{tabular}{|c|c|c|c|c|}
\hline$\lambda$ & $\tau_{0_{\lambda}}$ & $K_{\lambda}$ & $n_{\lambda}$ & coeficiente de correlação \\
\hline \hline 0 & 0.00 & $9.584056 \mathrm{e}-004$ & 1.00 & 0.9947985 \\
1 & $2.04961337455 \mathrm{e}-002$ & $2.11050417840 \mathrm{E}-002$ & 0.70 & 0.9921410 \\
2 & $1.47574163957 \mathrm{e}+000$ & $5.98136817997 \mathrm{E}-001$ & 0.50 & 0.9930564 \\
3 & $1.02360157132 \mathrm{e}+001$ & $3.47632404668 \mathrm{E}+000$ & 0.20 & 0.7847943 \\
4 & $3.34526692119 \mathrm{e}+001$ & $9.00285547868 \mathrm{E}+000$ & 0.10 & 0.3709573 \\
5 & $3.11478446371 \mathrm{E}+001$ & $5.87859436323 \mathrm{E}+000$ & 0.20 & 0.6926107 \\
6 & $9.58972846146 \mathrm{E}+000$ & $2.10963003946 \mathrm{E}+001$ & 0.20 & 0.9442958 \\
7 & $5.44890085562 \mathrm{E}+001$ & $1.32241645478 \mathrm{E}+001$ & 0.30 & 0.7657173 \\
\hline
\end{tabular}

Tabela 4.2: Tabela de valores das constantes $\tau_{0_{\lambda}}, K_{\lambda}$ e $n_{\lambda}$ obtidas por mínimos quadrados.

Os valores obtidos para as constantes $\tau_{0_{\lambda}}, K_{\lambda}$ e $n_{\lambda}(\lambda=0, \ldots, 7)$ encontram-se na tabela 4.2, apresentamos ainda na última coluna da tabela o coeficiente de correlação calculado. Com esta metodologia determinamos a viscosidade por amostras.

Observamos que o valor $K_{0}=9.584056 \mathrm{e}-004$ é significativo, uma vez que os livros de mecânica dos fluidos, por exemplo [56], apresentam valores tabelados muito próximo deste para a viscosidade da água, isto mostra que o reômetro está ajustado. O valor baixo da correlação quando $\lambda=4$ se deu 
em decorrência da não homogeneidade do material da amostra. Graficamente, o conjunto de equações ajustado e os dados observados são esboçados na figura 4.10 .

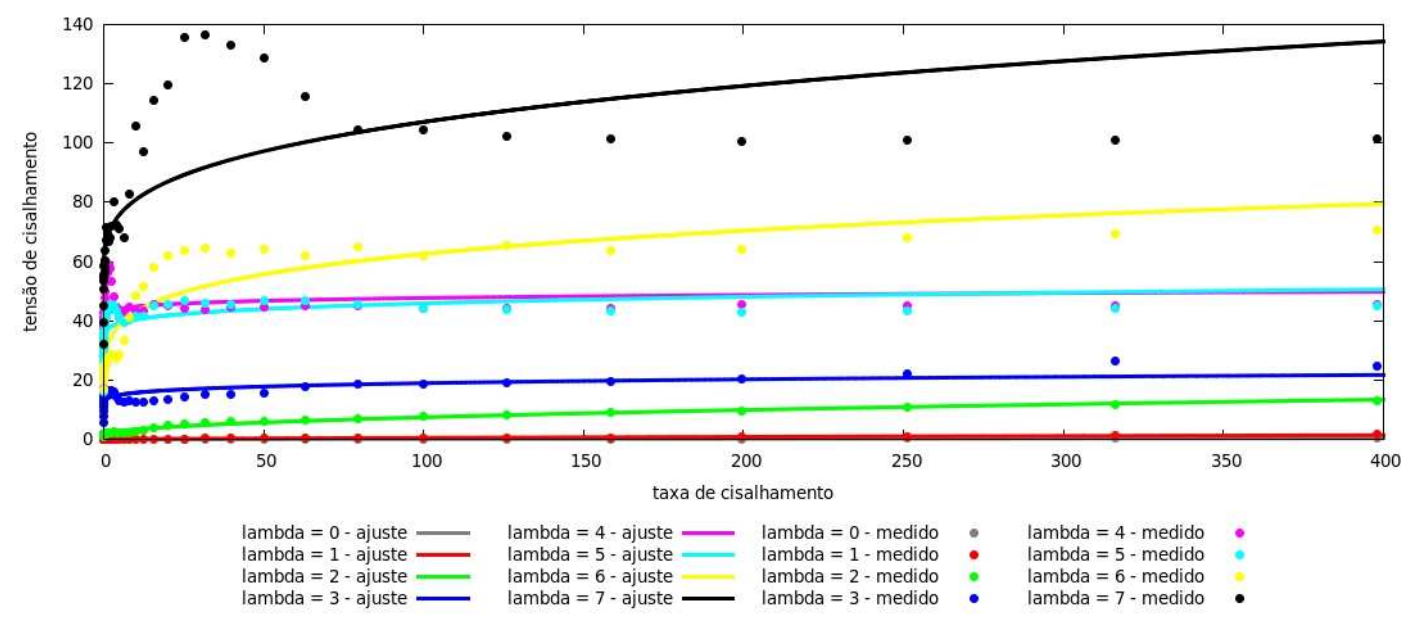

Figura 4.10: Gráficos das tensões $\dot{\gamma} \times \tau_{\lambda}$.

\begin{tabular}{c|cccccccc}
$\operatorname{cota}(\mathrm{m})$ & 0.0 & 0.0125 & 0.0375 & 0.0625 & 0.0875 & 0.1125 & 0.1625 & 0.1875 \\
\hline$c\left(\mathrm{Kg} / \mathrm{m}^{3}\right)$ & 0.0 & 30.68 & 65.72 & 136.15 & 166.40 & 142.26 & 282.52 & 256.21
\end{tabular}

Tabela 4.3: Tabela de cotas versus concentração de sedimento.

Por outro lado, quando realizamos o fatiamento do core II em cotas (ver tabela 4.3), nas respectivas concentrações (dados na tabela 4.1), podemos dizer que existe uma função $c: \mathcal{R} \rightarrow \mathcal{R}$ que correlaciona a tendência de aumento de concentração com a profundidade do core. Então a função $c(\operatorname{cota})$ ajustada por mínimos quadrados foi tal que:

$$
c(\cot a)=484.938901224(1.0-\exp [-4.36826790337 \cot a])
$$

cujo coeficiente de correlação foi de 0.9695301 , figura 4.11. Note que estendemos o gráfico da equação para além da dimensão do core II, acreditamos que a partir de 1 metro de profundidade praticamente a concentração se estabilizaria nas proximidades de $500 \mathrm{Kg} / \mathrm{m}^{3}$.

A função dada pela equação (4.2) além de ser utilizada para a modelagem da lei geral da viscosidade, é também utilizada como condição inicial em nosso modelo de transporte de sedimento. Esta equação representa a tendência da variação de concentração do sedimento no core quando o mesmo apresenta o fluido em estado de quiescência.

Como já afirmado anteriormente, entendemos que a viscosidade é variável em termos do modelo de Herschel-Bulkley em cada cota para diferentes concentrações de particulado. Pensando assim, o fluido sedimentar torna-se complexo porquê não há homogeneidade em si mesmo. 


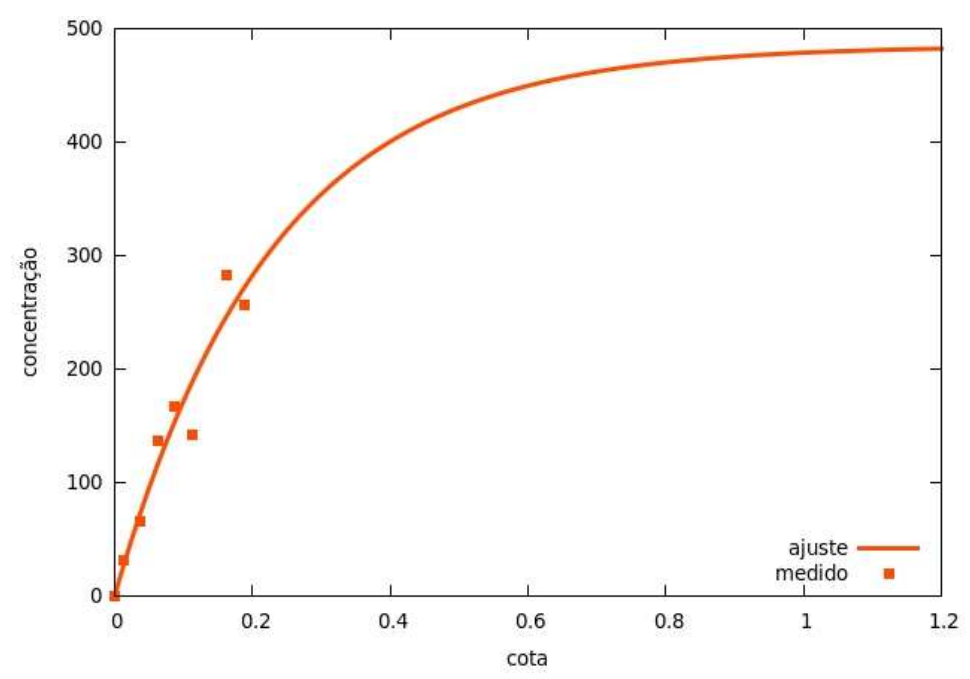

Figura 4.11: Gráfico da concentração em função das cotas.

Por exemplo se admitirmos que o fluido do core está em repouso, então a viscosidade na vizinhança de $\lambda=4$ é maior do que a viscosidade na vizinhança de $\lambda=3$. Porém, se o fluido é perturbado, digamos pela ascensão da bolha, então o arrasto de particulado que a bolha ocasiona pode fazer com que a afirmativa anterior possa não ser totalmente válida. Motivados então por esta circunstância, propomos um modelo global de viscosidade variável que capte esta complexidade do transporte.

Considerando o conjunto de equações (4.1) e a curva de concentração (4.2), a lei geral para a tensão de cisalhamento ajustada tem a forma:

$$
\tau(\dot{\gamma}, c)=\tau_{0}(c)+K(c) \dot{\gamma}^{n(c)}
$$

cujas funções $\tau_{0}(c), K(c)$ e $n(c)$ devem ser determinadas. Para isto aplicamos o ajuste por mínimos quadrados. A idéia final é encontrar expressões para estas funções que melhor descreva os parâmetros dos modelos dados em (4.1).

Uma vez calculada a concentração via equação (4.2) para cada $\lambda$ e considerando os dados da tabela 4.2 para as constantes $\tau_{0_{\lambda}}, K_{\lambda}$ e $n_{\lambda}$, então a tabela geral de tendência é expressa em 4.4.

Por fim, da tabela 4.4, correlacionando $c \operatorname{com} \tau_{0_{\lambda}}, K_{\lambda}$ e $n_{\lambda}$ respectivamente, encontramos as seguintes leis:

$$
\begin{aligned}
\tau_{0}(c) & =502.457791873(1.0-\exp [-0.000283528723819 c]) \\
K(c) & =0.000958406+0.000244983275307 c^{2} \\
n(c) & =\frac{1}{0.0195958139505 c+1}
\end{aligned}
$$


com os respectivos coeficientes de correlação 0.7580940, 0.8922147 e 0.9520509.

\begin{tabular}{|c|c|c|c|c|}
\hline$\lambda$ & $c$ & $\tau_{0_{\lambda}}$ & $K_{\lambda}$ & $n_{\lambda}$ \\
\hline \hline 0 & 0.00 & 0.00 & $9.584056 \mathrm{e}-004$ & 1.00 \\
1 & 25.76933979 & $2.04961337455 \mathrm{e}-002$ & $2.11050417840 \mathrm{E}-002$ & 0.70 \\
2 & 73.27268829 & $1.47574163957 \mathrm{e}+000$ & $5.98136817997 \mathrm{E}-001$ & 0.50 \\
3 & 115.8615817 & $1.02360157132 \mathrm{e}+001$ & $3.47632404668 \mathrm{E}+000$ & 0.20 \\
4 & 154.0444445 & $3.34526692119 \mathrm{e}+001$ & $9.00285547868 \mathrm{E}+000$ & 0.10 \\
5 & 188.2771024 & $3.11478446371 \mathrm{E}+001$ & $5.87859436323 \mathrm{E}+000$ & 0.20 \\
6 & 246.4841969 & $9.58972846146 \mathrm{E}+000$ & $2.10963003946 \mathrm{E}+001$ & 0.20 \\
7 & 271.1535076 & $5.44890085562 \mathrm{E}+001$ & $1.32241645478 \mathrm{E}+001$ & 0.30 \\
\hline
\end{tabular}

Tabela 4.4: Tabela geral de tendência para a tensão.

Destacamos que as equações dadas em (4.4) foram encontradas tomando como ponto de partida a concentração nula de particulado, uma vez que nesta situação a relação constitutiva newtoniana para a tensão de cisalhamento tem de ser utilizada. Observamos também que evidentemente existem inumeras equações que poderiam ser utilizadas para se fazer o ajuste, mas avaliamos que aquelas que apresentamos são boas candidatas para expressar o comportamento da viscosidade o qual estamos modelando.

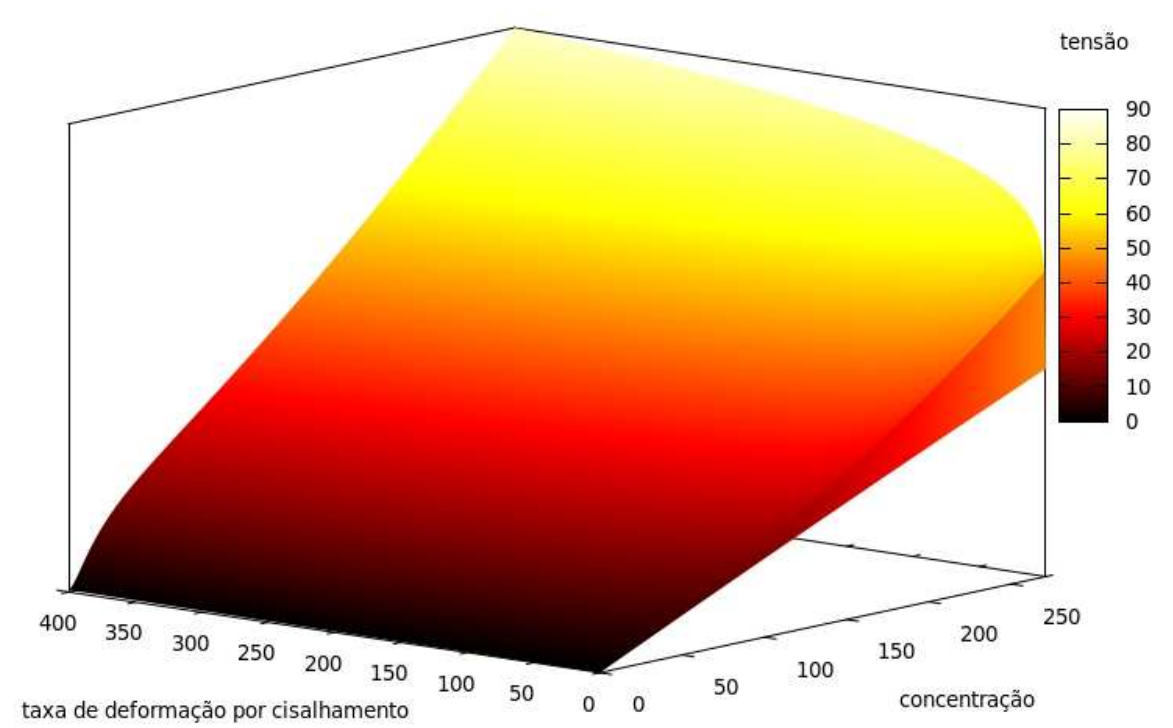

Figura 4.12: Gráfico da lei geral para a tensão de cisalhamento.

A figura 4.12 mostra a superfície gerada pela equação (4.3) no domínio $c \times \dot{\gamma}=[0,271.15] \times$ 
$[0,400]$. Por simples inspeção em (4.3), quando $c=0$ temos a equação newtoniana $\tau(\dot{\gamma}, 0)=0+$ $0.000958406 \dot{\gamma}$. Pode ser observado também que a medida em que a concentração cresce, a superfície tem crescimento não linear com comportamento dado pelo modelo Herschel-Bulkley. Ainda nesta linha, chamamos a atenção para a ocorrência do aumento na tensão limite de escoamento $\tau_{0}(c)$.

Dividindo a equação (4.3) por $\dot{\gamma}$, encontramos a viscosidade aparente escrita na forma:

$$
\eta(\dot{\gamma}, c)=\frac{\tau_{0}(c)}{\dot{\gamma}}+K(c)[\dot{\gamma}]^{n(c)-1}
$$

lembrando que $\tau_{0}(c), K(c)$ e $n(c)$ são as equações (4.4).

Observando ainda a tabela 4.1, vemos que não há variação brusca na massa específica que caracterize o fluido como compressível, desta forma calculamos a massa específica média da matéria para o modelo como $\rho_{m}=929.9308$. Em nosso código numérico trabalhamos com a viscosidade cinemática, dividindo então a equação (4.5) por $\rho_{m}$, encontramos:

$$
\nu(\dot{\gamma}, c)=\frac{\tau_{0}(c)}{\rho_{m} \dot{\gamma}}+K^{\prime}(c)[\dot{\gamma}]^{n(c)-1}
$$

em que $K^{\prime}(c)=\frac{K(c)}{\rho_{m}}$ e lembrando que $\tau_{0}(c), K(c)$ e $n(c)$ são as equações (4.4). A equação (4.6) é a viscosidade variável modelada para o fluido sedimentar que utilizamos na resolução do nosso problema.

\subsection{Modelagem Geométrica para Bolha em Ascensão}

Inúmeros artigos tratam da descrição da forma geométrica das bolhas e suas implicações na questão de seu movimento. Sabemos que dependendo do fluido no qual elas se movimentam e de seus parâmetros característicos, a forma geométrica que elas podem assumir são variadas. A partir disto, nesta seção temos por objetivo descrever a modelagem geométrica que algumas bolhas podem admitir e em qual contexto isto ocorre, quando o fluido é o sedimento.

Em seu livro, Clift et al. [29] constrói um mapa de formatos (esférico, elíptico e calota esférica) em que as bolhas podem admitir para regiões de valores da velocidade terminal. Nesta situação ele correlaciona a velocidade terminal de ascensão com o diâmetro equivalente. O mapa de Clift et al., figura 4.13, mostra que bolhas esféricas ocorrem na região em amarelo, o regime elipsoidal na região azul e por final o regime calota esférica na região em vermelho para $R e>4700$ numa ampla faixa de tamanhos de bolhas.

Uma bolha pode iniciar seu movimento em um formato e ao longo de sua ascensão alterar sua geometria. Por exemplo, uma bolha pode passar da forma esférica para calota esférica. Muitos 
pesquisadores estudam as questões físicas que propiciam esta mudança, em particular Amaya-Bower e Lee [7] fornecem uma explanação sobre o formato das bolhas para alguns casos em seu artigo.

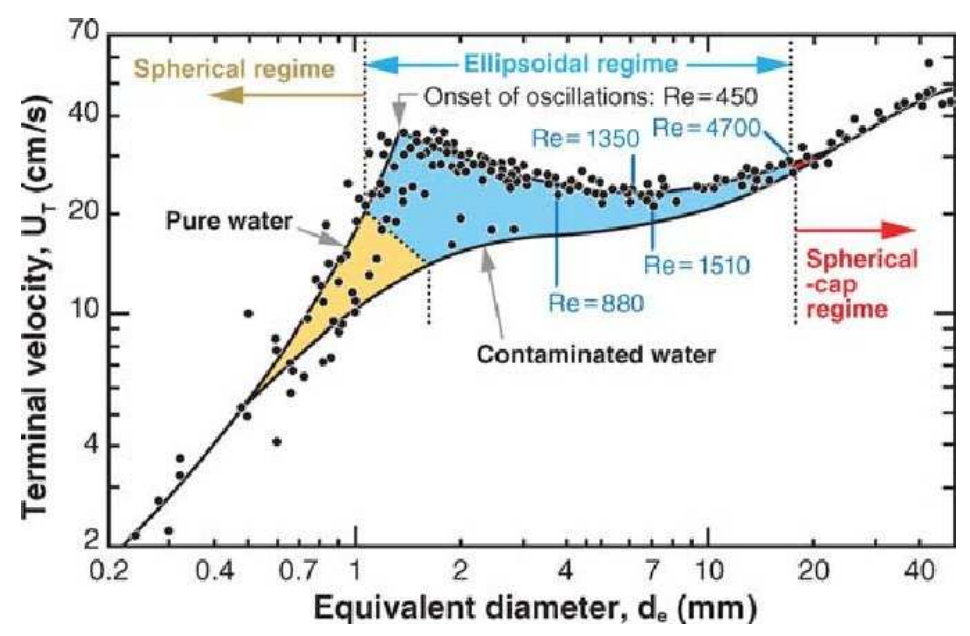

Figura 4.13: Velocidade terminal de bolha (na água) em função do diâmetro equivalente [29].

Além das mudanças geométricas, alterações na trajetória também são comuns de ocorrer. As trajetórias mais triviais são: retilínea, espiralada e zigzag. Wu e Gharib [140] estudaram experimentalmente a forma e o caminho percorrido por bolhas de ar ascendendo em água na faixa de diâmetro 0.1-0.2 cm. Os autores abordam no artigo que nesta faixa as bolhas possuem duas formas estáveis, a esférica e elíptica. E comprovaram que bolhas esféricas se movem de uma maneira mais lenta do que as elipsoidais de volume equivalente. Mostraram também que bolhas de diâmetro até nas proximidades de $0.15 \mathrm{~cm}$ se movimentam retilineamente, bolhas esféricas maiores seguem um caminho em zigzag enquanto que bolhas elipsoidais também maiores movimentam-se num caminho em espiral.

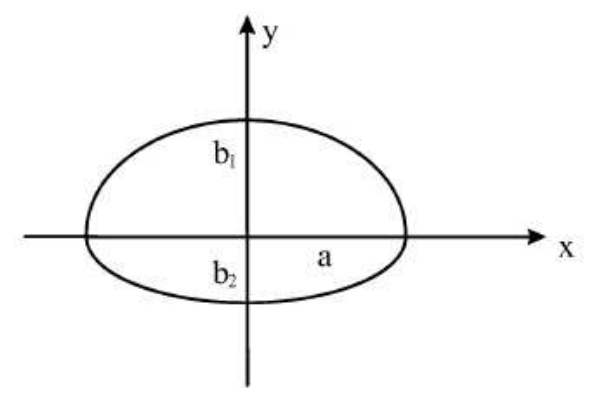

Figura 4.14: Forma variável com $a$ sendo o raio e $b_{1}, b_{2}$ os semi-eixos maior e menor [15].

As geometrias de bolhas não estão limitadas somente àquelas descritas anteriormente, mas também sobre variações destas. Bozzano e Dente [15] estudaram o movimento de bolhas no sistema ar-líquido em que a trajetória dominante era linear (negligenciando os movimentos secundários he- 
licoidal, zigzag, oscilatório etc.), e a forma era computada em função do diâmetro equivalente. A figura 4.14 exibe um formato característico de bolha estudada.

Hua e Lou [54] realizaram um amplo estudo sobre a ascensão de bolhas em fluidos viscosos e exibiram um mapa, figura 4.15 , de predição do formato final. Neste mapa foram considerados as razões de densidade $\frac{\rho_{c}}{\rho_{d}}=1000$, de viscosidade $\frac{\mu_{c}}{\mu_{d}}=100, R e^{*}=\frac{\rho_{c} g^{1 / 2} D^{3 / 2}}{\mu_{l}}$ e $B o^{*}=\frac{\rho_{c} g D^{2}}{\sigma}$, onde $D$ é o diâmetro efetivo da bolha.

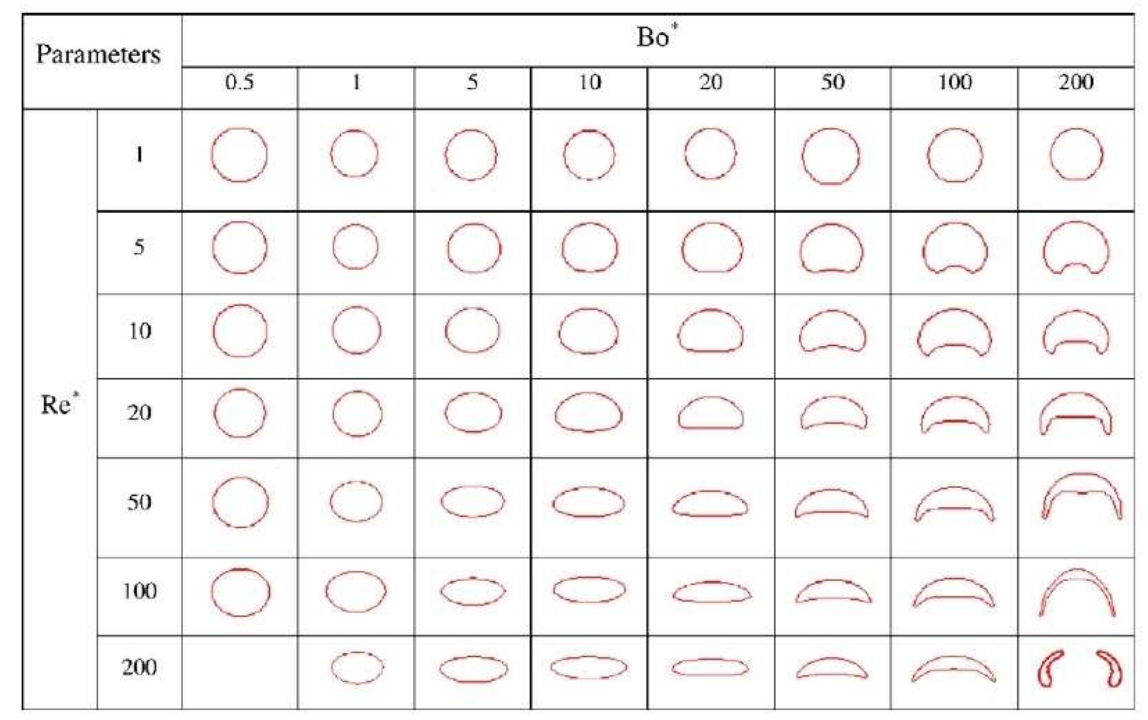

Figura 4.15: Mapa do formato de bolhas quando $\frac{\rho_{c}}{\rho_{d}}=1000$ e de viscosidade $\frac{\mu_{c}}{\mu_{d}}=100$ [54].

Em todas as considerações anteriores a fase contínua era de fluido newtoniano. Quando o fluido é não-newtoniano a variação da viscosidade promove alterações adicionais na dinâmica do movimento das bolhas, alguns estudos tem comprovado isto. Denis Rodrigue afirma que: embora uma grande quantidade de trabalhos tenha sido realizada sobre o movimento de bolhas de gás em fluidos nãonewtonianos, um quadro completo ainda não está disponível [100].

Zhang et al. [143] estudaram o movimento axissimétrico de bolhas em fluido viscoso do tipo pseudoplástico (shear-thinning) e o efeito não-newtoniano foi modelado via o modelo de Carreau. Neste estudo eles consideraram as razões de densidade $\frac{\rho_{c}}{\rho_{d}}=1000 \mathrm{e}$ de viscosidade $\frac{\eta_{c}}{\eta_{d}}=10000 \mathrm{e}$ obtiveram resultados com bolhas em formato oblato.

A dinâmica de uma bolha (com 1 milímetro de tamanho) de ar movimentando-se por uma solução de $1 \%$ de poliacrilamida/água foi investigada em [109]. Experimentalmente, o caminho oscilatório realizado pela bolha na solução foi comparado com bolhas ascendendo na água. Os autores encontraram diferenças na geometria do caminho percorrido, atribuindo estas diferenças aos efeitos viscoelásticos do fluido na esteira da bolha. 
No trabalho de Jiménez et al. [58] os autores trataram de calcular o movimento de bolhas através de fluidos newtonianos e viscoelásticos. Eles consideraram também o sistema axissimétrico para valores altos das razões de densidade e viscosidade do sistema gás-líquido. Obtiveram resultados sobre bolhas do tipo calota elipsoidal oblato (oblate ellipsoidal cap bubble) e calota esférica (spherical cap bubble) (para fluido newtoniano). E resultados do movimento de bolhas com geometria cujo bordo de fuga era cúspide (característica de bolhas de gás que se movem em fluidos viscoelásticos.), figura 4.16 .
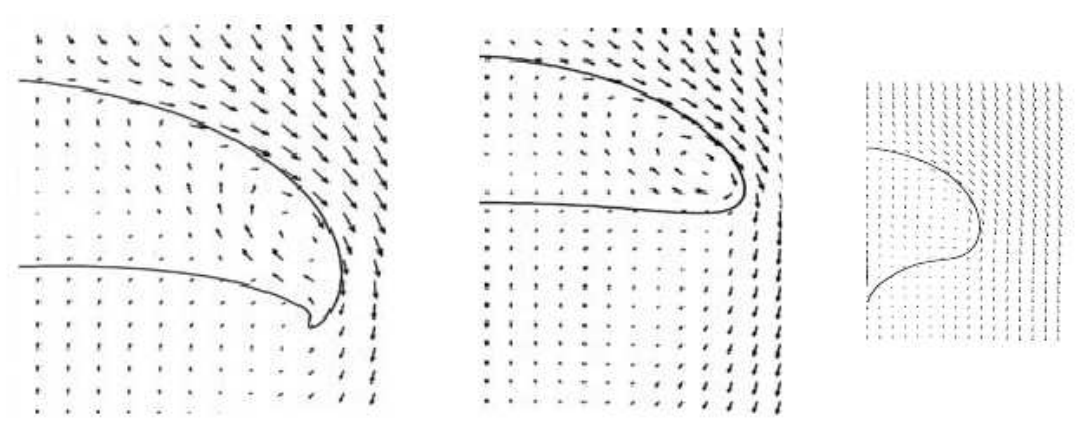

Figura 4.16: Formatos: calota elipsoidal oblato (esquerda), calota esférica (centro) e com bordo de fuga cúspide (direita) [58].

E para finalizar, Herrera-Velarde et al. [50] analisaram o escoamento de uma bolha de ar numa solução tipo PAAm (poliacrilamida). O estudo mostrou a ocorrência de descontinuidade na velocidade terminal nas vizinhanças de um volume crítico. Eles exibem a configuração do escoamento e as geometrias típicas da bolha nesta situação para diferentes volumes, figura 4.17.
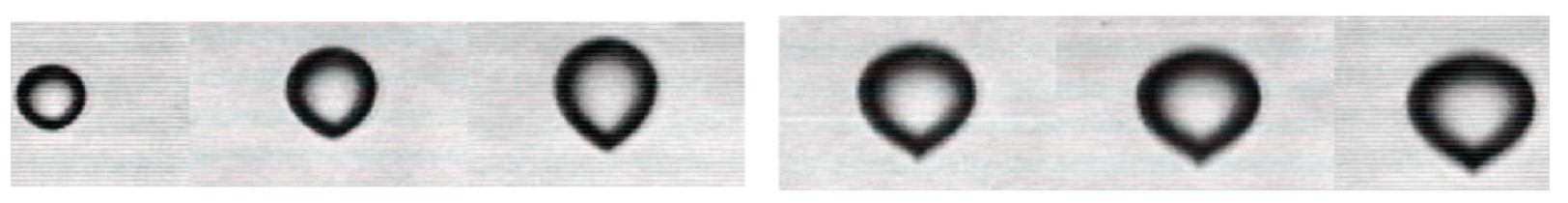

Figura 4.17: Formatos: Formas para volume abaixo (esquerda) e acima (direita) do crítico [50].

Neste estudo nos propusemos modelar a geometria da bolha que permitisse tratar diferentes formas de nosso interesse. A cada simulação partimos de uma geometria limitada por uma circunferência (ver figura 3.3), então devido ao acoplamento entre as equações (3.21), (3.32) e (3.39) a forma geométrica é alterada até a sua forma final, quando a velocidade terminal da bolha é atingida. Nós utilizamos como base a teoria das Cônicas e os parâmetros de forma Razão de Aspecto e Fator de Distorção, para alterar a forma geométrica. A modelagem é descrita como segue. 
Considere que a razão de aspecto $(E)$ e o fator de distorção $(\gamma)$ sejam calculados no nível de tempo $t+\Delta t$ da seguinte forma:

$$
E^{t+\Delta t}=\frac{b_{1}^{t+\Delta t}+b_{2}^{t+\Delta t}}{2 a^{t}} \quad \gamma^{t+\Delta t}=\frac{2 b_{2}^{t+\Delta t}}{b_{1}^{t+\Delta t}+b_{2}^{t+\Delta t}}
$$

onde $b_{1}^{t+\Delta t}, b_{2}^{t+\Delta t}$ e $a^{t}$ são respectivamente os semi-eixos vertical (inferior, superior) e horizontal. Resolvendo o sistema de equações em (4.7) nas incógnitas $b_{1}^{t+\Delta t}$ e $b_{2}^{t+\Delta t}$ obtém-se:

$$
b_{1}^{t+\Delta t}=a^{t} E^{t+\Delta t}\left(2-\gamma^{t+\Delta t}\right) \quad b_{2}^{t+\Delta t}=a^{t} E^{t+\Delta t} \gamma^{t+\Delta t}
$$

e os valores $b_{1}^{t+\Delta t}$ e $b_{2}^{t+\Delta t}$ ficam determinados quando explicitamente forem conhecidos $E^{t+\Delta t}, \gamma^{t+\Delta t}$ e o raio $a^{t}$.

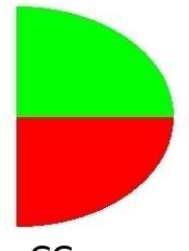

$\mathrm{CC}$

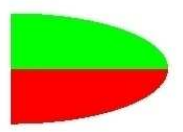

ee

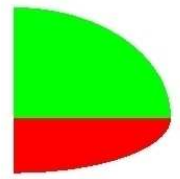

eE

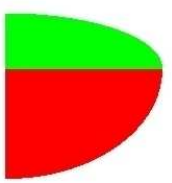

$\mathrm{Ee}$

Figura 4.18: Geometrias de interesse.

Para calcular $E^{t+\Delta t}$ e $\gamma^{t+\Delta t}$ partimos do fato de que o raio no tempo $t$ já é conhecido, quando se está calculando os valores dos semi-eixos verticais. Por outro lado, no caso axissimétrico as formas cônicas utilizadas em nosso modelo são um quarto de regiões limitadas por circunferência e elípse. Ou seja, fazemos composições de partes de cônicas para propor o formato da bolha considerando o semi-eixo horizontal comum às partes, então não perdemos continuidade na forma. Sendo que as configurações geométricas em nossas simulações são composições como está ilustrado na figura 4.18.

\begin{tabular}{|c|c|c|}
\hline Modelo & semi-eixos & fator de distorção \\
\hline \hline$C C$ & $b_{1}^{t+\Delta t}=b_{2}^{t+\Delta t}=a^{t}$ & $\gamma^{t+\Delta t}=1.0$ \\
$e e$ & $b_{1}^{t+\Delta t}=b_{2}^{t+\Delta t}<a^{t}$ & $\gamma^{t+\Delta t}=1.0$ \\
$e E$ & $b_{1}^{t+\Delta t}<b_{2}^{t+\Delta t}$ & $\gamma^{t+\Delta t}>1.0$ \\
$E e$ & $b_{1}^{t+\Delta t}>b_{2}^{t+\Delta t}$ & $\gamma^{t+\Delta t}<1.0$ \\
\hline
\end{tabular}

Tabela 4.5: Tabela de valores para os modelos.

Nesta figura, para cada configuração, a região hachurada em verde é a parte superior da bolha e a vermelha a parte inferior, e a junção das partes constitui um formato de bolha. Por exemplo, $C C$ é 
a união das regiões limitadas por duas circunferências. Os modelos mostrados na figura 4.18 estão submetidos aos valores dados na tabela 4.5 a seguir.

Nós determinamos o valor de $E^{t+\Delta t}$ via a correlação (4.9), adaptada daquela que foi proposta por Vakhrushev e utilizada em [23] e [24]

$$
E^{t+\Delta t}= \begin{cases}1.0 & \text { se } T a<0.3 \\ \left(0.77+0.24 \tanh \left(1.9\left(0.40-\log _{10} T a\right)\right)\right)^{2} & \text { se } 0.3<T a<20.0 \\ 0.30 & \text { se } 20<T a\end{cases}
$$

com $T a=\operatorname{Re}^{t} M o^{0.23}$ sendo o número de Tadaki.

$\mathrm{O}$ valor de $\gamma^{t+\Delta t}$ é declarado segundo o tipo de modelo a ser simulado (ver tabela 4.5), então nós propomos a modelagem do fator de distorção através da relação

$$
\gamma^{t+\Delta t}=\left\{\begin{array}{c}
1.0 \quad \text { se o modelo é: } C C, e e \\
2.0-\frac{1.0}{\exp (t * T a)} \text { se o modelo é: } e E \\
-2.0+\frac{1.0}{\exp (t * T a)} \text { se o modelo é: } E e
\end{array}\right.
$$

A relação (4.10) foi desta forma proposta levando em consideração que: se o modelo é $C C$ ou $e e$ a bolha não apresenta distorção em toda a simulação e isto se reproduz fazendo $\gamma^{t+\Delta t}=1.0$ nas equações (4.8). Porém, quando simulamos os casos $e E$ e Ee há ocorrência de distorção na bolha. De modo análogo ao proposto por Vakhrushev, na determinação de $E^{t+\Delta t}$, também optamos por usar o número de Tadaki mas com crescimento e decrescimento exponencial no tempo de simulação.

Como não consideramos perda ou ganho de massa por parte da bolha, visto que desejamos simular a ascensão sem que ocorram processos químicos e/ou biológicos na interação entre os meios disperso e contínuo, o valor do semi-eixo horizontal é ajustado no tempo $t+\Delta t$ (e denotado como $a^{t+\Delta t}$ ) a fim de que o volume seja preservado. Considerando $v o l^{0}$ o volume da bolha no tempo $t=0, v l_{1}^{t+\Delta t}$ e $v o l_{2}^{t+\Delta t}$ os volumes referentes as regiões vermelha e verde respectivamente, de algum modelo da figura 4.18 no espaço tridimensional para o tempo $t+\Delta t \geq 0$, então o valor de $a^{t+\Delta t}$ é calculado a partir da relação $v o l^{0}=v o l_{1}^{t+\Delta t}+v_{o l}^{t+\Delta t}$, ou seja:

$$
v o l^{0}=\frac{1}{2}\left[\frac{4}{3} \pi\left(a^{t+\Delta t}\right)^{2} b_{1}^{t+\Delta t}+\frac{4}{3} \pi\left(a^{t+\Delta t}\right)^{2} b_{2}^{t+\Delta t}\right]
$$

e isto implica que

$$
a^{t+\Delta t}=\sqrt{\frac{1.5 v o l^{0}}{\pi\left(b_{1}^{t+\Delta t}+b_{2}^{t+\Delta t}\right)}}
$$

Sabendo que a cada lapso de tempo a ascensão da bolha se dá por meio do movimento de seu centro de massa $\left(r_{c m}, z_{c m}\right)$ e que sua geometria é alterada, então via teoria das Cônicas as equações 
que modelam o contorno são:

$$
z=-b_{1}^{t+\Delta t} \sqrt{1-\left(\frac{r-r_{c m}}{a^{t+\Delta t}}\right)^{2}}+z_{c m} \quad \text { e } \quad z=b_{2}^{t+\Delta t} \sqrt{1-\left(\frac{r-r_{c m}}{a^{t+\Delta t}}\right)^{2}}+z_{c m}
$$

Utilizamos o conjunto de equações em (4.12) respectivamente para as regiões vermelha e verde junto com a equação (4.11) quando a simulação ocorre para um dos casos $C C, e e, e E$ e $E e$. 


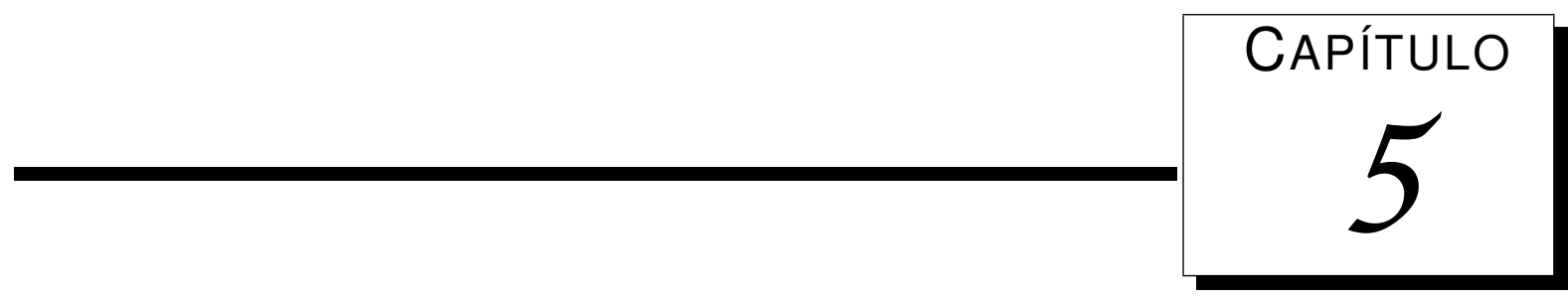

\section{Modelo Matemático}

\subsection{Formulação do Modelo Axissimétrico}

Nos limitamos a estudar alguns casos de ascensão da bolha no sistema de coordenadas cilíndricas no contexto axissimétrico $(r, 0, z)$. O domínio estudado em nosso trabalho é mostrado na figura 5.1. Em nossas simulações partimos sempre de uma bolha circular axissimétrica com raio inicial $r_{b}$, limitada pela curva $C$ de centróide $\left(r_{c m}, z_{c m}\right)$. Os termos $\rho_{d}, \nu_{d}$ representam a densidade e viscosidade do gás enquanto que $\rho_{c}, \nu_{c}$ representam a densidade e viscosidade do fluido. Finalmente, $R$ e $H$ são as dimensões horizontal e vertical respectivamente com $h$ sendo o valor máximo na vertical.

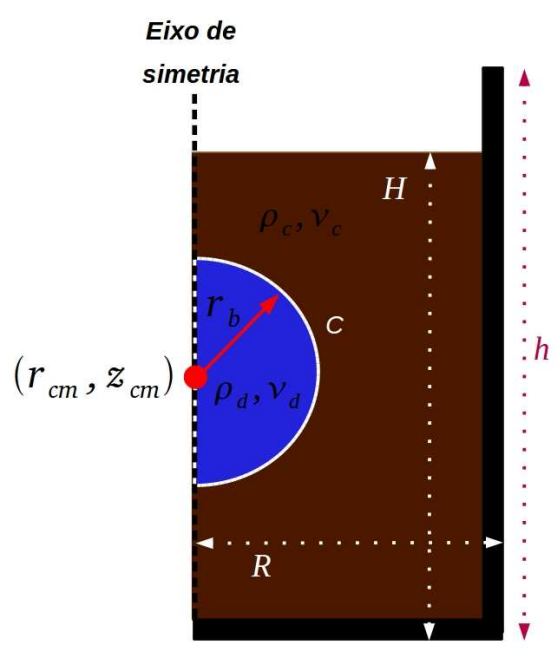

Figura 5.1: Domínio utilizado. 
No sistema axissimétrico, realizamos as devidas transformações nas equações governantes conforme expresso em [2] e [53]. Partindo do sistema Orz, em notação matricial, o campo de velocidades do fluido é dado por

$$
v_{j}=\left(\begin{array}{lll}
u(r, z, t) & 0 & v(r, z, t)
\end{array}\right)
$$

e temos ainda as seguintes relações:

$$
\begin{aligned}
& \frac{\partial()}{\partial x_{j}}=\left(\frac{1}{r} \frac{\partial(r)}{\partial r} \quad 0 \frac{\partial()}{\partial z}\right) \\
& \frac{\partial v_{i} v_{j}}{\partial x_{j}}=\left(\frac{1}{r} \frac{\partial(r u u)}{\partial r}+\frac{\partial(u v)}{\partial z} \quad 0 \quad \frac{1}{r} \frac{\partial(r u v)}{\partial r}+\frac{\partial(v v)}{\partial z}\right) \\
& \frac{\partial p}{\partial x_{j}}=\left(\begin{array}{lll}
\frac{\partial p}{\partial r} & 0 & \frac{\partial p}{\partial z}
\end{array}\right) \\
& \frac{\partial^{2} v_{i}}{\partial x_{j}^{2}}=\left(\frac{1}{r} \frac{\partial}{\partial r}\left(r \frac{\partial u}{\partial r}\right)+\frac{\partial^{2} u}{\partial z^{2}}-\frac{u}{r^{2}} \quad 0 \quad \frac{1}{r} \frac{\partial}{\partial r}\left(r \frac{\partial v}{\partial r}\right)+\frac{\partial^{2} v}{\partial z^{2}}\right) \\
& \frac{\partial \nu}{\partial x_{j}}=\left(\begin{array}{lll}
\frac{\partial \nu}{\partial r} & 0 & \frac{\partial \nu}{\partial z}
\end{array}\right) \\
& \frac{\partial v_{i}}{\partial x_{j}}+\frac{\partial v_{j}}{\partial x_{i}}=\left(\begin{array}{ccc}
2 \frac{\partial u}{\partial r} & 0 & \frac{\partial u}{\partial z}+\frac{\partial v}{\partial r} \\
0 & 2 \frac{u}{r} & 0 \\
\frac{\partial v}{\partial r}+\frac{\partial u}{\partial z} & 0 & 2 \frac{\partial v}{\partial z}
\end{array}\right) \\
& g_{j}=\left(\begin{array}{lll}
g_{r} & 0 & g_{z}
\end{array}\right)
\end{aligned}
$$

Admitimos inicialmente que o fluido circundante à bolha está em repouso. Num lapso de tempo, a resultante das forças atuantes da bolha perturba o fluido e isto promove o seu movimento. As equações matemáticas que modelam este movimento são: a equação da continuidade (3.21) em conjunto com as equações de Navier-Stokes (3.32).

Considerando a relação 5.1, da equação (3.21) temos a equação da continuidade no sistema cilíndrico axissimétrico

$$
\frac{1}{r} \frac{\partial(r u)}{\partial r}+\frac{\partial v}{\partial z}=0
$$


e trabalhando com os termos 5.2-5.7, obtemos a partir da equação (3.32) as equações de Navier-Stokes no sistema axissimétrico

$$
\begin{aligned}
\frac{\partial u}{\partial t} & +\frac{1}{r} \frac{\partial(r u u)}{\partial r}+\frac{\partial(u v)}{\partial z}=-\frac{1}{\rho_{c}} \frac{\partial p}{\partial r} \\
& +\nu_{c}\left[\frac{1}{r} \frac{\partial}{\partial r}\left(r \frac{\partial u}{\partial r}\right)+\frac{\partial^{2} u}{\partial z^{2}}-\frac{u}{r^{2}}\right]+\left[2 \frac{\partial u}{\partial r} \frac{\partial \nu_{c}}{\partial r}+\left(\frac{\partial v}{\partial r}+\frac{\partial u}{\partial z}\right) \frac{\partial \nu_{c}}{\partial z}\right]+g_{r} \\
\frac{\partial v}{\partial t} & +\frac{1}{r} \frac{\partial(r v u)}{\partial r}+\frac{\partial(v v)}{\partial z}=-\frac{1}{\rho_{c}} \frac{\partial p}{\partial z} \\
& +\nu_{c}\left[\frac{1}{r} \frac{\partial}{\partial r}\left(r \frac{\partial v}{\partial r}\right)+\frac{\partial^{2} v}{\partial z^{2}}\right]+\left[2 \frac{\partial v}{\partial z} \frac{\partial \nu_{c}}{\partial z}+\left(\frac{\partial v}{\partial r}+\frac{\partial u}{\partial z}\right) \frac{\partial \nu_{c}}{\partial r}\right]+g_{z}
\end{aligned}
$$

Em relação a viscosidade, quando simulamos casos de ascensão em fluidos newtonianos tomamos a viscosidade como constante $\left(\nu_{c} \equiv \nu_{c t e}\right)$. Com isto o terceiro termo do segundo membro das equações (5.9) e (5.10) são suprimidos, o que faz simplificações nas equações do modelo.

Porém, nas simulações com o fluido sedimentar, utilizamos o modelo constitutivo newtoniano generalizado e a viscosidade é calculada via a equação (4.6).

Em particular, lembrando que a razão de cisalhamento é $\dot{\gamma}=\sqrt{\frac{1}{2} \operatorname{tr}\left(D_{i j}{ }^{2}\right)}$, mediante a relação (5.6) ela é calculada via a expressão:

$$
\dot{\gamma}=\sqrt{2\left(\frac{\partial u}{\partial r}\right)^{2}+2\left(\frac{\partial v}{\partial z}\right)^{2}+2\left(\frac{u}{r}\right)^{2}+\left(\frac{\partial u}{\partial z}+\frac{\partial v}{\partial r}\right)^{2}}
$$

como pode ser observado em [127]. A concentração local é obtida da equação de transporte advectivadifusiva (3.36), que no sistema axissimétrico é escrita por

$$
\frac{\partial c}{\partial t}+\frac{1}{r} \frac{\partial(r u c)}{\partial r}+\frac{\partial(v c)}{\partial z}=D^{m}\left[\frac{1}{r} \frac{\partial}{\partial r}\left(r \frac{\partial c}{\partial r}\right)+\frac{\partial^{2} c}{\partial z^{2}}\right]
$$

assim a viscosidade toma a forma $\nu_{c} \equiv \nu_{c}(\dot{\gamma}, c)$, já enumerada anteriormente por (4.6), expressa por:

$$
\nu_{c}(\dot{\gamma}, c)=\frac{\tau_{0}(c)}{\rho_{m} \dot{\gamma}}+K^{\prime}(c)[\dot{\gamma}]^{n(c)-1}
$$

onde $K^{\prime}(c)=\frac{K}{\rho_{m}}$.

Em nosso modelo consideramos que as leis que governam a ascensão da bolha são aquelas dadas no sistema de equações diferenciais (3.39). O empuxo atua na direção do eixo de simetria no sentido para cima, o seu ponto de localização é no centróide do volume da bolha $\left(r_{c m}, z_{c m}\right)$ (ver figura 5.1), ele é representado por

$$
\mathbf{E}=\left(\begin{array}{lll}
0 & 0 & \rho_{c} g_{z} v o l
\end{array}\right)
$$

de modo análogo, o peso da bolha age na direção do eixo de simetria mas em sentido contrário ao empuxo. A aplicação do peso é também no centróide $\left(r_{c m}, z_{c m}\right)$ e dado na forma 


$$
\mathbf{P}=\left(\begin{array}{lll}
0 & 0 & \rho_{d} g_{z} v o l
\end{array}\right)
$$

e uma vez que a resistência ao movimento da bolha pode ser expressa por $\mathbf{F V}=\left(\begin{array}{lll}F V_{r} & 0 & F V_{z}\end{array}\right)$, então o sistema de equações (3.39) resulta em

$$
\left\{\begin{array} { r l } 
{ \frac { d u _ { c m } } { d t } } & { = \frac { 1 } { \rho _ { d } v o l } [ F V _ { r } ] } \\
{ \frac { d r _ { c m } } { d t } } & { = u _ { c m } }
\end{array} \quad \mathrm { e } \quad \left\{\begin{array}{rl}
\frac{d v_{c m}}{d t} & =\frac{1}{\rho_{d} v o l}\left[\rho_{c} g_{z} v o l-\rho_{d} g_{z} v o l+F V_{z}\right] \\
\frac{d z_{c m}}{d t} & =v_{c m}
\end{array}\right.\right.
$$

Como estamos trabalhando no contexto axissimétrico, resulta que $F V_{r}=0$ e consequentemente $u_{c m}=0$ e $r_{c m}=0$. Entretanto se $\mathbf{n}=\left(\begin{array}{lll}n_{1} & 0 & n_{3}\end{array}\right)^{T}$ é o vetor normal, operando sobre a equação (3.38) encontramos

$$
F V_{z}=\int_{C} 2 \pi r\left[\mu\left(\frac{\partial v}{\partial r}+\frac{\partial u}{\partial z}\right) n_{1}+\left(2 \mu \frac{\partial v}{\partial z}\right) n_{3}\right] d l
$$

Portanto, a movimentação do centro de massa da bolha $\left(r_{c m}, z_{c m}\right)$ se dá via a resolução do sistema de equações

$$
\left\{\begin{aligned}
\frac{d v_{c m}}{d t} & =\frac{1}{\rho_{d} v o l}\left[g_{z} \operatorname{vol}\left(\rho_{c}-\rho_{d}\right)+\int_{C} 2 \pi r\left(\mu\left(\frac{\partial v}{\partial r}+\frac{\partial u}{\partial z}\right) n_{1}+\left(2 \mu \frac{\partial v}{\partial z}\right) n_{3}\right) d l\right] \\
\frac{d z_{c m}}{d t} & =v_{c m}
\end{aligned}\right.
$$

com $r_{c m}=0$ em todo o transcorrer das simulações.

A cada movimentação do centro de massa $\left(r_{c m}, z_{c m}\right)$, a forma da bolha poderá ser alterada conforme abordamos na seção 4.2 através do uso das equações (4.11) e (4.12) para os casos $C C, e e, e E$, Ee.

Devido a simetria, o centro de massa é expresso por [51]:

$$
r_{c m}=0.0 \quad \text { e } \quad z_{c m}=\frac{1}{\int_{D} d A} \int_{D} \tilde{y} d A
$$

onde $D$ é a área (em azul) delimitada pela curva $C$, figura 5.1. Se $P=-\frac{\widetilde{y}^{2}}{2}$ e $Q=0$, então do teorema (A.0.1) temos que $\int_{D} \widetilde{y} d A=-\frac{1}{2} \int_{C} \widetilde{y}^{2}$ e sabendo do cálculo vetorial que podemos escrever $D=\int_{D} d A=-\int_{C} z d r$, o centro de massa fica

$$
r_{c m}=0.0
$$$$
z_{c m}=-\frac{1}{2 D} \int_{C} z^{2} d r
$$ 
Portanto, em nosso código computacional calculamos o novo centro de massa a cada lapso de tempo para a nova forma encontrada para a bolha. O que completa o equacionamento do nosso modelo para ascensão.

\subsection{Condições Auxiliares}

Na intenção de que a dinâmica do movimento da bolha imersa ao fluido esteja consistente com a física do problema, as condições auxiliares devem ser impostas corretamente. Para isto, dividimos o domínio de interesse do problema numa grade estacionária e rotulamos os elementos (quadrados) da grade da maneira mostrada na figura 5.2 (esquerda).
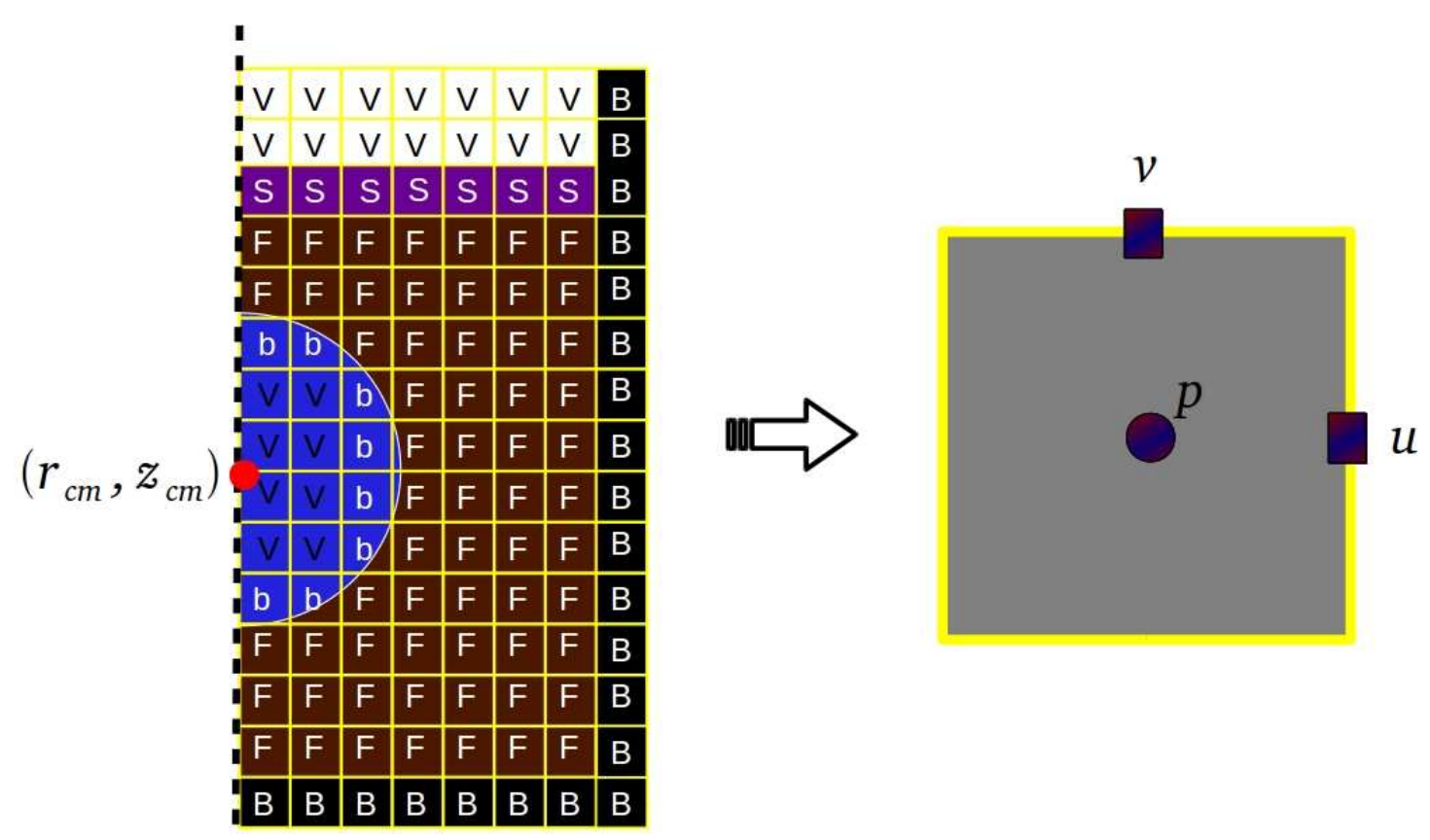

Figura 5.2: Configuração de celulas no domínio (esquerda) e localização da velocidade e pressão na célula (direita).

Na figura 5.2 (esquerda), que está desprovida de escala, temos a grade em amarelo dividindo o domínio em células. A cada célula associamos o vetor velocidade $(u, v)$ a sua face e o escalar pressão $p$ ao centro da mesma, figura 5.2 (direita). Os rótulos nas células são tais que:

- Células de fluido (fluid cells) (F): são células que contém fluido onde as equações de continuidade, Navier-Stokes e correlatas ao movimento do fluido são resolvidas.

- Células vazias (empty cells) (V): são células que não contém alguma informação, mas mapeiam regiões do domínio. Nas simulações não é resolvida qualquer equação sobre elas. 
- Células de fronteira (boundary cells) (B): são aquelas em que as condições de contorno de parede rígida são impostas. O fluido não está definido sobre estas células.

- Células de fronteira livre (surface cells) (S): são células que contém fluido com o intuito de modelar a superfície livre. Estas células são o lugar geométrico de posicionamento e orientação da superfície livre.

- Células de fronteira da bolha (bubble cells) (b): são células cujas condições de contorno da parede não rígida da bolha são impostas. Estão sempre adjacentes a células de fluido.

Como condição inicial, admitimos em nossas simulações que no primeiro instante as células de fluido (F), que envolvem a bolha, são tais que o campo de velocidades do fluido é tomado como nulo. As celulas (S) da superfície livre são localizadas no domínio e o campo de velocidades é também nulo. Finalmente, a bolha é localizada no domínio através do seu centro de massa $\left(r_{c m}, z_{c m}\right)$.

Com este cenário inicial as forças atuantes na bolha são calculadas e a resultante é obtida, que levada ao sistema de equações (5.13) promove a movimentação da bolha e consequentemente do fluido. Porém para que haja consistência na movimentação, as condições de fronteira devem ser corretamente aplicadas. Passamos então a descrição dessas condições enumeradas abaixo.

\section{Condição de Fronteira no Contorno Rígido:}

A condição de não escorregamento (no-slip) é aplicada sobre as células do contorno rígido para todo o tempo de simulação, logo impomos

$$
u(r, z)=0 \quad \text { e } \quad v(r, z)=0
$$

\section{Condição de Fronteira no Eixo de Simetria:}

Sob o eixo de simetria, onde $r=0$, a condição de escorregamento livre (free-slip) é aplicada às células adjacentes ao eixo. O fluido não transpõe o eixo de simetria e não há perda friccional adjacente a esta fronteira, então consideramos:

$$
u(r, z)=0 \quad \text { e } \quad \frac{\partial v(r, z)}{\partial n}=0
$$

onde $n$ é a direção normal.

\section{Condição de Fronteira na Superfície Livre:}

Com o movimento ascendente da bolha o campo de velocidades e pressão das células a sua frente sofrem alterações em seus valores, como o nosso interesse é simular a ascensão numa 
geometria cujo bordo não influencie os resultados simulados, decidimos minimizar a influência do contorno superior via condição de fronteira na superfície livre.

Fazemos em nossas simulações a superfície livre (contorno superior) longe o suficiente do contorno inferior tal que a mesma não saia do repouso. Sendo n e m os vetores unitários normal exterior e tangente à superfície livre, $\sigma$ o tensor das tensões, então

$$
\text { n. }(\boldsymbol{\sigma} . \mathbf{n})=0 \quad \text { e } \quad \text { m. }(\boldsymbol{\sigma} \cdot \mathbf{n})=0
$$

onde $\mathbf{n}=\left(\begin{array}{lll}n_{1} & 0 & n_{3}\end{array}\right)^{T}$ e $\mathbf{m}=\left(\begin{array}{lll}-n_{3} & 0 & n_{1}\end{array}\right)^{T}$ [46], [129], [76].

Como,

$$
\boldsymbol{\sigma . n}=\left(\begin{array}{c}
\left(-p+2 \mu \frac{\partial u}{\partial r}\right) n_{1}+\mu\left(\frac{\partial u}{\partial z}+\frac{\partial v}{\partial r}\right) n_{3} \\
0 \\
\mu\left(\frac{\partial v}{\partial r}+\frac{\partial u}{\partial z}\right) n_{1}+\left(-p+2 \mu \frac{\partial v}{\partial z}\right) n_{3}
\end{array}\right)
$$

então para as equações (5.18) temos

$$
\begin{aligned}
& \text { n. }(\boldsymbol{\sigma} \cdot \mathbf{n})= \\
& \left(-p+2 \mu \frac{\partial u}{\partial r}\right) n_{1}^{2}+\mu\left(\frac{\partial u}{\partial z}+\frac{\partial v}{\partial r}\right) n_{1} n_{3}+\mu\left(\frac{\partial v}{\partial r}+\frac{\partial u}{\partial z}\right) n_{1} n_{3}+\left(-p+2 \mu \frac{\partial v}{\partial z}\right) n_{3}^{2}=0 \\
& \text { m. }(\boldsymbol{\sigma} \cdot \mathbf{n})= \\
& -\left(-p+2 \mu \frac{\partial u}{\partial r}\right) n_{1} n_{3}-\mu\left(\frac{\partial u}{\partial z}+\frac{\partial v}{\partial r}\right) n_{3}^{2}+\mu\left(\frac{\partial v}{\partial r}+\frac{\partial u}{\partial z}\right) n_{1}^{2}+\left(-p+2 \mu \frac{\partial v}{\partial z}\right) n_{1} n_{3}=0
\end{aligned}
$$

mas como $|\mathbf{m}|=\sqrt{n_{1}^{2}+n_{3}^{2}}$ e portanto $n_{1}^{2}+n_{3}^{2}=1$, as equações anteriores são simplificadas e assumem a forma

$$
\begin{array}{r}
2 \mu\left[\left(\frac{\partial u(r, z)}{\partial z}+\frac{\partial v(r, z)}{\partial r}\right) n_{1} n_{3}+\frac{\partial u(r, z)}{\partial r} n_{1}^{2}+\frac{\partial v(r, z)}{\partial z} n_{3}^{2}\right]=p \\
\left(\frac{\partial u(r, z)}{\partial z}+\frac{\partial v(r, z)}{\partial r}\right)\left(n_{1}^{2}-n_{3}^{2}\right)+2\left(\frac{\partial v(r, z)}{\partial z}-\frac{\partial u(r, z)}{\partial r}\right) n_{1} n_{3}=0
\end{array}
$$

\section{Condição de Fronteira na Superfície da Bolha:}

Observe na figura 5.2 (esquerda), que o lugar onde o contorno da bolha passa têm as células rotuladas por (b), estas células demarcam a superfície da bolha. Para estas células, calculamos e aplicamos valores sobre $u(r, z)$ e $v(r, z)$ inspirados no conceito de representação integral de uma função $f$ num domínio $\Omega$ em termos da função distribuição delta de Dirac. Para obter informações detalhadas sobre a representação integral consultar os trabalhados [88] e [19]. 
Neste trabalho de tese, em particular, adaptamos o conceito de representação integral de uma função na condição de fronteira da superfície da bolha. A motivação foi o fato de que a avaliação das velocidades $u(r, z)$ e $v(r, z)$, nas faces das células $(\mathbf{b})$, pode ser a média dos valores vizinhos (do contorno) ponderada por uma função núcleo.

Para explicar a aplicação da técnica de representação integral admita, por exemplo, que o caso $e E$ representado na figura 4.18 esteja em processo de simulação. Observando a figura 5.3 (esquerda), considere que a bolha esteja localizada no centro de massa $\left(r_{c m}^{1}, z_{c m}^{1}\right)$ no tempo $t=t_{1}$, cujo contorno é $C^{1}$ com o ponto $P \in C^{1}$ de coordenadas $\left(r_{1}, z_{1}\right)$.

No tempo $t_{2}=t_{1}+\Delta t$ e sem perda de generalidade, os equacionamentos de ascensão levam o centro de massa $\left(r_{c m}^{1}, z_{c m}^{1}\right)$ para a localização $\left(r_{c m}^{I}, z_{c m}^{I}\right)$, nesta localização intermediária a nova forma é calculada.

Para a nova forma são calculados o novo centro de massa $\left(r_{c m}^{2}, z_{c m}^{2}\right)$ e o contorno $C^{2}$. Nesta passagem de cálculos, o ponto $P \in C^{1}$ sofre uma translação no espaço e é rotulado por $\widehat{P} \in C^{2}$ com as coordenadas dadas por $\left(r_{2}, z_{2}\right)$. Deste feito, calculamos a velocidade do ponto $\widehat{P}$ por meio das relações $U=\frac{r_{2}-r_{1}}{\Delta t}$ e $V=\frac{z_{2}-z_{1}}{\Delta t}$. Seguindo esta estratégia para todos os pontos de contorno teremos a velocidade do contorno $C^{2}$, de onde definimos $\operatorname{Ver}\left(\widehat{P}_{k}\right)=\left[r_{k}, z_{k}, U_{k}, V_{k}\right]$.

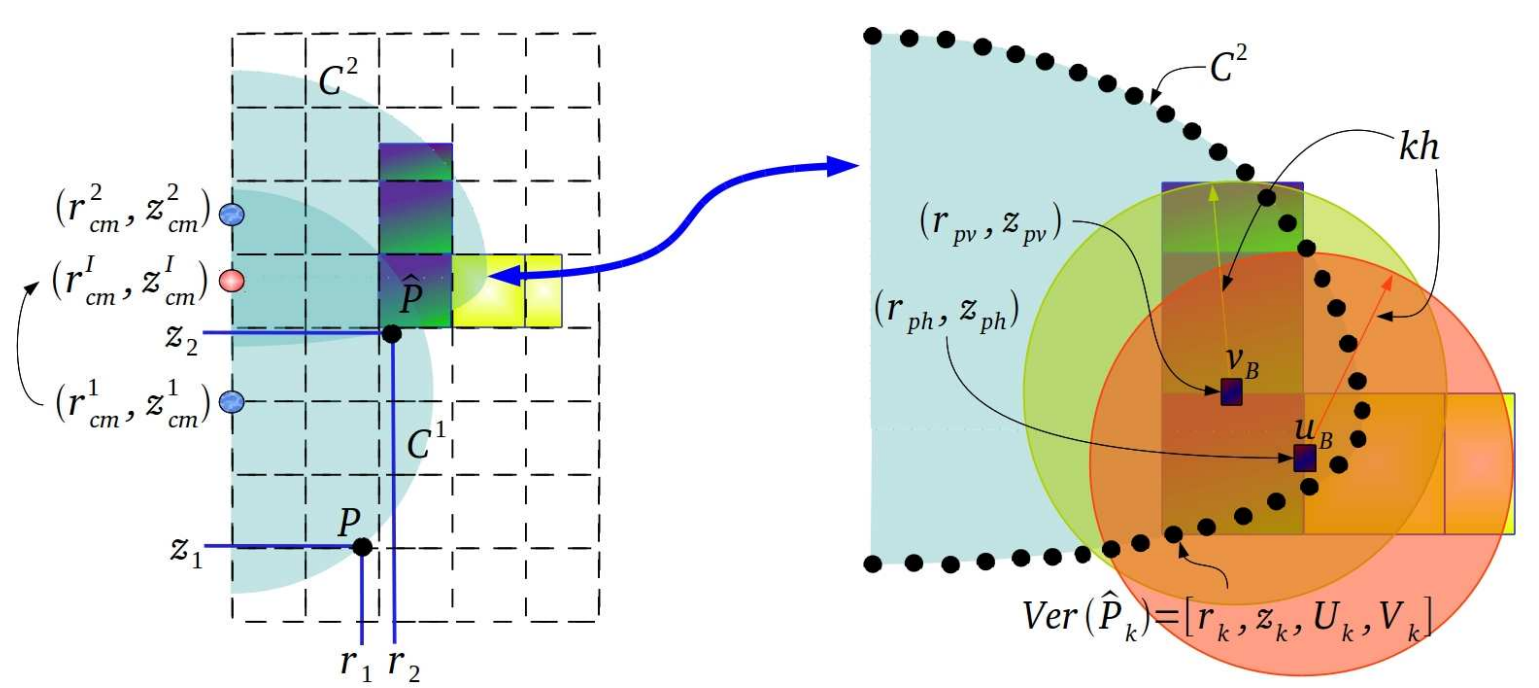

Figura 5.3: Mudança de forma (esquerda) e esquema de cálculo da condição de contorno para a bolha (direita).

Observando agora a figura 5.3 (direita), seja $\operatorname{Ver}\left(\widehat{P}_{k}\right)=\left[r_{k}, z_{k}, U_{k}, V_{k}\right]$ a matriz de informação dos vértices, de quatro colunas e $n$ linhas $(k=1, \cdots, n)$. As duas primeiras colunas são relativas a localização do ponto e as duas últimas as componentes de velocidade nas direções 
horizontal e vertical respectivamente.

Se $f$ é a componente de velocidade da célula (b) e $f: \mathcal{R} \rightarrow \mathcal{R}$ é tal que sua representação integral é definida através da convolução de $f$ por uma função suave $W_{h}: \mathcal{R} \rightarrow \mathcal{R}$, conhecida como função núcleo, então:

$$
u_{B}=\int_{C^{2}} U^{m} * W_{h}(R) d r \quad \text { e } \quad v_{B}=\int_{C^{2}} V^{m} * W_{h}(R) d z
$$

onde $R=\frac{\left\|r_{p h}-r^{m}\right\|}{h}$ (no cálculo de $u_{B}$ ) e $R=\frac{\left\|z_{p v}-z^{m}\right\|}{h}$ (no cálculo de $v_{B}$ ), $U^{m}=\frac{U_{k}+U_{k+1}}{2}, V^{m}=\frac{V_{k}+V_{k+1}}{2}, r^{m}=\frac{r_{k}+r_{k+1}}{2}, z^{m}=\frac{z_{k}+z_{k+1}}{2} \operatorname{para} k=1, \cdots, n-1$.

O núcleo é uma função que deve ser: suficientemente suave, normalizado, positivo, decrescente, simétrico e ter suporte compacto [89].

Suporte compacto significa $W_{h}(R)=0$ quando $R>\kappa h$, $h$ é denominado comprimento suave e $\kappa$ é um fator de escala associado ao núcleo. Na literatura são utilizados vários tipos de funções núcleo, em nosso trabalho utilizamos a Gaussiana. Embora a Gaussiana não possui suporte compacto ela decai rapidamente para zero, logo possui virtualmente a propriedade de suporte compacto [88]. A função Gaussiana que utilizamos neste trabalho de tese foi

$$
W_{h}(R)=\left(\frac{1}{h}\right) e^{-R^{2}}
$$

além disto, empregamos o raio $\kappa h$ igual a 1.5 células como pode ser observado na figura 5.3 (direita), note que os conjuntos de pontos do contorno sob o raio $\kappa h$ são diferentes para a célula (b). As equações que exprimem a condição de contorno a partir da pespectiva do movimento da bolha ficam dadas como

$$
\left\{\begin{array}{l}
u_{B}=\int_{C^{2}} U^{m}\left(\frac{1}{h}\right) e^{-\left(\frac{\left\|r_{p h}-r^{m}\right\|}{h}\right)^{2}} d r \\
v_{B}=\int_{C^{2}} V^{m}\left(\frac{1}{h}\right) e^{-\left(\frac{\left\|z_{p v}-z^{m}\right\|}{h}\right)^{2}} d z
\end{array}\right.
$$

Em fim, neste trabalho de tese resolveremos o problema de ascensão de bolha, com mudança de forma, no sistema axissimétrico. Consideramos que a bolha assume a forma circular axissimétrica e é envolta pelo fluido em repouso no início do tempo. Nos tempos subsequentes o conjunto de equações diferenciais dado pelas equações (5.8), (5.9), (5.10), (5.13) (com $r_{c m}=0$ ) são resolvidos, respeitando as condições auxiliares impostas ao modelo.

Em nosso modelo efetuamos a adimensionalização das variáveis. Com isto conseguimos diminuir o número de variáveis do problema e utilizar os números adimensionais, listados na seção 3.1 página 
30 descritos em (3.10)-(3.17), para descrever o comportamento e a forma da ascensão da bolha e o escoamento ao seu redor. Prosseguimos então o nosso texto com a metodologia de adimensionalização.

\subsection{Adimensionalização}

Em todo o nosso texto desenvolvemos as equações de interesse no contexto dimensional. Munson et. al [80] afirmam que existe uma abordagem alternativa quando conhecemos as equações que descrevem o fenômeno que desejamos analisar. Nesta situação podemos desenvolver as leis de semelhança a partir das equações que descrevem o fenômeno pelo processo de adimensionalização. A adimensionalização consiste na normalização das grandezas envolvidas no escoamento e identifica os parâmetros que o governam. Disto surgem parâmetros adimensionais, logo problemas em escalas de dimensões diferentes, mas com os mesmos parâmetros adimensionais, terão resultados equivalentes e portanto são similares [115].

Considere que os parâmetros de escala $L$ (comprimento), $U$ (velocidade), $\nu_{0}$ (viscosidade), $\rho_{0}$ (densidade), $g_{0}$ (gravidade), $c_{0}$ (concentração) e $\tau_{0}$ sejam conhecidos, então podemos escrever as seguintes relações adimensionais:

$$
\begin{array}{lllll}
\bar{r}=\frac{r}{L} & \bar{z}=\frac{z}{L} & \bar{u}=\frac{u}{U} & \bar{v}=\frac{v}{U} & \bar{t}=\frac{t}{L / U} \\
\bar{g}=\frac{g}{g_{0}} & \bar{\rho}=\frac{\rho}{\rho_{0}} & \bar{\nu}=\frac{\nu}{\nu_{0}} & \bar{c}=\frac{c}{c_{0}} & \overline{\dot{\gamma}}=\frac{\dot{\gamma}}{U / L} \\
\overline{\text { vol }}=\frac{v o l}{L^{3}} & \overline{d L}=\frac{d L}{L} & \bar{p}=\frac{p}{\rho U^{2}} & \bar{\tau}_{0}=\frac{\tau_{0}}{\nu_{0} \rho_{0}(U / L)} & \bar{K}^{\prime}=\frac{K^{\prime}}{(U / L)^{1-n} \nu_{0}}
\end{array}
$$

Substituindo as devidas relações adimensionais na equação (5.8) obtemos

$$
\frac{1}{L \bar{r}} \frac{\partial(L \bar{r} U \bar{u})}{\partial(L \bar{r})}+\frac{\partial(U \bar{v})}{\partial(L \bar{z})}=0
$$

que simplificada fica

$$
\frac{1}{\bar{r}} \frac{\partial(\bar{r} \bar{u})}{\partial \bar{r}}+\frac{\partial \bar{v}}{\partial \bar{z}}=0
$$


Levando agora as relações adimensionais em (5.9) encontramos

$$
\begin{aligned}
\frac{\partial(U \bar{u})}{\partial\left(\frac{L}{U} \bar{t}\right)} & +\frac{1}{L \bar{r}} \frac{\partial(L \bar{r} U \bar{u} U \bar{u})}{\partial(L \bar{r})}+\frac{\partial(U \bar{u} U \bar{v})}{\partial(L \bar{z})}= \\
& -\frac{1}{\rho_{c}} \frac{\partial\left(\rho_{c} U^{2} \bar{p}\right)}{\partial(L \bar{r})}+\nu_{0} \bar{\nu}_{c}\left[\frac{1}{L \bar{r}} \frac{\partial}{\partial(L \bar{r})}\left(L \bar{r} \frac{\partial(U \bar{u})}{\partial(L \bar{r})}\right)+\frac{\partial^{2}(U \bar{u})}{\partial(L \bar{z})^{2}}-\frac{(U \bar{u})}{(L \bar{r})^{2}}\right] \\
& +\left[2 \frac{\partial(U \bar{u})}{\partial(L \bar{r})} \frac{\partial\left(\nu_{0} \bar{\nu}_{c}\right)}{\partial(L \bar{r})}+\left(\frac{\partial(U \bar{v})}{\partial(L \bar{r})}+\frac{\partial(U \bar{u})}{\partial(L \bar{z})}\right) \frac{\partial\left(\nu_{0} \bar{\nu}_{c}\right)}{\partial(L \bar{z})}\right]+g_{0} \bar{g}_{r}
\end{aligned}
$$

que pode ser ainda escrita na forma

$$
\begin{aligned}
\frac{\partial \bar{u}}{\partial \bar{t}} & =-\frac{1}{\bar{r}} \frac{\partial(\bar{r} \bar{u} \bar{u})}{\partial \bar{r}}-\frac{\partial(\bar{u} \bar{v})}{\partial \bar{z}}-\frac{\partial \bar{p}}{\partial \bar{r}}+\frac{\bar{\nu}_{c}}{R e}\left[\frac{1}{\bar{r}} \frac{\partial}{\partial \bar{r}}\left(\bar{r} \frac{\partial \bar{u}}{\partial \bar{r}}\right)+\frac{\partial^{2} \bar{u}}{\partial \bar{z}^{2}}-\frac{\bar{u}}{\bar{r}^{2}}\right] \\
& +\frac{1}{R e}\left[2 \frac{\partial \bar{u}}{\partial \bar{r}} \frac{\partial \bar{\nu}_{c}}{\partial \bar{r}}+\left(\frac{\partial \bar{v}}{\partial \bar{r}}+\frac{\partial \bar{u}}{\partial \bar{z}}\right) \frac{\partial \bar{\nu}_{c}}{\partial \bar{z}}\right]+\frac{1}{F r} \bar{g}_{r}
\end{aligned}
$$

de modo análogo encontramos também

$$
\begin{aligned}
\frac{\partial \bar{v}}{\partial \bar{t}} & =-\frac{1}{\bar{r}} \frac{\partial(\bar{r} \bar{u} \bar{v})}{\partial \bar{r}}-\frac{\partial(\bar{v} \bar{v})}{\partial \bar{z}}-\frac{\partial \bar{p}}{\partial \bar{z}}+\frac{\bar{\nu}_{c}}{R e}\left[\frac{1}{\bar{r}} \frac{\partial}{\partial \bar{r}}\left(\bar{r} \frac{\partial \bar{v}}{\partial \bar{r}}\right)+\frac{\partial^{2} \bar{v}}{\partial \bar{z}^{2}}\right] \\
& +\frac{1}{R e}\left[2 \frac{\partial \bar{v}}{\partial \bar{z}} \frac{\partial \bar{\nu}_{c}}{\partial \bar{z}}+\left(\frac{\partial \bar{v}}{\partial \bar{r}}+\frac{\partial \bar{u}}{\partial \bar{z}}\right) \frac{\partial \bar{\nu}_{c}}{\partial \bar{r}}\right]+\frac{1}{F r} \bar{g}_{z}
\end{aligned}
$$

Uma vez que a viscosidade pode ser dada por $\nu_{c}(\dot{\gamma}, c)=\frac{\tau_{0}(c)}{\rho_{m} \dot{\gamma}}+K^{\prime}(c)[\dot{\gamma}]^{n(c)-1}$, equação (4.6), da substituição das relações adimensionais encontramos

$$
\nu_{0} \bar{\nu}_{c}=\frac{\nu_{0} \rho_{0}\left(\frac{U}{L}\right) \bar{\tau}_{0}}{\bar{\rho}_{m} \rho_{0}\left(\frac{U}{L}\right) \overline{\dot{\gamma}}}+\left(\frac{U}{L}\right)^{1-n} \nu_{0} \bar{K}^{\prime}\left[\left(\frac{U}{L}\right) \overline{\dot{\gamma}}\right]^{n-1}
$$

que resulta em

$$
\bar{\nu}_{c}=\frac{\bar{\tau}_{0}}{\bar{\rho}_{m} \overline{\dot{\gamma}}}+\bar{K}^{\prime}[\overline{\dot{\gamma}}]^{n-1}
$$

Mas das igualdades dadas pelas equações (4.4) temos também

$$
\begin{aligned}
\nu_{0} \rho_{0}\left(\frac{U}{L}\right) \bar{\tau}_{0} & =502.457791873\left(1.0-\exp \left[-0.000283528723819 c_{0} \bar{c}\right]\right) \\
\bar{K}^{\prime}\left(\frac{U}{L}\right)^{1-n} \nu_{0} & =\frac{1}{\rho_{0} \bar{\rho}_{m}}\left(0.000958406+0.000244983275307 c_{0}^{2} \bar{c}^{2}\right)
\end{aligned}
$$

ou seja

$$
\begin{aligned}
\bar{\tau}_{0} & =\left[\frac{1}{\nu_{0} \rho_{0} U / L}\right] 502.457791873\left(1.0-\exp \left[-0.000283528723819 c_{0} \bar{c}\right]\right) \\
\bar{K}^{\prime} & =\left[\frac{1}{\left(\frac{U}{L}\right)^{1-n} \nu_{0} \rho_{0} \bar{\rho}_{m}}\right]\left(0.000958406+0.000244983275307 c_{0}^{2} \bar{c}^{2}\right) \\
n & =\frac{1}{0.0195958139505 c_{0} \bar{c}+1}
\end{aligned}
$$


e substituindo as devidas relações adimensionais na equação da razão de cisalhamento (5.11) teremos

$$
\frac{U}{L} \overline{\dot{\gamma}}=\sqrt{2\left(\frac{\partial(U \bar{u})}{\partial(L \bar{r})}\right)^{2}+2\left(\frac{\partial(U \bar{v})}{\partial(L \bar{z})}\right)^{2}+2\left(\frac{(U \bar{u})}{(L \bar{r})}\right)^{2}+\left(\frac{\partial(U \bar{u})}{\partial(L \bar{z})}+\frac{\partial(U \bar{v})}{\partial(L \bar{r})}\right)^{2}}
$$

ou

$$
\overline{\dot{\gamma}}=\sqrt{2\left(\frac{\partial \bar{u}}{\partial \bar{r}}\right)^{2}+2\left(\frac{\partial \bar{v}}{\partial \bar{z}}\right)^{2}+2\left(\frac{\bar{u}}{\bar{r}}\right)^{2}+\left(\frac{\partial \bar{u}}{\partial \bar{z}}+\frac{\partial \bar{v}}{\partial \bar{r}}\right)^{2}}
$$

e finalizando, para a equação de transporte (5.12) fazemos

$$
\frac{\partial\left(c_{0} \bar{c}\right)}{\partial\left(\frac{L}{U} \bar{t}\right)}+\frac{1}{L \bar{r}} \frac{\partial\left(L \bar{r} U \bar{u} c_{0} \bar{c}\right)}{\partial(L \bar{r})}+\frac{\partial\left(U \bar{v} c_{0} \bar{c}\right)}{\partial(L \bar{z})}=D^{m}\left[\frac{1}{L \bar{r}} \frac{\partial}{\partial(L \bar{r})}\left(L \bar{r} \frac{\partial\left(c_{0} \bar{c}\right)}{\partial(L \bar{r})}\right)+\frac{\partial^{2}\left(c_{0} \bar{c}\right)}{\partial(L \bar{z})^{2}}\right]
$$

que fica na forma

$$
\frac{\partial \bar{c}}{\partial \bar{t}}+\frac{1}{\bar{r}} \frac{\partial(\bar{r} \bar{u} \bar{c})}{\partial \bar{r}}+\frac{\partial(\bar{v} \bar{c})}{\partial \bar{z}}=\frac{1}{P e}\left[\frac{1}{\bar{r}} \frac{\partial}{\partial \bar{r}}\left(\bar{r} \frac{\partial \bar{c}}{\partial \bar{r}}\right)+\frac{\partial^{2} \bar{c}}{\partial \bar{z}^{2}}\right]
$$

então teremos finalmente a determinação de $\bar{\nu}_{c} \equiv \bar{\nu}_{c}(\overline{\dot{\gamma}}, \bar{c})$.

Nas equações do movimento do centro de massa da bolha, equações (5.13), realizamos as substituições das relações adimensionais devidas e encontramos

$$
\begin{aligned}
& \frac{d\left(U \bar{v}_{c m}\right)}{d\left(\frac{L}{U} \bar{t}\right)}=\frac{g_{0} \bar{g}_{z} L^{3} \overline{v o l}\left(\bar{\rho}_{c} \rho_{0}-\bar{\rho}_{d} \rho_{0}\right)}{\bar{\rho}_{d} \rho_{0} L^{3} v o l}+\frac{1}{\bar{\rho}_{d} \rho_{0} L^{3} \overline{v o l}} \\
\mathrm{e} \quad & \int_{C} 2 \pi(L \bar{r})\left(\nu_{0} \bar{\nu} \rho_{0}\left(\frac{\partial(U \bar{v})}{\partial(L \bar{r})}+\frac{\partial(U \bar{u})}{\partial(L \bar{z})}\right) n_{1}+\left(2 \nu_{0} \bar{\nu} \rho_{0} \frac{\partial(U \bar{v})}{\partial(L \bar{z})}\right) n_{3}\right) L \bar{d} l \\
\frac{d\left(U \bar{v}_{c m}\right)}{d\left(\frac{L}{U} \bar{t}\right)} & =U \bar{v}_{c m}
\end{aligned}
$$

que após as operações de simplificação nos forneceu o sistema

$$
\left\{\begin{aligned}
\frac{d \bar{v}_{c m}}{\bar{d} t} & =\frac{1}{\bar{\rho}_{d} v \bar{o} l}\left[\frac{1}{F r} \bar{g}_{z} \overline{v o l}\left(\bar{\rho}_{c}-\bar{\rho}_{d}\right)+\int_{C} 2 \pi \bar{r}\left(\frac{\bar{\nu}_{c}}{R e}\left(\frac{\partial \bar{v}}{\partial \bar{r}}+\frac{\partial \bar{u}}{\partial \bar{z}}\right) n_{1}+\left(\frac{2 \bar{\nu}_{c}}{R e} \frac{\partial \bar{v}}{\partial \bar{z}}\right) n_{3}\right) \overline{d l}\right] \\
\frac{d \bar{z}_{c m}}{\bar{d} t} & =\bar{v}_{c m}
\end{aligned}\right.
$$

Quanto as condições de fronteira realizamos também as devidas aplicações das relações adimensionais e utilizamos nas nossas simulações as equações adimensionais equivalentes.

O nosso modelo matemático é constituído pelas equações: de continuidade, Navier-Stokes e de movimentação do centro de massa da bolha (adimensionais) sujeito às condições iniciais e de fronteira (adimensionais). O modelo foi resolvido numericamente via o método de diferenças finitas e algumas técnicas, quanto a metodologia numérica, foram desenvolvidas e aplicadas em nosso código computacional. Sendo assim, prosseguimos agora em nosso texto discutindo esta questão. 


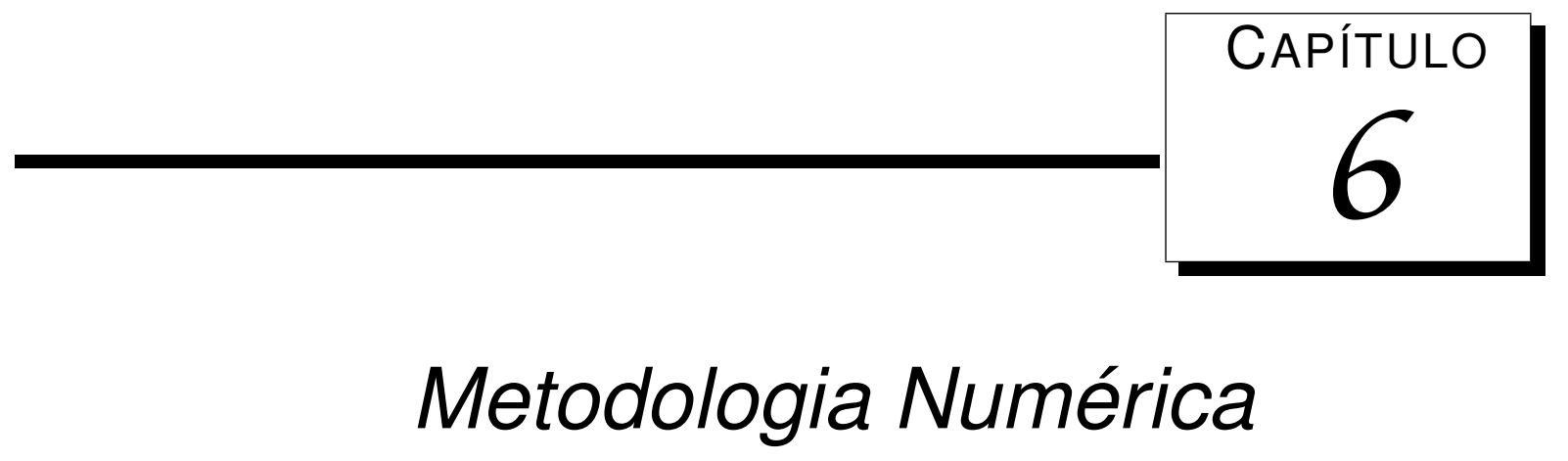

\subsection{Método GENSMAC}

Nos propusemos neste trabalho de tese modelar, simular e visualizar: o fluido circundante a uma bolha de gás, o escoamento deste fluido ao redor da bolha e a mudança da forma da bolha, com o objetivo final de estudar a ascensão de uma bolha de metano no sedimento. Utilizamos para isto um grid computacional axissimétrico que modela uma pequena porção do fundo de um lago. As equações que governam o campo de escoamento são resolvidas sob o grid estacionário, e a bolha se move através do grid por conta da solução numérica do sistema de equações do centro de massa.

Para simularmos a ascensão nós partimos do código numérico FREEFLOW-AXI, que modela e resolve numericamente o escoamento de fluidos newtonianos axissimétrico com superfície livre [85]. Primeiramente estendemos o código FREEFLOW-AXI objetivando resolver também problemas de fluidos não-newtonianos com container imerso interagindo com o fluido, esta extensão deu origem ao código FREEFLOW-AXI:newtonian/non-newtonian. No FREEFLOW-AXI:N/Non, está implementado o método GENSMAC (Generalized-Simplified-Marker-and-Cell), que é fundamentado nas idéias do método SMAC (Simplified-Marker-and-Cell). O GENSMAC é uma técnica de solução em diferenças finitas, engendrado sob uma malha deslocada, que resolve escoamentos de fluidos viscosos incompressíveis em domínios gerais [130]. Uma das grandes vantagens do método é o uso de partículas marcadoras para localizar a superfície livre do fluido. Para mais detalhes sobre o método, no contexto axissimétrico, consultar também a referência [124] e [76] para problemas tridimensionais. 
Em linhas gerais o algoritmo 1 (página 73) é construído sob o método GENSMAC, resolve as equações da mecânica dos fluidos via o método das projeções, e o sistema de equações do movimento do centro de massa pelo método de Euler explícito.

Assumimos que em um dado instante de tempo $\bar{t}_{0}$ o campo de velocidade $\bar{v}_{j}\left(\bar{t}_{0}, \bar{r}, \bar{z}\right)$ é conhecido, as condições de fronteira para a velocidade e pressão são dadas, o centro de massa da bolha e sua forma são também conhecidos. Calculamos então os campos de velocidade e pressão, o centro de massa da bolha e sua nova forma no tempo $\bar{t}=\bar{t}_{0}+\bar{\Delta} t$.

Observamos que no tempo inicial $\bar{t}_{0}$ o campo $\widetilde{\bar{p}}$ é considerado e o mesmo satisfaz as equações (5.18-adimensionalizada) da superfície livre. Utilizamos a equação (4.2-adimensionalizada) para modelar um campo vertical de concentração de material particulado, no tempo inicial, se o modelo não-newtoniano está sendo utilizado.

Para os outros tempos temos:

1. que a viscosidade é calculada, ou é constante, conforme o modelo simulado;

2. uma rotina otimiza o valor $\bar{t}_{0}$ tomando por base as restrições - (a) movimento das partículas, (b) critério de estabilidade que envolve o número de Reynolds e a viscosidade e (c) movimento do centro de massa da bolha [46] [25];

3. os campos de velocidades intermediárias $(\widetilde{\bar{u}}, \widetilde{\bar{v}})$ são calculados;

4. a equação de Poisson em termos do potencial de velocidade $\psi$ é resolvida através do método dos Gradientes Conjugados;

5. os campos de velocidade e pressão são corrigidos, decorrente do potencial $\psi$ e das velocidades $\widetilde{\bar{u}}, \widetilde{\bar{v}}$

6. com a velocidade e pressão do fluido, o centro de massa da bolha e sua forma são obtidos via o termo $F V_{\bar{z}}$. Neste termo temos o acoplamento entre as partes hidrodinâmica/bolha;

7. as posições das partículas marcadoras são atualizadas pelo método de Euler;

todos os procedimentos anteriormente enumerados são calculados respeitando as condições de contorno impostas.

Nesta seção procuramos destacar a estrutura de simulação do código FREEFLOW-AXI:N/Non com movimento de objeto imerso, na seção seguinte trataremos das aproximações numéricas efetuadas nas equações do algoritmo 1. 


\section{Algorithm 1 Algoritmo do simulador do código FREEFLOW-AXI:N/Non}

Inicializa $\bar{t}_{0}, \bar{v}_{j}, \widetilde{\bar{p}}, \bar{c}$

2: while $\bar{t}<\bar{t}_{\text {final }}$ do

4: $\quad \bar{\nu}_{c}=\left\{\right.$ cte,$\left.\frac{\overline{\tau_{0}}}{\bar{\rho}_{m} \overline{\dot{\gamma}}}+\bar{K}^{\prime}[\overline{\dot{\gamma}}]^{n-1}\right\}$

6: $\quad \bar{d} t \leftarrow \bar{\Delta} t$

8: $\quad \frac{\partial \bar{u}}{\partial \bar{t}}=-\frac{\partial \widetilde{\bar{p}}}{\partial \bar{r}}-\frac{1}{\bar{r}} \frac{\partial(\bar{r} \bar{u} \bar{u})}{\partial \bar{r}}-\frac{\partial(\bar{u} \bar{v})}{\partial \bar{z}}+\frac{\bar{\nu}_{c}}{R e}\left[\frac{1}{\bar{r}} \frac{\partial}{\partial \bar{r}}\left(\bar{r} \frac{\partial \bar{u}}{\partial \bar{r}}\right)+\frac{\partial^{2} \bar{u}}{\partial \bar{z}^{2}}-\frac{\bar{u}}{\bar{r}^{2}}\right]$ $+\frac{1}{R e}\left[2 \frac{\partial \bar{u}}{\partial \bar{r}} \frac{\partial \bar{\nu}_{c}}{\partial \bar{r}}+\left(\frac{\partial \bar{v}}{\partial \bar{r}}+\frac{\partial \bar{u}}{\partial \bar{z}}\right) \frac{\partial \bar{\nu}_{c}}{\partial \bar{z}}\right]+\frac{1}{F r} \bar{g}_{r}$

10: $\frac{\partial \bar{v}}{\partial \bar{t}} \quad=\quad-\frac{\partial \widetilde{\bar{p}}}{\partial \bar{z}}-\frac{1}{\bar{r}} \frac{\partial(\bar{r} \bar{u} \bar{v})}{\partial \bar{r}}-\frac{\partial(\bar{v} \bar{v})}{\partial \bar{z}}+\frac{\bar{\nu}_{c}}{R e}\left[\frac{1}{\bar{r}} \frac{\partial}{\partial \bar{r}}\left(\bar{r} \frac{\partial \bar{v}}{\partial \bar{r}}\right)+\frac{\partial^{2} \bar{v}}{\partial \bar{z}^{2}}\right]$ $+\frac{1}{R e}\left[2 \frac{\partial \bar{v}}{\partial \bar{z}} \frac{\partial \bar{\nu}_{c}}{\partial \bar{z}}+\left(\frac{\partial \bar{v}}{\partial \bar{r}}+\frac{\partial \bar{u}}{\partial \bar{z}}\right) \frac{\partial \bar{\nu}_{c}}{\partial \bar{r}}\right]+\frac{1}{F r} \bar{g}_{z}$

12: $\quad \frac{\partial}{\partial \bar{r}}\left(\bar{r} \frac{\partial \psi}{\partial \bar{r}}\right)+\bar{r} \frac{\partial^{2} \psi}{\partial \bar{z}^{2}}=\omega, \quad$ onde $\quad \omega=\frac{\partial(\bar{r} \widetilde{\bar{u}})}{\partial \bar{r}}+\bar{r} \frac{\partial \widetilde{\bar{v}}}{\partial \bar{z}}$

14: for all cell $_{F, S}$ do

16:

\section{end for}

$$
\bar{u} \leftarrow \widetilde{\bar{u}}-\left[\frac{\partial \psi}{\partial \bar{r}}+\frac{\partial \psi}{\partial \bar{z}}\right] \quad, \quad \bar{v} \leftarrow \widetilde{\bar{v}}-\left[\frac{\partial \psi}{\partial \bar{r}}+\frac{\partial \psi}{\partial \bar{z}}\right] \quad, \quad \bar{p} \leftarrow \widetilde{\bar{p}}+\frac{\psi}{\bar{d} t}
$$

18: $\quad$ procedure MOVIMENTO $=(C C, e e, e E, E e)$

20:

$$
\overline{F V_{\bar{z}}}=\int_{C} 2 \pi \bar{r}\left[\frac{\bar{\nu}_{c}}{R e}\left(\frac{\partial \bar{v}}{\partial \bar{r}}+\frac{\partial \bar{u}}{\partial \bar{z}}\right) n_{1}+\left(\frac{2 \bar{\nu}_{c}}{R e} \frac{\partial \bar{v}}{\partial \bar{z}}\right) n_{3}\right] \bar{d} l
$$

22: $\quad \frac{d \bar{v}_{c m}}{\bar{d} t}=\frac{1}{\bar{\rho}_{d} \operatorname{vol}}\left[\frac{1}{F r} \bar{g}_{z} \operatorname{vol}\left(\bar{\rho}_{c}-\bar{\rho}_{d}\right)+F V_{\bar{z}}\right] \quad, \quad \frac{d \bar{z}_{c m}}{\bar{d} t}=\bar{v}_{c m}$

24: $\quad \operatorname{Ver}\left(\widehat{\widehat{P}}_{k}\right)=\left[\bar{r}_{k}, \bar{z}_{k}, \bar{U}_{k}, \bar{V}_{k}\right] \quad, \quad \bar{r}_{c m}=0.0 \quad, \quad \bar{z}_{c m}=-\frac{1}{2 D} \int_{C} z^{2} d r$

\section{end procedure}

26: $\quad \frac{d \bar{r}}{d \bar{t}}=\bar{u} \quad, \quad \frac{d \bar{z}}{d \bar{t}}=\bar{v} \quad$ (movimentação de partículas)

28: $\quad \bar{t} \leftarrow \bar{t}_{0}+\bar{\Delta} t$ 


\subsection{Aproximações Numéricas}

Para não carregarmos demasiadamente a notação matemática das aproximações numéricas que trataremos a seguir suprimimos a "barra" sobre as variáveis adimensionalizadas e as caracterizações das fases contínua e dispersa. As equações diferenciais do nosso modelo matemático são resolvidas numericamente através da metodologia das diferenças finitas. O método de diferenças finitas consiste em aproximar as derivadas presentes nas equações diferencias por expressões algébricas. É mais comum encontrarmos estas expressões nomeadas como aproximações por diferenças. Finalmente o conjunto destas equações algébricas é resolvido numa malha decorrente da discretização do domínio.

Fizemos a discretização do domínio, figura 5.2 (esquerda), adimensionalizada, construindo uma malha estruturada cujos elementos são quadrados.
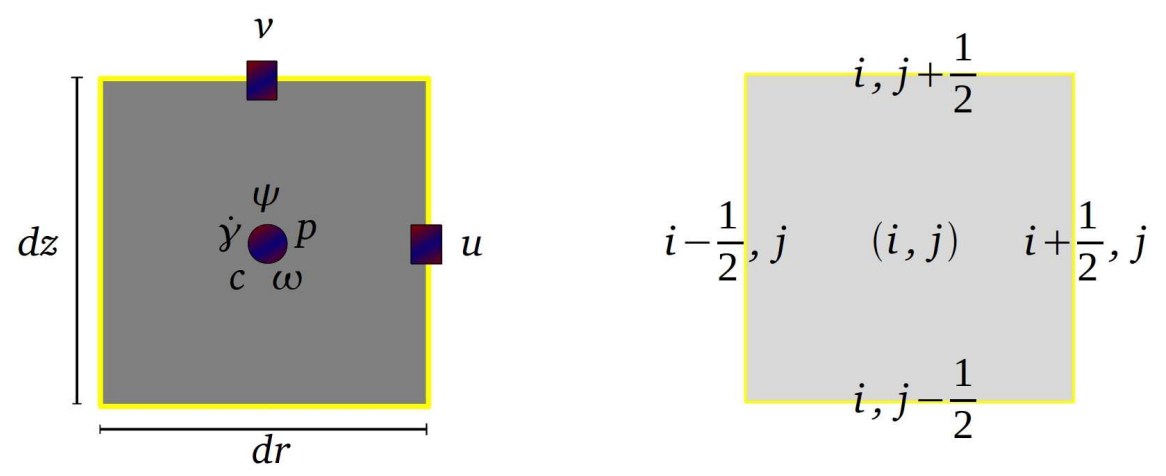

Figura 6.1: Localização das variáveis (esquerda) e rótulos da célula (direita).

Como observado na figura 6.1 (esquerda), o elemento é de dimensão $d r \times d z$ com as componentes de velocidade $(u, v)$ localizadas nas faces, contudo os escalares pressão $(p)$, potencial de velocidade $(\psi)$, divergente de velocidade $(\omega)$ são localizados no centro da célula. Ademais, os termos taxa de cisalhamento $(\dot{\gamma})$ e concentração $(c)$ são localizados no centro da célula, logo a viscosidade $(\nu)$ é calculada no centro também.

Este arranjo para as variáveis velocidade e pressão impedem o aparecimento de oscilações no cálculo da velocidade e pressão, além disto, permite simplificações nas condições de contorno e torna desnecessária a condição de fronteira para a pressão [46].

Empregamos em nosso modelo numérico o esquema de rotulagem de índices exibido na figura 6.1 (direita) para as variáveis. Se as dimensões do domínio computacional são $R \times h$ (figura 5.1) e dispondo de $n r$ células na direção horizontal e $n z$ células na vertical, de modo que $d r=\frac{R}{n r}$ e $d z=\frac{h}{n z}$, então teremos que $i=1, \ldots, n r$ e $j=1, \ldots, n z$. 
O método de diferenças finitas é empregado em diversos tipos de problemas. Uma descrição completa sobre o método e algumas aplicações em problemas de equações parabólicas, hiperbólicas e elípticas pode ser verificado em [114]. Ao leitor interessado na aplicação do método em problemas de dinâmica dos fluidos computacional consultar também [45].

Em geral as aproximações por diferenças podem ser do tipo: avançada, centrada e atrasada. Contudo dependendo das características físicas intríncecas à alguma derivada presente na equação, aproximações mais elaboradas são feitas com o intuito de obter resultados numéricos mais realísticos. Um exemplo disto é o estudo de técnicas aproximativas para termos convectivos.

Rafael A. B. de Queiroz [97], em seu trabalho de mestrado, trabalhou sobre esquemas upwind de alta resolução para o controle da difusão numérica. Dois novos esquemas: ALUS (Adaptive Linear Upwind Scheme) e o TOPUS (Third-Order Polynomial Upwind Scheme) foram desenvolvidos para aproximar termos convectivos como aqueles que se apresentam nas equações de Navier-Stokes. Ele conclui que os esquemas são estratégias robustas para capturar descontinuidades, qualitativamente superiores a esquemas já consagrados na literatura e efetivos no estudo de escoamentos complexos com superfícies livres.

Na linha dos esquemas para o termo convectivo, Giseli A. B. de Lima [69] propõe dois novos esquemas upwind de alta resolução, nomeados por FDPUS-C1 (Five-Degree Polynomial Upwind Scheme of $C^{1}$ Class) e SDPUS-C1 (Six-Degree Polynomial Upwind Scheme of $C^{1}$ Class). Em particular, os resultados numéricos com o SDPUS-C1 apresentaram desempenho similar (mas ligeiramente melhor) na comparação com o TOPUS, sendo assim implementamos o esquema SDPUS-C1 no tratamento dos termos convectivos das equações de concentração e de Navier-Stokes do nosso modelo matemático.

Uma vez que o termo convectivo pode ser escrito na forma $C O N V(\phi)=\frac{1}{r} \frac{\partial(r u \phi)}{\partial r}+\frac{\partial(v \phi)}{\partial z}$, os termos $u, v$ são as velocidades de convecção e $\phi$ é a variável convectada com $\phi=\{u, v, c\}$.

Por simplicidade, para exemplificar a discretização do termo convectivo assumimos que $\phi=u$ é transportada na direção $z$ segundo os esquemas das figuras 6.2 e 6.3 .

Se $A=(i+1 / 2, j), f=(i+1 / 2, j+1 / 2)$ e $g=(i+1 / 2, j-1 / 2)$, a aproximação da derivada (no ponto $A$ ) na direção $z$, presente no termo convectivo, fica:

$$
\left.\frac{\partial(v u)}{\partial z}\right|_{A}=\frac{1}{d z}\left[v_{i+1 / 2, j+1 / 2} u_{i+1 / 2, j+1 / 2}-v_{i+1 / 2, j-1 / 2} u_{i+1 / 2, j-1 / 2}\right]
$$

$\operatorname{com} v_{i+1 / 2, j+1 / 2}=\frac{v_{i+1, j+1 / 2}+v_{i, j+1 / 2}}{2}$ e $v_{i+1 / 2, j-1 / 2}=\frac{v_{i+1, j-1 / 2}+v_{i, j-1 / 2}}{2}$. Mas para os termos convectados a aproximação se dá pelo esquema SDPUS-C1, que leva em consideração as posições $D, R, U$ e o sinal das velocidades nos pontos $f, g$. Ou seja: 

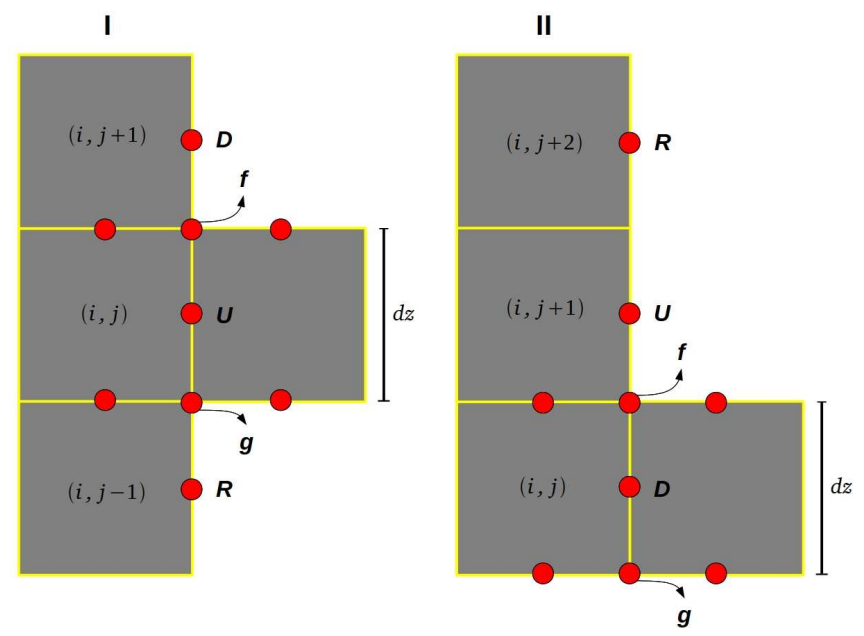

Figura 6.2: Esquema SDPUS-C1 no ponto $A=(i+1 / 2, j)$ para $v_{i+1 / 2, j+1 / 2}$.

1. Quando $v_{i+1 / 2, j+1 / 2} \geq 0$ são assumidas as posições $D=(i+1 / 2, j+1), R=(i+1 / 2, j-1)$, $U=(i+1 / 2, j)$ (ver figura 6.2-I) e então:

$$
u_{i+1 / 2, j+1 / 2}= \begin{cases}u_{i+1 / 2, j-1}+\left(u_{i+1 / 2, j+1}-u_{i+1 / 2, j-1}\right) S_{\hat{u}_{i+1 / 2, j}} & , \quad \hat{u}_{i+1 / 2, j} \in[0,1] \\ u_{i+1 / 2, j} & , \quad \hat{u}_{i+1 / 2, j} \notin[0,1]\end{cases}
$$

onde

$$
\begin{aligned}
S_{\hat{u}_{i+1 / 2, j}=} & 24 \hat{u}_{i+1 / 2, j}^{6}-76 \hat{u}_{i+1 / 2, j}^{5}+92 \hat{u}_{i+1 / 2, j}^{4} \\
& -52 \hat{u}_{i+1 / 2, j}^{3}+12 \hat{u}_{i+1 / 2, j}^{2}+\hat{u}_{i+1 / 2, j} \\
\mathrm{e} & \\
\hat{u}_{i+1 / 2, j}= & \frac{u_{i+1 / 2, j}-u_{i+1 / 2, j-1}}{u_{i+1 / 2, j+1}-u_{i+1 / 2, j-1}}
\end{aligned}
$$

2. Quando $v_{i+1 / 2, j+1 / 2}<0$ são assumidas as posições $D=(i+1 / 2, j), R=(i+1 / 2, j+2)$, $U=(i+1 / 2, j+1)$ (ver figura 6.2-II) e então:

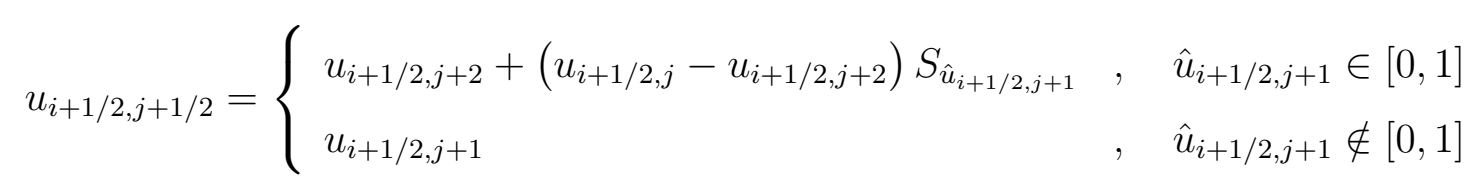

onde

$$
\begin{aligned}
S_{\hat{u}_{i+1 / 2, j+1}=} & 24 \hat{u}_{i+1 / 2, j+1}^{6}-76 \hat{u}_{i+1 / 2, j+1}^{5}+92 \hat{u}_{i+1 / 2, j+1}^{4} \\
& -52 \hat{u}_{i+1 / 2, j+1}^{3}+12 \hat{u}_{i+1 / 2, j+1}^{2}+\hat{u}_{i+1 / 2, j+1} \\
\mathrm{e} & \\
\hat{u}_{i+1 / 2, j+1}= & \frac{u_{i+1 / 2, j+1}-u_{i+1 / 2, j+2}}{u_{i+1 / 2, j}-u_{i+1 / 2, j+2}}
\end{aligned}
$$



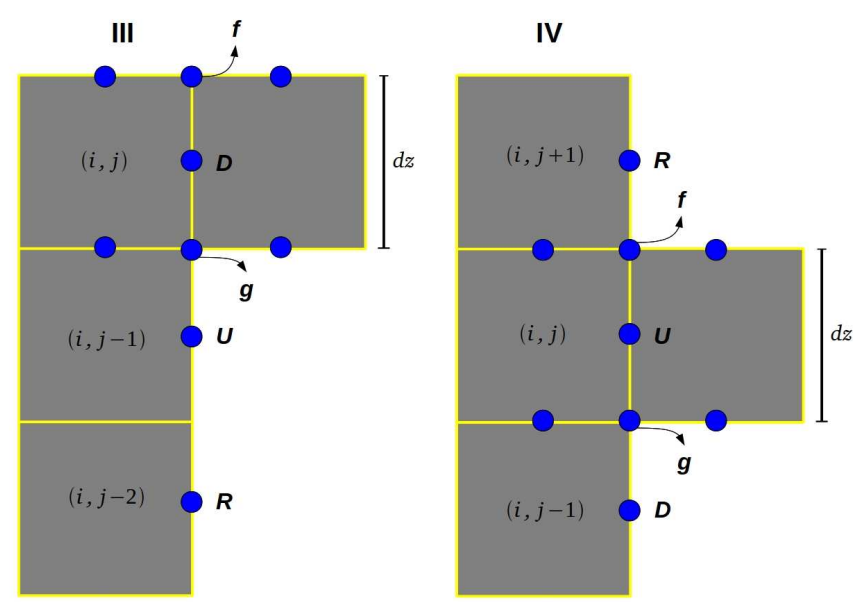

Figura 6.3: Esquema SDPUS-C1 no ponto $A=(i+1 / 2, j)$ para $v_{i+1 / 2, j-1 / 2}$.

3. Quando $v_{i+1 / 2, j-1 / 2} \geq 0$ são assumidas as posições $D=(i+1 / 2, j), R=(i+1 / 2, j-2)$, $U=(i+1 / 2, j-1)$ (ver figura 6.3-III) e então:

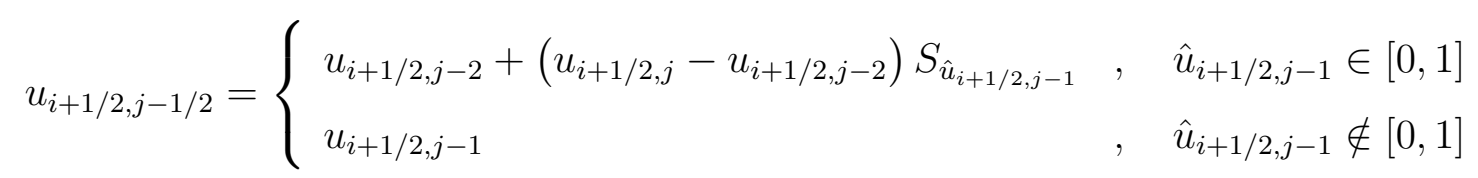

onde

$$
\begin{aligned}
S_{\hat{u}_{i+1 / 2, j-1}}= & 24 \hat{u}_{i+1 / 2, j-1}^{6}-76 \hat{u}_{i+1 / 2, j-1}^{5}+92 \hat{u}_{i+1 / 2, j-1}^{4} \\
& -52 \hat{u}_{i+1 / 2, j-1}^{3}+12 \hat{u}_{i+1 / 2, j-1}^{2}+\hat{u}_{i+1 / 2, j-1}
\end{aligned}
$$

e

$$
\hat{u}_{i+1 / 2, j-1}=\frac{u_{i+1 / 2, j-1}-u_{i+1 / 2, j-2}}{u_{i+1 / 2, j}-u_{i+1 / 2, j-2}}
$$

4. Quando $v_{i+1 / 2, j-1 / 2}<0$ são assumidas as posições $D=(i+1 / 2, j-1), R=(i+1 / 2, j+1)$, $U=(i+1 / 2, j)$ (ver figura 6.3-IV) e então:

$$
u_{i+1 / 2, j-1 / 2}= \begin{cases}u_{i+1 / 2, j+1}+\left(u_{i+1 / 2, j-1}-u_{i+1 / 2, j+1}\right) S_{\hat{u}_{i+1 / 2, j}} & , \quad \hat{u}_{i+1 / 2, j} \in[0,1] \\ u_{i+1 / 2, j} & , \quad \hat{u}_{i+1 / 2, j} \notin[0,1]\end{cases}
$$

onde

$$
\begin{aligned}
S_{\hat{u}_{i+1 / 2, j}=}= & 24 \hat{u}_{i+1 / 2, j}^{6}-76 \hat{u}_{i+1 / 2, j}^{5}+92 \hat{u}_{i+1 / 2, j}^{4} \\
& -52 \hat{u}_{i+1 / 2, j}^{3}+12 \hat{u}_{i+1 / 2, j}^{2}+\hat{u}_{i+1 / 2, j}
\end{aligned}
$$

$\mathrm{e}$

$$
\hat{u}_{i+1 / 2, j}=\frac{u_{i+1 / 2, j}-u_{i+1 / 2, j+1}}{u_{i+1 / 2, j-1}-u_{i+1 / 2, j+1}}
$$


De modo análogo ao que fizemos anteriormente, $\phi=c$ é transportada na direção $r$ segundo os esquemas das figuras 6.4 e 6.5 .

Se $A=(i, j), f=(i+1 / 2, j)$ e $g=(i-1 / 2, j)$, a aproximação da derivada (no ponto $A$ ) na direção $r$, presente no termo convectivo, fica:

$$
\left.\frac{1}{r} \frac{\partial(r u c)}{\partial r}\right|_{A}=\frac{1}{r_{i, j} d z}\left[r_{i+1 / 2, j} u_{i+1 / 2, j} c_{i+1 / 2, j}-r_{i-1 / 2, j} u_{i-1 / 2, j} c_{i-1 / 2, j}\right]
$$

com $u_{i+1 / 2, j}$ e $u_{i-1 / 2, j}$ conhecidos. Para os termos convectados a aproximação é realizada pelo esquema SDPUS-C1 como segue:

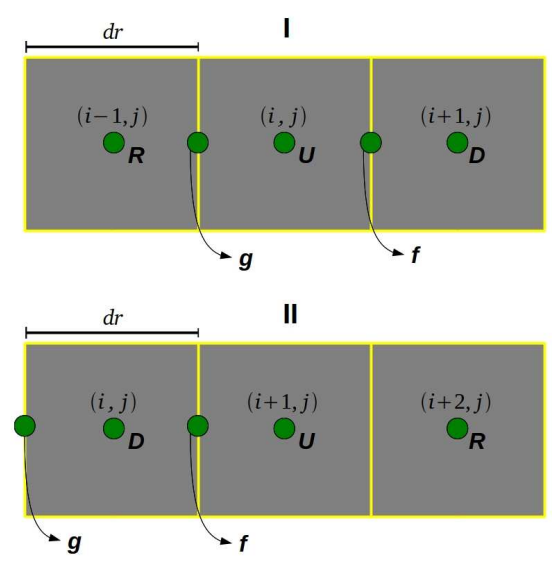

Figura 6.4: Esquema SDPUS-C1 no ponto $A=(i, j)$ para $u_{i+1 / 2, j}$.

1. Quando $u_{i+1 / 2, j} \geq 0$ são assumidas as posições $D=(i+1, j), R=(i-1, j), U=(i, j)$ (ver figura 6.4-I) e então:

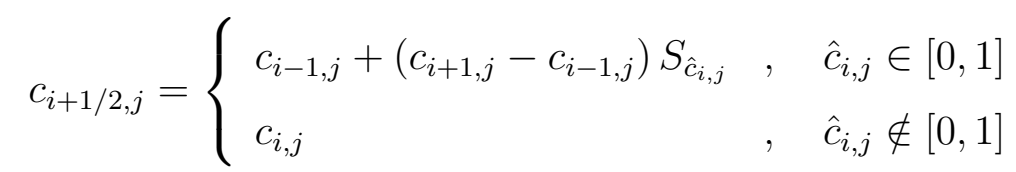

onde

$$
\begin{aligned}
S_{\hat{c}_{i, j}}= & 24 \hat{c}_{i, j}^{6}-76 \hat{c}_{i, j}^{5}+92 \hat{c}_{i, j}^{4} \\
& -52 \hat{c}_{i, j}^{3}+12 \hat{c}_{i, j}^{2}+\hat{c}_{i, j}
\end{aligned}
$$

e

$$
\hat{c}_{i, j}=\frac{c_{i, j}-c_{i-1, j}}{u_{i+1, j}-u_{i-1, j}}
$$

2. Quando $u_{i+1 / 2, j}<0$ são assumidas as posições $D=(i, j), R=(i+2, j), U=(i+1, j)$ (ver figura 6.4-II) e então:

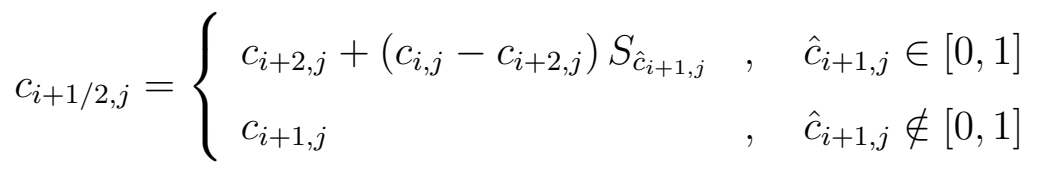


onde

$$
\begin{aligned}
S_{\hat{c}_{i+1, j}}= & 24 \hat{c}_{i+1, j}^{6}-76 \hat{c}_{i+1, j}^{5}+92 \hat{c}_{i+1, j}^{4} \\
& -52 \hat{c}_{i+1, j}^{3}+12 \hat{c}_{i+1, j}^{2}+\hat{c}_{i+1, j}
\end{aligned}
$$

e

$$
\hat{c}_{i+1, j}=\frac{c_{i+1, j}-c_{i+2, j}}{c_{i, j}-c_{i+2, j}}
$$
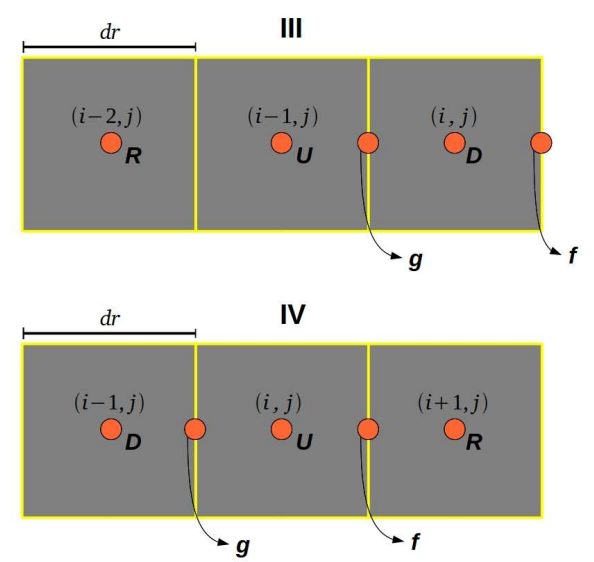

Figura 6.5: Esquema SDPUS-C1 no ponto $A=(i, j)$ para $u_{i-1 / 2, j}$.

3. Quando $u_{i-1 / 2, j} \geq 0$ são assumidas as posições $D=(i, j), R=(i-2, j), U=(i-1, j)$ (ver figura 6.5-III) e então:

$$
c_{i-1 / 2, j}= \begin{cases}c_{i-2, j}+\left(c_{i, j}-c_{i-2, j}\right) S_{\hat{c}_{i-1, j}} & , \\ c_{i-1, j} & \hat{c}_{i-1, j} \in[0,1] \\ c_{i-1, j} \notin[0,1]\end{cases}
$$

onde

$$
\begin{aligned}
S_{\hat{c}_{i-1, j}}= & 24 \hat{c}_{i-1, j}^{6}-76 \hat{c}_{i-1, j}^{5}+92 \hat{c}_{i-1, j}^{4} \\
& -52 \hat{c}_{i-1, j}^{3}+12 \hat{c}_{i-1, j}^{2}+\hat{c}_{i-1, j} \\
\mathrm{e} & \\
\hat{c}_{i-1, j}= & \frac{c_{i-1, j}-c_{i-2, j}}{c_{i, j}-c_{i-2, j}}
\end{aligned}
$$

4. Quando $u_{i-1 / 2, j}<0$ são assumidas as posições $D=(i-1, j), R=(i+1, j), U=(i, j)$ (ver figura 6.5-IV) e então:

$$
c_{i-1 / 2, j}=\left\{\begin{array}{lll}
c_{i+1, j}+\left(c_{i-1, j}-c_{i+1, j}\right) S_{\hat{c}_{i, j}} & , & \hat{c}_{i, j} \in[0,1] \\
c_{i, j} & , & \hat{c}_{i, j} \notin[0,1]
\end{array}\right.
$$


onde

$$
\begin{aligned}
S_{\hat{c}_{i, j}}= & 24 \hat{c}_{i, j}^{6}-76 \hat{c}_{i, j}^{5}+92 \hat{c}_{i, j}^{4} \\
& -52 \hat{c}_{i, j}^{3}+12 \hat{c}_{i, j}^{2}+\hat{c}_{i, j} \\
\mathrm{e} & \\
\hat{c}_{i, j}= & \frac{c_{i, j}-c_{i+1, j}}{c_{i-1, j}-c_{i+1, j}}
\end{aligned}
$$

A descrição detalhada do esquema SDPUS-C1 pode ser encontrada em [70]. Como o esquema é construído sobre três pontos $(D, R$ e $U)$, no cálculo próximo as fronteiras usamos o esquema FOU (First Order Upwind) [39] de primeira ordem. Portanto, com os comentários e desenvolvimentos sobre as aproximações por diferenças temos as seguintes equações discretizadas.

Utilizando as aproximações: avançada, SDPUS-C1 e centrada, para as respectivas derivadas presentes na equação (5.26), obtemos:

$$
\begin{aligned}
c_{i, j}^{N+1}= & c_{i, j}^{N}-d t C O N V(c)+ \\
& \frac{d t}{P e}\left[\frac{r_{i+1, j} c_{i+1, j}-2 r_{i, j} c_{i, j}+r_{i-1, j} c_{i-1, j}}{r_{i, j} d r^{2}}+\frac{c_{i, j+1}-2 c_{i, j}+c_{i, j-1}}{d z^{2}}\right]
\end{aligned}
$$

aplicando diferenças centrais nas derivadas da equação (5.25) e tomando média no termo $\left(\frac{u}{r}\right)^{2}$, a equação discreta de $\dot{\gamma}$ no centro da célula fica:

$$
\begin{aligned}
\dot{\gamma}_{i, j} & =\left[2\left(\frac{u_{i+1 / 2, j}-u_{i-1 / 2, j}}{d r}\right)^{2}+2\left(\frac{v_{i, j+1 / 2}-v_{i, j-1 / 2}}{d z}\right)^{2}+2\left(\frac{u_{i+1 / 2, j}+u_{i-1 / 2, j}}{2 r_{i}}\right)^{2}\right. \\
& +\left(\frac{u_{i+1 / 2, j+1}+u_{i-1 / 2, j+1}-u_{i+1 / 2, j-1}+u_{i-1 / 2, j-1}}{4 d z}\right. \\
& \left.\left.+\frac{v_{i+1, j+1 / 2}+v_{i+1, j-1 / 2}-v_{i-1, j+1 / 2}+u_{i-1, j-1 / 2}}{4 d r}\right)^{2}\right]^{\frac{1}{2}}
\end{aligned}
$$

que substituidas na equação (5.24) (linha 4 do algoritmo 1) nos fornece a equação discreta para a viscosidade

$$
\nu_{i, j}=\frac{\tau_{0}\left(c_{i, j}^{N+1}\right)}{\rho_{m} \dot{\gamma}_{i, j}}+K^{\prime}\left(c_{i, j}^{N+1}\right)\left[\dot{\gamma}_{i, j}\right]^{n\left(c_{i, j}^{N+1}\right)-1}
$$

Nas equações de Navier-Stokes adimensionais empregamos diferenças avançadas no termo temporal, esquema SDPUS-C1 no termo convectivo e diferenças centrais nas derivadas de primeira e segunda ordens, então as equações discretas para o campo de velocidades intermediário (linhas 8 e 10 do algoritmo 1$)$, nas faces $\left(i+\frac{1}{2}, j\right) \mathrm{e}\left(i, j+\frac{1}{2}\right)$, ficam na forma: 


$$
\begin{aligned}
& \widetilde{u}_{i+1 / 2, j}^{N+1}=\widetilde{u}_{i+1 / 2, j}^{N}-d t\left[C O N V(u)+\frac{\left.\widetilde{p}_{i+1, j}-\widetilde{p}_{i, j}\right]}{d r}\right] d t \frac{\left(\nu_{i+1, j}+\nu_{i, j}\right) / 2}{R e} \\
& {\left[\frac{r_{i+1} u_{i+3 / 2, j}-2 r_{i+1 / 2} u_{i+1 / 2, j}+r_{i} u_{i-1 / 2, j}}{r_{i+1 / 2} d r^{2}}+\frac{u_{i+1 / 2, j+1}-2 u_{i+1 / 2, j}+u_{i+1 / 2, j-1}}{d z^{2}}-\frac{u_{i+1 / 2, j}}{r_{i+1 / 2}^{2}}\right]} \\
& +\frac{d t}{R e}\left[2 \frac{u_{i+3 / 2, j}-u_{i-1 / 2, j}}{2 d r} \frac{\nu_{i+1, j}-\nu_{i, j}}{d r}+\left(\frac{v_{i+1, j+1 / 2}+v_{i+1, j-1 / 2}-v_{i, j+1 / 2}-v_{i, j-1 / 2}}{2 d r}+\right.\right. \\
& \left.\left.\frac{u_{i+1 / 2, j+1}-u_{i+1 / 2, j-1}}{2 d z}\right) \frac{\left(\nu_{i, j+1}+\nu_{i+1, j+1}-\nu_{i, j-1}-\nu_{i+1, j-1}\right)}{4 d z}\right]+\frac{d t}{F r} g_{r} \\
& \widetilde{v}_{i, j+1 / 2}^{N+1}=\widetilde{v}_{i, j+1 / 2}^{N}-d t\left[C O N V(v)+\frac{\left.\widetilde{p}_{i, j+1}-\widetilde{p}_{i, j}\right]+d t \frac{\left(\nu_{i, j+1}+\nu_{i, j}\right) / 2}{d z}}{R e}\right] \\
& {\left[\frac{\left.r_{i+1 / 2} v_{i+1, j+1 / 2}-2 r_{i} v_{i, j+1 / 2}+r_{i-1 / 2} v_{i-1, j+1 / 2}+\frac{v_{i, j+3 / 2}-2 v_{i, j+1 / 2}+v_{i, j-1 / 2}}{d z^{2}}\right]}{r_{i} d r^{2}}\right]+\frac{d t}{F r} g_{r}} \\
& +\frac{d t}{R e}\left[2 \frac{v_{i, j+3 / 2}-v_{i, j-1 / 2}}{2 d z} \frac{\nu_{i, j+1}-\nu_{i, j}}{d z}+\left(\frac{v_{i+1, j+1 / 2}-v_{i-1, j+1 / 2}}{2 d r}+\right.\right. \\
& \left.\left.\frac{u_{i+1 / 2, j+1}+u_{i-1 / 2, j+1}-u_{i+1 / 2, j}-u_{i-1 / 2, j}}{2 d z}\right) \frac{\left(\nu_{i+1, j+1}+\nu_{i+1, j}-\nu_{i-1, j+1}-\nu_{i-1, j}\right)}{4 d r}\right]
\end{aligned}
$$

Agora na equação de Poisson (linha 12 do algoritmo 1) aplicando diferenças centrais nas derivadas, no centro da célula $(i, j)$, resulta que:

$$
A_{E} \psi_{i+1, j}+A_{O} \psi_{i-1, j}+A_{P} \psi_{i, j}+A_{N} \psi_{i, j+1}+A_{S} \psi_{i, j-1}=S
$$

onde

$$
\begin{array}{ll}
A_{E}=-r_{i+1 / 2} & A_{O}=-r_{i-1 / 2} \\
A_{P}=4 r_{i} & A_{N}=-r_{i} \\
A_{S}=-r_{i} & S=-h\left(r_{i+1 / 2} \widetilde{u}_{i+1 / 2, j}-r_{i-1 / 2} \widetilde{u}_{i-1 / 2, j}\right)-h r_{i}\left(\widetilde{v}_{i, j+1 / 2}-\widetilde{v}_{i, j-1 / 2}\right)
\end{array}
$$

A fronteira da bolha é aproximada por um aglomerado de células, anteriormente denominadas por (b), que estão em contato com células (F) em 8 configurações distintas. Uma vez que a força $F V_{z}$ é dada pela integral sobre $C$ (linha 20 do algoritmo 1), então a mesma é aproximada como

$$
F V_{z} \simeq \sum_{L=1}^{n b} F_{L}
$$

com $F_{L}=2 \pi r\left[\frac{\nu}{R e}\left(\frac{\partial v}{\partial r}+\frac{\partial u}{\partial z}\right) n_{1}+\left(\frac{2 \nu}{R e} \frac{\partial v}{\partial z}\right) n_{3}\right] d l$ sendo a força local e $n b$ o número total de células do tipo (b).

O primeiro tipo de configuração é mostrado na figura 6.6. A célula em tom cinza mais escuro representa a célula (b) que contém o contorno da bolha, enquanto que a célula em tom cinza claro é 
uma célula de fluido. A seta indica a direção e sentido da força que o fluido exerce sobre a célula (b). Neste caso a normal é $n=\left(n_{1}, n_{2}, n_{3}\right)=(-1,0,0)$ e então a força local fica simplificada e dada por:

$$
F_{L}=-2 \pi r \frac{\nu}{R e}\left(\frac{\partial v}{\partial r}+\frac{\partial u}{\partial z}\right) d z
$$

e as derivadas são aproximadas por diferenças centrais.

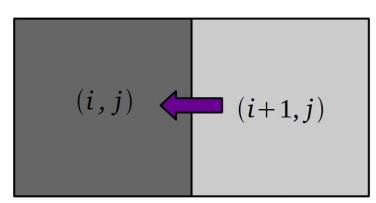

Figura 6.6: Caso 1 para célula (b).

De modo análogo mostramos a seguir os outros casos e seus respectivos valores simplificados $\operatorname{para} F_{L}$ :

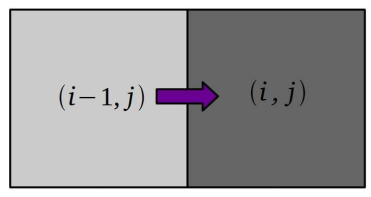

$$
F_{L}=2 \pi r \frac{\nu}{R e}\left(\frac{\partial v}{\partial r}+\frac{\partial u}{\partial z}\right) d z
$$

Figura 6.7: Caso 2 para célula (b).

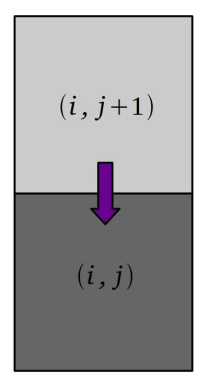

$$
F_{L}=-2 \pi r\left(\frac{2 \nu}{R e} \frac{\partial v}{\partial z}\right) d r
$$

Figura 6.8: Caso 3 para célula (b).

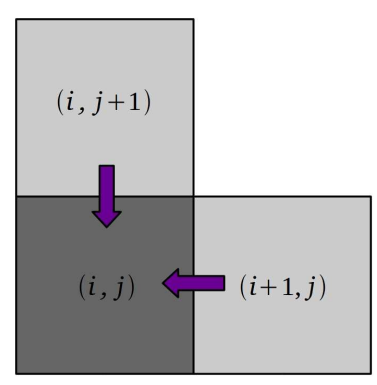

$$
F_{L}=2 \pi r\left[-\frac{\nu}{R e}\left(\frac{\partial v}{\partial r}+\frac{\partial u}{\partial z}\right) d z-\left(\frac{2 \nu}{R e} \frac{\partial v}{\partial z}\right) d r\right]
$$

Figura 6.9: Caso 4 para célula (b). 


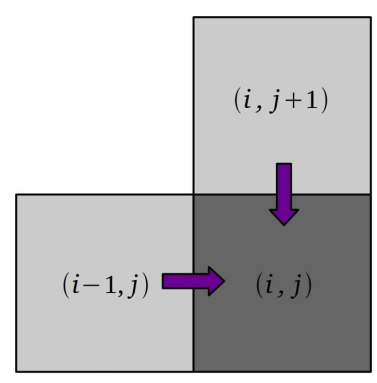

$$
F_{L}=2 \pi r\left[\frac{\nu}{R e}\left(\frac{\partial v}{\partial r}+\frac{\partial u}{\partial z}\right) d z-\left(\frac{2 \nu}{R e} \frac{\partial v}{\partial z}\right) d r\right]
$$

Figura 6.10: Caso 5 para célula (b).

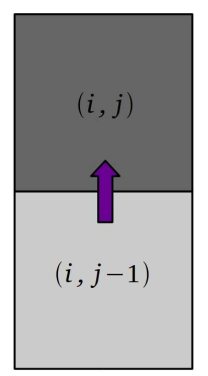

$$
F_{L}=2 \pi r\left(\frac{2 \nu}{R e} \frac{\partial v}{\partial z}\right) d r
$$

Figura 6.11: Caso 6 para célula (b).

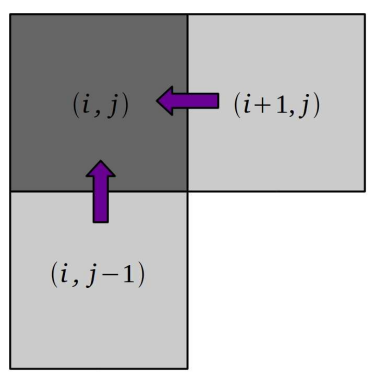

$$
F_{L}=2 \pi r\left[-\frac{\nu}{R e}\left(\frac{\partial v}{\partial r}+\frac{\partial u}{\partial z}\right) d z+\left(\frac{2 \nu}{R e} \frac{\partial v}{\partial z}\right) d r\right]
$$

Figura 6.12: Caso 7 para célula (b).

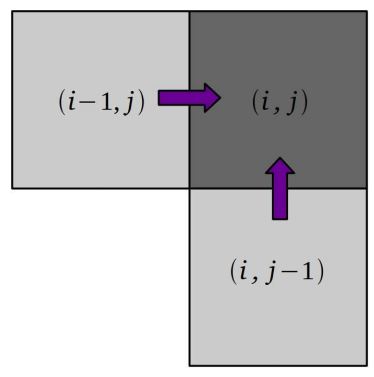

$$
F_{L}=2 \pi r\left[-\frac{\nu}{R e}\left(\frac{\partial v}{\partial r}+\frac{\partial u}{\partial z}\right) d z+\left(\frac{2 \nu}{R e} \frac{\partial v}{\partial z}\right) d r\right]
$$

Figura 6.13: Caso 8 para célula (b).

Com a força $F V_{z}$ discreta calculada, equação (6.5), finalmente encontramos a velocidade e posição do centro de massa da bolha (linha 22 do algoritmo 1). Ou seja, 


$$
\begin{aligned}
v_{c m}^{N+1} & =v_{c m}^{N}+\frac{d t}{\rho_{d} v o l}\left[\frac{1}{F r} g_{z} \operatorname{vol}\left(\rho_{c}-\rho_{d}\right)+\sum_{L=1}^{n b} F_{L}\right] \\
z_{c m}^{N+1} & =z_{c m}^{N}+d t v_{c m}^{N}
\end{aligned}
$$

Fechando esta seção, lembrando que as equações da mecânica dos fluidos e de movimentação da bolha são aproximadas pelo esquema Euler explícito, então as mesmas ficam submetidas à restrições no passo de tempo. A metodologia é estável quando o passo de tempo $d t$ leva em consideração as seguintes restrições:

$$
d t_{1}<\frac{d r}{U_{\max }} \quad \text { e } \quad d t_{2}<\frac{d z}{V_{\max }} \quad \text { e } \quad d t_{3}<\frac{R e}{2 \nu_{\max }}\left\{\frac{d r^{2} d z^{2}}{d r^{2}+d z^{2}}\right\}
$$

onde $U_{\max }$ e $V_{\max }$ são os máximos valores de velocidades (na comparação entre fluido e centro de massa da bolha) e $\nu_{\max }$ é o maior valor da viscosidade do fluido. Portanto o $d t$ otimizado fica expresso por $d t=\min \left\{d t_{1}, d t_{2}, d t_{3}\right\}$ [46] [25].

O código FREEFLOW-AXI:N/Non é composto de três módulos (Modelador - Simulador - Visualizador) no qual cada um têm especificidades distintas. O código é uma atualização do FREEFLOWAXI, passamos agora a tratar destas questões.

\subsection{Atualizações Realizadas no FREEFLOW-AXI}

Afirmamos na seção anterior que o código FREEFLOW-AXI:N/Non é uma extensão do FREEFLOW-AXI, estruturalmente o novo código continua sendo composto pelas plataformas Modelador - Simulador - Visualizador.

Nós adicionamos ao FREEFLOW-AXI [85] o seguinte:

\section{- Modelador}

1. botões de entrada de dados referente a massa específica nas fases contínua $\left(\rho_{c}\right)$ e dispersa $\left(\rho_{d}\right)$

2. botão do valor da escala de concentração de material particulado;

3. botão de definição do número de Schmidt, que define o coeficiente de dispersão para o número de Peclet;

4. botão de escolha de metodologia (newtoniano/não-newtoniano);

5. botão de inserção de dados de objeto geométrico que admite movimento; 
6. botão de dados de concentração de material particulado para a construção do campo de concentração;

7. rotina de parâmetros do modelo Herschel-Bulkley;

No Modelador inserimos os parâmetros referêntes ao domínio, velocidades, massa específica, concentração e setamos as células dos tipos: F, V, B, S e b. Ainda no Modelador, todas as variáveis são adimensionalizadas e os números adimensionais são calculados também.

\section{- Simulador}

1. rotina que otimiza o passo temporal $d t$

2. rotina que calcula a força viscosa $\left(\overline{F V} \bar{z}_{\bar{z}}\right)$ para todas as células $\mathbf{b}$;

3. rotina que simula o movimento, aqui nós calculamos as velocidades $\left(u_{c m}, v_{c m}\right)$ e posição $\left(r_{c m}, z_{c m}\right)$ do centro de massa e a forma da bolha;

4. rotina que calcula a condição de contorno para a bolha em termos da representação integral ponderada por uma função núcleo;

5. rotinas para o cálculo da equação de convecção-advecção da concentração e de $\dot{\gamma}$;

6. rotina que calcula a viscosidade variável;

7. rotina que calcula as velocidades, via equações de Navier-Stokes, para fluidos não-newtonianos escritas pelo modelo newtoniano generalizado;

No Simulador são lidos os dados salvos no modelador e as equações governantes do modelo são resolvidas numericamente por ciclos, como exibido no algoritmo 1. O Simulador foi totalmente adaptado para contemplar a questão do movimento de "slices" em fluido newtoniano generalizado. Os resultados quanto a valores de velocidade, pressão, concentração, viscosidade e velocidade/localização da bolha são salvos para os tempos de interesse.

\section{- Visualizador}

1. rotina para visualização do campo de viscosidade do fluido;

2. rotina para visualização do campo de concentração de material particulado;

3. rotina para visualização do campo da taxa de cisalhamento (Shear-Rate);

4. adequação das funções para que permitam a visualização do movimento de objetos geométricos; 
Os dados salvos no Simulador são lidos no Visualisador, este por sua vez, permite-nos a visualização gráfica dos resultados obtidos na simulação para tempos pré-fixados. Ou seja, fazemos a visualização do domínio do modelo estudado e das variáveis de campo: velocidade, pressão e viscosidade do fluido. E ainda a visualização da concentração de material particulado, da taxa de cisalhamento, localização e forma de objeto geométrico imerso ao fluido.

Finalizamos então todo o equacionamento Matemático, Numérico e Computacional que desenvolvemos para resolver o nosso problema. Agora apresentamos no capítulo a frente os resultados numéricos da nossa metodologia. 


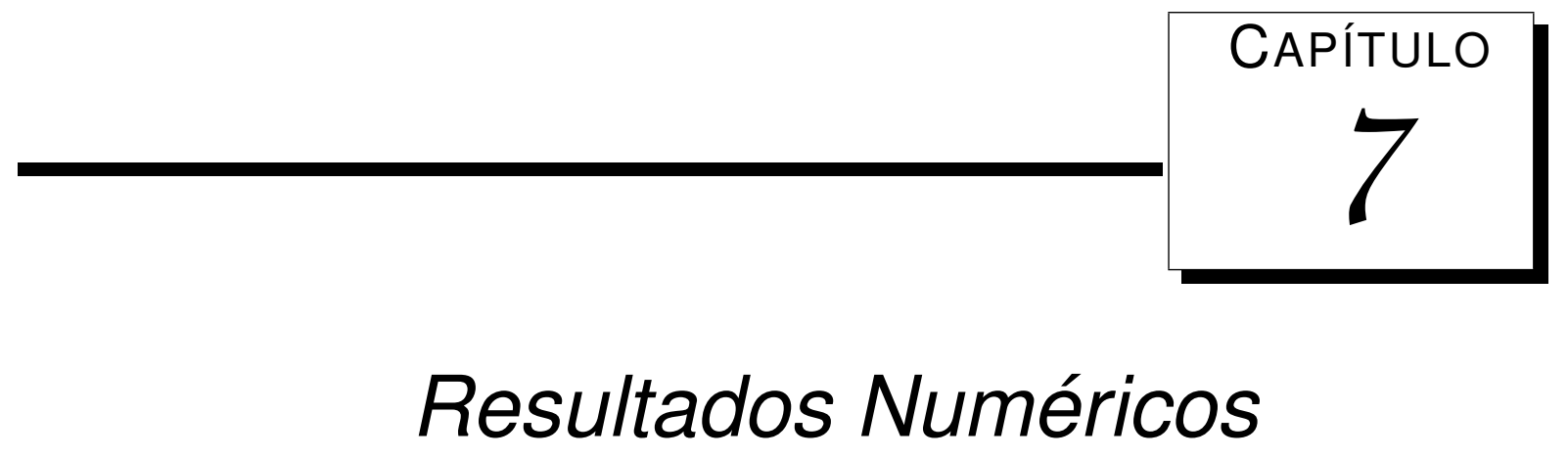

A Física nos ensina que é comum em problemas elementares considerar a força de resistência ao movimento. A força de atrito entre duas superfícies é o caso mais comum. O experimento mostra que neste tipo de interação a força de atrito depende principalmente da força normal que pressiona uma superfície contra a outra e da rugosidade das superfícies. E tem um determinado valor se um corpo está parado em relação ao outro e outro valor, geralmente menor, se existe movimento relativo entre os corpos. Em algumas situações onde a força de resistência é muito grande, o corpo é levado rapidamente ao movimento de velocidade constante [83]. É o caso, por exemplo, de uma bolha ascendendo num fluido.

Se admitirmos (idealmente) inicialmente uma bolha em repouso, imersa em um fluido, também parado, temos que as forças de empuxo, peso e resistência ao movimento não estão em equilíbrio. Nesta situação a bolha inicia seu movimento com aceleração positiva. Com o passar do tempo o movimento passa de acelerado para uniforme, porquê as forças tendem ao equilíbrio fazendo a aceleração ir para zero. Quando a bolha se encontra em movimento uniforme dizemos que a mesma assume a velocidade terminal. Sob a velocidade terminal podemos calcular o Número de Reynolds da bolha $\left(R e_{B}\right)$, por exemplo.

Clift et al. [30] descreve a forma geométrica que bolhas de ar assumem quando se movimentam na água e esboça um mapa fundamentado nos números adimensionais de Reynolds e Bond (ver seção 3.10 página 30) figura 7.1. No mapa as formas podem ser: esférica (spherical), elíptica (elipsoidal), calota esférica calombada (dimpled spherical cap), contornada (skirted), oscilada (wobbling) e calota 
esférica (spherical cap).

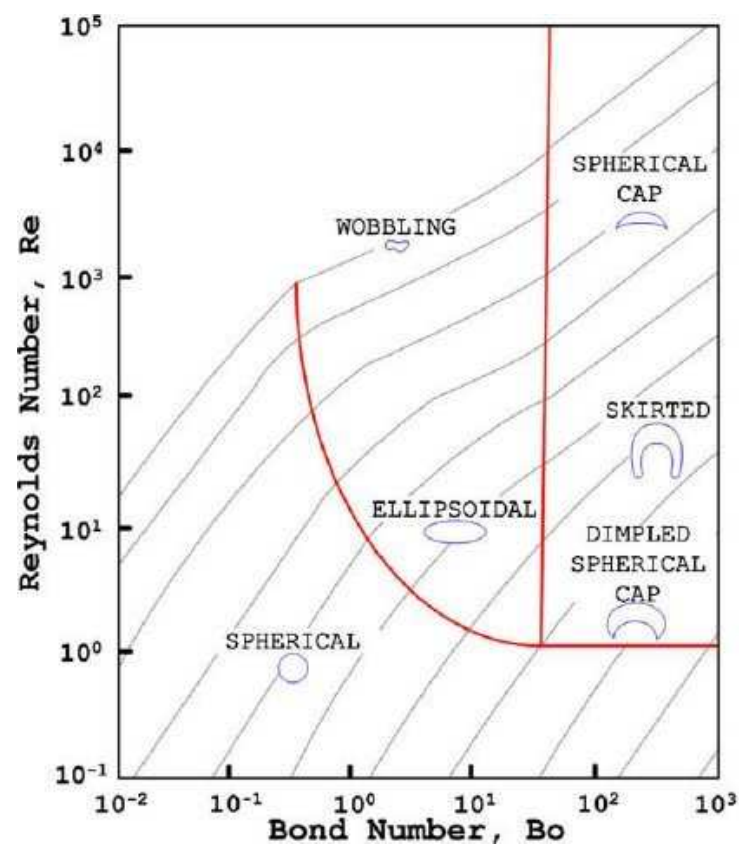

Figura 7.1: Forma de bolhas de ar ascendendo em água [30].

Por outro lado, Herrera-Velarde et al. [50] assim como Brenn, G. e Pilz, C. [16], analisando o escoamento para valores próximos do volume crítico onde ocorre a quebra de continuidade da velocidade terminal, tratam em seus trabalhos de bolhas que se movem em líquidos não-newtonianos e que podem assumir a forma de uma lágrima invertida (teardrop).

Não obstante, Annaland, M. V. S. et al. [8] estudaram a ascensão de bolhas num meio fluido com a presença de partículas sólidas distribuídas, a intensão deles era tratar a simulação no sisterma gás-líquido-sólido. Neste trabalho a bolha assumia a forma elíptica calombada (dimpled elipsoidal).

Acreditamos que formas similares a estas, anteriormente descritas, também podem ocorrer para bolhas no fluido sedimentar. Quando fizemos a coleta dos cores na lagoa do Óleo percebemos a presença de bolhas nos cores, isto pode ser observado na figura 7.2.
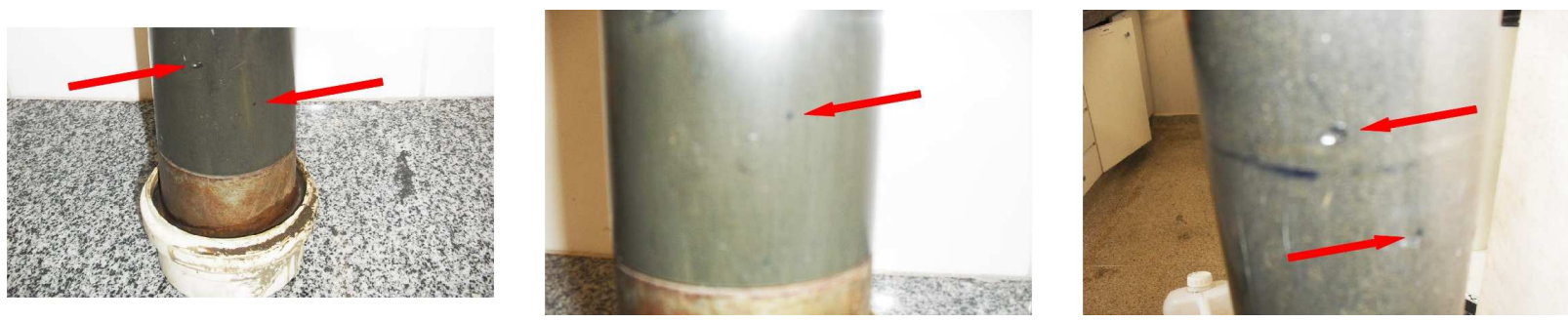

Figura 7.2: Presença de bolhas no core.

Procuramos fazer um estudo numérico sobre algumas das bolhas descritas anteriormente neste 
capítulo e inferir a ascensão no fluido sedimentar. Dividimos o nosso estudo em vários conjuntos de simulações, no qual discutimos as questões de interesse numérico e de validação do nosso código computacional. Estas simulações nos forneceram a base científica para finalmente detalharmos a ascensão da bolha no fluido sedimentar.

Em todas as simulações que realizamos admitimos inicialmente que a bolha assume o formato esférico, com $r_{0}$ sendo o raio inicial na posição $s_{0}$. O parâmetro $s_{0}$ é a localização inicial do centro de massa da bolha sobre o eixo de simetria. O diâmetro $L$ é tomado como o parâmetro de escala de comprimento e $U=\sqrt{g_{0} L}$ é a velocidade característica do sistema. Além disto, adotamos também a nomenclatura $M_{k}: n i \times n j$ para a distribuição de pontos que discretiza o domínio do problema e isto significa: k-ésima malha " $M_{k}$ " de $n i$ pontos na direção radial e $n j$ pontos na direção vertical. Uma outra nomenclatura que também utilizamos é com respeito ao domínio de interesse, dada por: $R \times{ }^{l} h$ significando o l-ésimo domínio de dimensões $R$ na direção radial e $h$ na vertical.

Utilizamos o símbolo “.” para indicar a dimensão do parâmetro e o sistema internacional de unidades SI como a referência. Em todos os conjuntos de simulações realizados temos que:

$$
L, R, h, s_{0}, r_{0} \doteq m \quad, \quad U \doteq \frac{m}{s} \quad, \quad \nu_{0} \doteq \frac{m^{2}}{s} \quad, \quad \rho_{c}, \rho_{d} \doteq \frac{k g}{m^{3}}
$$

As simulações foram divididas em duas categorias (fluidos newtonianos/não-newtonianos) para bolhas esféricas e não esféricas, como segue.

\subsection{Validação}

Admitindo o fluido newtoniano e que a bolha preserve a forma esférica, para o primeiro conjunto de simulações os dados de entrada do código estão organizamos conforme exibido na tabela 7.1.

\begin{tabular}{|c|c|c|c|c|c|c|c|}
\hline \multirow{2}{*}{$\begin{array}{c}\text { Modelos } \\
\text { simulados }\end{array}$} & \multicolumn{7}{|c|}{ Dados de entrada } \\
\cline { 2 - 8 } & $L$ & $U$ & $\nu_{0}$ & $\rho_{c}$ & $\rho_{d}$ & $s_{0}$ & $r_{0}$ \\
\hline \hline S-1 & 0.001 & 0.099045 & 0.0000013 & 997.0 & 99.7 & 0.003 & 0.0005 \\
\hline \hline S-2 & 0.001 & 0.099045 & 0.0000013 & 997.0 & 9.97 & 0.003 & 0.0005 \\
\hline \hline S-3 & 0.001 & 0.099045 & 0.0000013 & 997.0 & 1.184 & 0.003 & 0.0005 \\
\hline \hline S-4 & 0.001 & 0.099045 & 0.0000013 & 997.0 & 0.717 & 0.003 & 0.0005 \\
\hline \hline S-5 & 0.0015 & 0.1213054 & 0.0000013 & 997.0 & 1.184 & 0.0045 & 0.00075 \\
\hline
\end{tabular}

Tabela 7.1: Tabela de parâmetros de entrada do primeiro conjunto de simulações. 
Com o objetivo de verificar a independência de malha nas soluções numéricas utilizamos os dados S-1 e simulamos a ascensão da bolha em várias malhas. No domínio $R \times h=0.009 \times 0.030$, resolvemos numericamente as equações governantes nas malhas $M_{1}: 45 \times 150, M_{2}: 60 \times 200$, $M_{3}: 90 \times 300, M_{4}: 105 \times 350$ e impomos o valor $1.0 \times 10^{-06}$ para o erro na solução numérica da equação de Poisson. Das simulações encontramos os resultados resumidos na figura 7.3.

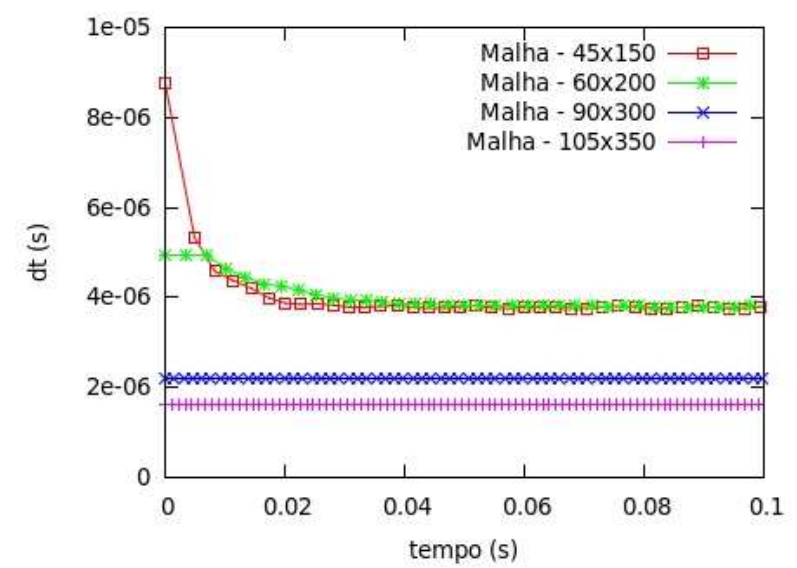

\begin{tabular}{|c|c|c|c|}
\hline S-1 & $d r=d z$ & $D M C F$ & $D M C S$ \\
\hline \hline$M_{1}$ & 0.00020 & $O\left(10^{-07}\right)$ & $O\left(10^{-19}\right)$ \\
\hline \hline$M_{2}$ & 0.00015 & $O\left(10^{-07}\right)$ & $O\left(10^{-21}\right)$ \\
\hline \hline$M_{3}$ & 0.00010 & $O\left(10^{-07}\right)$ & $O\left(10^{-19}\right)$ \\
\hline \hline$M_{4}$ & 0.000085714 & $O\left(10^{-07}\right)$ & $O\left(10^{-20}\right)$ \\
\hline
\end{tabular}

Figura 7.3: Resultados quanto a convergência para S-1 nas malhas $M_{1}: 45 \times 150, M_{2}: 60 \times 200$, $M_{3}: 90 \times 300$ e $M_{4}: 105 \times 350$.

A evolução do $d t$ é exibida na figura 7.3 (esquerda). Observe que no uso das malhas $M_{1}$ e $M_{2}$ os valores de $d t$ são significativamente distantes em $t=0$, ao longo do tempo eles sofrem decaimento e estabilizam praticamente no mesmo valor no final da simulação. Porém nas malhas $M_{3}$ e $M_{4} \mathrm{o}$ valor de $d t$ permanece estático em $2.19020 \times 10^{-06}$ e $1.60913 \times 10^{-06}$, respectivamente, em toda a simulação. Estes comportamentos diferentes entre si são decorrentes do refinamento de malha e consequentemente das restrições estabelecidas sobre $d t$, para que haja estabilidade na resolução numérica das equações de Navier-Stokes e de movimentação do centro de massa.

Na tabela da figura 7.3 (direita) mostramos que o divergente médio das células do tipo $\mathbf{F}$ (DMCF) e o divergente médio das células do tipo $\mathbf{S}(D M C S)$ mantiveram-se abaixo da $O\left(10^{-06}\right)$, entendemos que aquelas ordens de grandeza são ótimos indicativos da conservação da massa de fluido. Observamos ainda que para malha mais fina do que estas que exibimos, não obtivemos resultado mais expressivo. $\mathrm{O}$ valor de $d t$ fica abaixo de $10^{-06}$ e o tempo de simulação é relevantemente alto, inviabilizando o uso do nosso modelo matemático/computacional.

O perfil de velocidade do centro de massa pode ser observado na figura 7.4 (esquerda). Veja que o refinamento da malha implica em diferentes valores para a velocidade terminal. Além disto, a curvatura do gráfico da velocidade é menos acentuada quando aumentamos o refinamento, isto é devido a maior acurácia no cálculo da força de resistência ao movimento $F V_{z}$. Com refinamentos sucessivos há um maior número de células do tipo b em nossos cálculos. Se denotarmos $V_{k}^{T}$ como 
a velocidade terminal da bolha na k-ésima malha temos que $V_{k}^{T}$ está em processo de convergência, uma vez que o Erro $=\left|V_{k+1}^{T}-V_{k}^{T}\right| \rightarrow 0$ conforme pode ser observado nos resultados da figura 7.5.
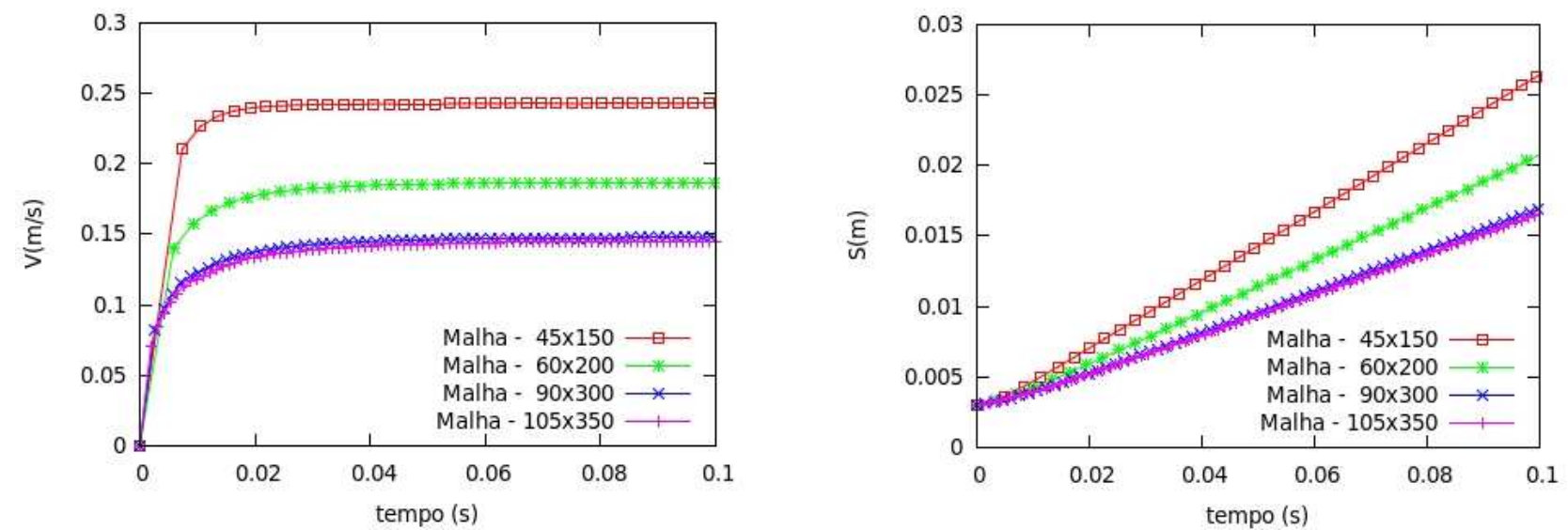

Figura 7.4: Perfis de velocidade e posição do centro de massa da bolha para $\mathrm{S}-1$, nas malhas $M_{1}$ : $45 \times 150, M_{2}: 60 \times 200, M_{3}: 90 \times 300$ e $M_{4}: 105 \times 350$.

Observe também na figura 7.4 (direita) que os gráficos de posição exibem curvatura mais expressiva para tempos de simulação $t<0.04$, e praticamente evolui linearmente no restante do tempo de simulação. Na parte linear do gráfico da posição é justamente quando as forças atuantes no movimento de ascensão entram praticamente em equilíbrio, consequentemente a resultante das forças fica próxima de zero.

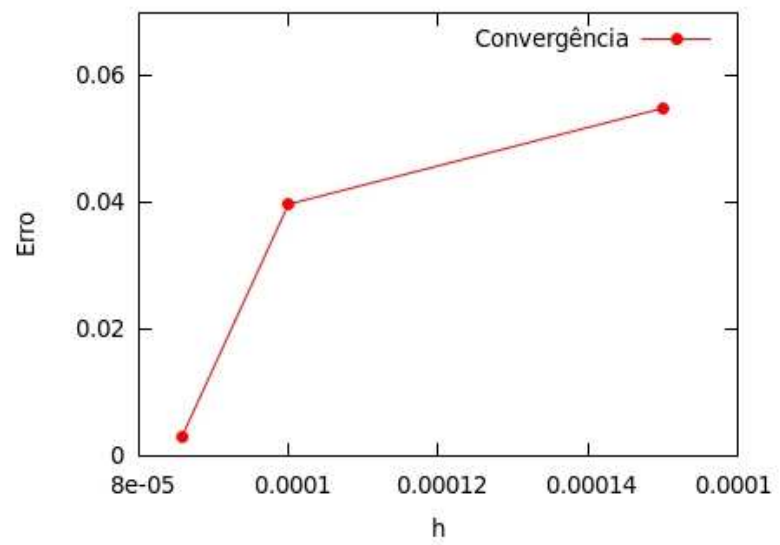

\begin{tabular}{|c|c|c|c|}
\hline Malhas & $V_{k}^{T}$ & $h$ & Erro \\
\hline \hline$M_{1}$ & 0.242819 & 0.00020 & \\
\hline \hline$M_{2}$ & 0.187884 & 0.00015 & 0.054935 \\
\hline \hline$M_{3}$ & 0.148132 & 0.00010 & 0.039752 \\
\hline \hline$M_{4}$ & 0.145238 & 0.00008 & 0.002894 \\
\hline
\end{tabular}

Figura 7.5: Indicativo de convergência via velocidade terminal da bolha no tempo $t=0.1 \mathrm{~s}$.

Mukundakrishnan, K. et al. [79] estudaram o tamanho do domínio de solução $(R \times h)$ para os casos de bolhas do tipo esférica e calota-esférica-contornada (spherical-cap-skirted). Eles explicam que os efeitos de parede são notados quando as dimensões do canal são reduzidas para um dado valor. O número de Reynolds da bolha diminui quando a redução é feita, então a velocidade do centro de massa pode ser não realística. Então, eles empregaram em suas simulações a condição de que $R \geq 6 L$ 
e $h \geq 3 L$. Concluíram que o movimento da bolha resultou em valores de velocidade terminal e forma correspondentes àqueles em um meio infinito.

Kumar, S. S. em seu trabalho de doutoramento [63], estudando o tamanho do domínio na direção horizontal, argumentou que ele deve ser grande o suficiente tal que os efeitos de parede sobre a ascensão da bolha possam ser ignorados na simulação, e a bolha pode ser assumida ascender em um líquido parado. Para isto, ele considerou dois conjuntos de simulações para avaliar a velocidade terminal. O efeito do domínio para as condições de simulação para um fluido nomeado por S5 e um diâmetro de bolha de 5 milímetros foram tais que, a velocidade terminal da bolha foi calculada com diferentes larguras do canal. Kumar observou que a velocidade terminal foi considerada apropriada quando a largura do canal aumentou a partir de um dado valor. Concluiu que a condição sobre o tamanho horizontal do domínio é que o mesmo precisa ser em torno de 8 vezes o diâmetro da bolha.

Sendo assim, diante a estes fatos levantados, além do refinamento de malha trabalhamos também sobre a questão da variação da dimensão radial do domínio.

Fixamos $d r=d z=0.0001$ e resolvemos numericamente as equações do nosso modelo em três domínios: $R \stackrel{l}{\times} h=\{0.003 \times 0.030,0.006 \times 0.030,0.009 \times 0.030\}$ para $l=1,2,3$ respectivamente.

Os gráficos da velocidade para os três domínios utilizados estão mostrados na figura 7.6. Veja que a redução no valor de $R$ para $R \stackrel{l}{\times} h$ dimimui o valor da velocidade terminal, que vêm de encontro com as argumentações de Mukundakrishnan, K. et al. e Kumar, S. S.

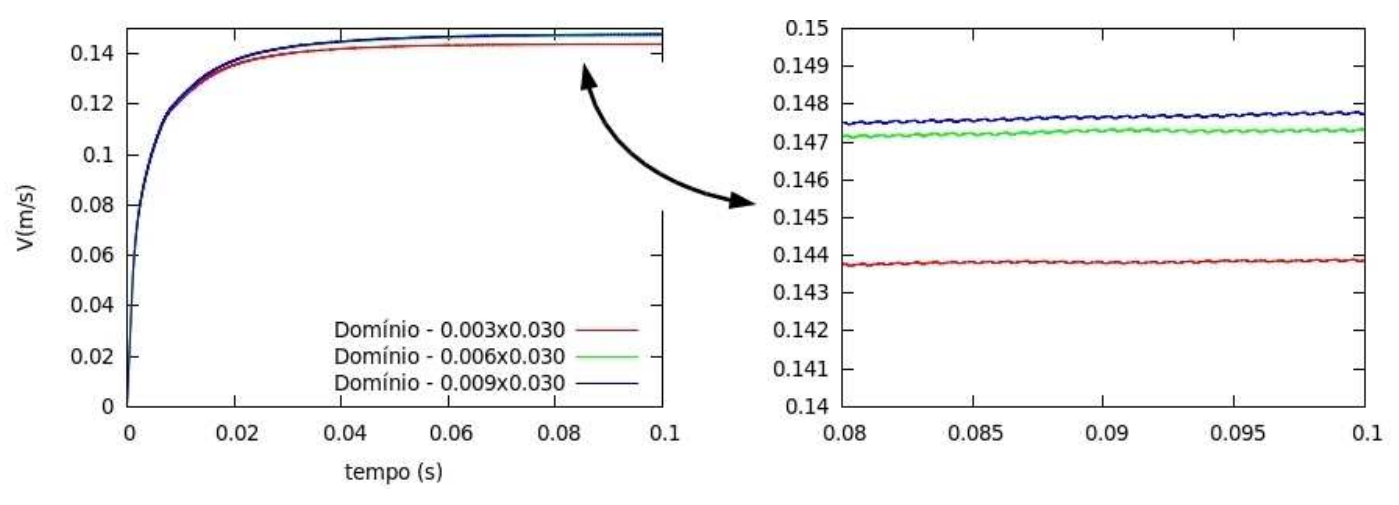

Figura 7.6: Perfis de velocidade do centro de massa da bolha para S-1, nos domínios $R \stackrel{1}{\times} h, R \stackrel{2}{\times} h$ e $R \stackrel{3}{\times} h$.

Após vários testes realizados com nosso código, consideramos que as nossas condições sobre $R, h$ deveriam ser $R=9 L$ e $h=3 R$. Estas condições nos forneceram o requisito de concluir que o movimento da bolha resulta em valores, da velocidade terminal e forma, correspondentes àqueles em um meio infinito. Esta afirmação será mais justificada a seguir quando abordaremos as simulações no 
sistemas: ar/água e hidrogênio/glicerina ${ }_{1}$.

Observe que $R \stackrel{1}{\times} h$ não verifica as condições de Mukundakrishnan, K. et al. e Kumar, S. S. e também não satisfaz a nossa. O domínio $R \stackrel{2}{\times} h$ não verifica a condição de Kumar, S. S. e a nossa, porém $R \stackrel{3}{\times} h$ verifica todas as condições.

Portanto, nas simulações que seguem consideramos em nossos cálculos $R=9 L, h=3 R$ e um refinamento de malha $M_{k}: n i \times n j$ que assegure um erro nos cálculos da conservação da massa na $O\left(10^{-06}\right)$.

Além das questões de refinamento de malha e dimensionamento de domínio, estudamos também a razão de densidades. Observe na tabela 7.1 que os dados de S-1 até S-4 estão sobre os mesmos valores de entrada exceto em $\rho_{d}$. Nestes dados de simulações temos respectivamente as razões $\frac{\rho_{c}}{\rho_{d}}=10.0$, 100.0, 842.06, 1390.51. Para cada razão de densidades efetuamos a simulação no domínio $R \stackrel{3}{\times} h$ com a malha $M_{3}$.

Percebemos que as simulações tornaram-se mais difíceis quando aumentamos o valor da razão de densidades. Acreditamos que esta dificuldade ocorreu porquê o fluido experimenta um maior valor de intensidade da resultante por parte da bolha e isto exigiu mais iterações no cálculo do método dos Gradientes Conjugados. Porém, o valor de $d t$ ficou em $2.19020 \times 10^{-06}$ para todas estas simulações.

Observe, no tempo $t=0.1$, que o número de Reynolds da bolha $\left(R e_{B}=L V^{T} / \nu_{0}\right)$ aumentou na medida em que a razão de densidades aumenta, figura 7.7 (esquerda). Com o aumento da razão de densidades ocorre o surgimento de correntes espúrias no fluido circundante à bolha, que leva ao aparecimento de oscilações na velocidade da bolha, como pode ser observado na figura 7.7 (direita).

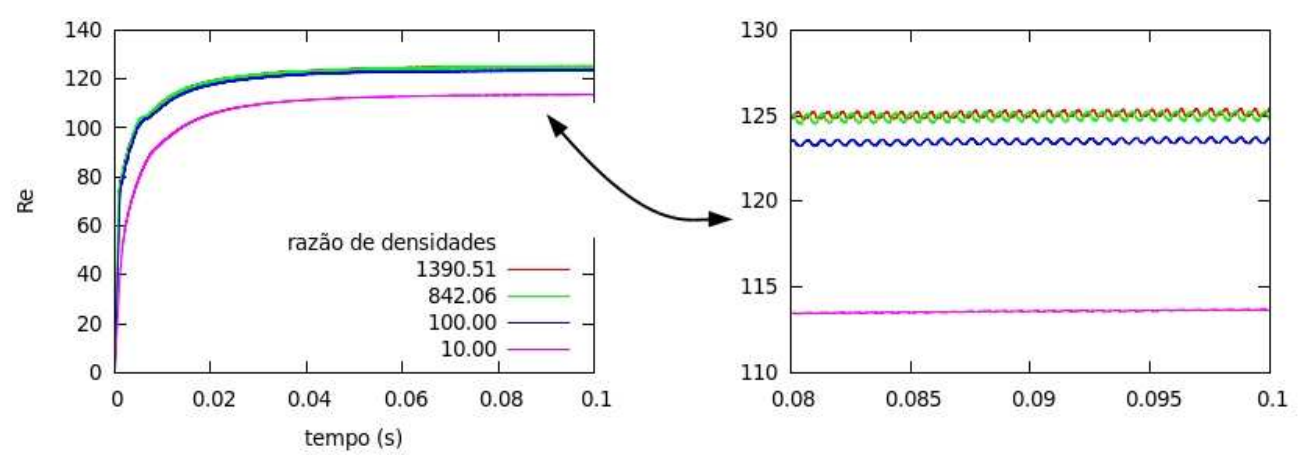

Figura 7.7: Número de Reynolds para bolhas nos casos S-1, S-2, S-3 e S-4.

No artigo [82], os autores afirmam que há poucas metodologias eficientes que simulam a ascensão de pequenas bolhas, de diâmetro próximo a 1 milímetro e com alta razão de densidades. E que, a fim de reduzir as correntes espúrias, alguns pesquisadores usam baixa razão de densidades. Com o nosso trabalho desenvolvido até aqui, tentamos trazer um pouco mais de informações sobre a simulação de 
pequenas bolhas a alta razão de densidades. O nosso código numérico é hábil em resolver este tipo de problema e ratificamos esta afirmação comparando nossos resultados com a literatura.

Os resultados encontrados até aqui e as discussões feitas sobre eles nos encorajaram comparar nossas simulações com alguns daqueles da literatura. Escolhemos cinco casos, o primeiro (caso I) uma bolha com $L=0.001 \mathrm{~m}$ e o segundo (caso II) uma bolha com $L=0.0015 \mathrm{~m}$, estudados no sistema ar/água com preservação de forma.

Além destes consideramos ainda uma bolha com $L=0.0075 \mathrm{~m}$ (caso III) e $L=0.02 \mathrm{~m}$ (caso IV) estudados no sistema nitrogênio/glicerina ${ }_{1}$ com mudança de forma. E fechando esta seção, avaliamos a ascensão de uma bolha de diâmetro $L=0.02 \mathrm{~m}$ (caso $\mathrm{V}$ ) no sistema nitrogênio/sedimento também com mudança de forma. Os parâmetros adimensionais empregados são os números de Reynolds (equação 3.10) e Bond (equação 3.16) para classificar a forma da bolha.

\section{Caso I}

Considerando então dados de S-3:

$$
R \stackrel{3}{\times} h \quad, \quad M_{3}: 90 \times 300
$$

encontramos $R e \approx 76.2$ e $B o \approx 0.13(\operatorname{com} \sigma=0.0756 N / m)$, que segundo o mapa da figura 7.1 a forma da bolha em ascensão é do tipo esférica.

Os gráficos da velocidade do centro de massa e posição, em função do tempo, podem ser vistos na figura 7.8. Nesta figura (esquerda) exibimos o nosso resultado junto com aqueles obtidos por Hong Xu e Chokri Guetari [141] e Dijkhuizen, W. et al. [33], a velocidade por nós encontrada se mostra em boa concordância com as literaturas. A localização do centro de massa, calculada por nosso código, é mostrada na mesma figura (direita).
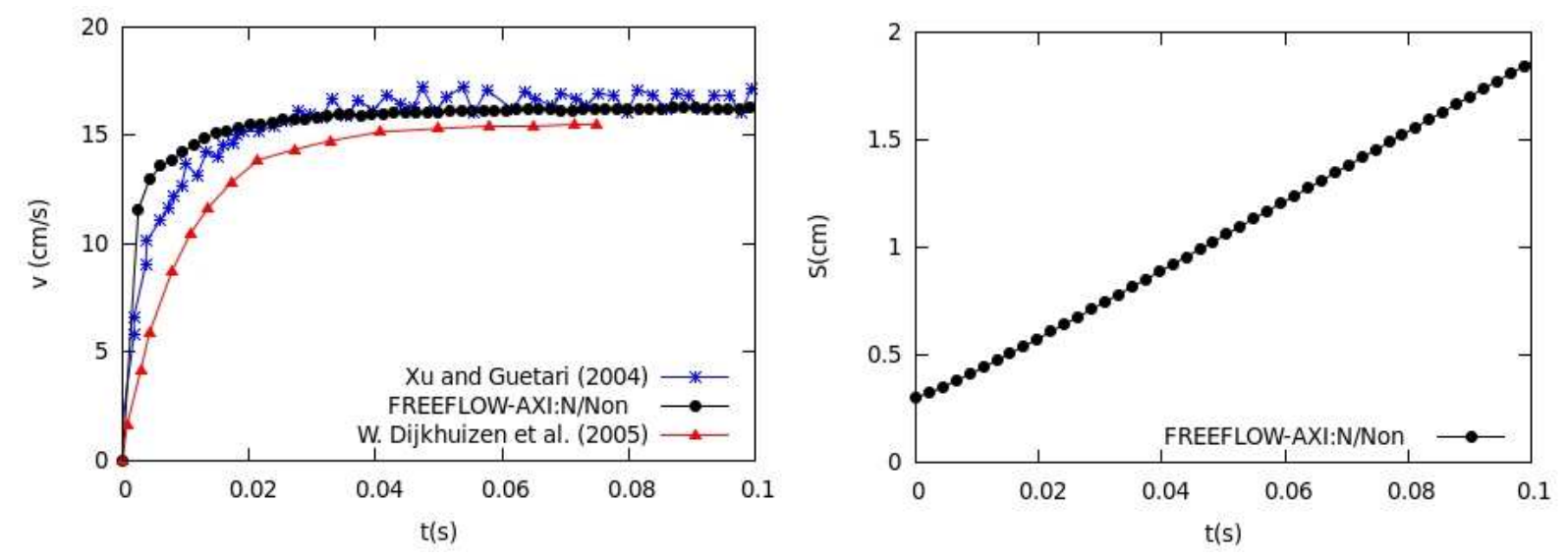

Figura 7.8: Velocidade do centro de massa da bolha com $L=0.001 \mathrm{~m}$ (esquerda) e posição em função do tempo (direita). 
No tempo inicial admitimos um campo de pressão natural (pressão hidrostática) para o fluido parado, figura 7.9. Em seguida, alguns campos de velocidade (adimensional) são mostrados na figura 7.10 na geometria axissimétrica. No lado esquerdo apresentamos os mapas de cor referente a componente $u$ do vetor velocidade e no lado direito a componente $v$.

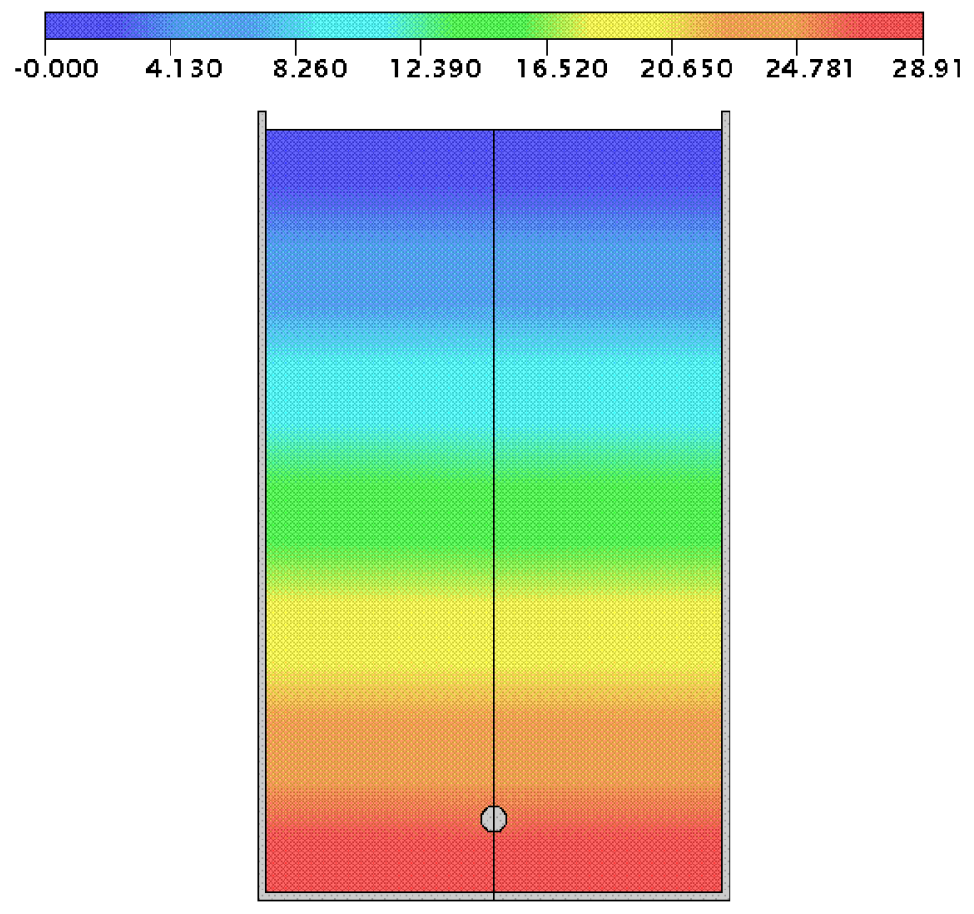

Figura 7.9: Representação do campo de pressão no inicio da simulação.

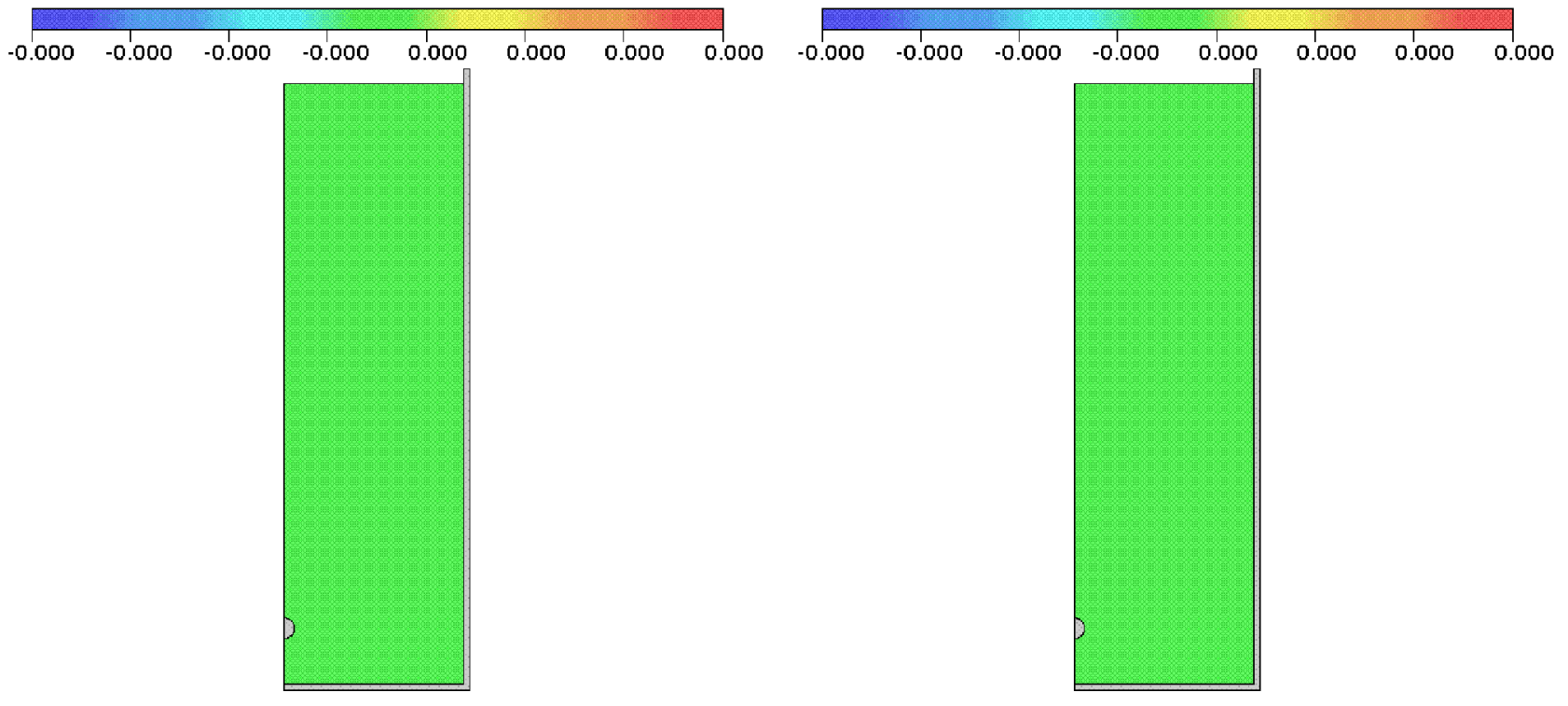

$$
t=0.0 \mathrm{~s}
$$




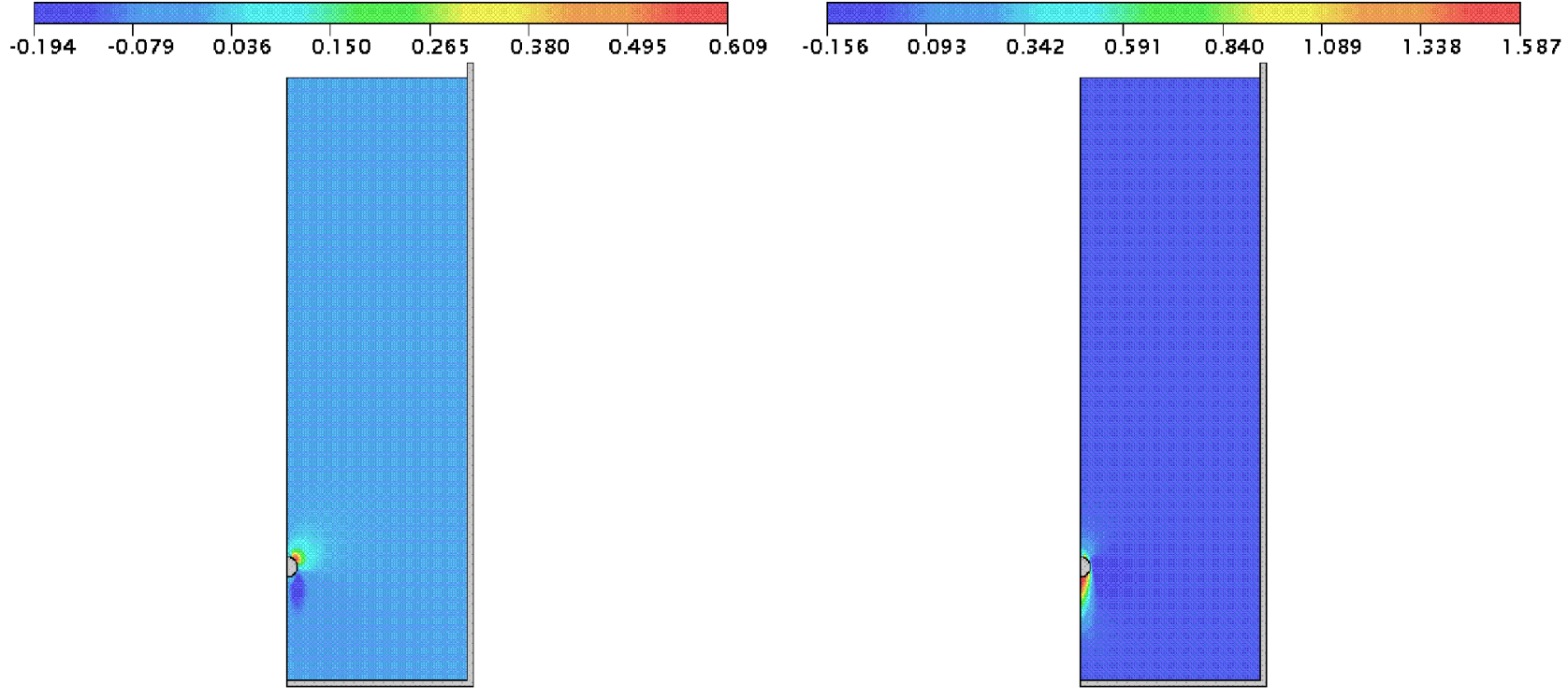

$$
t=0.02 \mathrm{~s}
$$

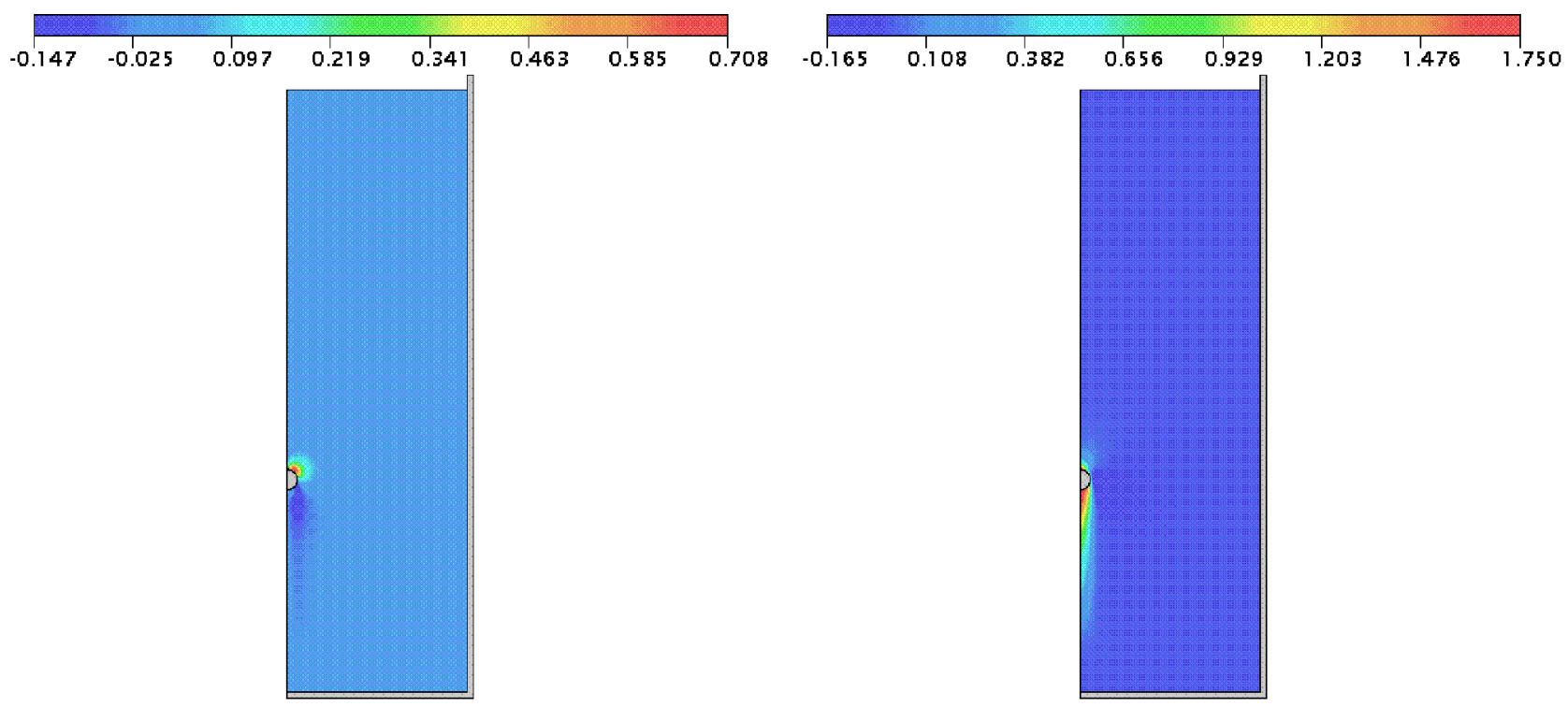

$$
t=0.05 \mathrm{~s}
$$

Figura 7.10: Representação das componentes $u$ (esquerda) e $v$ (direita) do vetor velocidade.

Em particular, quando a velocidade terminal da bolha está praticamente assumida encontramos os campos, adimensionais, de pressão (superior) e velocidade (inferior) exibidos na figura 7.11.

Observe que ao longo da simulação o movimento da bolha produz alterações nos valores da velocidade do fluido. A bolha desenvolve uma esteira ao longo da simulação, que aumenta em comprimento com o passar do tempo até que o movimento se torna uniforme. 
Na região logo a frente da bolha o fluido tem velocidade menor do que aquela do contorno da mesma, isto promove resistência ao movimento. Podemos dizer que a bolha se choca ao fluido a cada lapso de tempo, em intensidades diferenciadas e periódicas por um princípio de ação/reação (entre a bolha e o fluido circundante). O choque, do ponto de vista numérico, torna a resolução das equações de Navier-Stokes um processo difícil. A aplicação de métodos aproximativos nos termos convectivos que não capte adequadamente a física do problema pode levar a resultados não verdadeiros. O método SDPUS-C1 é modelado para tratar este tipo de dificuldade.



Figura 7.11: Representação do campo de pressão (superior) e das componentes $u$ (esquerda-inferior) e $v$ (direita-inferior) do vetor velocidade no tempo $t=0.1 \mathrm{~s}$.

Em contrapartida, na região logo atrás da bolha (por conta da constante diferença de pressão) a mesma exerce força sobre a massa de fluido colocando-o em movimento com expressiva velocidade. Por conta da dinâmica entre os termos convectivos e difusivos nas equações de Navier-Stokes a geometria do deslocamento dessa massa toma a forma da esteira. Neste caso também temos o choque entre a bolha e o fluido, mas em magnitude menor do que aquela dita no parágrafo anterior. Analogamente o SDPUS-C1 é apto no tratamento desta situação, uma vez que é um esquema upwind de alta resolução e preparado para resolver as equações em regiões de choque.

Após a passagem da bolha o fluido não sofre mais interferências bruscas. O processo de dissipação se evidência e os termos elípticos da equação de Navier-Stokes tornam-se dominantes. As 
aproximações centradas nestes termos captam esta questão e o fluido tende a se tornar quiescente.

\section{Caso II}

Clift, R. et al. [30] calculou experimentalmente a velocidade terminal de uma bolha esférica de diâmetro $L=0.0015$ m. Nadooshan, A. A. e Shirani, E. [82] utilizaram as densidades reais do ar e da água para esta bolha e obtiveram resultados em boa concordância com os dados experimentais de Clift, R. et al.

Utilizando os dados de S-5:

$$
R \stackrel{4}{\times} h=0.0135 \times 0.0405 \quad, \quad M_{5}: 90 \times 270
$$

nós realizamos a simulação para a bolha de mesmo diâmetro e comparamos a nossa solução com os das literaturas [30] e [82]. Uma boa concordância entre os resultados foi obtida também.

De fato, nesta situação temos $R e \approx 139.97$ e $B o \approx 0.30$, que segundo o mapa da figura 7.1 a forma da bolha em ascensão é também do tipo esférica. Os valores de $D M C F$ e $D M C S$ ficaram aproximadamente da $O\left(10^{-07}\right)$ e $O\left(10^{-19}\right)$ respectivamente.

$\mathrm{O}$ valor de $d t$ exibiu comportamento tal como aquele da figura 7.12. Note que até por volta do tempo $0.02 \mathrm{~s}$ o valor de $d t$ sofre forte queda. Isto se deve a um retardo no equilíbrio entre as forças de empuxo, peso e viscosa quando comparado ao caso I. Logo, esta questão se transfere ao fluido na qualidade de perturbação. Portanto, para que as restrições de estabilidade sobre as equações de Navier-Stokes sejam verificadas o valor de $d t$ segue o corportamento esboçado na figura. Após o tempo $0.02 \mathrm{~s} \mathrm{o} d t$ apresenta tendência a se estabilizar, porém em ligeira queda.

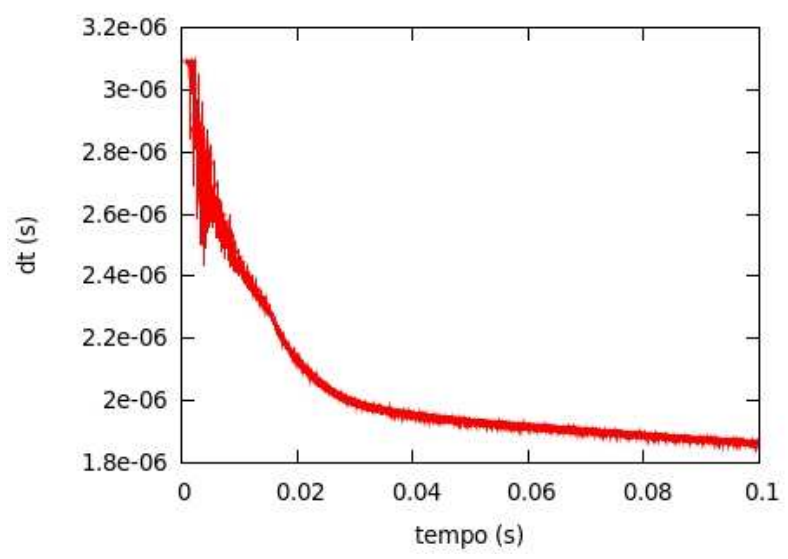

Figura 7.12: Evolução de $d t$ no caso da bolha esférica com $L=1.5$ milímetros de diâmetro.

Os gráficos da velocidade do centro de massa e posição podem ser observados na figura 7.13. Na figura esquerda mostramos os três resultados para a velocidade e na direita a localização do centro 
de massa. Observe que na comparação com o caso I, um aumento em 50\% no diâmetro da bolha (passando de 0.001 para 0.0015 dá como resultado um aumento de aproximadamente 100\% no valor da velocidade terminal, compare as figuras 7.8 e 7.13. Finalmente, na figura 7.14 esboçamos os campos, adimensionais, de pressão (figura superior) e de velocidades (inferior esquerda/direita) da bolha no tempo $t=0.1 \mathrm{~s}$ em movimento praticamente uniforme.
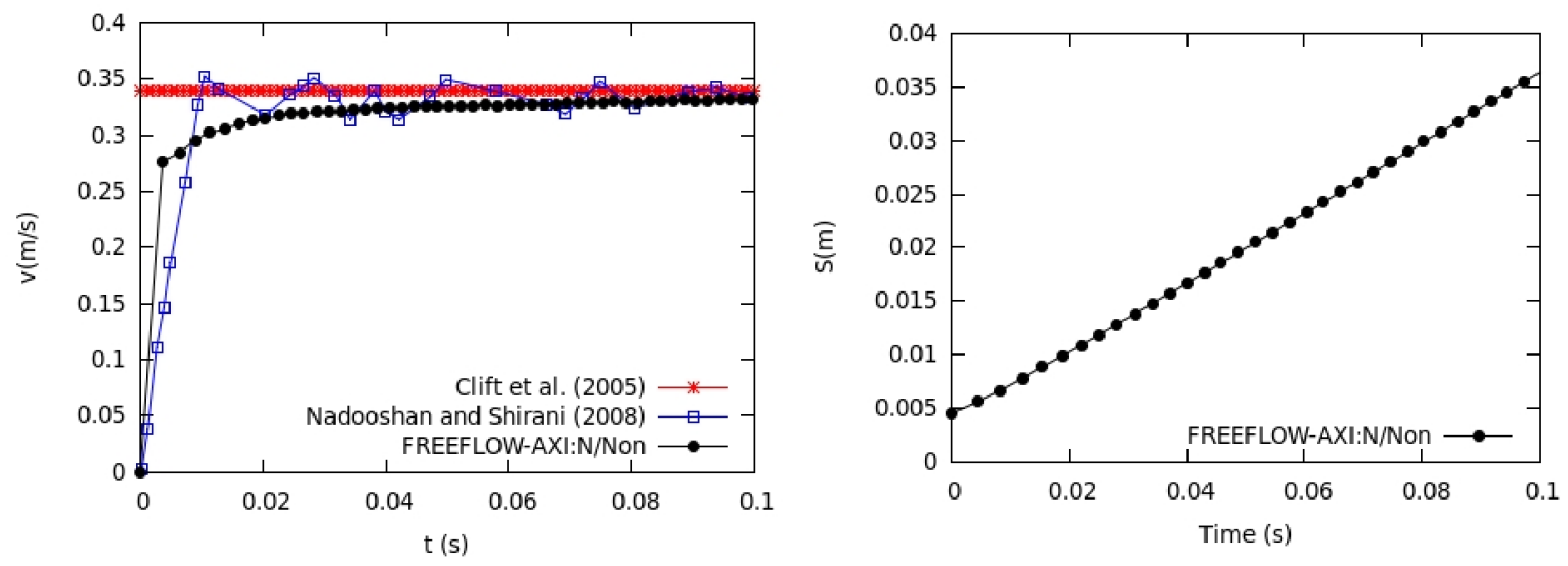

Figura 7.13: Velocidade do centro de massa da bolha com $L=1.5$ milímetros (esquerda) e Posição em função do tempo (direita).
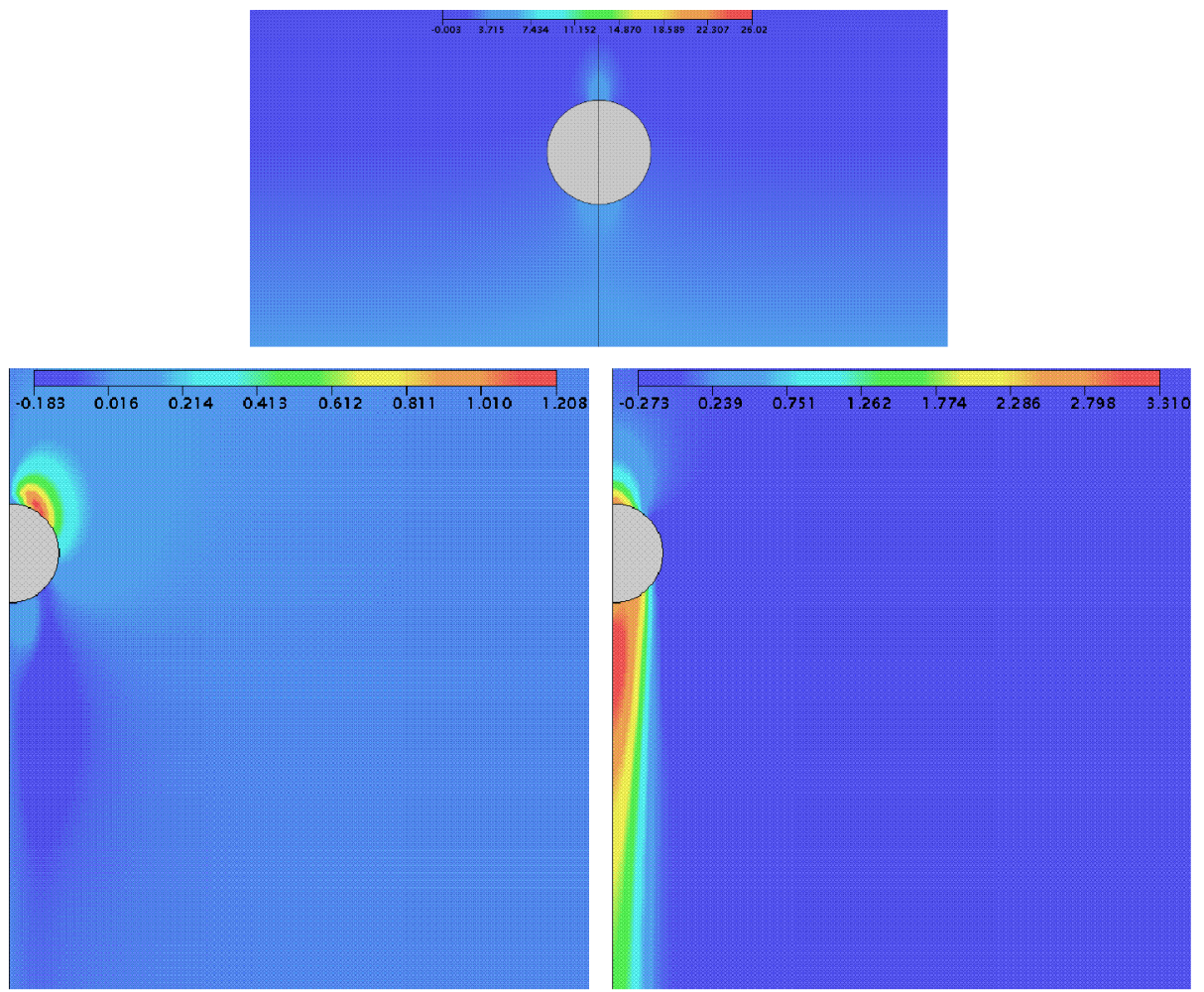

Figura 7.14: Representação do campo de pressão (superior) e das componentes $u$ (esquerda-inferior) e $v$ (direita-inferior) do vetor velocidade no tempo $t=0.1 \mathrm{~s}$. 
Nos casos (III) e (IV) a seguir empregamos como fluidos de trabalho o nitrogênio e a glicerina ${ }_{1}$. Entendemos por glicerina ${ }_{1}$ o fluido de características newtonianas que decorre da diluição da glicerina pura pela adição de água da maneira realizada no trabalho de Fabiana R. G. Melo [77].

O nosso interesse em utilizar estes fluidos vem do fato que, o nitrogênio possui valor de densidade muito próximo do valor da densidade do ar e esta diluição para a glicerina proporciona um fluido cuja viscosidade é maior do que a da água. Portanto os efeitos da viscosidade são mais relevantes proporcionando uma outra dinâmica para velocidade de ascensão e forma da bolha, bem como também para o escoamento do fluido ao redor da mesma. Nos casos que exibiremos a seguir a trajetória de ascensão é também retilínea assegurando a base de validação do nosso código numérico.

Em seu trabalho de doutorado, Fabiana R. G. Melo [77] estudou experimentalmente o movimento de bolhas em líquidos newtonianos incompressíveis em meio infinito e estagnado. Em um de seus estudos ela analisou a ascensão no sistema nitrogênio/glicerina ${ }_{1}$. Ela constatou que neste sistema a bolha assume trajetória praticamente retilínea. Quanto ao formato, ela observou que as pequenas bolhas são do tipo elipsoidal e as grandes bolhas são no formato cápsula esférica.

Sob condições similares ao estudo em [77] nós consideramos agora o segundo conjunto de simulações, cujos dados de entrada estão organizados na tabela 7.2. Nestas simulações avaliamos os casos III e IV. O caso III é referente a uma pequena bolha e o IV a grande bolha, segundo a denominação entendida em [77].

\begin{tabular}{|c|c|c|c|c|c|c|c|}
\hline \multirow{2}{*}{$\begin{array}{c}\text { Modelos } \\
\text { simulados }\end{array}$} & \multicolumn{7}{|c|}{ Dados de entrada } \\
\cline { 2 - 8 } & $L$ & $U$ & $\nu_{0}$ & $\rho_{c}$ & $\rho_{d}$ & $s_{0}$ & $r_{0}$ \\
\hline \hline S-6 & 0.0075 & 0.271247 & 0.00009072 & 1218.0 & 1.04 & 0.0225 & 0.00375 \\
\hline \hline S-7 & 0.02 & 0.442944 & 0.00009072 & 1218.0 & 1.04 & 0.06 & 0.01 \\
\hline
\end{tabular}

Tabela 7.2: Tabela de parâmetros de entrada do segundo conjunto de simulações.

Para os casos (III e IV) citados acima, partimos inicialmente com a bolha no formato esférico. Nestes casos os parâmetros da mudança de forma (razão de aspecto/fator de distorção) são importantes. Então a razão de aspecto foi classificada segundo a correlação proposta por Vakhrushev, equação (4.9) e o fator de distorção foi assumido mediante a equação (4.10).

Com os parâmetros de forma denotados e vistos na figura 3.3, calculamos os valores $b_{1}$ e $b_{2}$ via equações em (4.8). Em seguida, obtemos $a$ através da equação (4.11). Lembramos que esta equação permite que o volume da bolha seja preservado. Os valores $b_{1}, b_{2}$ e $a$ são recalculados a cada lapso de tempo. Nos casos III e IV a forma final assumida pelas bolhas foram ee e $e E$ respectivamente, análogas àquelas que foram mencionadas anteriormente (ver figura 4.18). 


\section{Caso III}

Admitimos neste caso dados de S-6:

$$
R \stackrel{5}{\times} h=0.0675 \times 0.2025 \quad, \quad M_{5}: 90 \times 270
$$

encontrando $R e \approx 22.42$ e $B o \approx 38.18$.

Os gráficos da velocidade e posição do centro de massa são mostrados na figura 7.15. Observe que com o aumento da bolha há maior instabilidade no perfil de velocidade para $t<0.15$. Nós percebemos neste caso estudado que $t \simeq 0.3$ foi o tempo para que a velocidade assumisse um valor praticamente uniforme.
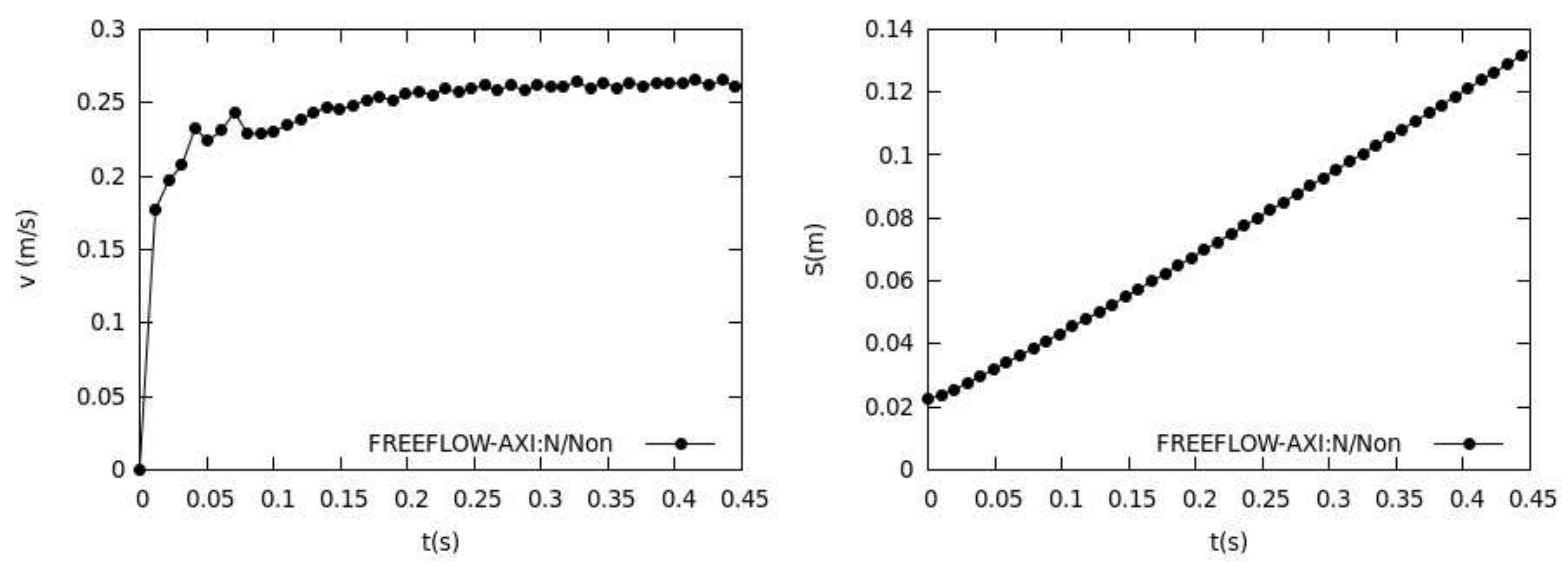

Figura 7.15: Velocidade do centro de massa para uma pequena bolha de nitrogênio na glicerina ${ }_{1}$ (esquerda) e posição em função do tempo (direita).

O número de Tadaki ( $T a=R e^{t} M o^{0.23}$ ), utilizado na análise da ascensão de bolhas e gotas ficou como o esboçado na figura 7.16 (esquerda).
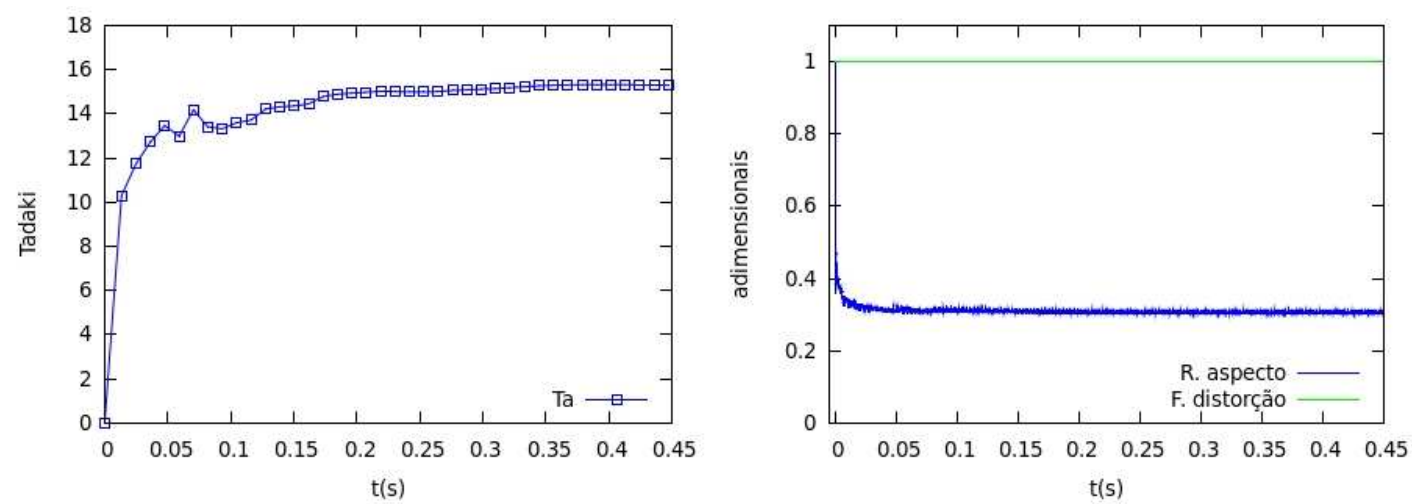

Figura 7.16: Número de Tadaki (esquerda) e razão de aspecto/fator de distorção (direita) calculados para uma pequena bolha de nitrogênio ascendendo em glicerina ${ }_{1}$. 
Assim, a razão de aspecto e o fator de distorção que são calculados em função $T a$ tiveram performance segundo a figura 7.16 (direita). Neste caso a mudança de forma é influenciada apenas pela razão de aspecto, porquê o fator de distorção é tomado como a unidade.

Uma vez que o fator de distorção é unitário, então os termos $b_{1}$ e $b_{2}$ são iguais e dependendentes apenas da razão de aspecto. Sendo assim, a sua evolução neste caso simulado é apresentada na figura 7.17, observe no tempo $t=0.0$ que $b_{1}=b_{2}=a$. Note que os valores de $b_{1}, b_{2}$ decrescem assintoticamente para 0.001702 . Por outro lado, o número $a$ aumenta assintoticamente para 0.005565 para que o volume da bolha seja preservado.

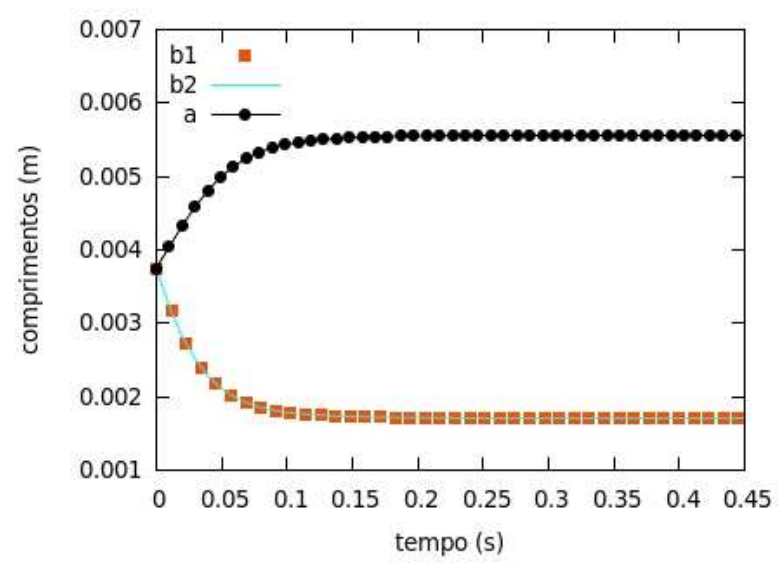

Figura 7.17: Evolução dos valores $b_{1}, b_{2}$ e $a$ para uma pequena bolha de nitrogênio ascendendo em glicerina ${ }_{1}$.

Devido a viscosidade e o tamanho da bolha foi necessário maior valor de tempo para obter a velocidade terminal. Neste caso a simulação pode ser visualizada na figura 7.18, aqui exibimos alguns campos de velocidade (adimensional). Veja a forma se alterando até a elipsoidal (ee).

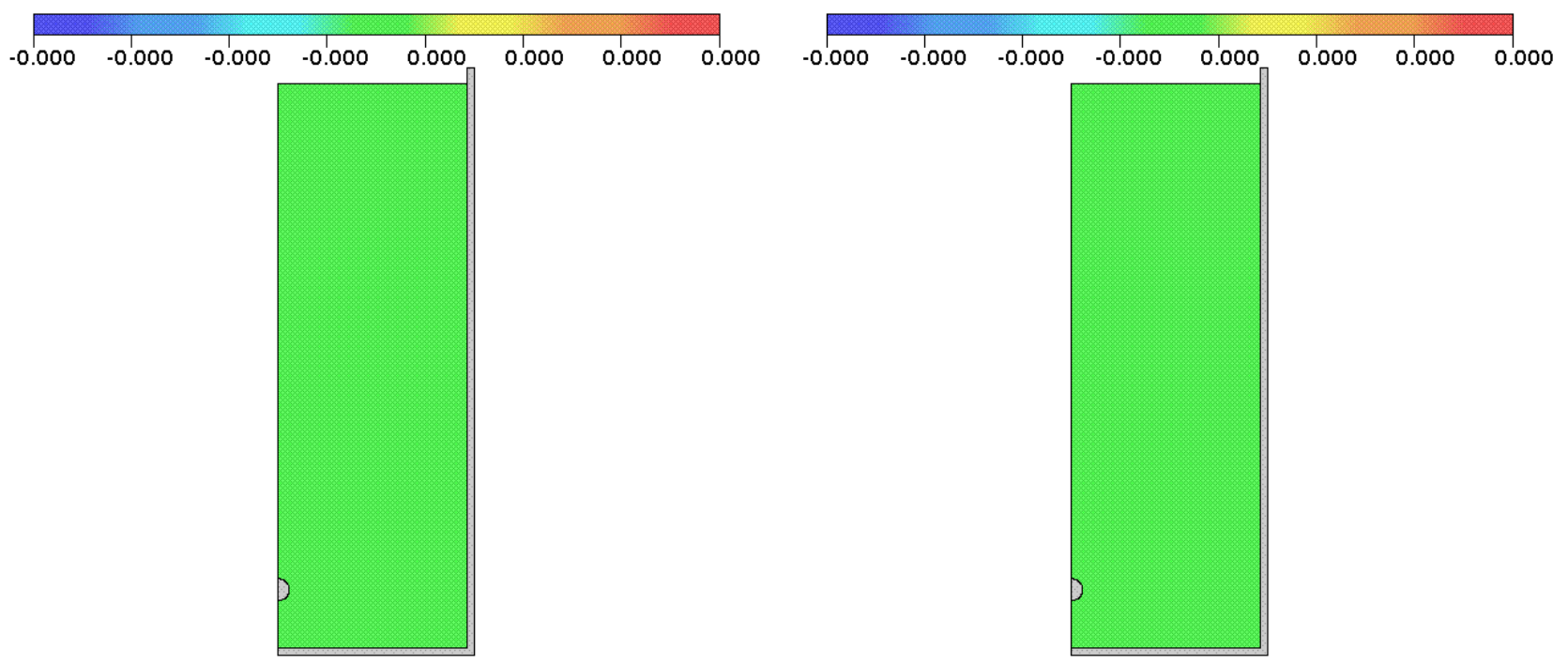

$t=0.0 \mathrm{~s}$ 


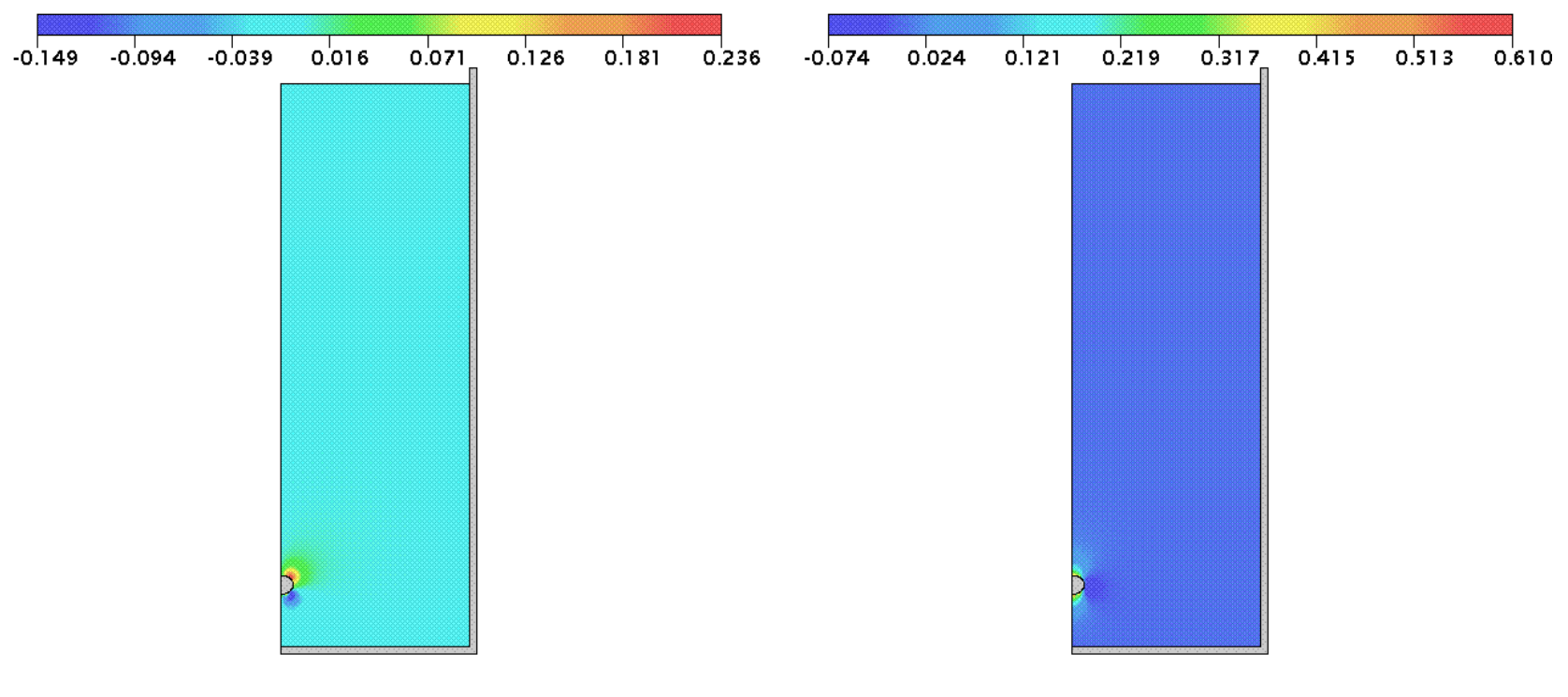

$$
t=0.01 \mathrm{~s}
$$

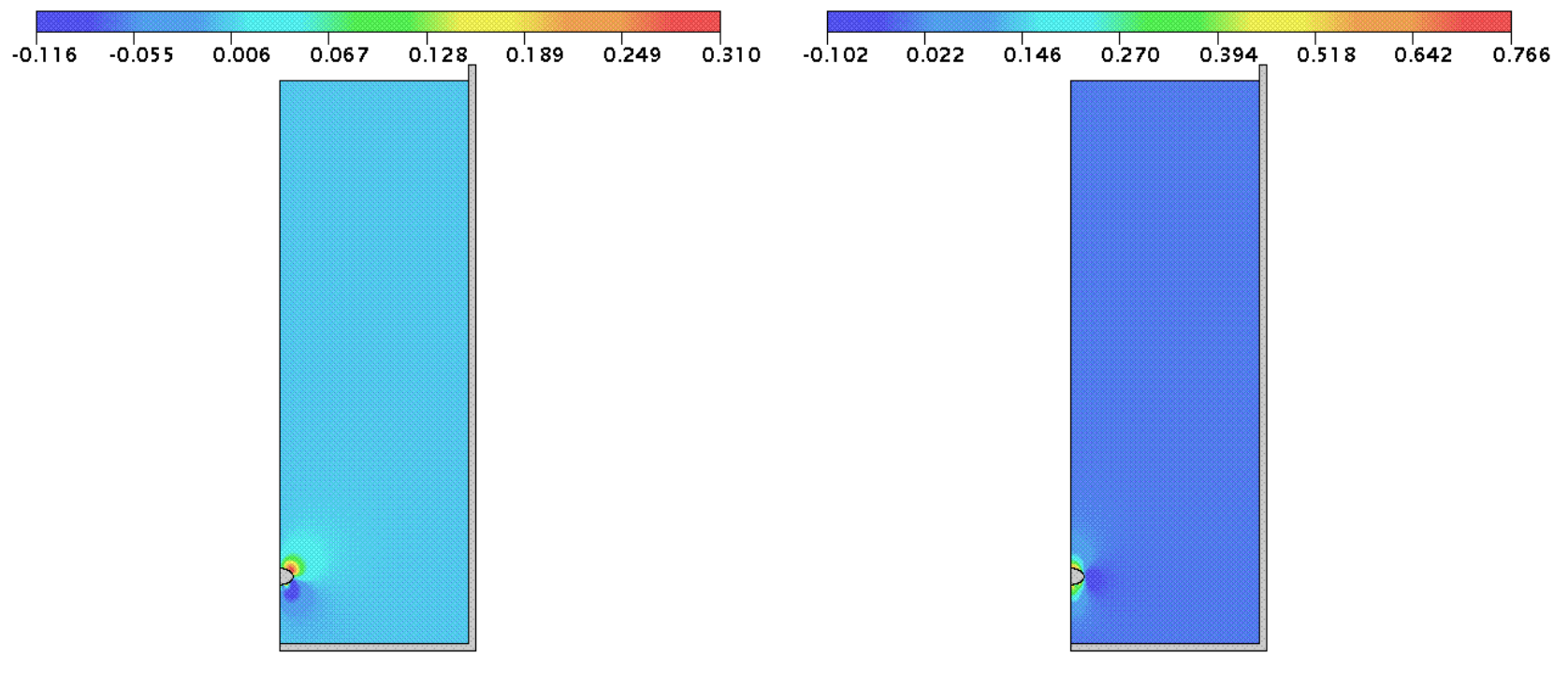

$t=0.02 \mathrm{~s}$
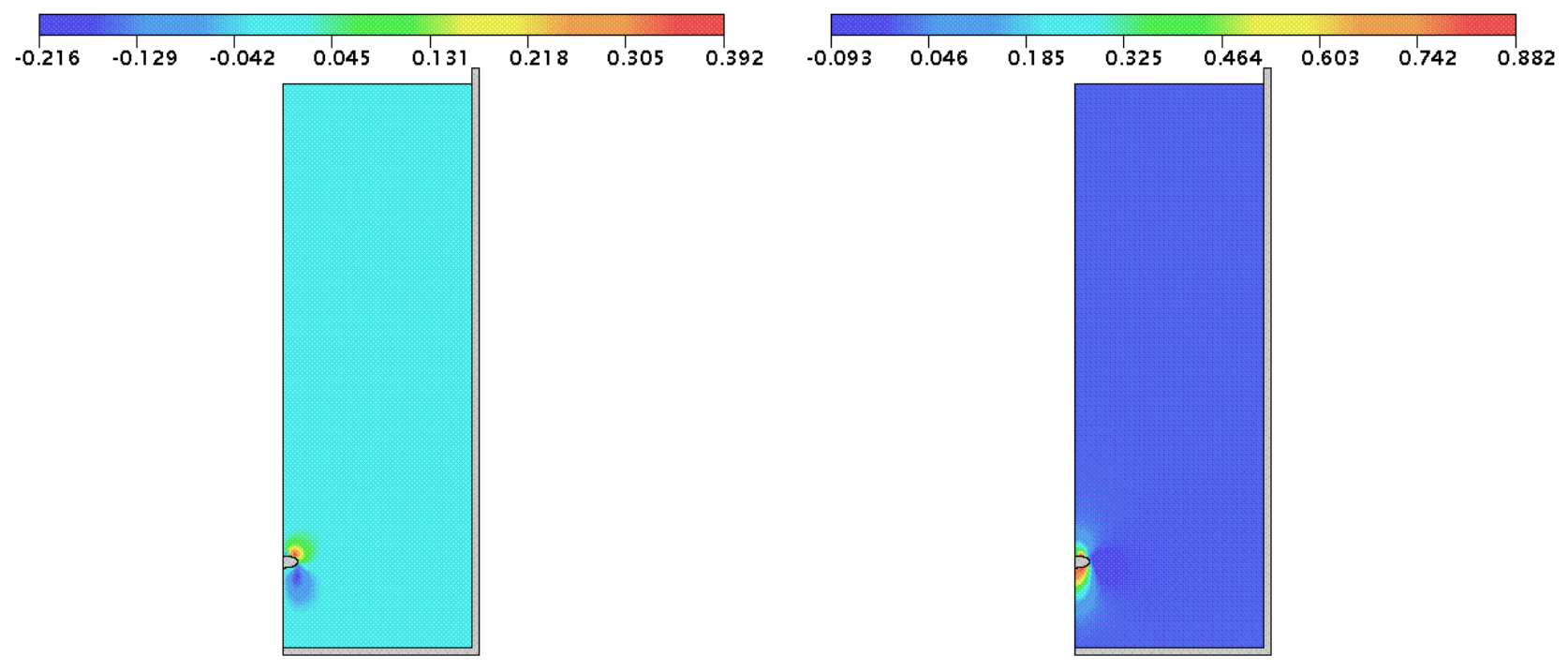

$$
t=0.05 \mathrm{~s}
$$




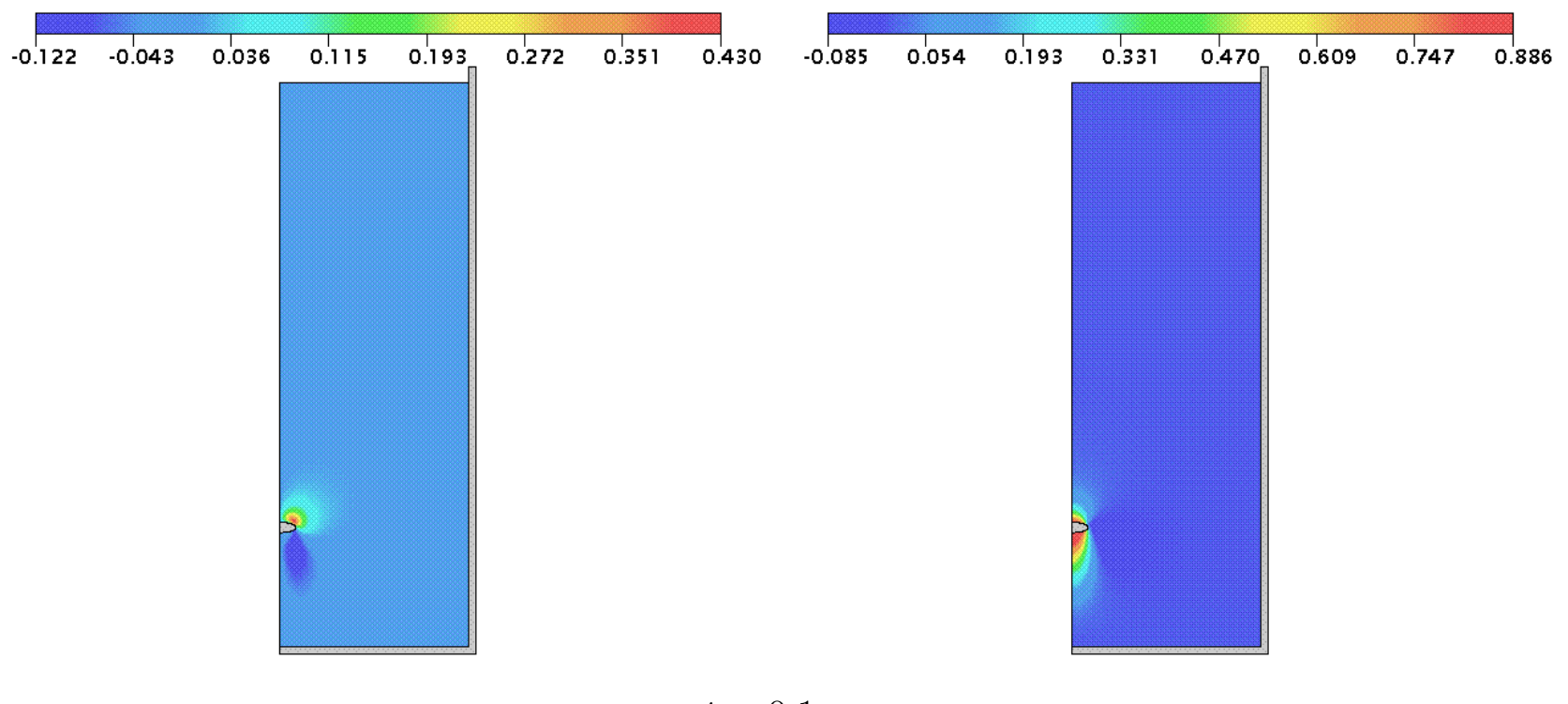

$$
t=0.1 \mathrm{~s}
$$
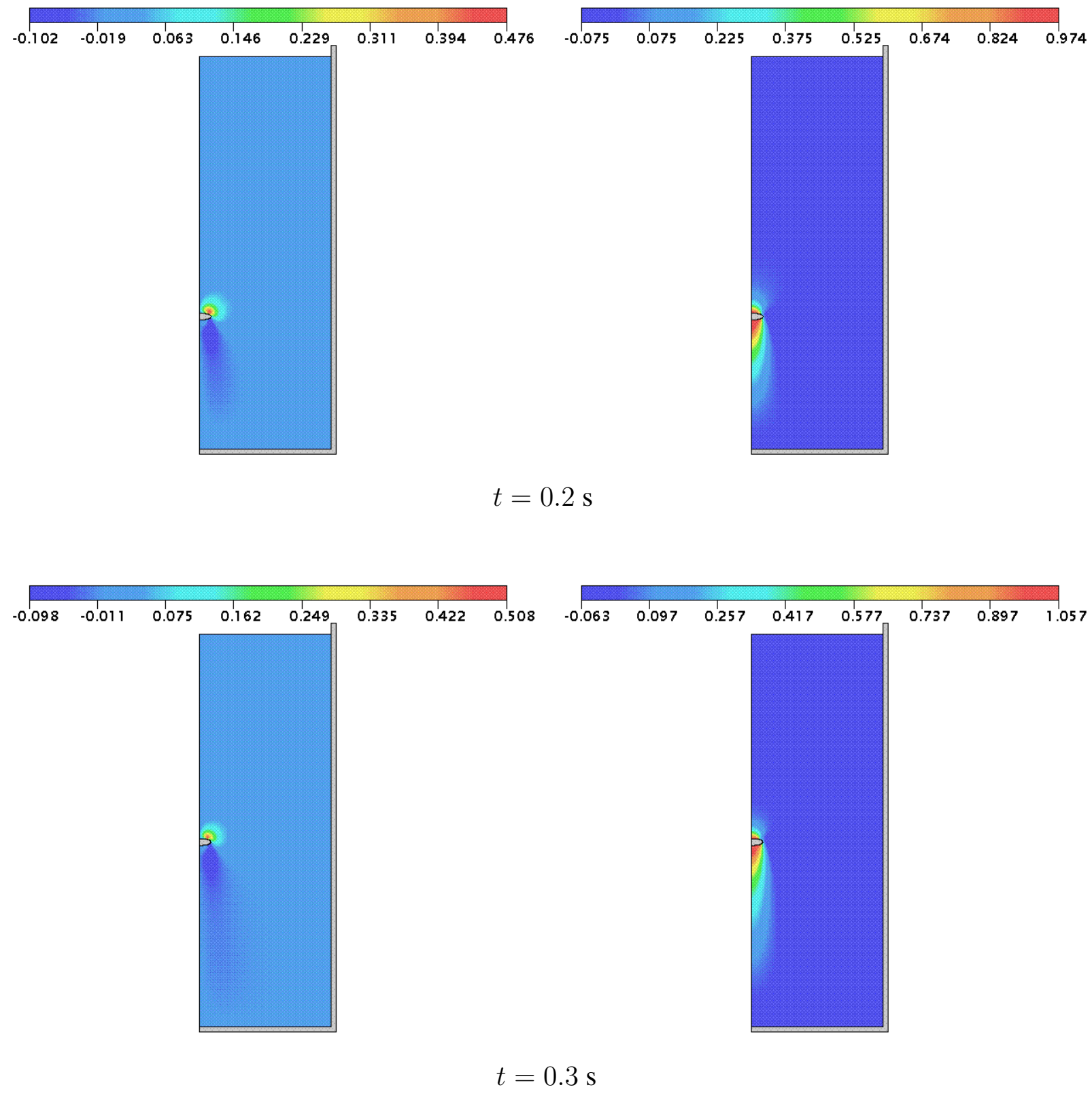


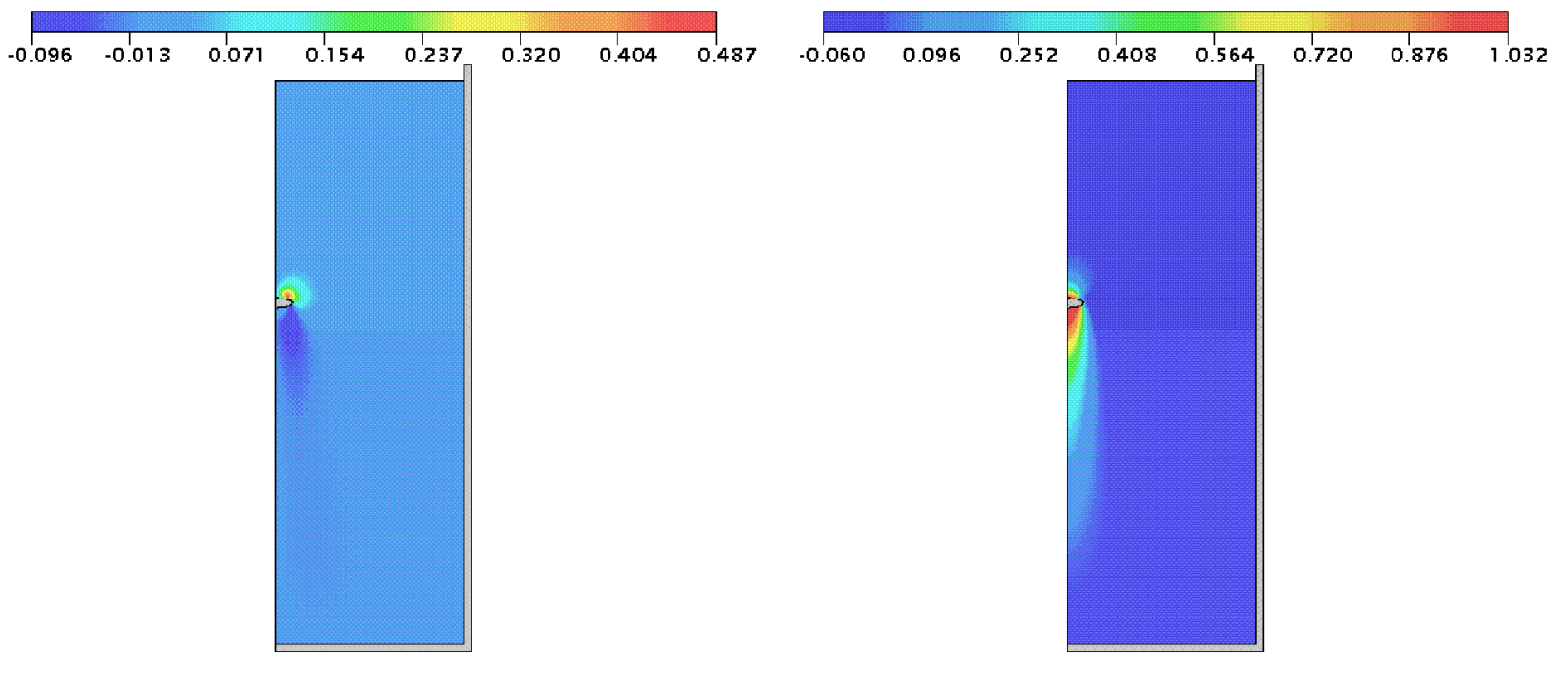

$$
t=0.4 \mathrm{~s}
$$

Figura 7.18: Representação das componentes $u$ (esquerda) e $v$ (direita) do vetor velocidade.

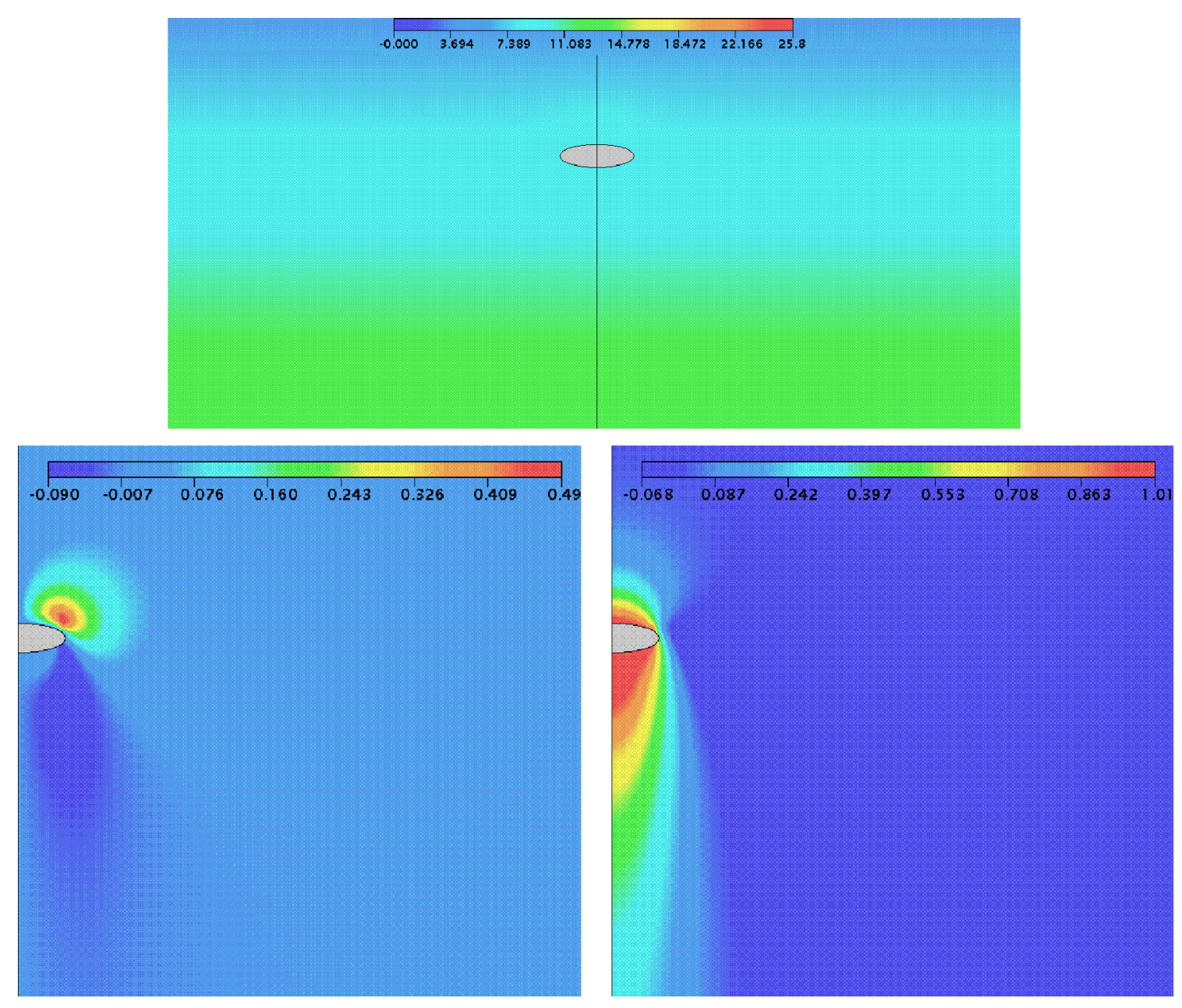

Figura 7.19: Representação do campo de pressão (superior) e das componentes $u$ (esquerda-inferior) e $v$ (direita-inferior) do vetor velocidade no tempo $t=0.45 \mathrm{~s}$. 
Em particular, quando o movimento entrou praticamente em regime uniforme o campo de pressão e velocidades ficou segundo o esboço da figura 7.19.

Na figura 7.20 (esquerda) mostramos uma visualização por nós encontrada para a bolha do presente caso no tempo $t=0.45 \mathrm{~s}$. Na mesma figura (direita) esboçamos também a forma encontrada por Melo, F. R. G. [77] em três momentos distintos após alcançada a velocidade terminal. A trajetória linear do caminho de ascensão fica evidenciada.

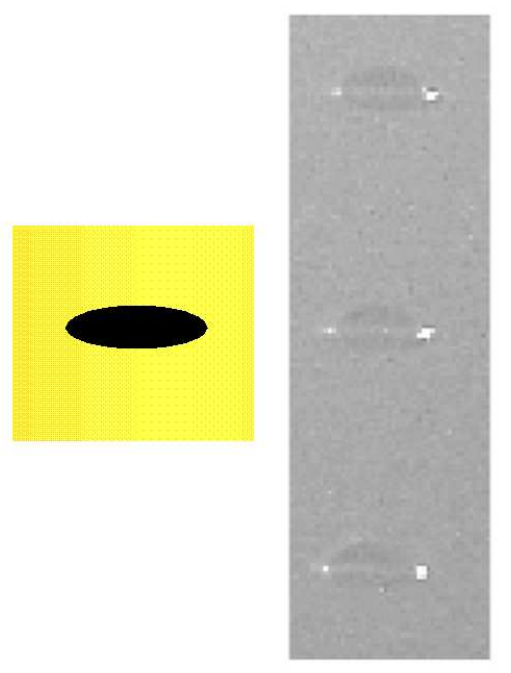

Figura 7.20: Visualização do nosso resultado (esquerda) e formato encontrado por Melo, F. R. G. [77] (direita), da forma final para uma pequena bolha de nitrogênio ascendendo em glicerina ${ }_{1}$.

Em [77] a autora encontrou experimentalmente a velocidade terminal de $0.21494 \mathrm{~m} / \mathrm{s}$ e $a=$ $0.00584 \mathrm{~m}$, em nossa simulação obtivemos os respectivos valores $0.26 \mathrm{~m} / \mathrm{s}$ e $a=0.005565 \mathrm{~m}$.

\section{Caso IV}

Seja agora dados de S-7:

$$
R \stackrel{6}{\times} h=0.180 \times 0.54 \quad, \quad M_{6}: 137 \times 411
$$

neste caso obtivemos $R e \approx 97.65$ e $B o \approx 271.55$.

Os gráficos da velocidade e posição do centro de massa são mostrados na figura 7.21. Nós observamos que o aumento de volume da bolha, neste caso estudado comparado com o anterior, exigiu maior tempo para que a velocidade assumisse um valor de velocidade terminal. Conforme pode ser visto na figura, a bolha entra em movimento praticamente uniforme após $t=0.7$. 

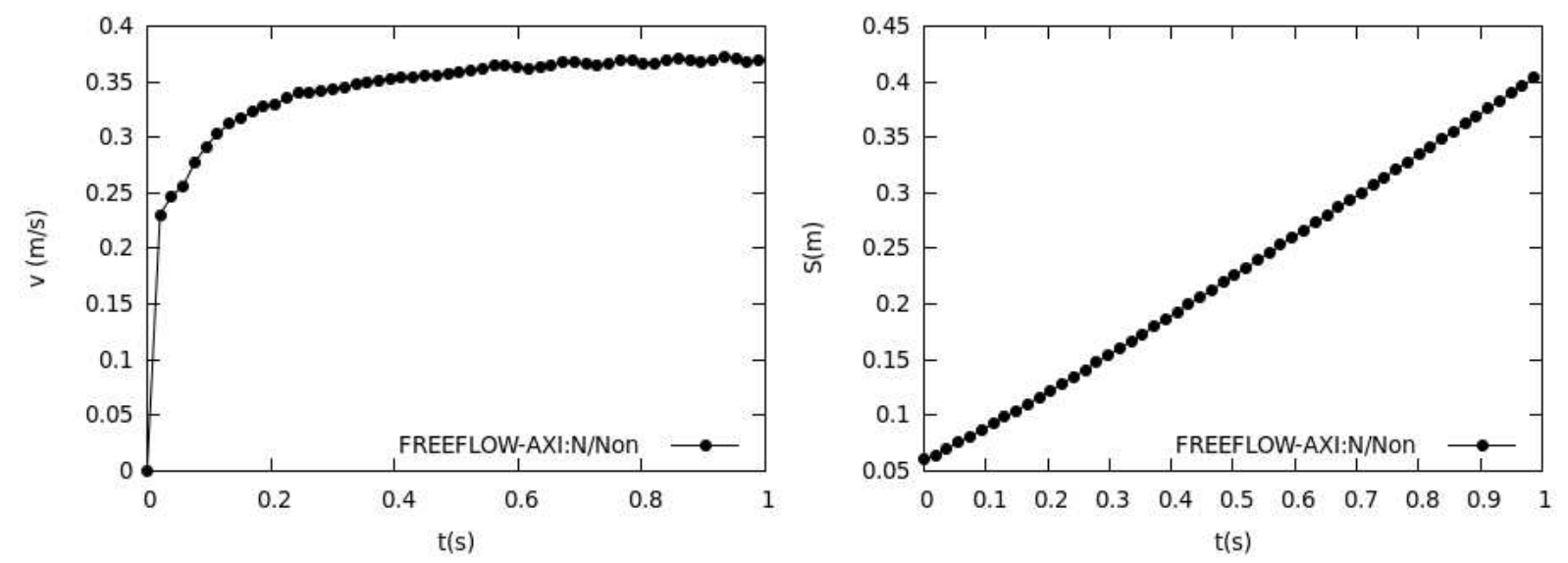

Figura 7.21: Velocidade do centro de massa para uma grande bolha de nitrogênio na glicerina (es- $^{-}$ querda) e posição em função do tempo (direita).

O número de Tadaki, a razão de aspecto e o fator de distorção estão mostrados na figura 7.22. Veja que nesta situação a razão de aspecto decai para 0.3 e estabiliza neste patamar quando o número de Tadaki supera o valor 20.0 (ver equação (4.9)). Além disto, o fator de distorção cresce assintoticamente até o valor 2.0 (ver equação (4.10)). Ou seja, o formato é influenciado pelas duas relações de forma.
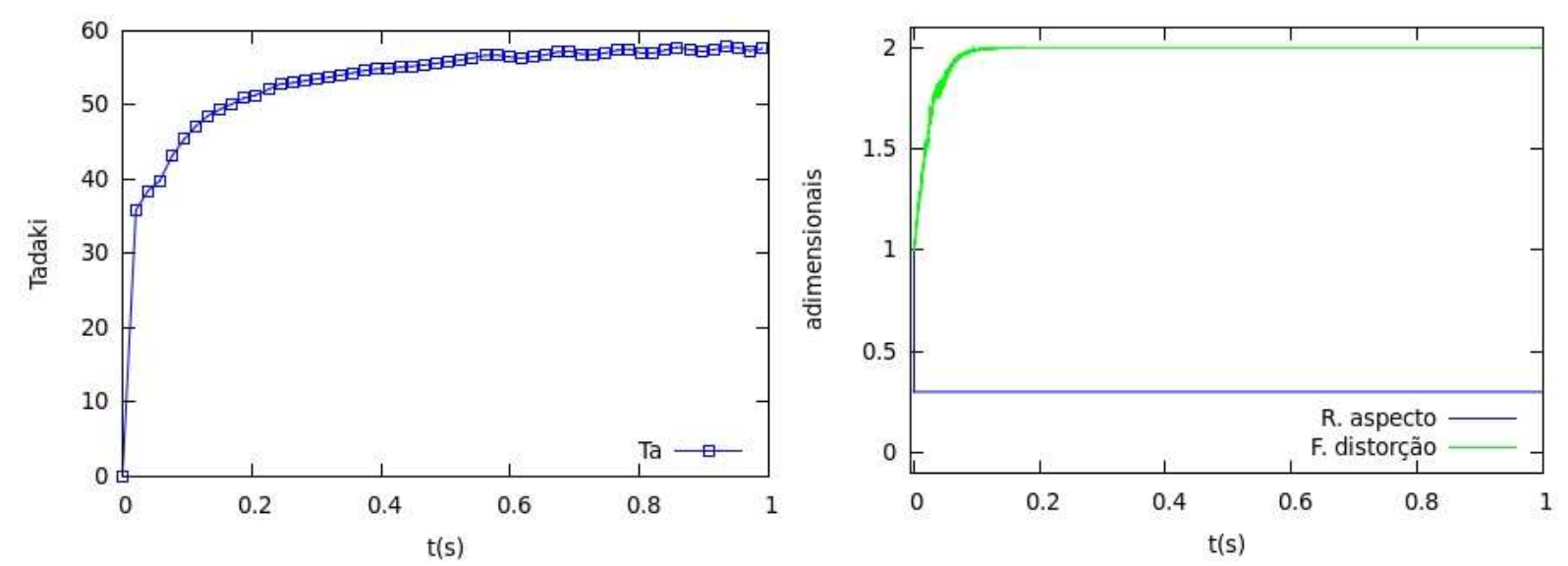

Figura 7.22: Número de Tadaki (esquerda) e razão de aspecto/fator de distorção (direita) calculados para uma grande bolha de nitrogênio ascendendo em glicerina ${ }_{1}$.

Uma vez que a razão de aspecto e o fator de distorção são variáveis e evoluem para os patamares 0.3 e 2.0 respectivamente, as influências destes sobre $b_{1}$ e $b_{2}$ são diferenciadas (ver equações em (4.8)). $\mathrm{O}$ valor de $b_{1}$ decresce para próximo de zero, enquanto que $b_{2}$ decresce até por volta de $t=0.023$. Neste tempo a bolha tem a forma muito próxima da elipsoidal. Após este tempo, $b_{2}$ cresce até atingir um patamar nas proximidades de 0.009 assumindo a forma final cápsula esférica, figura 7.23. 


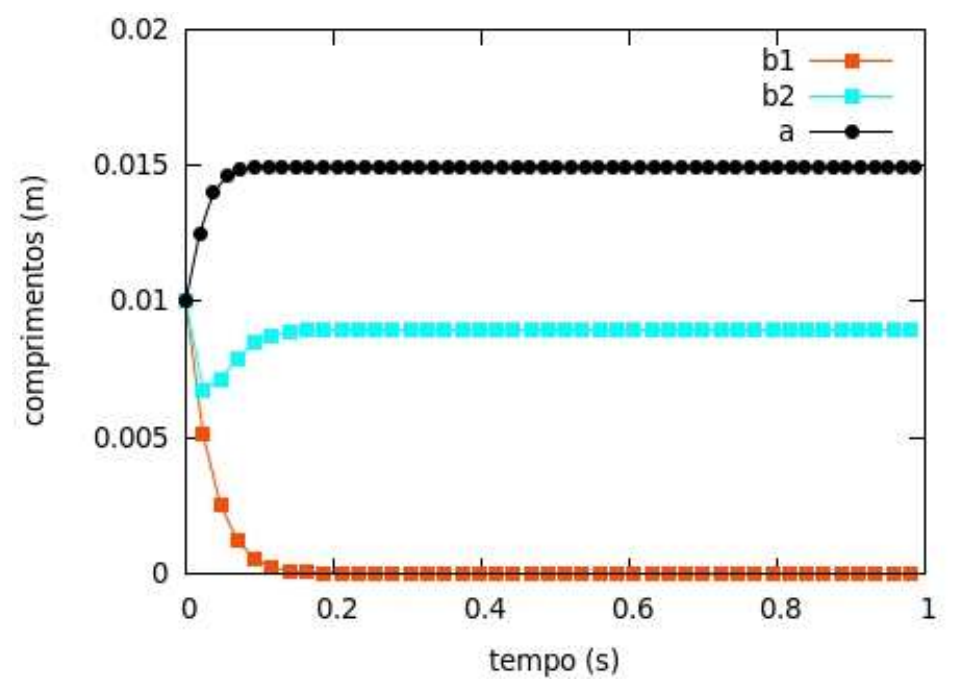

Figura 7.23: Evolução dos valores $b_{1}, b_{2}$ e $a$ para uma grande bolha de nitrogênio ascendendo em glicerina $_{1}$.

Por outro lado, o valor de $a$ aumenta até atingir um valor próximo de 0.015 equação (4.11). Isto ocorre no intuito de que o volume da bolha seja preservado. Ressaltamos que $b_{1}$, $b_{2}$ e $a$ são recalculados a cada lapso de tempo.

Exibimos também alguns campos de velocidade (adimensional) na figura 7.24. Note que agora a bolha muda a sua forma até obter a forma elipsoidal, por volta de $0.02 \mathrm{~s}$, a partir disto ela vai tomando o formato da cápsula esférica $(e E)$.

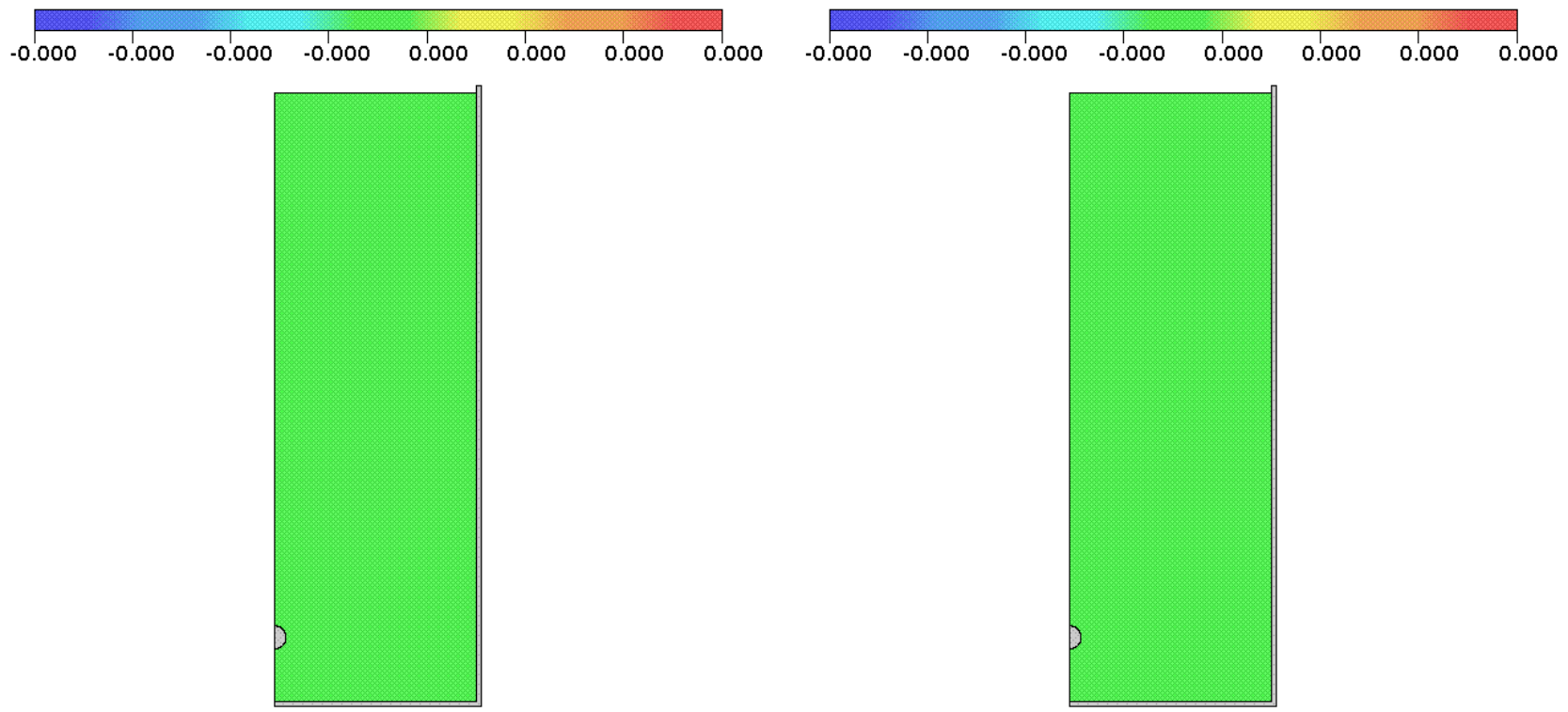

$$
t=0.0 \mathrm{~s}
$$




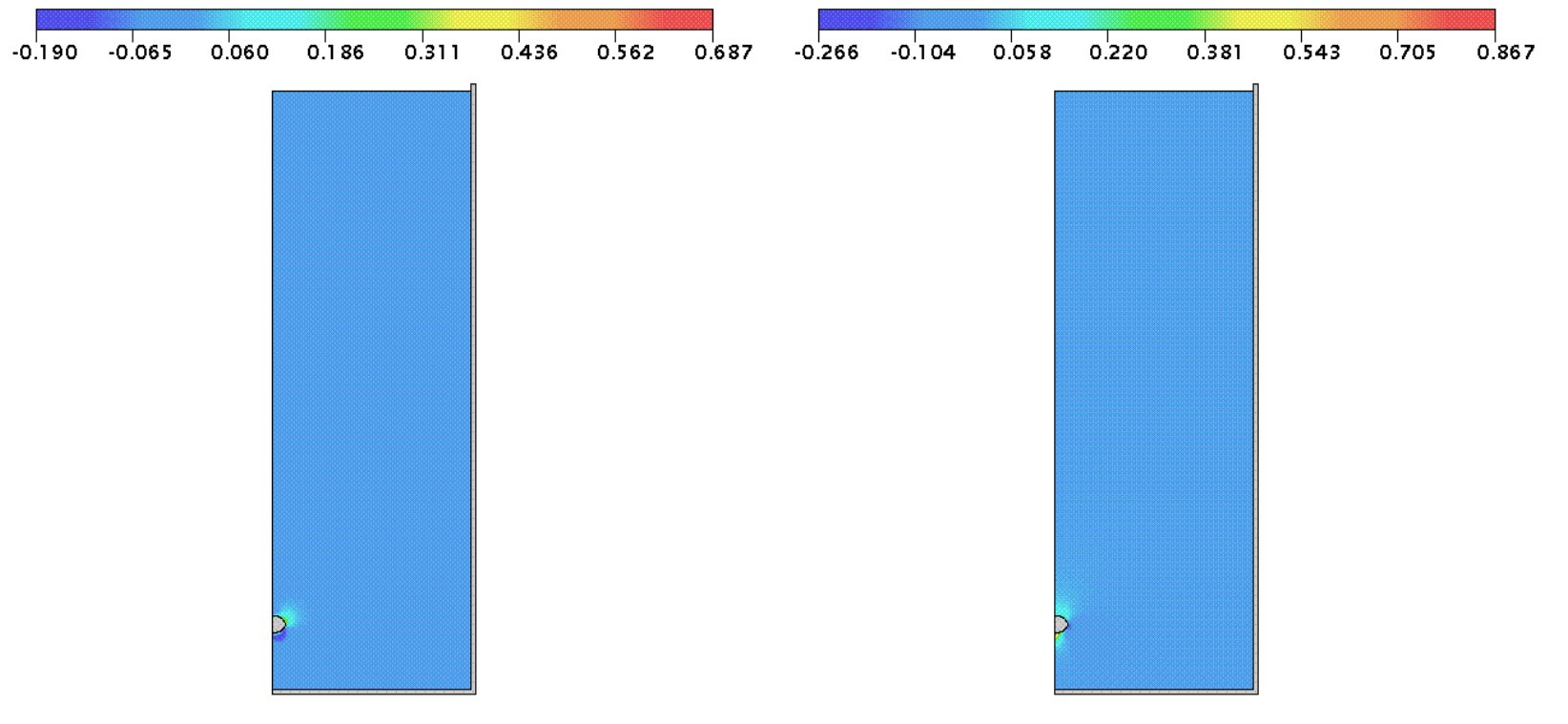

$t=0.01 \mathrm{~s}$

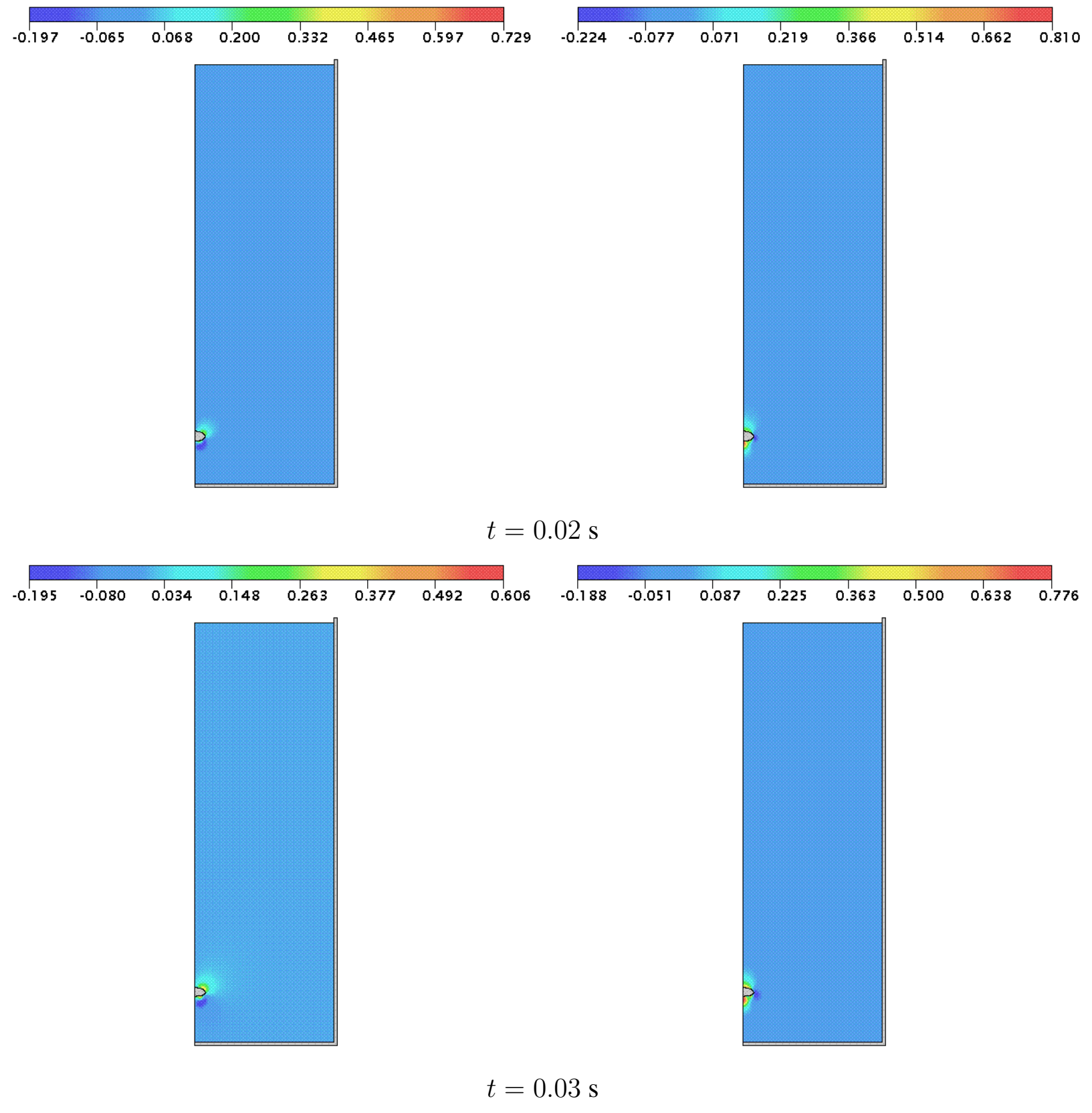




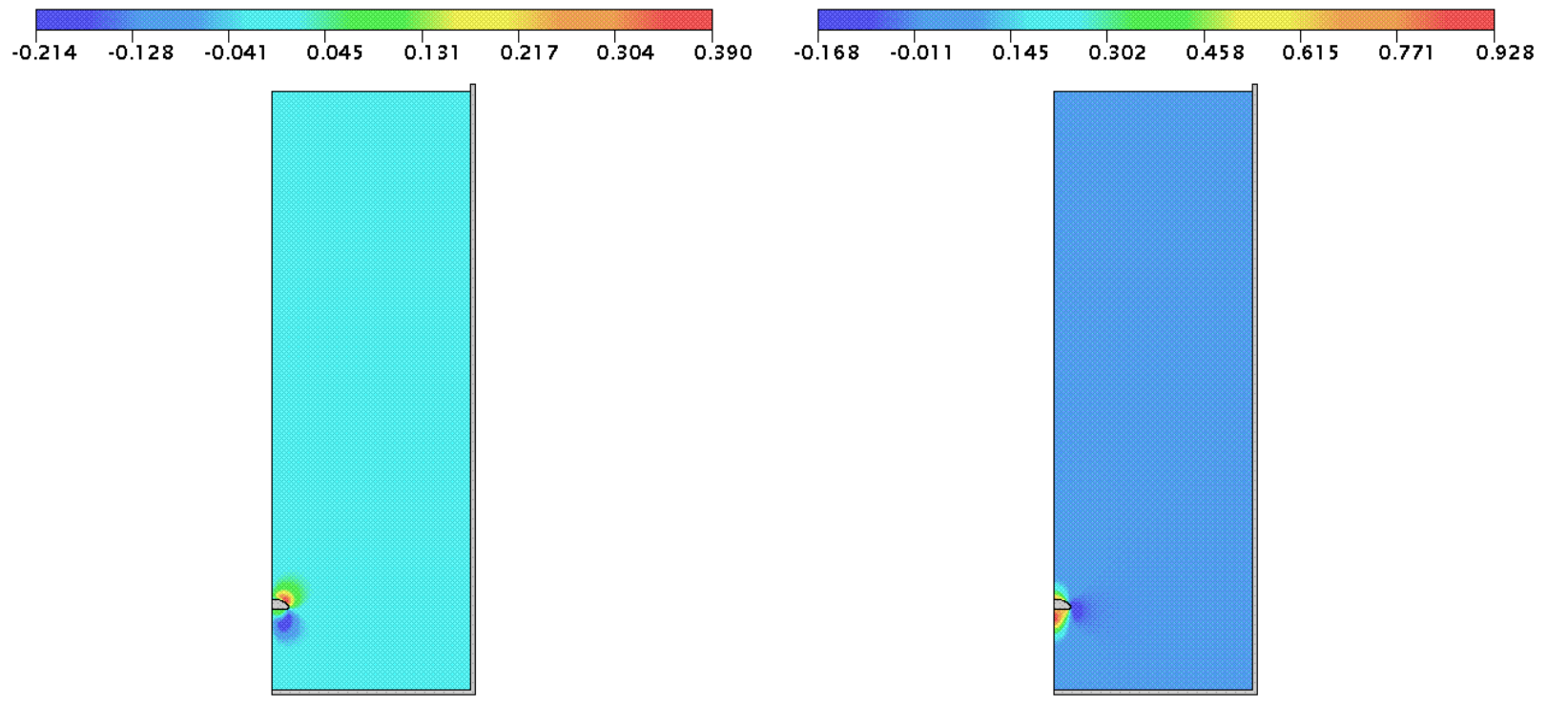

$t=0.07 \mathrm{~s}$

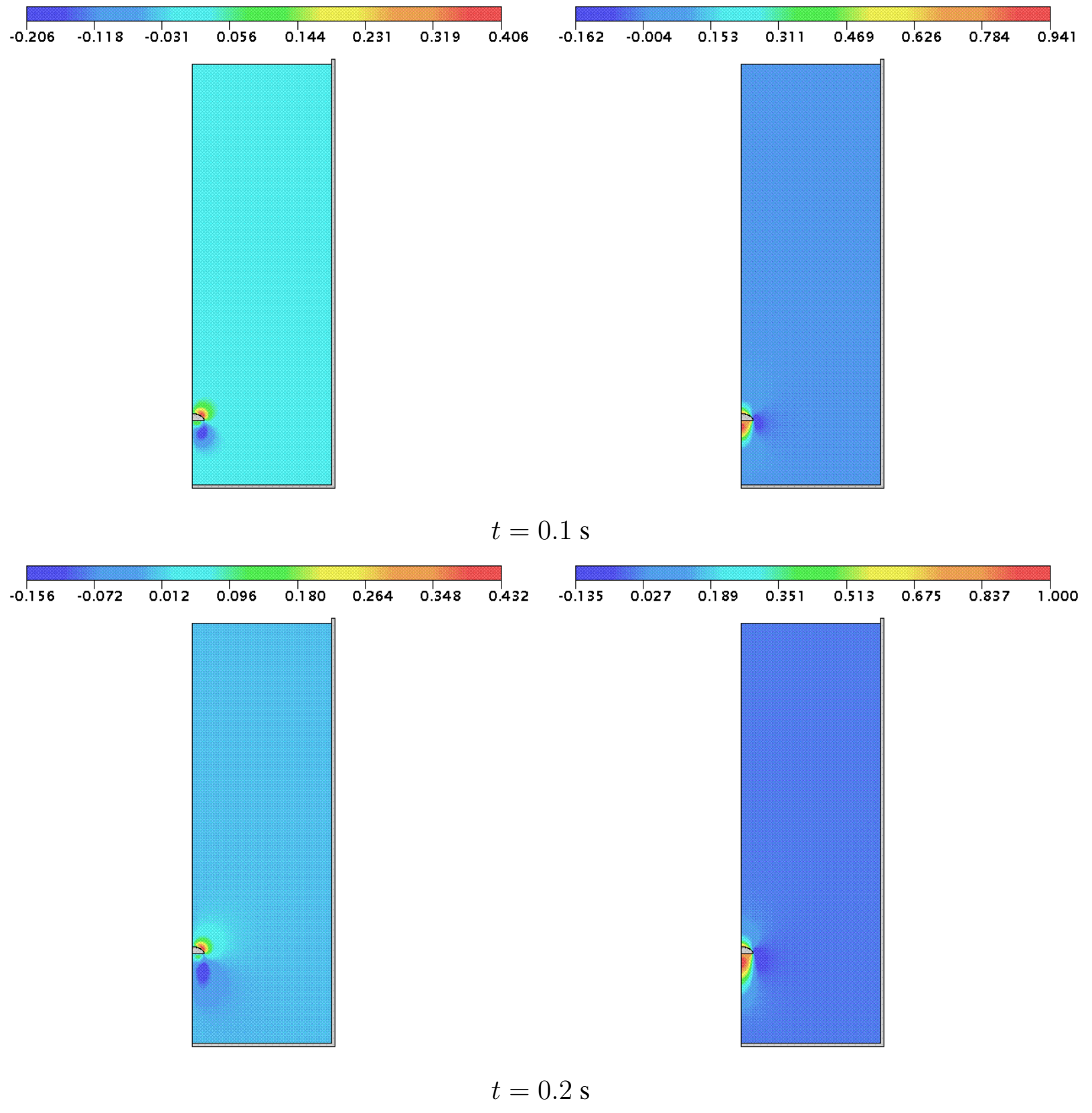



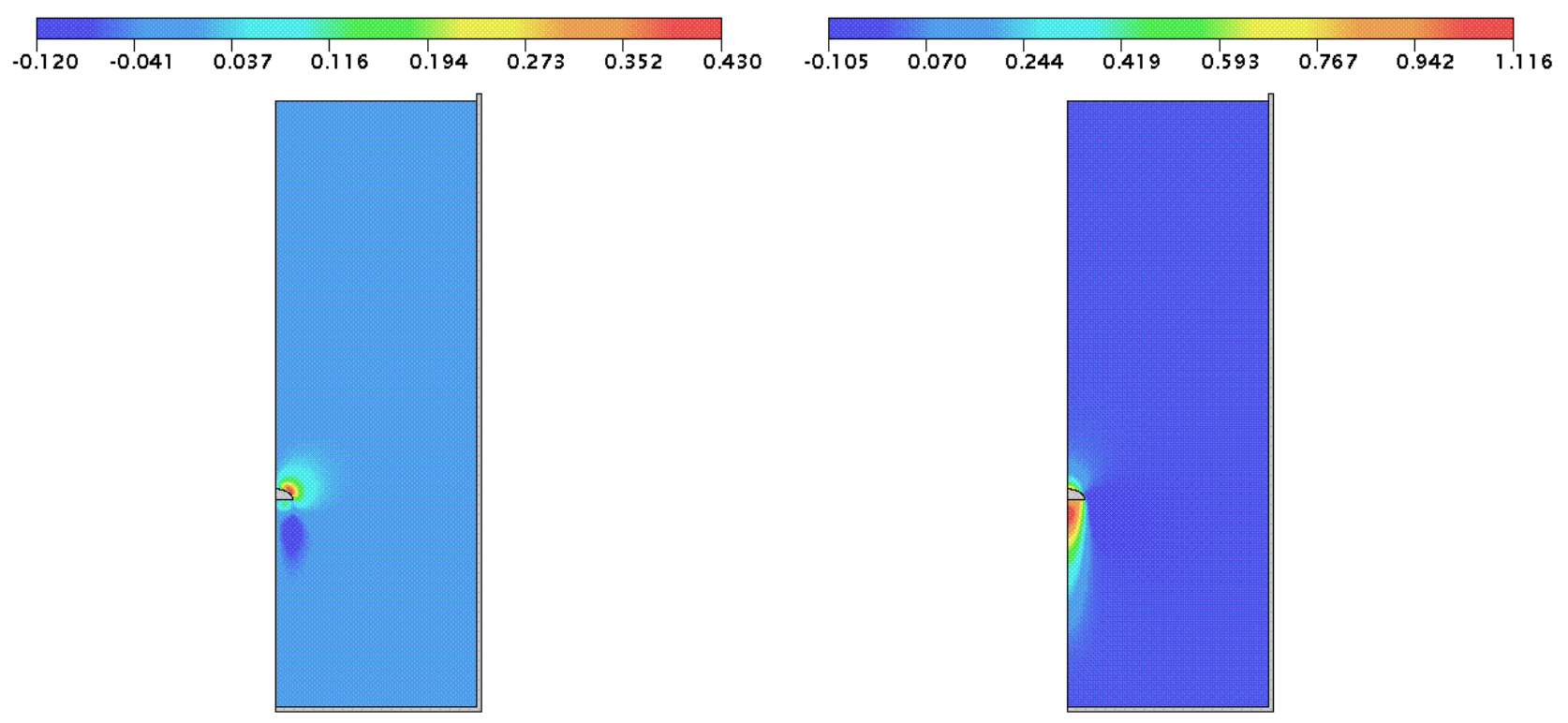

$t=0.4 \mathrm{~s}$

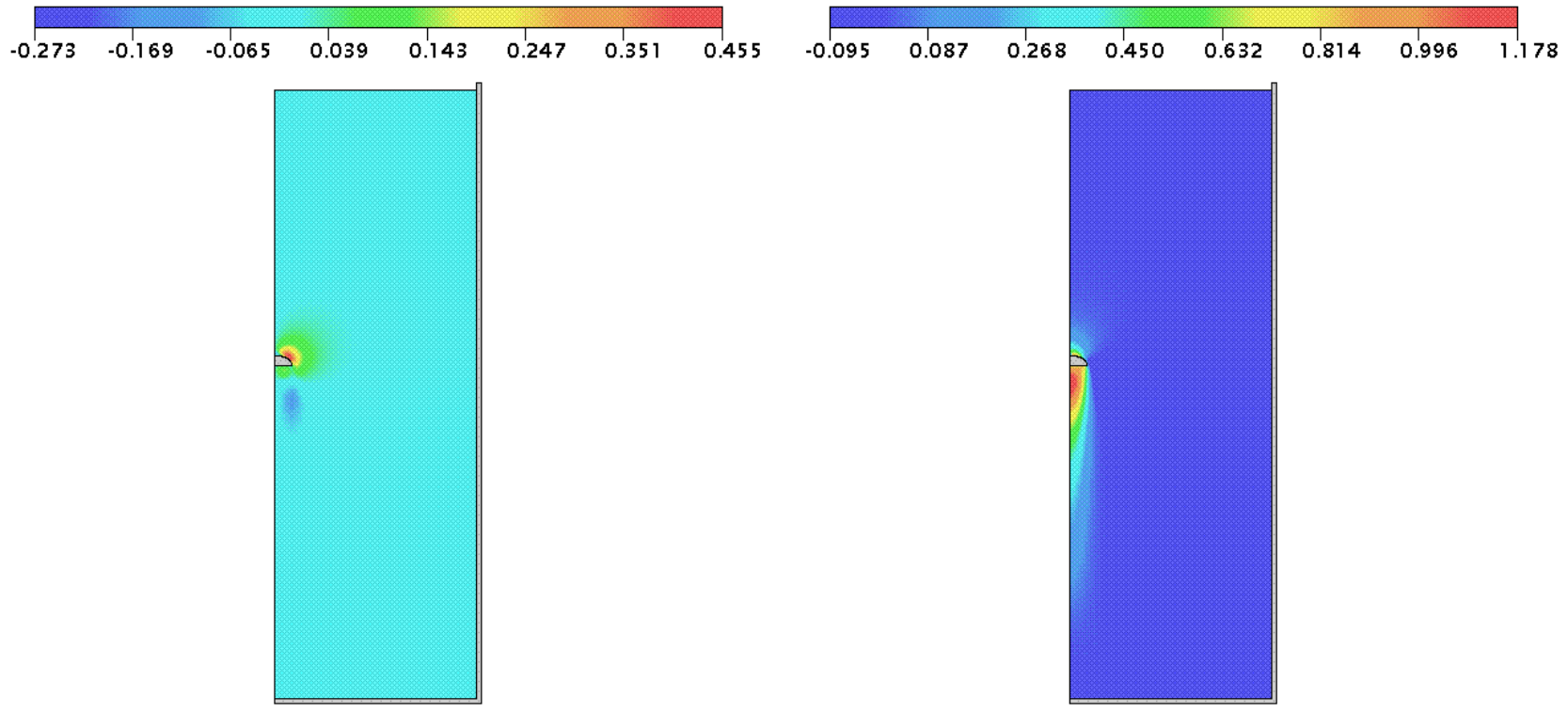

$t=0.7 \mathrm{~s}$

Figura 7.24: Representação das componentes $u$ (esquerda) e $v$ (direita) do vetor velocidade.

Também para este caso, nós utilizamos um campo de pressão natural para o início da simulação. Finalmente, quando o movimento é praticamente uniforme os campos de pressão e velocidades ficam dados como o apresentado na figura 7.25.

Observe que a forma da bolha resulta num mapa de cor, para a velocidade, diferente daqueles outros que nós exibimos anteriormente. Existem valores positivos para a velocidade radial na região inferior da bolha. Os maiores valores da velocidade na direção vertical estão praticamente descolados da parte inferior da bolha. 


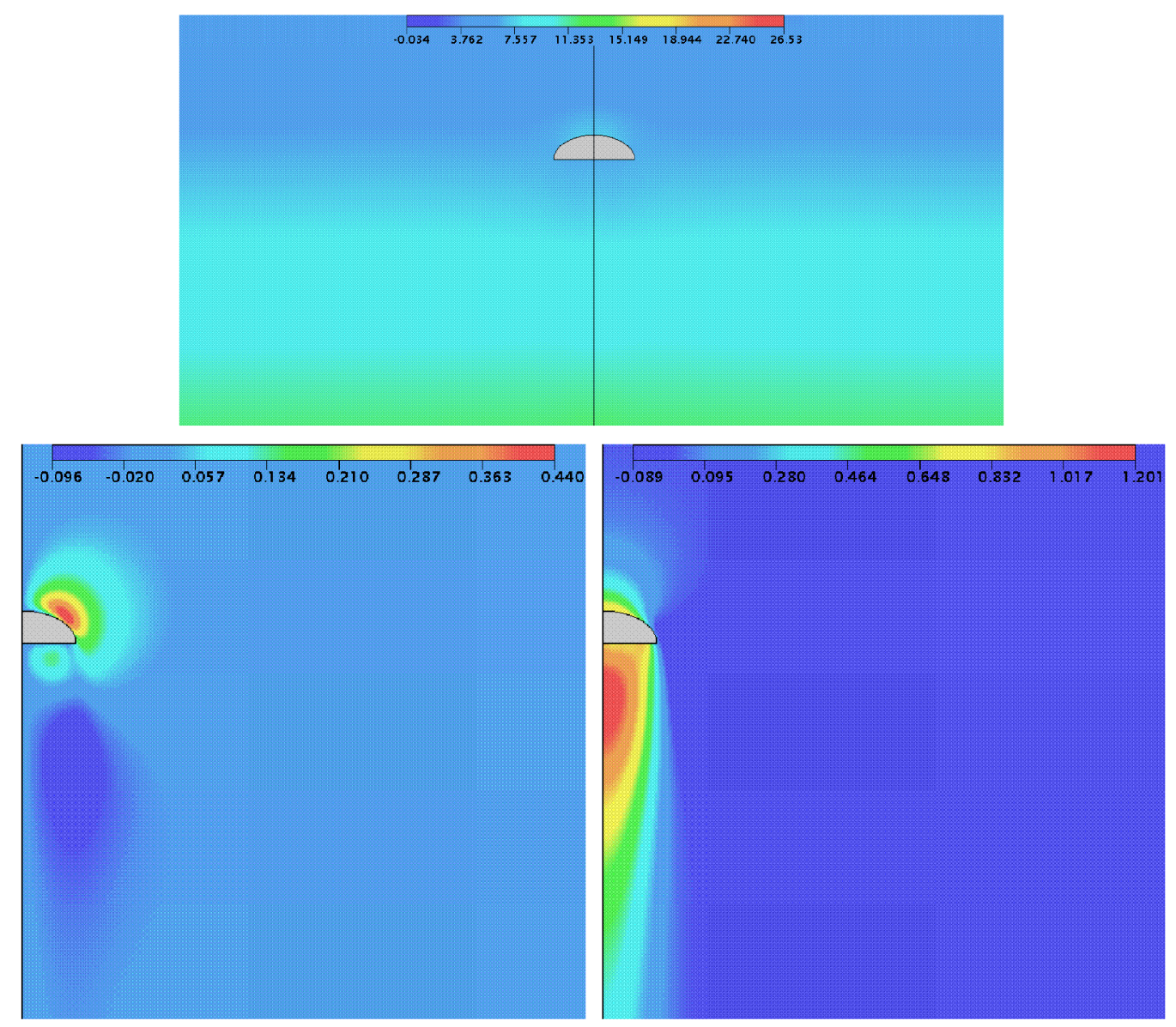

Figura 7.25: Representação do campo de pressão (superior) e das componentes $u$ (esquerda-inferior) e $v$ (direita-inferior) do vetor velocidade no tempo $t=1.0 \mathrm{~s}$.

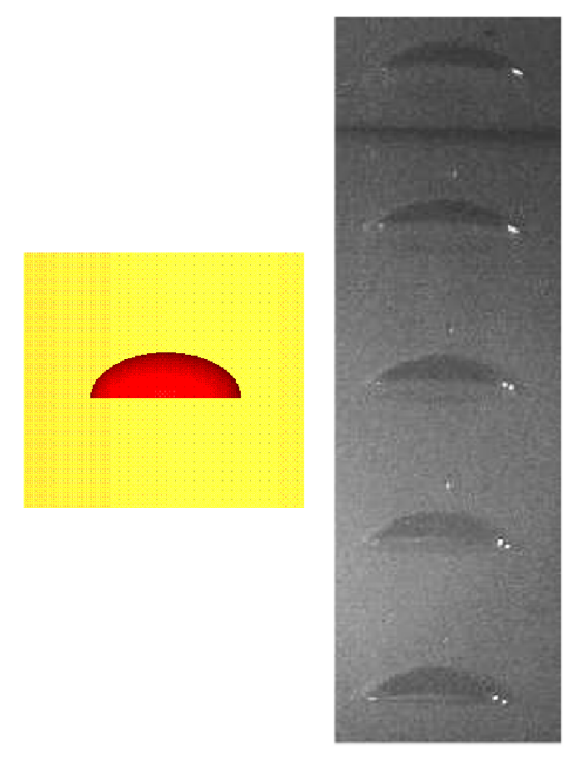

Figura 7.26: Visualização do nosso resultado (esquerda) e formato encontrado por Melo, F. R. G. [77] (direita), da forma final para uma grande bolha de nitrogênio ascendendo em glicerina ${ }_{1}$. 
Na figura 7.26 (esquerda) apresentamos uma visualização por nós calculada no tempo $t=1.0 \mathrm{~s}$, na mesma figura (direita) esboçamos também a forma que Melo, F. R. G. [77] encontrou, onde também cinco momentos distintos (após alcançada a velocidade terminal) são mostrados para enfatizar a trajetória linear do caminho de ascensão. Ainda, a autora obteve experimentalmente a velocidade terminal de 0.36671 e $a=0.01774$, em nossa simulação obtivemos respectivamente os valores 0.363488 e $a=0.015$.

Agora no último caso desta seção, caso $\mathrm{V}$, tratamos da ascensão num meio não-newtoniano. Neste caso o fluido em questão é o sedimento, objeto de estudo neste trabalho de tese, cuja viscosidade é variável ainda para o fluido em estado de quiescência.

O domínio onde efetuamos a simulação é análogo ao core II da figura 4.6, mas com uma pequena extensão contemplando a água praticamente livre de partículas sólidas, figura 7.27. Nesta figura a região compreendida pelo segmento A tem 0.20 metros e B é ajustado tal que verifique as nossas condições sobre o domínio $(R=9 L$ e $h=3 R)$.

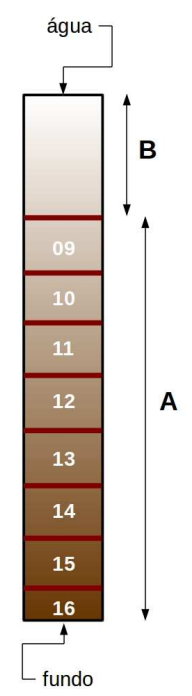

Figura 7.27: Core II com extensão.

A região rotulada por 16 é aquela onde consideramos a maior concentração de material particulado na profundidade 0.20, da equação (4.2) sai $c_{0}=282.5139$. Em contrapartida, acima daquela rotulada por 9 a concentração é considerada nula uma vez que há apenas água.

Nós consideramos ainda em nossas simulações o valor mínimo de 10.0 para a taxa de cisalhamento. Para valores menores do que este a viscosidade se torna muito alta o que inviabiliza a simulação, visto que o número de Reynolds torna-se muito baixo e o nosso modelo apresentou dificuldades na simulação. Sendo assim o campo de viscosidade, equação (4.6), considerado é como o apresentado na figura 7.28 . 


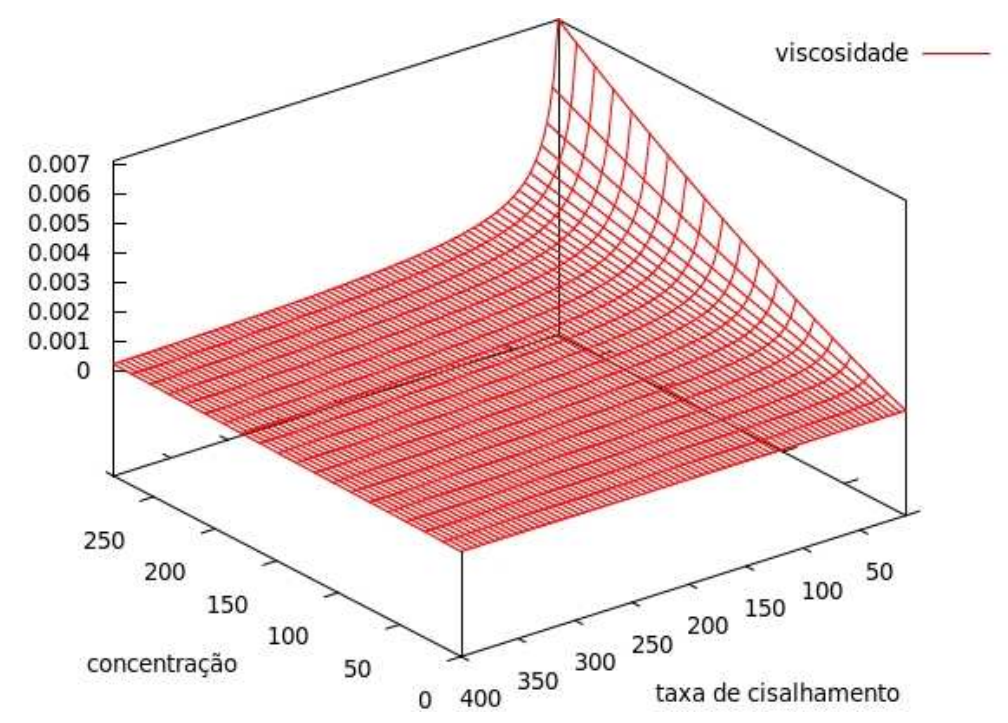

Figura 7.28: Campo de viscosidade.

O terceiro conjunto consiste apenas no modelo S-8. Os dados de entrada estão organizados na tabela 7.3, adicionalmente apresentamos a escala de concentração $c_{0}$. Antes de descrevermos nossos resultados fazemos algumas considerações correlatas a este caso.

\begin{tabular}{|c|c|c|c|c|c|c|c|c|}
\hline \multirow{2}{*}{$\begin{array}{c}\text { Modelo } \\
\text { simulado }\end{array}$} & \multicolumn{8}{|c|}{ Dados de entrada } \\
\cline { 2 - 10 } & $L$ & $U$ & $\nu_{0}$ & $\rho_{c}$ & $\rho_{d}$ & $c_{0}$ & $s_{0}$ & $r_{0}$ \\
\hline \hline S-8 & 0.02 & 0.442944 & 0.007149 & 929.9308 & 1.04 & 282.5139 & 0.18 & 0.01 \\
\hline
\end{tabular}

Tabela 7.3: Tabela de parâmetros de entrada do terceiro conjunto (S-8).

Os pesquisadores Annaland, M. V. S.; Deen, N. G; Kuipers, J. A. M. [8] realizaram um estudo numérico sobre a ascensão de bolhas num sistema gás-líquido-sólido. No trabalho eles apresentaram um modelo matemático combinando as equações de escoamentos multifásicos newtoniana com a segunda lei de Newton para o movimento de partículas sólidas depositada no meio líquido.

No artigo os pesquisadores simularam o movimento de ascensão da bolha induzindo o transporte de partículas sólidas, promovendo um gradiente de concentração do particulado. Além disto, eles quantificaram o efeito retardador sobre a velocidade da bolha neste novo cenário de simulação. Nesta nova dinâmica, eles exibiram seus resultados para vários tempos sob várias quantidades de partículas sólidas em suspensão e o que isto altera o formato da bolha.

Quanto a questão do transporte sedimentar Blinsky, M. et al. [12] qualifica o número de Peclet $(P e)$, equação (3.14), como o admensional que carrega a qualificação do transporte de sedimento. Ou seja, na ausência de fontes o parâmetro $P e$ pode ser útil para classificar tipos de lagos. Lagos muito 
rasos são caracterizados por valores muito pequenos de $P e$ e muito pouco gradiente de concentração é observado. Por outro lado, lagos profundos são caracterizados por valores grandes de $P e$.

Como o número de Schmidt ( $S c$ ), equação (3.13), é decorrente da razão entre Peclet e Reynolds então utilizamos este adimensional para quantificar o coeficiente de difusão neste trabalho de tese. Em todas as nossas simulações com o sedimento modelado admitimos $S c=10000$, que implica em simular casos de lagos com gradiente de concentração significativo. Desta forma, fizemos uma analógia qualitativa entre o nosso resultado com o que Annaland, M. V. S. et al. obtiveram, porquê os problemas são similares.

\section{Caso V}

Admitindo dados de S-8:

$$
R \stackrel{6}{\times} h=0.18 \times 0.54 \quad, \quad M_{5}: 90 \times 270
$$

a evolução do $d t$ ficou conforme o gráfico da figura 7.29. Neste caso temos uma bolha cuja massa a ser deslocada é grande quando comparada aos casos anteriores, sendo assim a velocidade de ascensão também é maior e consequentemente as restrições de estabilidade sobre as equações governantes são mais exigidas, o que exibiu o gráfico da figura citada.

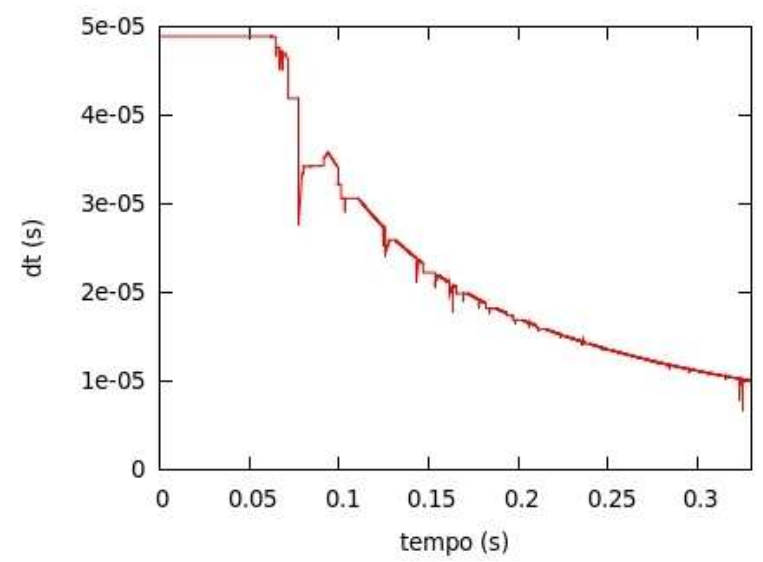

Figura 7.29: Evolução do $d t$.

Os gráficos da velocidade e posição do centro de massa são mostrados na figura 7.30 cujo nosso interesse está em analisar a ascensão nas imediações da interface sedimento/água, até por volta do tempo $t=0.33$.

Observamos que a bolha é inicialmente posicionada em 0.18. Com a crescente evolução da velocidade ela passa pela posição 0.2 (interface sedimento/água) a uma velocidade de 0.146 e permitimos a simulação evoluir até o patamar $t=0.33$, cuja velocidade é próxima de 0.25 na posição 0.217 . 
Note que a velocidade terminal da bolha simulada no caso IV (que difere desta apenas na questão da viscosidade) é ligeiramente maior do que neste caso, então podemos inferir que esta diferença é relacionada ao fato de que os efeitos viscosos são expressivamente maiores. A consequência disto é uma outra evolução para o formato da bolha, neste caso a forma final assumida é ( $E e$ ) (ver figura 4.18).
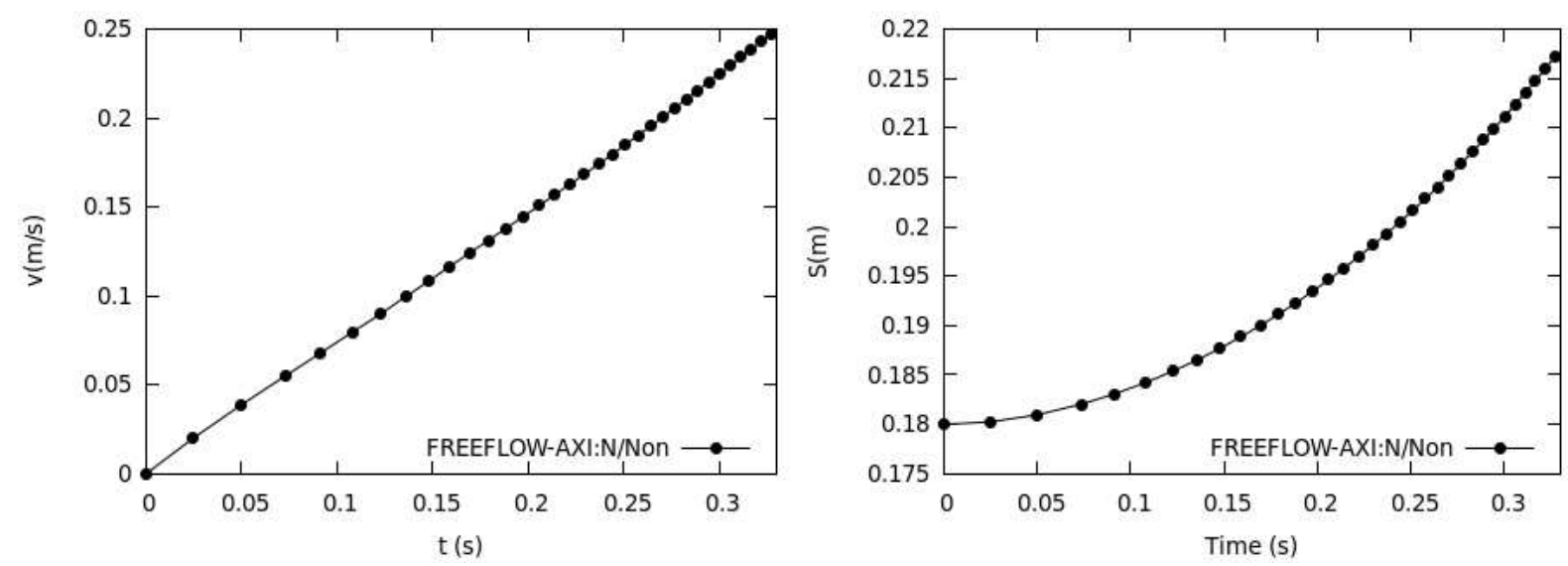

Figura 7.30: Velocidade do centro de massa para uma bolha de nitrogênio no sedimento (esquerda) e posição em função do tempo (direita).

Como pode ser observado no gráfico da figura 7.31 o sedimento atua de forma diferenciada nos parâmetros $b_{1}, b_{2}$ e $a$. O valor $b_{2}$ decresce muito mais que $b_{1}$, ao passo que $a$ aumenta para preservar o volume da bolha. Até por volta de $t=0.05$ o formato é elipsoidal, após este tempo a evolução dos parâmetros de forma levam a bolha a assumir a forma final elíptica calombada $(E e)$.

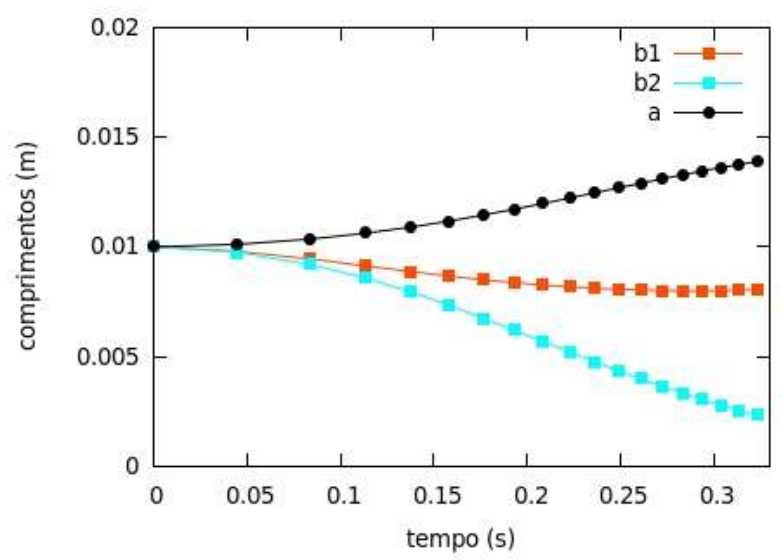

Figura 7.31: Evolução dos valores $b_{1}, b_{2}$ e $a$ para uma bolha de nitrogênio ascendendo no sedimento.

Exibimos a seguir alguns campos de velocidade (adimensional) na figura 7.32. Note que a bolha muda a sua forma até obter um formato próximo do elipsoidal em $t=0.1$. Porém, por volta de 
$t=0.2$ a forma $(E e)$ vai sendo mais evidenciada. Observe ainda que nos dois tempos exibidos os campos de velocidade são substancialmente diferentes, este fato é devido a constante mudança de forma e a variação da viscosidade do fluido.
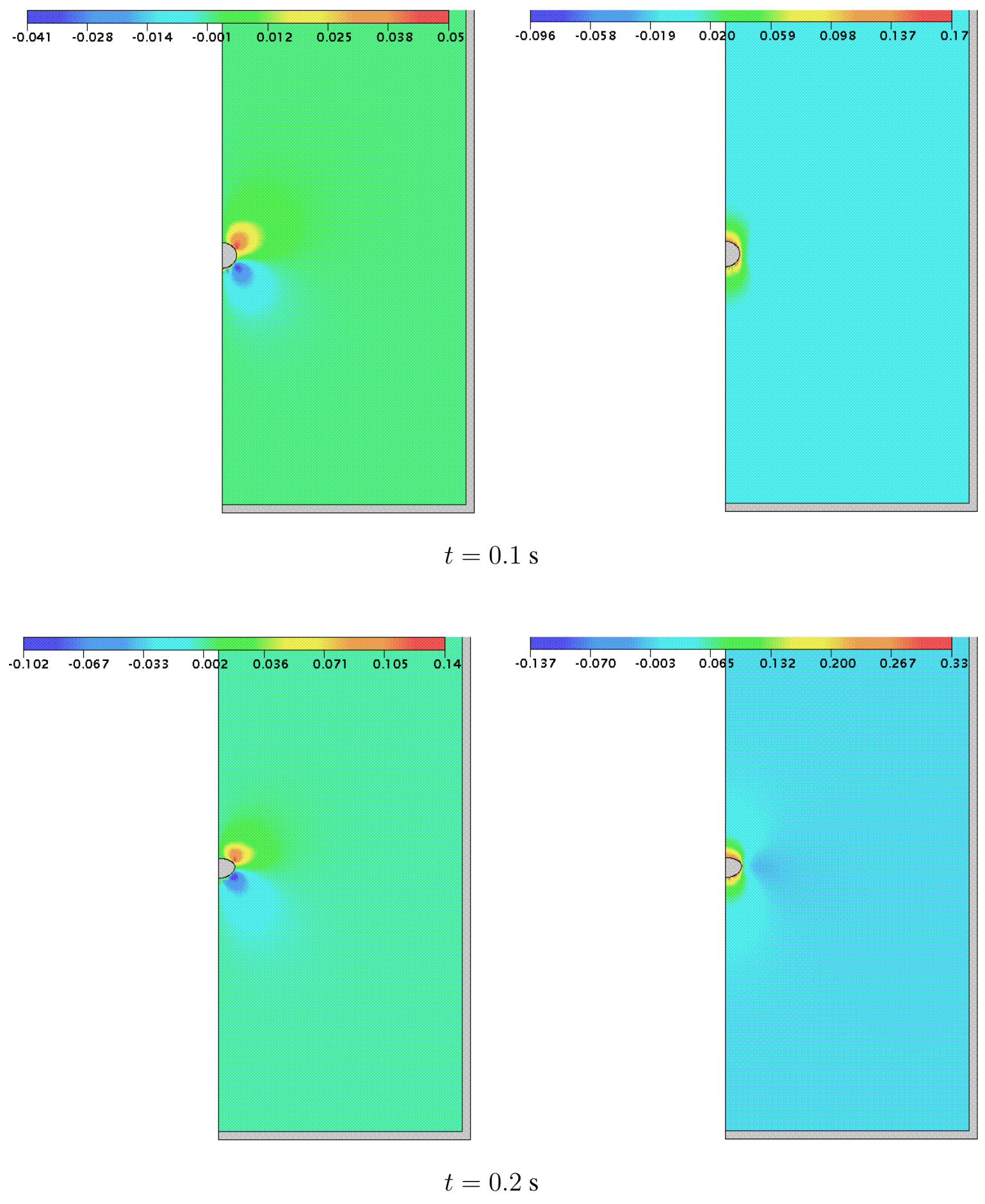

Figura 7.32: Representação das componentes $u$ (esquerda) e $v$ (direita) do vetor velocidade.

Também para este caso, nós utilizamos um campo de pressão natural para o início da simulação análogo àqueles que já mostramos anteriormente. O campo de velocidades para o tempo $t=0.33$ 
é mostrado na figura 7.33. Neste tempo a forma $(E e)$ está completamente desenvolvida. Este caso também mostra um mapa de cor diferenciado para a velocidade. Chamamos a atenção para a região abaixo da bolha. Note que os valores negativos para a velocidade radial e o campo não tão desenvolvido para a componente vertical (quando comparado aos casos anteriores) são devidos ao arrasto de particulado que altera consideravelmente a viscosidade.
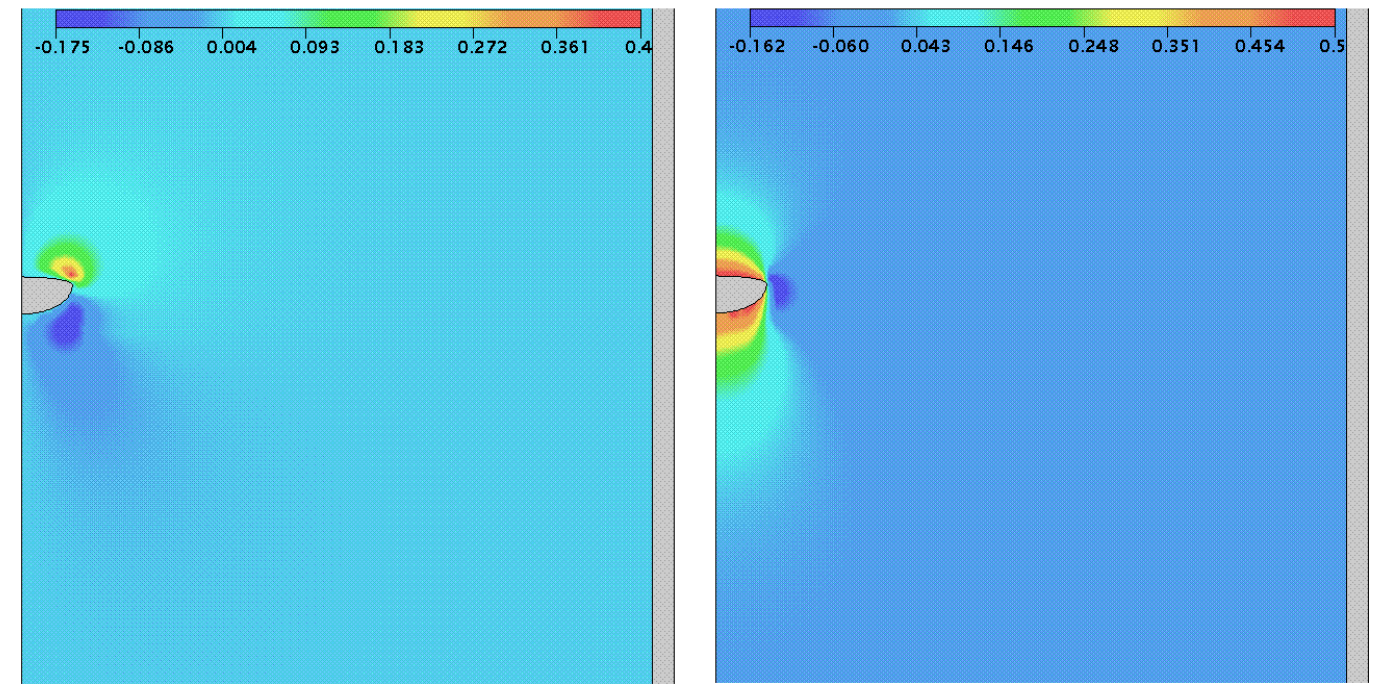

Figura 7.33: Representação das componentes $u$ (esquerda) e $v$ (direita) do vetor velocidade no tempo $t=0.33 \mathrm{~s}$.

Já para o campo de concentração adimensional temos a sua evolução conforme o gráfico da figura 7.34. Veja que o movimento de ascensão produz arrasto de particulado. O arrasto induz a diminuição da velocidade terminal.
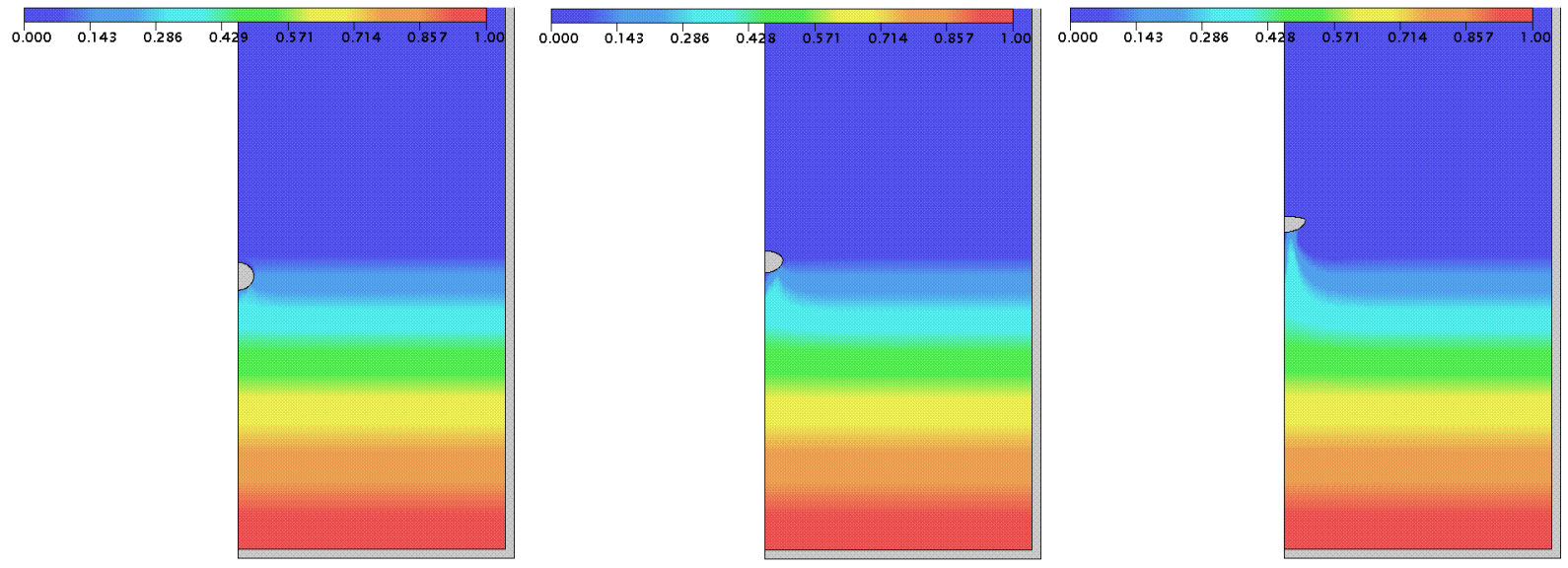

Figura 7.34: Representação do campo de concentração nos tempos $t=0.1 \mathrm{~s}$ (esquerda) e $t=0.2 \mathrm{~s}$ (centro) e $t=0.33 \mathrm{~s}$ (direita).

Quanto a viscosidade adimensional, mostramos seu gráfico na figura 7.35. Como a região de 
esteira (ver figura 7.33, por exemplo) é aquela onde ocorrem os maiores valores da taxa de cisalhamento e nesta região temos o arrasto de material sedimentar, então na esteira o campo de viscosidade é similar ao da concentração e isto auxilía a mudança de forma da bolha.
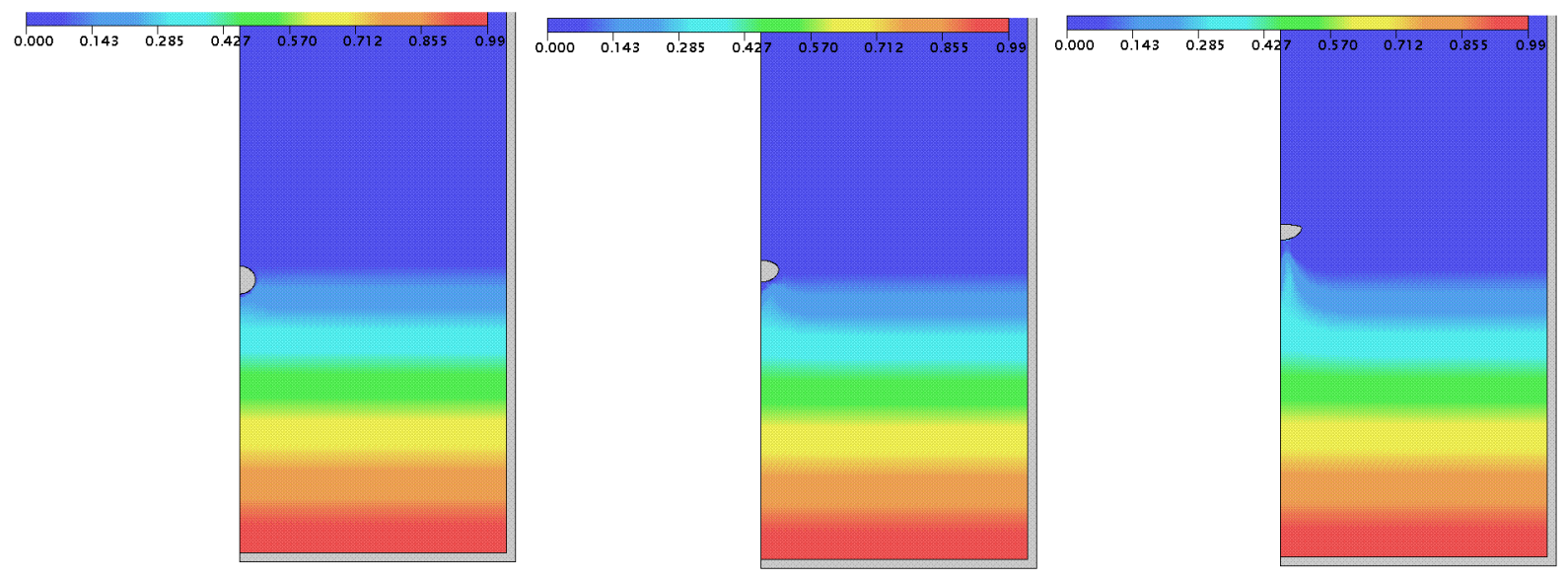

Figura 7.35: Representação do campo de viscosidade nos tempos $t=0.1 \mathrm{~s}$ (esquerda) e $t=0.2 \mathrm{~s}$ (centro) e $t=0.33 \mathrm{~s}$ (direta).

Em fim, a viscosidade atua na intenção de obstruir o movimento da bolha, mas como a força de empuxo é relevante isto causa o movimento, consequentemente, o arrasto de partículas sedimentares. Como a tensão superficial é suficiente para manter a integridade da bolha, então o resultado de todas estas atuações é a alteração da forma para o aspecto elíptico calombado ( $E e)$.
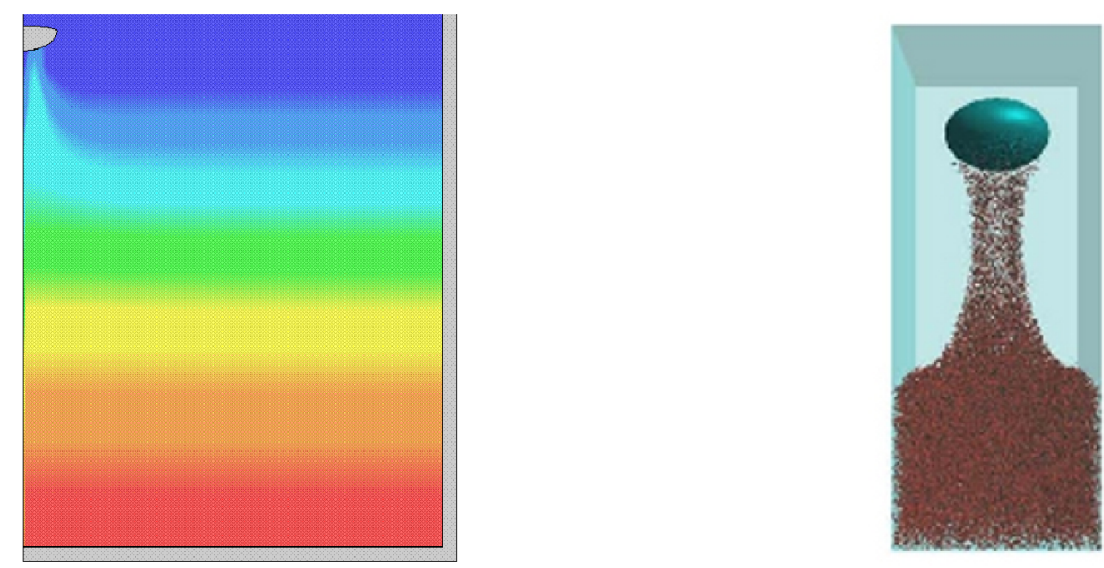

Figura 7.36: Comparação qualitativa caso V (esquerda) e Annaland, M. V. S. et al. [8] (direita).

Na figura 7.36 chamamos a atenção para o mesmo comportamento, quanto a ascensão da bolha e transporte de sedimento, entre o nosso resultado e aquele obtido por Annaland, M. V. S. et al. A esquerda mostramos uma vista mais aproximada do campo de concentração no tempo $t=0.33 \mathrm{~s}$, na direita está o resultado para bolha de diâmetro $L=0.02$. 


\subsection{Aplicação em Reservatórios Hidráulicos}

Lembramos ao leitor que em geral um reservatório hidráulico é formado a partir da obstrução do fluxo natural de um rio reduzindo a sua capacidade de transporte do sedimento. Da redução, surge o processo de sedimentação da matéria orgânica suspensa e este fenômeno pode resultar em condições favoráveis à metanogênese. Se o leito tem matérial orgânico em alta taxa de produção de metano e esta excede a de difusão vertical, isto leva a formação das bolhas de metano.

\begin{tabular}{|c|c|c|c|c|c|c|c|c|}
\hline \multirow{2}{*}{$\begin{array}{c}\text { Modelos } \\
\text { simulados }\end{array}$} & \multicolumn{7}{|c|}{ Dados de entrada } \\
\cline { 2 - 9 } & $L$ & $U$ & $\nu_{0}$ & $\rho_{c}$ & $\rho_{d}$ & $c_{0}$ & $s_{0}$ & $r_{0}$ \\
\hline \hline S-4 & 0.001 & 0.099045 & 0.0000013 & 997.0 & 0.717 & 0.0 & 0.003 & 0.0005 \\
\hline \hline S-9 & 0.02 & 0.442944 & 0.007149 & 929.9308 & 0.717 & 282.5139 & 0.18 & 0.01 \\
\hline \hline S-10 & 0.03 & 0.542494 & 0.007149 & 929.9308 & 0.717 & 282.5139 & 0.175 & 0.015 \\
\hline \hline S-11 & 0.05 & 0.700357 & 0.007149 & 929.9308 & 0.717 & 282.5139 & 0.175 & 0.025 \\
\hline
\end{tabular}

Tabela 7.4: Tabela de parâmetros de entrada do quarto conjunto de simulações.

O processo Físico-Químico-Biológico citado no parágrafo acima não foi modelado nesta tese, nós partimos da existência de uma bolha de gás de metano no formato esférico já constituída. O nosso trabalho foi modelar e resolver alguns casos via modelagem Matemática-Computacional, cujos resultados são detalhados a seguir. O quarto conjunto de simulações consiste dos modelos com os parâmetros apresentados na tabela 7.4.

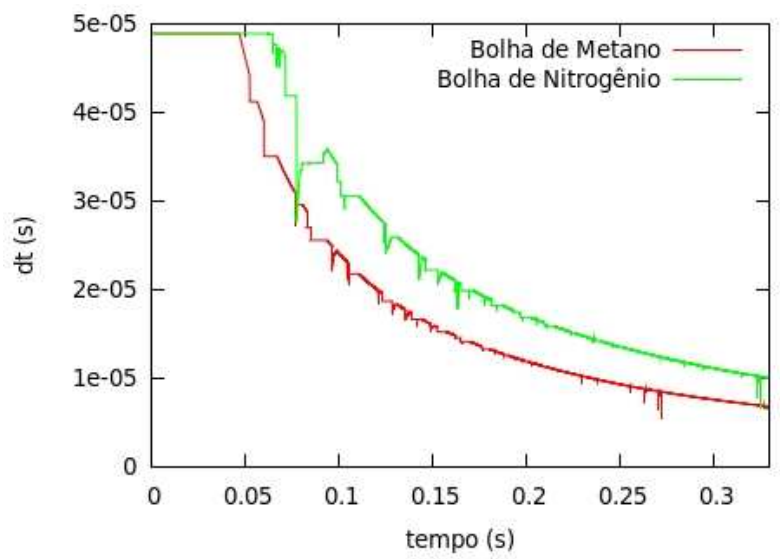

Figura 7.37: Evolução do $d t$.

Considerando o modelo S-9 no domínio $R \stackrel{6}{\times} h$ na malha $M_{5}$ e comparando-o àquele do caso V, temos que ambos diferem apenas na caracterização da fase dispersa. Como o metano apresenta menor 
valor para a densidade em relação ao nitrogênio, então desta diferença temos implicações relevantes sobre o comportamento de ascensão da bolha. Desta forma fazemos algumas considerações sobre a bolha de metano a partir dos resultados conhecidos do caso V.

A evolução de $d t$ em nossas simulações é esboçada na figura 7.37. Observe que a simulação com o metano é mais restritiva do que com o nitrogênio, mas o padrão de $d t$ para ambos é similar.
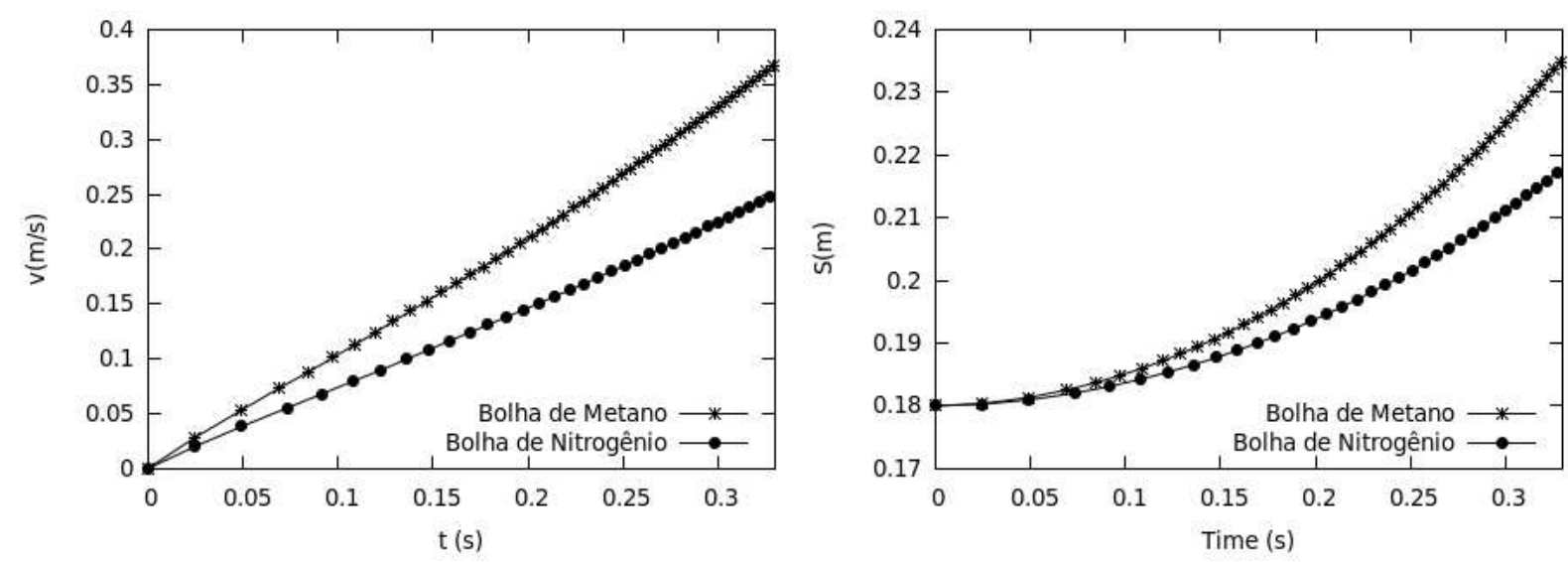

Figura 7.38: Velocidade do centro de massa para a bolha de metano e de nitrogênio no sedimento (esquerda) e posição em função do tempo (direita).

Os gráficos da velocidade e posição do centro de massa são mostrados na figura 7.38. Atente que a diferença de densidade implica que a bolha de metano ascende em maior velocidade do que a de nitrogênio. Inicialmente as bolhas são posicionadas em 0.18 , passados $t=0.33$ s quantificamos que a bolha de metano tem sua velocidade $44 \%$ maior e que a posição é $8.3 \%$ a mais na comparação com a bolha de nitrogênio.

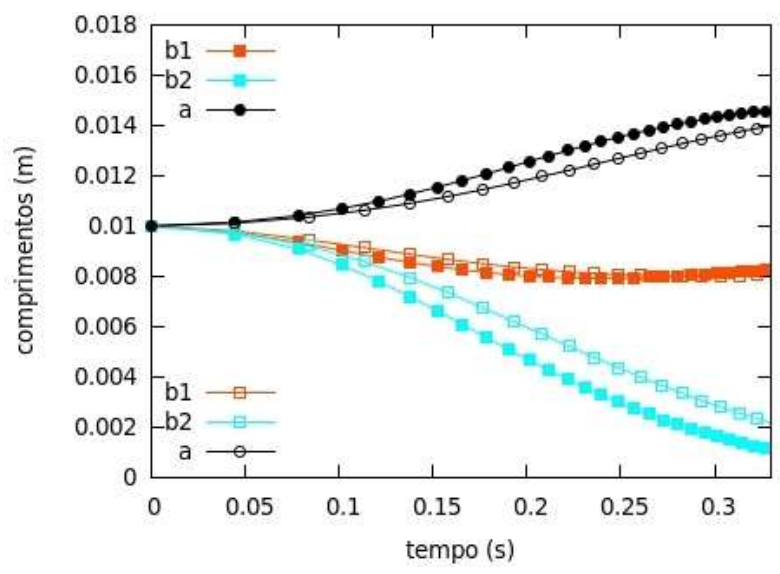

Figura 7.39: Evolução dos valores $b_{1}, b_{2}$ e $a$ para bolhas de metano (símbolos fechados) e nitrogênio (símbolos abertos) ascendendo no sedimento. 
Como pode ser constatado no gráfico da figura 7.39 o sedimento atua diferentemente nos parâmetros $b_{1}, b_{2}$ e $a$ para as bolhas. No gráfico, os valores $b_{1}, b_{2}$ e $a$ representados por símbolos abertos são com respeito a bolha de nitrogênio e os fechados em relação a de metano. A variação nos parâmetros de forma seguem a mesma tendência para ambos os tipos de bolhas, saem inicialmente do tipo esférico passando pelo formato elipsoidal e finalmente assumem a forma elíptica calombada ( $E e)$.
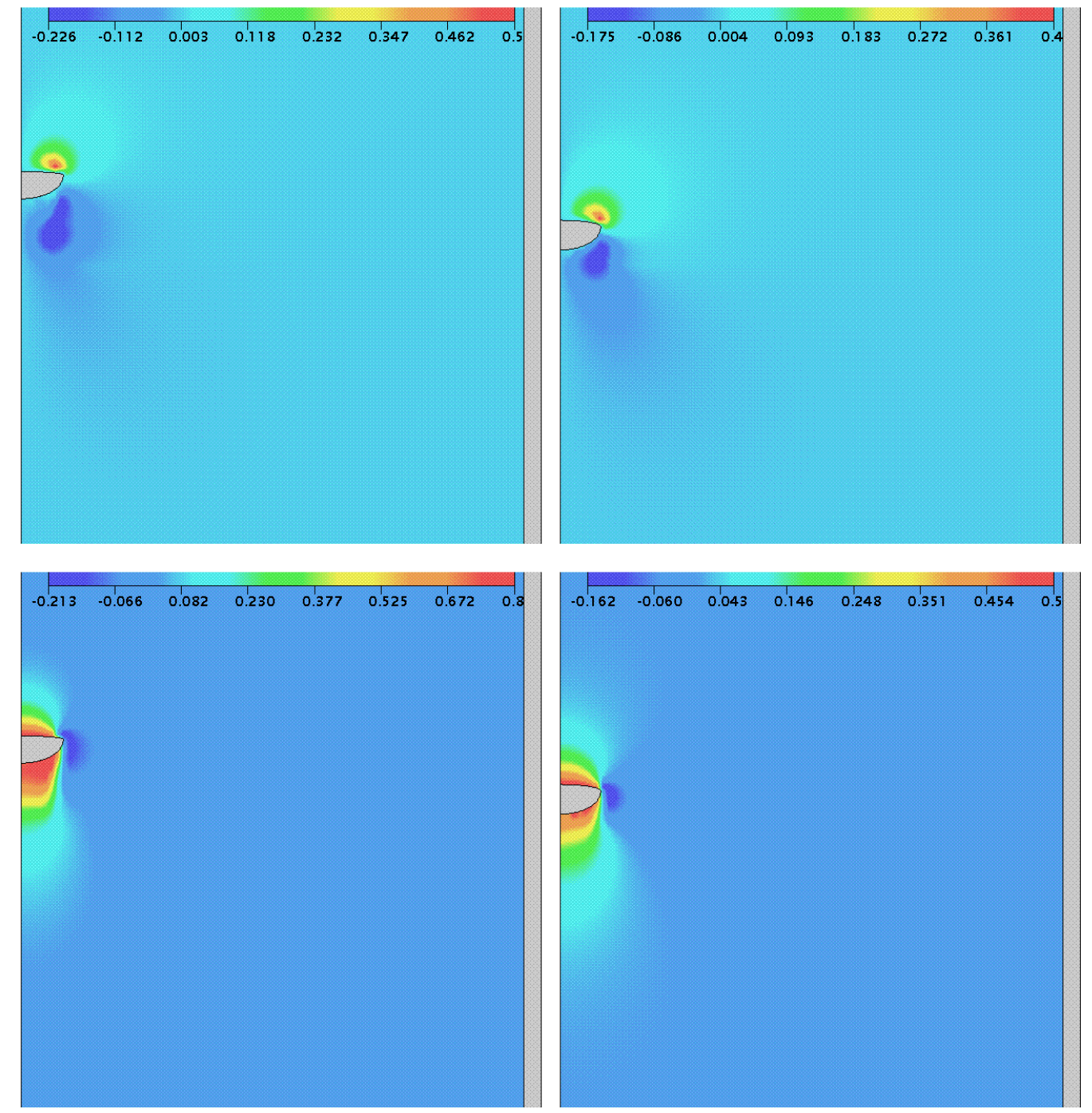

Figura 7.40: Representação das componentes $u$ (superior) e $v$ (inferior) do vetor velocidade no tempo $t=0.33 \mathrm{~s}$.

Na figura 7.40 mostramos os campos de velocidades no tempo $t=0.33 \mathrm{~s}$ para ambas as bolhas. $\mathrm{Na}$ esquerda as componentes $u$ (superior) e $v$ (inferior) da bolha de metano e na direita o campo da bolha de nitrogênio. Como a bolha de metano sobe a uma maior velocidade então a mesma perturba uma região maior de fluido e em maior magnitude. Percebemos que isto fez com que o gradiente conjugado necessitasse de mais iterações para a convergência. O SDPUS-C1 mostrou-se versátil na resolução deste problema, uma vez que os divergentes médios para células dos tipos F/S estiveram 
em patamares por nós aceitável.
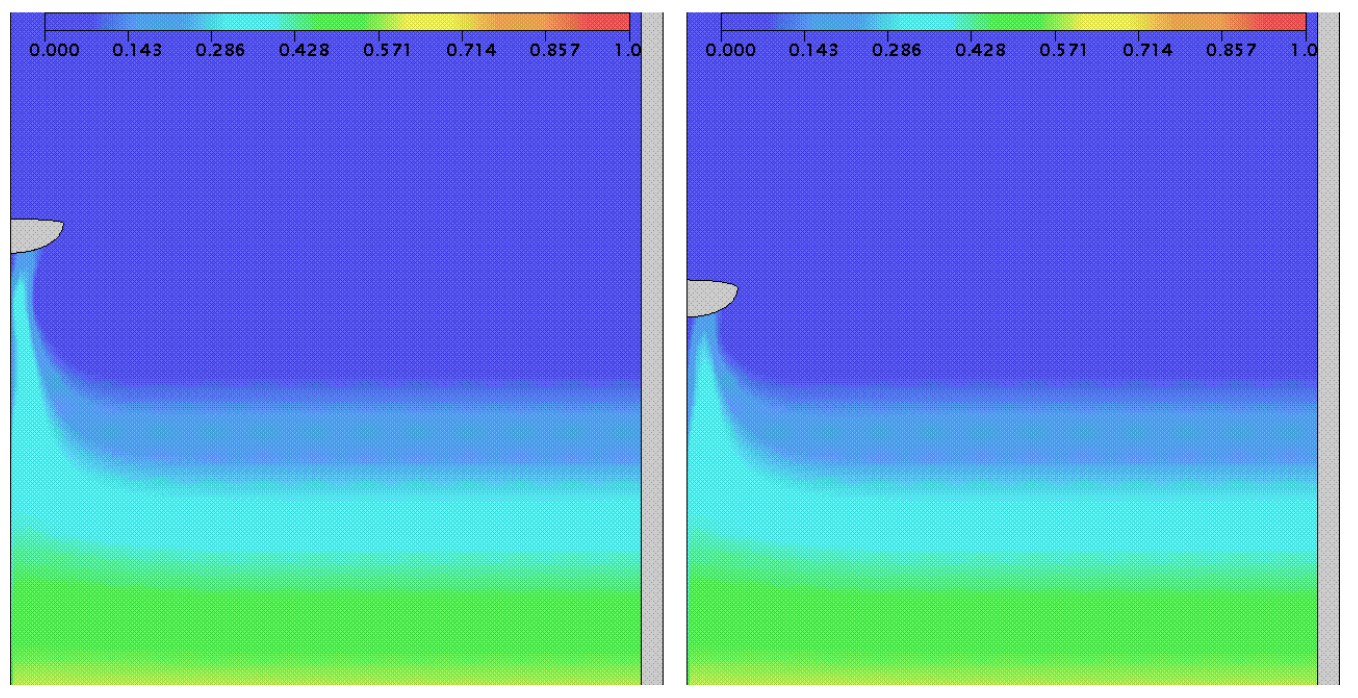

Figura 7.41: Representação do campo de concentração no tempo $t=0.33 \mathrm{~s}$ das bolhas de metano (esquerda) e nitrogênio (direta).

Note que a diferença substancial na velocidade leva a regiões de esteira bem diferentes, este fato tem forte influência no transporte de material sólido como pode ser visto na figura 7.41. Veja que a bolha de metano deixa a região de transporte mais alongada.
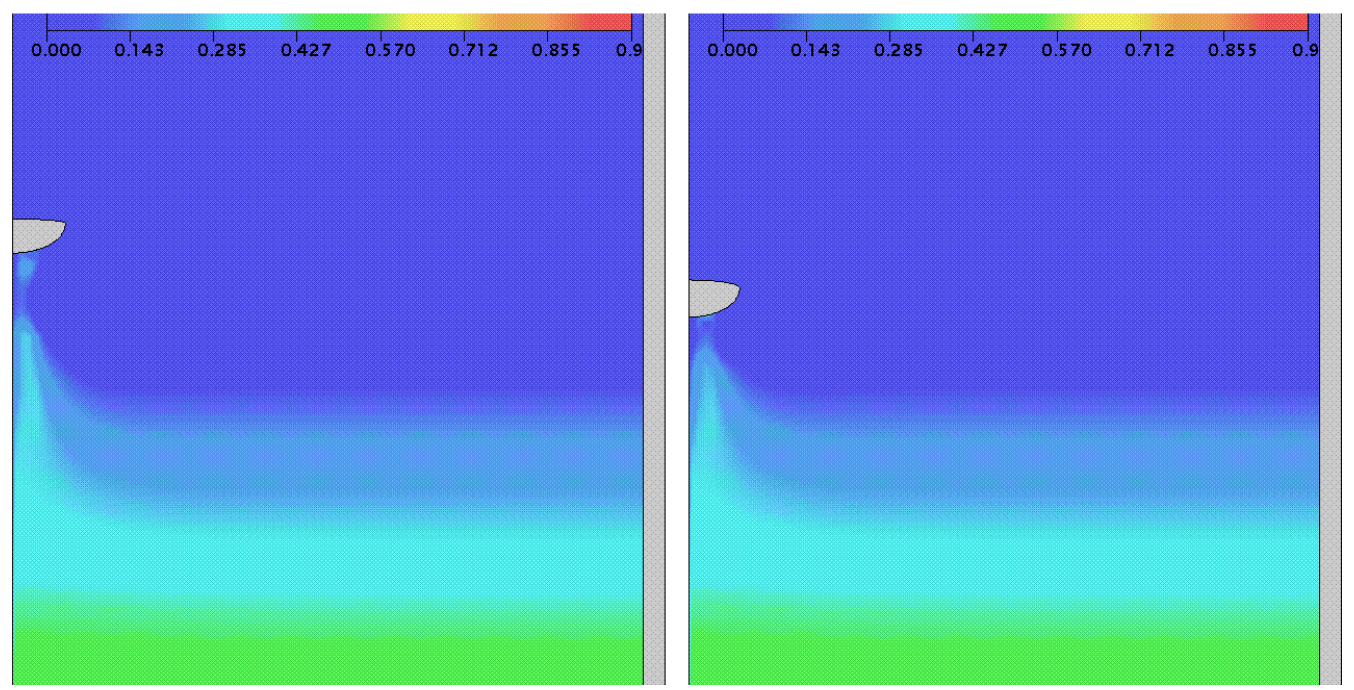

Figura 7.42: Representação do campo de viscosidade no tempo $t=0.33 \mathrm{~s}$ das bolhas de metano (esquerda) e nitrogênio (direta).

Quanto a viscosidade mostramos seu gráfico na figura 7.42. Como a região de esteira da bolha de metano é maior do que aquela da bolha de nitrogênio isto se reflete também no campo de viscosidade. Se a bolha de metano ascende a uma velocidade maior do que a de nitrogênio vemos que a mesma 
ainda transporta uma pequena quantidade de partículas sólidas, logo abaixo de si, alterando sensivelmente a viscosidade neste lugar. Isto contribuiu para aumentar o valor de $b_{1}$ nas proximidades do tempo $t=0.33$ (veja a figura 7.39).

Como o gás carbônico e o metano são os gases de efeito estufa mais comuns, e uma vez que a razão entre suas densidades é cerca de 2.75 (sob mesmas condições de temperatura e pressão), podemos dizer que o metano teria mais facilidade de desprendimento do sedimento do que o gás carbônico. Pois a razão de densidades entre o nitrogênio e o metano é próxima de 1.45.

Para analisarmos a influência do aumento de volume da bolha de metano no seu movimento, na região da interface sedimento/água, admitimos os modelos S-10 e S-11 nos respectivos domínios $R \stackrel{7}{\times} h=0.27 \times 0.81$ e $R \stackrel{8}{\times} h=0.45 \times 1.35$ na malha $M_{5}$. Sob estes dados as simulações foram tais que os divergentes médios das células $F / S$ foram da mesma ordem do caso V.

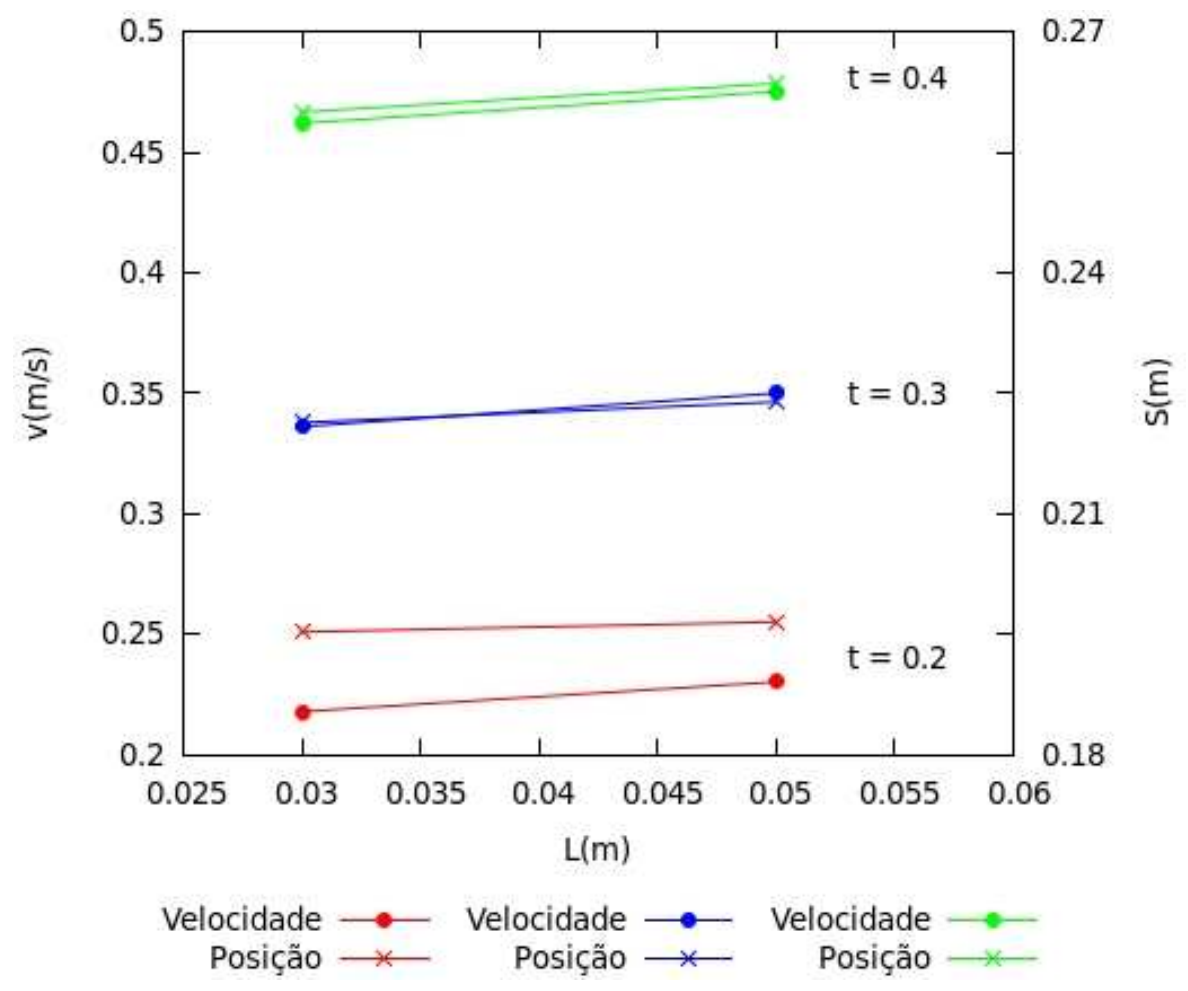

Figura 7.43: Representação da velocidade e posição no tempo em três momentos distintos para bolhas de metano nos diâmetros $L=0.03$ e $L=0.05$.

Evidentemente as bolhas dos modelos mencionados no parágrafo acima apresentaram velocidades de ascensão maiores, uma em relação a outra, e igualmente para a posição como está ilustrado na figura 7.43. Por exemplo no tempo $t=0.2$, um aumento em $66,6 \%$ no diâmetro (passando de 0.03 para 0.05 ) levou aos acréscimos de $5.64 \%$ na velocidade e $0.63 \%$ na posição.

Na figura 7.44 mostramos os campos de velocidades, concentração e viscosidade no tempo $t=0.4$ 
para bolha com diâmetro 0.03 e de modo análogo para aquela de diâmetro 0.05. Primeiramente observe que os formatos das bolhas são bem distintos, a bolha maior possui mais área de contato com o fluido do que a bolha menor, então a inércia a ser vencida para produzir a mudança de forma é mais lenta na bolha maior, uma vez que ela possui mais massa e tem contato com o fluido não-newtoniano em valores de maior magnitude da viscosidade. Mas os campos de velocidades apresentaram-se com o mesmo tipo de comportamento, formando a esteira das bolhas.

Por outro lado, o arasto de cada uma das bolhas movimenta quantidades diferenciadas de material sedimentar para concentrações também diferentes. A bolha maior movimenta particulado de regiões mais profundas de seu domínio onde o fluido é mais viscoso, observe os mapas de cor dos dois casos. Este fenômeno aliado a taxa de cisalhamento, que assume os campos da figura 7.45, dão como resultado os campos de viscosidade mostrados na figura 7.44 .





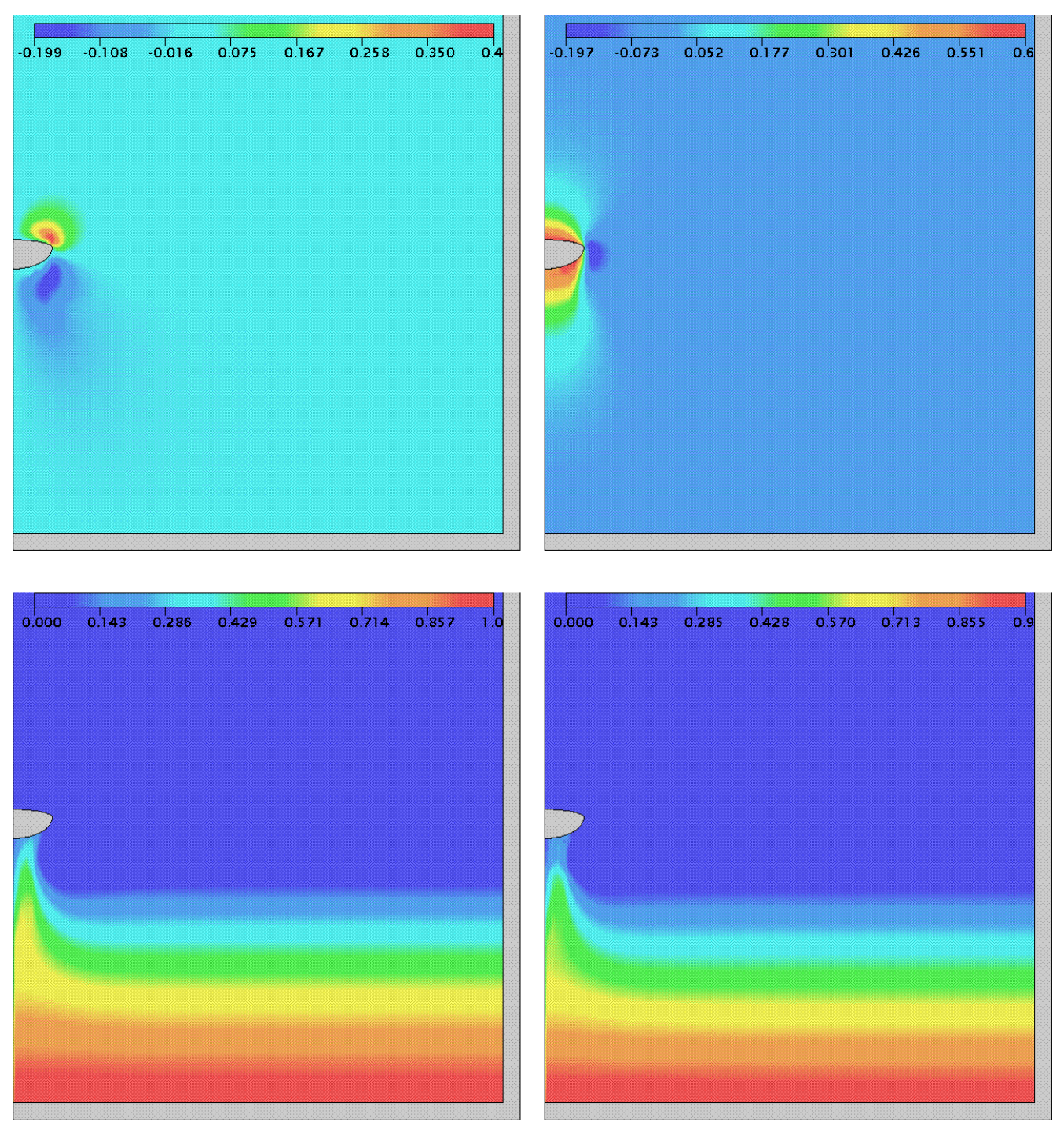

$$
L=0.05
$$

Figura 7.44: Representação das componentes $u$ e $v$ (superior-esquerda/direita) e dos campos de concentração e viscosidade (inferior-esquerda/direita) no tempo $t=0.4 \mathrm{~s}$.
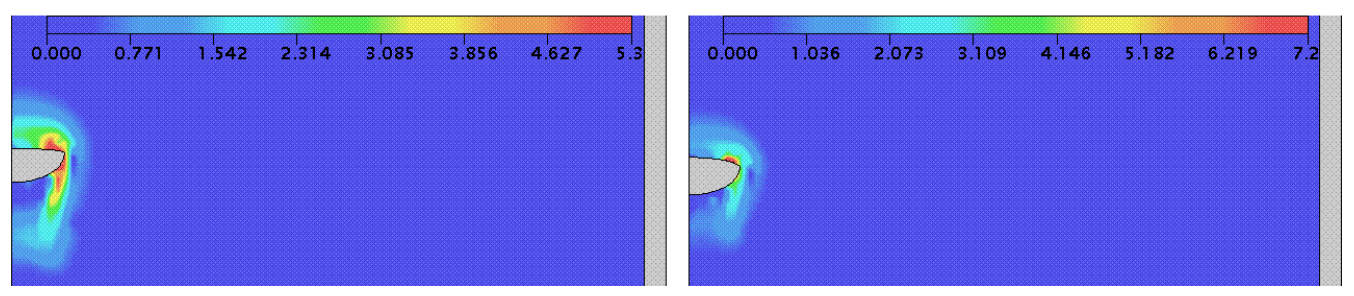

Figura 7.45: Taxa de cisalhamento das bolhas nos diâmetros $L=0.03$ (esquerda) e $L=0.05$ (direita).

Ao posicionar qualquer uma das bolhas em locais mais profundos do que aqueles que mostramos, percebemos que elas praticamente não se movimentavam, o movimento era extremamente lento. Isto 
implicava em baixos valores de $d t$ proibitivos do ponto de vista da nossa capacidade de simulação, ou o código divergia.

Acreditamos que estes fenômenos ocorreram por causa do alto valor da força viscosa, que praticamente inibia a ascensão. Do ponto de vista físico isto é perfeitamente plausível, caminhando no sentido da profundidade a porcentagem de água diminui dando mais espaço para partículas sólidas, o que eleva o valor da viscosidade.

Uma outra questão é que, após vencido o sedimento a bolha ascende em água (fluido newtoniano) e disto as forças de empuxo e peso e do fluido circundante tendem ao equilíbrio dando por fim a velocidade terminal. Para fechar nossos resultados consideramos uma pequena bolha de metano ascendendo na água, onde fazemos uma analogia com o caso I.

Com o caso I trabalhado, inferimos a ascensão da bolha no sistema metano/água. Admitindo agora dados de S-4:

$$
R \stackrel{3}{\times} h \quad, \quad M_{3}: 90 \times 300
$$

obtivemos $d t=2.19020 \times 10^{-06}$, análogo ao valor calculado no caso I.
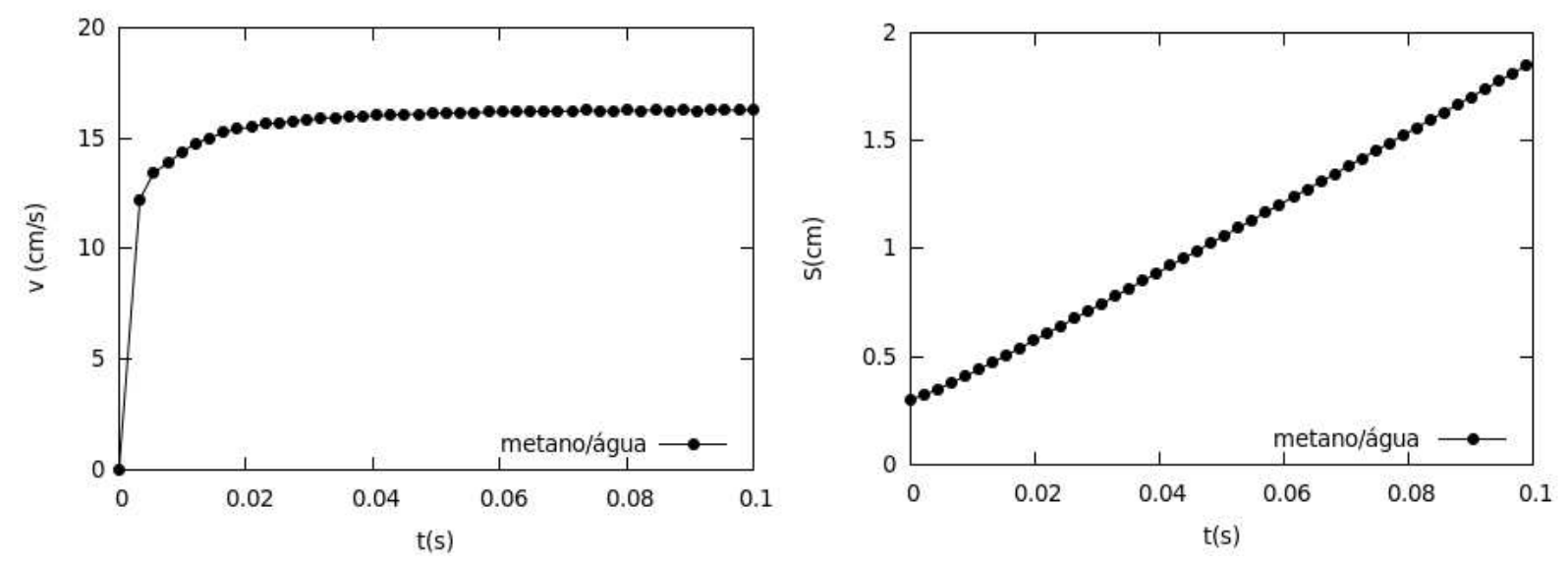

Figura 7.46: Velocidade do centro de massa da bolha com $L=1.0$ milímetro (esquerda) e Posição em função do tempo (direita).

Os gráficos da velocidade e posição do centro de massa são mostrados na figura 7.46. Observando esta figura e o resultado do caso I por nós encontrado (ver figura 7.8) vemos que não há diferenças relevantes. Ou seja a mudança do sistema ar/água para o sistema metano/água têm praticamente a mesma dinâmica. Partimos também de um campo de pressão natural, análogo ao exibido anteriormente no caso I para o início do tempo, e efetuamos a simulação deste caso até o tempo $t=0.1 \mathrm{~s}$. Os campos de pressão e velocidade adimensionais, da bolha de metano ascendendo na água quando a velocidade terminal é atingida, são mostrados na figura 7.47. 


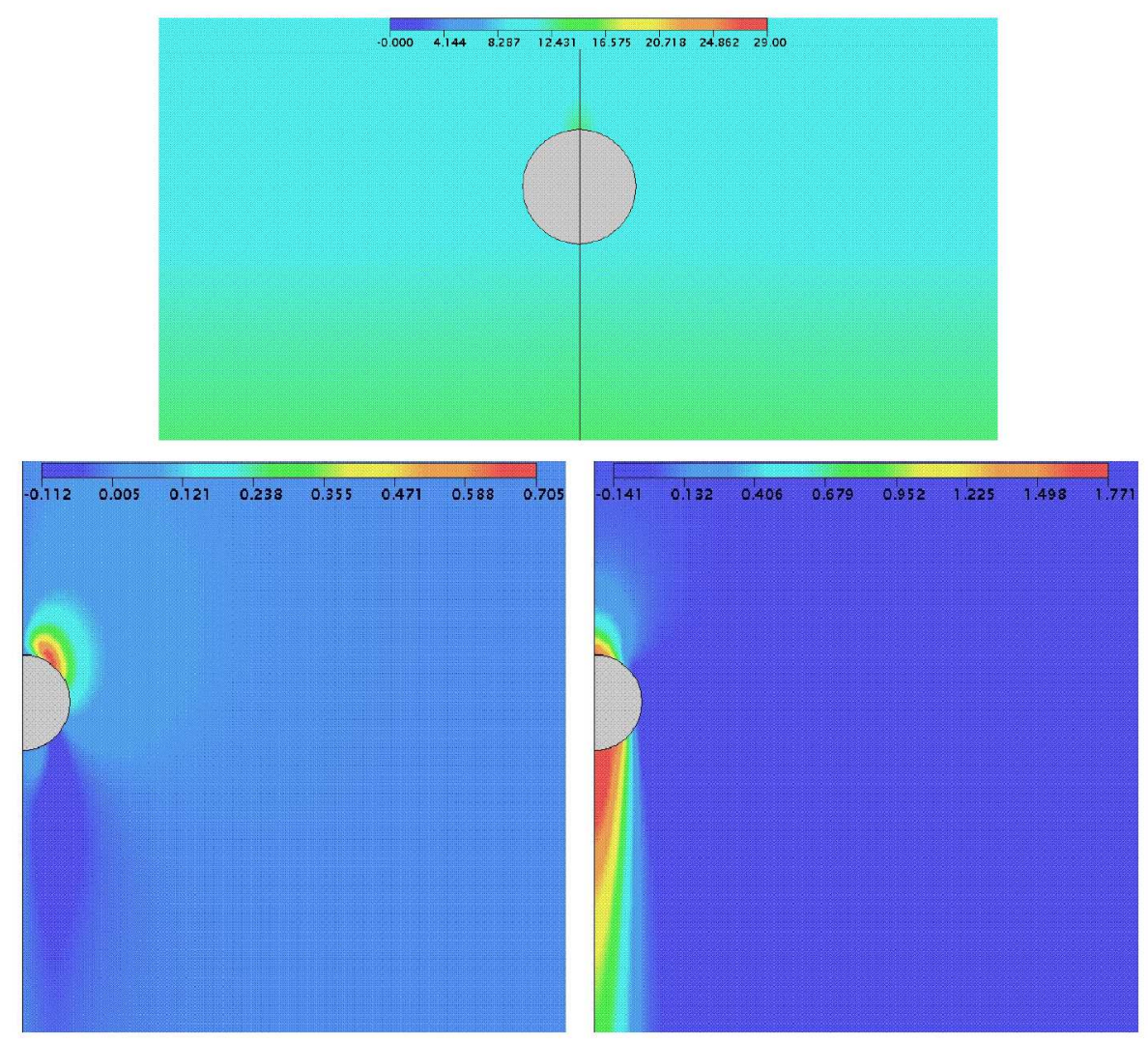

Figura 7.47: Representação do campo de pressão (superior) e das componentes $u$ (esquerda-inferior) e $v$ (direita-inferior) do vetor velocidade no tempo $t=0.1 \mathrm{~s}$.

Com os resultados pormenorizados sobre a ascensão de bolhas esférica e não esféricas nos fluidos newtonianos e sedimentar, passamos agora a fazer algumas considerações finais sobre o nosso trabalho de tese. 


\section{CAPÍTULO 8 \\ Considerações Finais}

\subsection{Conclusões}

Objetivamos com este trabalho de tese de doutoramento, estudar a ascensão de alguns tipos de bolhas no contexto axissimétrico em fluidos newtonianos e não-newtoniano. Em particular o fluido não-newtoniano considerado é uma amostra de sedimento do fundo da lagoa do Óleo.

Evidentemente a ascensão de uma bolha através da interface sedimento/água ocorre claramente num sistema de três fases (gás-sólido-água), que é de grande complexidade Matemática em virtude do fluido sedimentar ser não homogêneo. Nós procuramos simplificar o problema de três fases em uma única fase (fluido) na intenção de obter soluções consistentes com a Física do problema e que concorde com resultados da literatura quando possível.

A nossa simplificação toma por hipótese básica: tratar a ascensão da bolha imersa como a interação entre as equações da mecânica dos fluidos (EMF) e a equação do movimento do centro de massa (EMCM) da mesma. Resolvemos as equações da mecânica dos fluidos somente na fase contínua. Resolvemos também as equações de movimentação do centro de massa, para encontrar $\left(r_{c m}, z_{c m}\right)$, onde o acoplamento entre (EMF) e (EMCM) se dá através da força viscosa $\left(F V_{z}\right)$. Sempre respeitando as condições de contorno impostas ao problema.

Uma outra contribuição que aceitamos ser importante é o tratamento dado a mudança de forma da bolha. O uso dos parâmetros de forma: razão de aspecto e fator de distorção, aliados ao cálculo das formas cónicas, permitiram obter formatos razoáveis com o que de fato é presenciado. Entendemos 
também o formato da superfície da bolha como local de passagem de valores de velocidade para o fluido, acreditamos que a representação integral de uma função (que adaptamos para a condição de contorno) pode ser uma alternativa à condição free-slip, uma vez que ela pondera a contribuição de valores vizinhos via função núcleo a todo lapso de tempo.

Lembramos que velocidade e posição do centro de massa são variáveis amplamente mensuradas em diversos trabalhos que tratam deste tema. Acreditamos então, que uma das contribuições deste trabalho está em resolver o problema de ascensão de três fases (gás-sólido-água) em apenas uma fase (fluido). Para validar nossa estratégia, mostramos nossos resultados em concordância com alguns da literatura.

Por outro lado e já amplamente explanado, o sedimento pode ser modelado como um fluido nãonewtoniano. O sedimento difere de outros fluidos não-newtonianos por ser não homogêneo. Em estado de quiescência o sedimento apresenta viscosidade variável, passando de seu maior valor para o valor da viscosidade da água quando no sentido contrário ao da profundidade. Alguns trabalhos modelam este tipo de fluido via relação de Bingham ou através da forma mais geral Herschel-Bulkley.

Nós coletamos sedimento na lago do Óleo, propusemos um ajuste por mínimos quadrados (partindo da relação de Herschel-Bulkley) para cada amostra do core. Finalmente, equacionamos a lei geral da viscosidade que leva em consideração a concentração de partículas de matéria orgânica e a taxa de cisalhamento. Então em nosso modelo de uma fase as equações de Navier-Stokes, presentes em EMF, podem ser por hipótese não-newtonianas e a força $\left(F V_{z}\right)$ leva em consideração a viscosidade variável. Entendemos que esta estratégia adotada também constitui-se numa contribuição deste trabalho.

Do ponto de vista numérico, argumentamos que o crescimento da razão de densidades $\left(\rho_{c} / \rho_{d}\right)$ traz dificuldades adicionais à resolução do problema de ascensão. Porém a implementação do esquema upwind de alta ordem SDPUS-C1, nos termos convectivos das equações de Navier-Stokes e de transporte, ameniza as dificuldades uma vez que esse esquema é preparado para dar resultados em ordens mais altas de precisão.

Descrevemos no início deste trabalho as informações básicas quanto a formação e liberação de metano a partir do sedimento anóxico. Mostramos alguns mecânismos, com nossos resultados numéricos, de como se procede a ascensão de bolhas de metano na profundidade de aproximadamente 20 centímetros no sedimento. E como o arrasto ocasionado pelo movimento da bolha altera os campos de concentração do material particulado e consequentemente a viscosidade local. Sugerindo que o desprendimento das bolhas está fortemente vinculado a viscosidade do fluido circundante.

Como o objetivo maior deste trabalho foi descrever, modelar, qualificar e quantificar a movi- 
mentação de alguns tipos de bolhas num contexto não trivial, esperamos ter contribuído com mais informações na direção de um entendimento mais amplo e apurado para o problema aqui abordado.

\subsection{Trabalhos Futuros}

A experiência adquirida com o desenvolvimento deste projeto nos possibilitou ver alguns pontos que ainda necessitam ser explorados, esclarecidos ou melhorados. Elencamos alguns deles como segue:

1. Desenvolvemos nosso trabalho no sistema axissimétrico e desta forma alguns casos de ascensão puderam ser resolvidos. Um desafio seria tratar o problema no espaço tridimensional onde outras trajetórias de ascensão pudessem ser simuladas, como por exemplo a zig-zag e a espiralada.

2. Além de tratarmos o problema de forma axissimétrica, dividimos o domínio em uma grade estacionária e inserimos a forma circular inicial da bolha, logo o grid do domínio não é coincidente com a forma da bolha. Uma outra maneira de modelar e resolver este problema seria tratá-lo no sistema de coordenadas generalizadas, onde o grid do domínio seria coincidente com a superfície da bolha e disto muitas das aplicações de técnicas matemáticas e computacionais seriam mais fáceis e precisas de serem aplicadas.

3. As equações do nosso modelo são resolvidas por esquemas explícitos o que implica na necessidade de restrições severas no passo de tempo, o que demanda muito tempo computacional nas simulações. Uma outra abordagem para trabalho futuro seria utilizar formulações implícitas, o que implicaria em melhoras na estabilidade da resolução do problema e passos de tempo maiores.

4. Em nosso trabalho a lei geral da viscosidade foi formulada tomando por base dados experimentais que nós obtivemos, é claro que sobre estes dados há imprecisões estatísticas e de medição. Uma questão a ser explorada seria o refinamento experimental. Ou seja, admitir um conjunto de vários cores e realizar fatiamentos mais precisos por instrumentação apropriada e de precisão, gerando com isto uma quantidade de dados mais massiva que permita avaliar a lei da viscosidade alicerçada em técnicas estatísticas.

5. A força $F V_{z}$ é calculada em nosso trabalho a partir de 8 configurações possíveis para as células do tipo (b), a única possibilidade que dispomos para aumentar a precisão da força viscosa é através do refinamento da malha, que é custoso do ponto de vista computacional. Uma possível 
melhoria no cálculo de $F V_{z}$ seria; após calculadas as forças para cada uma das células de bordo da bolha (b), calcular o valor da força viscosa $F V_{z}$ por meio de técnicas de interpolação sobre a superfície da bolha.

6. Na literatura observamos que os pesquisadores propuseram mapas de forma para diversos tipos de bolhas em função de números adimensionais, mas na grande maioria estes mapas contemplam fluidos newtonianos. Um outro ponto que julgamos ser possível de ser explorado é a construção de mapas para tipos diferenciados de sedimentos. Porquê as características limnológicas do sedimento de climas diferentes são diferentes, logo a ascensão de bolhas de metano podem ser também diferentes.

7. Para finalizar, entendemos que o nosso trabalho foi apenas o início de um estudo mais amplo sobre a ascensão de bolhas. Fomos motivados a realizar todo o desenvolvimento discutido, pela pergunta: Qual é a quantidade que os lagos das usinas hidrelétricas talvez contribuem para o aumento da quantidade de gases de efeito estufa, que implica no aquecimento global? Achamos que uma parte da resposta dessa pergunta seria - Admitindo um dado lago, desenvolve-se um projeto que resumidamente tenha como parte de suas metas técnicas as seguintes etapas:

(a) seleção de pequenas áreas no sedimento para quantificação dos principais parâmetros das bolhas;

(b) com amostras das pequenas áreas, modelar a viscosidade da área;

(c) simular o processo a quantidade e o tempo de ascensão de bolhas nas pequenas áreas;

(d) estimar a quantidade de metano ebulitivo do lago, liberado na coluna d'água, que por conseguinte é liberado na atmosfera;

Este, na nossa visão, também seria um possível trabalho maior a ser realizado. 


\section{Referências Bibliográficas}

[1] D. S. Abe, D. D. Adams, C. V. S. Galli, E. Sikar, and J. G. Tundisi. Sediment greenhouse gases (methane and carbon dioxide) in the lobo-broa reservoir, são paulo state, brazil: Concentrations and diffuse emission fluxes for carbon budget considerations. Lakes \& Reservoirs: Research and Management, 10:201-209, 2005.

[2] D. J. Acheson. Elementary Fluid Dynamics. Oxford University Press, Oxford, 1990.

[3] A. A. Agostinho and L. C. Gomes. Reservatório de Segredo: bases ecológicas para o Manejo. Maringá: EDUEM, 1997.

[4] F. T. Akyildiz and H. Bellout. Viscoelastic lubrication with phan-thein-tanner fluid (ptt). ASME J. Tribol., 126:288-291, 2004.

[5] M. Alonso and E. J. Finn. Fundamental University Physics, v. I - Mechanics. Addison Wesley, Massachusetts, 1967.

[6] J. L. Alquéres, M. F. Campos, R. F. Pimentel, M. F. M. Santos, and M. J. Marques. Plano nacional de energia elétrica 1993/2015 plano 2015. Technical report, Ministério das Minas e Energia, 1994.

[7] L. Amaya-Bower and T. Lee. Single bubble rising dynamics for moderate reynolds number using lattice boltzmann method. Computers \& Fluids, 39:1191-1207, 2010.

[8] M. V. S. Annaland, N. G. Deen, and J. A. M. Kuipers. Numerical simulation of gas-liquid-solid flows using a combined front tracking and discrete particle method. Chemical Engineering Science, 60:6188-6198, 2005. 
[9] K. B. Bartlett, P. M. Crill, D. I. Sebacher, R. C. Harriss, J. O. Wilson, and J. M. Melack. Methane flux from the central amazon floodplain. J. Geophys. Res., 93:1571-1582, 1988.

[10] D. Bastviken, J. Cole, M. Pace, and L. Tranvik. Methane emissions from lakes: Dependence of lake characteristics, two regional assessments, and a global estimate. GLOBAL BIOGEOCHEMICAL CYCLES, 18:1-12, 2004.

[11] D. Bastviken, J. Ejlertsson, and L. Tranvik. Measurement of methane oxidation in lakes: A comparison of methods. Environ. Sci. Technol., 36 (15):3354-3361, 2002.

[12] M. Belinsky, H. Rubin, Y. Agnon, E. Kit, and J. F. Atkinson. Characteristics of resuspension, settling and diffusion of particulate matter in a water column. Environmental Fluid Mechanics, $5: 415-441,2005$.

[13] M. Bianchessi. Atividade enzimática, cinética e modelagem matemática da decomposição de Utricularia breviscapa da lagoa do Óleo (Estação Ecológica de Jataí, Luiz Antônio - SP). $\mathrm{PhD}$ thesis, Programa de Pós-Graduação em Ecologia e Recursos Naturais-UFSCar, 2003.

[14] M. A. A. Bortoloti. Uma Formulação de Elementos Finitos para Problemas de Escoamentos Pseudoplásticos. PhD thesis, Petropólis, RJ: LNCC, 2006.

[15] G. Bozzano and M. Dente. Single bubble and drop motion modeling. In AIDIC Conference Series, 2009.

[16] G. Brenn and C. Pilz. The rise velocity jump discontinuity of bubbles in viscoelastic liquids. In 7 International Conference on Multiphase Flow, ICMF 2010, Tampa, FL, May 30 - June 4, 2010.

[17] C. Bullock. The archaea - a biochemical perspective. Biochemistry and Molecular Biology Education, 28:186 - 191, 1999.

[18] J. B. P. Cabral. Estudo do processo de assoreamento em reservatórios. Caminhos de Geografia, 6(14):62-69, 2005.

[19] F. P. Carmo. A Equação de Poisson e a Decomposição de Helmholtz-Hodge com Operadores SPH. PhD thesis, Programa de Pós-graduação em Matemática Aplicada do Departamento de Matemática do Centro Técnico Científico da PUC-Rio, 2008.

[20] N. O. Carvalho. Hidrossedimentologia Prática. Rio de Janeiro : CPRM, 1994. 
[21] P. Casper, S. C. Maberly, G. H. Hall, and B. J. Finlay. Fluxes of methane and carbon dioxide from a small productive lake to the atmosphere. Biogeochemistry, 49:1-19, 2000.

[22] A. L. C. Castro, L. B. Calheiros, and A. Z. B. Moura. Manual de desastres mistos volume iii. Technical report, Ministério da Integração Nacional, Secretaria Nacional de Defesa Civil, 2002.

[23] G. P. Celata, M. Cumo, F. D'Annibale, and A. Tomiyama. The wake effect on bubble rising velocity in one-component systems. International Journal of Multiphase Flow, 30:939- 961, 2004.

[24] G. P. Celata, F. D’Annibale, P. D. Marco, G. Memoli, and A. Tomiyama. Measurements of rising velocity of a small bubble in a stagnant fluid in one-and two-component systems. Experimental Thermal and Fluid Science, 31:609-23, 2007.

[25] H. N. Cezar. Simulação numérica de escoamentos com superfícies livres e obstáculos em movimento. Master's thesis, Instituto de Ciências Matemáticas e de Computação - ICMC/USP, 2003.

[26] A. Chakraborty and D. K. Bhattacharaya. A process-based mathematical model on methane production with emission indices for control. Bulletin of Mathematical Biology, 68:1293-1314, 2006.

[27] N. P. Cheremisinoff. Encyclopedia of Fluid Mechanics Volume 9 Polymer Flow Engineering. Gulf Publishing Company, Houston, Texas, 1990.

[28] E. R. Cirilo. Simulação do escoamento incompressível num coletor bidimensional. Master's thesis, Instituto de Matemática - Programa de Pós-Graduação em Matemática Aplicada, 2001.

[29] R. Clift, J. R. Grace, and M. E. Weber. Bubbles, Drops, and Particles. Dover Publications, New York, USA, 1978.

[30] R. Clift, J. R. Grace, and M. E. Weber. Bubbles, Drops, and Particles. Dover Publications, New York, 2005.

[31] M. A. Conant and F. R. Gold. A Geopolítca Energética. Editora Atlântida. Rio de Janeiro, 1981.

[32] H. T. Davis. Introduction to Nonlinear Differential Equation and Integral Equation. Dover Publications, New York, 1962. 
[33] W. Dijkhuizen, E. I. V. van den Hengel, N. G. Deen, M. van Sint Annaland, and J. A. M. Kuipers. Numerical investigation of closures for interface forces acting on single air-bubbles in water using volume of fluid and front tracking models. Chemical Engineering Science, 60:6169-6175, 2005.

[34] F. R. Eirich. Rheology: Theory and Applications. Academic Press Inc., New York, 1956.

[35] P. M. Fearnside. Hydroelectric dams in the brazilian amazon as sources of greenhouse gases. Environmental Conservation, 22:7-19, 1995.

[36] P. M. Fearnside. Greenhouse gas emissions from hydroelectric reservoir (brazil’s tucuruí dam) and the energy policy implications. Water, Air and Soil Pollution, 133:69-96, 2002.

[37] P. M. Fearnside. Greenhouse gas emissions from hydroelectric dams: Controversies provided a springboard for rethinking a supposedly clean energy source. Climatic Change, 66:1-8, 2004.

[38] E. E. Ferreira, P. R. G. Brandão, B. Klein, and A. E. C. Peres. Reologia de suspensões minerais: uma revisão. REM: R. Esc. Minas, 58(1):83-87, 2005.

[39] V. G. Ferreira. Análise e Implementação de Esquemas de Convecção e Modelos de Turbulência para Simulação de Escoamentos Incompressíveis Envolvendo Superfícies Livres. PhD thesis, Instituto de Ciências Matemáticas e de Computação - ICMC/USP, 2001.

[40] C. E. Fonseca. Uma investigação numérica de escoamentos planares de fluidos herschelbulkley regularizados empregando um método multi-campos de galerkin mínimos-quadrados. Master's thesis, Universidade Federal do Rio Grande do Sul- Programa de Pós-Graduação em Engenharia Mecânica, 2008.

[41] R. W. Fox and A. T. McDonald. Introdução à Mecânica dos Fluidos. LTC-Livros Técnicos e Científicos Editora S. A. Rio de Janeiro, 2001.

[42] C. Galy-Lacaux, R. Delmas, G. Kouadio, S. Richard, and P. Grosse. Long-term greenhouse gas emissions from hydroeletric reservoirs in tropical forest regions. Global Biogechemical Cycles., 13:503-517, 1999.

[43] I. C. Georg, R. V. P. Rezende, and C. R. Maliska. Estudo numérico do escoamento ascendente de uma bolha de gás em meio líquido. In Primeiro Encontro Brasileiro sobre Ebulição, Condensação e Escoamento Multifásico Líquido-Gás., 2008. 
[44] M. Gleiser. $O$ que seria do mundo sem as bolhas? http://marcelogleiser.blogspot.com/2000/05/o-que-seria-do-mundo-sem-as-bolhas.html. Acesso em Julho de 2009.

[45] M. Griebel, T. Dornseifer, and T. Neunhoeffer. Numerical Simulation in Fluid Dynamics: a practical introduction. SIAM monographs on mathematical modeling and computation. Philadelphia, 1998.

[46] L. Grossi. Solução numérica de escoamentos axissimétricos não-newtonianos com superfícies livres. Master's thesis, Instituto de Ciências Matemáticas e de Computação - ICMC/USP, 1997.

[47] F. Guérin, G. Abril, D. Serça, C. Delon, S. Richard, R. Delmas, A. Tremblay, and L. Varfalvy. Gas transfer velocities of co2 and ch4 in a tropical reservoir and its river downstream. Journal of Marine Systems, 66:161-172, 2007.

[48] Y. Hao and A. Prosperetti. A numerical method for three-dimensional gas-liquid flow computations. Journal of Computational Physics, 196:126-144, 2004.

[49] J. Harris. Rheology and non-newtonian flow. Longman Inc., New York, 1977.

[50] J. R. Herrera-Velarde, R. Zenit, D. Chehata, and B. Mena. The flow of non-newtonian fluids around bubbles and its connection to the jump discontinuity. Journal of NonNewtonian Fluid Mechanics, 111:199-209, 2003.

[51] R. C. Hibbeler. Mecânica Estática - 10 edição. Pearson Education do Brasil., 2005.

[52] E. J. Hobsbawm. A era das revoluções: Europa 1789-1848, tradução de Maria Tereza L. T. e Marcos Penchel. Editora Paz e Terra S/A. São Paulo - SP, 1977.

[53] K. A. Hoffmann, S. T. L. Chiang, M. S. Siddiqui, and M. Papadakis. Fundamental Equations of Fluid Mechanics. Engineering Education System, USA, 1996.

[54] J. Hua and J. Lou. Numerical simulation of bubble rising in viscous liquid. Journal of Computational Physics, 222:769-795, 2007.

[55] J. Hua, J. F. Stene, and P. Lin. Numerical simulation of $3 \mathrm{~d}$ bubbles rising in viscous liquids using a front tracking method. Journal of Computational Physics, 227:3358-3382, 2008.

[56] W. F. Hughes and J. A. Brighton. Dinâmica dos Fluidos. Editora McGraw-Hill do Brasil São Paulo, 1974. 
[57] J. T. Huttunen, T. S. Väisänen, S. K. Hellsten, and P. J. Martikainen. Methane fluxes at the sediment-water interface in some boreal lakes and resevoirs. Boreal Environment Research, $11: 27-34,2006$.

[58] E. Jiménez, M. Sussman, and M. Ohta. A computational study of bubble motion in newtonian and viscoelastic fluids. Fluid Dynamics \& Materials Processing, 1:97-107, 2005.

[59] J. Joyce and P. W. Jewell. Physical controls on methane ebullition from reservoirs and lakes. Environmental \& Engineering Geoscience, IX, No. 2:167- 178, 2003.

[60] C. A. Kelly, J. W. M. Rudd, R. A. Bodaly, N. P. Roulet, V. L. St.Louis, A. Heyes, T. R. Moore, S. Schiff, R. Aravena, K. J. Scott, B. Dyck, R. Harris, B. Warner, and G. Edwards. Increases in fluxes of greenhouse gases and methyl mercury following flooding of an experimental reservoir. Environ. Sci. Technol., 31(5):1334-1344, 1997.

[61] J. Kelman. Atlas de energia elétrica do brasil / agência nacional de energia elétrica. 2 ed. Technical report, Brasília: ANEEL., 2005.

[62] A. Kemenes. Estimativa das Emissões de Gases de Efeito Estufa (CO2 e CH4) pela Hidrelétrica de Balbina, Amazônia Central, Brasil. $\mathrm{PhD}$ thesis, Instituto Nacional de Pesquisas da Amazônia, Universidade Federal do Amazonas, Coordenação em Biologia Aquática e Pesca Interior, Manaus, 2006.

[63] S. S. Kumar. Computations of Bubble Dynamics with Heat Transfer. PhD thesis, School of Mechanical and Manufacturing Engineering Dublin City University, 2009.

[64] R. D. Lacerda, H. O. C. Guerra, G. B. Junior, M. L. F. Cavalcanti, and A. D. Barros. Determinação da condutividade hidráulica de um solo argiloso pelo método do perfil instantâneo. Revista de Biologia e Ciências da Terra, 5:1-8, 2005.

[65] M. B. Laruccia. Velocidade de sedimentação em fluidos não-newtonianos: Efeito da forma e da concentração de partículas. Master's thesis, Faculdade de Engenharia de CampinasUNICAMP, 1990.

[66] J. Lelieveld, P. J. Crutzen, and F. J. Dentener. Changing concentration, lifetime and climate forcing of atmospheric methane. Tellus, 50B:128-150, 1998.

[67] L. Z. Lessa. Simulação de escoamentos com inércia de um fluido viscoplástico através do método de elementos finitos via galerkin mínimos-quadrados. Master's thesis, Programa de 
Pós-Graduação em Engenharia Mecânica da Escola de Engenharia da Universidade Federal do Rio Grande do Sul, 2008.

[68] J. H. Lienhard. A Heat Transfer Textbook - Third Edition. Phlogiston Press Cambridge, Massachusetts, U.S.A., 2008.

[69] G. A. B. Lima. Desenvolvimento de estratégias de captura de descontinuidades para leis de conservação e problemas relacionados em dinâmica dos fluidos. Master's thesis, Instituto de Ciências Matemáticas e de Computação - ICMC/USP, 2010.

[70] G. A. B. Lima, V. G. Ferreira, E. R. Cirilo, A. Castelo, M. A. C. Candezanoa, I. V. M. Tasso, D. M. C. Sano, and L. V. A. Scalvi. A continuously differentiable upwinding scheme for the simulation of fluid flow problems. Applied Mathematics and Computation, 218:8614-8633, 2012.

[71] I. B. T. Lima. Emissão de Metano por Reservatórios Hidrelétricos Amazônicos Através de Leis de Potência. PhD thesis, Centro de Energia Nuclear na Agricultura, Universidade de São Paulo, Piracicaba, 2002.

[72] V. L. St. Louis, C. A. Kelly, É. Duchemin, J. W. M. Rudd, and D. M. Rosenberg. Reservoir surfaces as sources of greenhouse gases to the atmosphere: A global estimate. BioScience, 50:766-775, 2000.

[73] J. Lovelock. A Gaia Original. Crown Publishers, New York, 1991.

[74] G. A. Makhov and N. M. Bazhin. Methane emission from lakes. Chemospher, 38(6):1453$1459,1999$.

[75] E. M. Mattiusi, H. T. Coradin, W. M. Brondani, A. T. Franco, R. E. M. Morales, and A. L. Martins. Escoamento laminar de fluidos não-newtonianos em tubos de seção transversal elíptica. In 4 PDPETRO, Campinas, SP, 2007.

[76] S. McKee, M. F. Tome, V. G. Ferreira, J. A. Cuminato, A. Castelo, F. S. Sousa, and N. Mangiavacchi. The mac method. Computers \& Fluids, 37:907-930, 2008.

[77] F. R. G. Melo. Fluidodinâmica de Esferas Leves e Bolhas em Líquidos. PhD thesis, Programa de Pós-Graduação em Engenharia Química da Universidade Federal de Uberlândia, 2007.

[78] N. Monteiro. Itaipu, A Luz. Itaipu Binacional, 1999. 
[79] K. Mukundakrishnan, S. Quant, D. M. Eckmann, and P. S. Ayyaswamy. Numerical study of wall effects on buoyanty gas-bubble rise in a liquid-filled finite cylinder. Physical Review E, 76:1-15, 2007.

[80] B. R. Munson, D. F. Young, and T. H. Okiishi. Fundamentos da Mecânica dos Fluidos. Editora Edgard Blücher, 2004.

[81] W. MYINT, S. HOSOKAWA, and A. TOMIYAMA. Shapes of single drops rising through stagnant liquids. Journal of Fluid Science and Technology, 2:184-195, 2007.

[82] A. A. Nadooshan and E. Shirani. Numerical simulation of a single air bubble rising in water with various models of surface tension force. World Academy of Science, Engineering and Technology, 39:72-76, 2008.

[83] U. M. Neves. Estudo do movimento de um corpo sob ação de força viscosa usando uma porção de xampu, régua e relógio. Revista Brasileira de Ensino de Física., 28:387-390, 2006.

[84] T. Okabe, S. Amou, and M. Ishigaki. A simulation model for sedimentation process in gorgetype reservoirs. Sediment Problems: Strategies lor Monitoring, Prediction and Control (Proceedings of the Yokohama Symposium), 217:119-126, 1993.

[85] M. L. B. Oliveira. Freeflow-axi: Um ambiente de simulação de escoamentos axissimétricos com superfície livre. Master's thesis, Instituto de Ciências Matemáticas e de Computação ICMC/USP, 2002.

[86] P. M. Oliveira, A. M. Silva, G. Coelho, and R. A. Silva. Análise comparativa da caracterização físico-hídrica de um latossolo vermelho distrófico in situ e em laboratório. Irriga, 10(1):1-19, 2005.

[87] R. S. Oremland. Biogeochemistry of methanogenic bacteria. In: Biology of anaerobic microorganisms. Cap. 13. New York: John Wiley \& Sons., 1988.

[88] A. Paiva. Uma abordagem Lagrangeana para simulação de fluidos viscoplásticos e multifásicos. PhD thesis, Programa de Pós-graduação em Matemática Aplicada do Departamento de Matemática da PUC-Rio, 2007.

[89] A. Paiva, F. Petronetto, G. Tavares, and T. Lewiner. Simulação de fluidos sem malha: uma introducao ao método sph. 27 Colóquio Brasileiro de Matemática, 2008. 
[90] A. L. Pazzianto and M. H. V. Senise. História Moderna e Contemporânea. Editora Ática, 1997.

[91] P. Petracco. Efeitos das variáveis abióticas na produção primária de Egeria najas e Utricularia breviscapa na lagoa do Óleo (Estação Ecológica de Jataí, Luiz Antônio - SP). PhD thesis, Programa de Pós-Graduação em Ecologia e Recursos Naturais-UFSCar, 2006.

[92] T. Phillips and R. Owens. Computational Rheology. Imperial College Press, 2002.

[93] J. Pontes. Fenômenos de transferência. Technical report, COPPE/UFRJ, 1999.

[94] M. V. Possa and J. R. B. Lima. Comportamento reológico de polpas de minério. Série Tecnologia Mineral, 77:1-37, 2000.

[95] M. C. Potter and E. P. Scott. Ciências Térmicas: termodinâmica, mecânica dos fluidos e transmissão de calor. Thomson Learning. São Paulo, 2007.

[96] A. J. M. Queiroz, R. M. F. Figueirêdo, C. L. Silva, and M. E. R. M. C Mata. Comportamento reológico de méis de florada de silvestre. R. Bras. Eng. Agríc. Ambiental, 11(2):190-194, 2007.

[97] R. A. B. Queiroz. Desenvolvimento e teste de esquemas "upwind"de alta resolução e suas aplicações em escoamentos incompressíveis com superfícies livres. Master's thesis, Instituto de Ciências Matemáticas e de Computação - ICMC/USP, 2009.

[98] M. Reiner. Selected Papers on Rheology. Elsevier Scientific Publishing Company, New York, 1975.

[99] J. M. Roberts. O livro de ouro da história do mundo. Traduzido por Laura A. e Aurélio R. Ediouro, Rio de Janeiro, 2005.

[100] D. Rodrigue. A simple correlation for gas bubbles rising in power-law fluids. The Canadian Journal of Chemical Engineering, 80:289-292, 2002.

[101] N. M. L. Romeiro. Simulação Numérica de Modelos de Qualidade de Água Usando o Método de Elementos Finitos Estabilizados. PhD thesis, COPPE/UFRJ, D. Sc., Engenharia Civil, 2003.

[102] L. P. Rosa. Emissões de dióxido de carbono e metano pelos resevatórios hidrelétricos brasileiros: relatório final / centrais elétricas brasileiras s.a, dea, deaa. Technical report, Eletrobrás.DEA. DEAA., 2000. 
[103] J. W. M. Rudd and R. D. Hamilton. Methane cycling in a eutrophic shield lake and its effects on whole lake metabolism. Limnol. Oceanogr, 23:337-348, 1978.

[104] E. O. Santos. Contabilização das Emissões Líquidas de Gases de Efeito Estufa de Hidrelétricas: Uma Análise Comparativa entre Ambientes Naturais e Reservatórios Hidrelétricos. $\mathrm{PhD}$ thesis, COPPE/UFRJ., 2006.

[105] F. L. Santos, G. F. Maciel, and V. M. Moraes. Evolução de frentes de lama em canais - parte i: Uma proposta reológica de herschel-bulkley a partir de uma base experimentalista física. Revista Brasileira de Recursos Hídricos, 8:95-105, 2003.

[106] M. A. Santos, L. P. Rosa, B. Matvienko, E. O. Santos, C. H. E. D. Rocha, E. Sikar, M. B. Silva, and A. M. P. B. Junior. Emissões de gases de efeito estufa por reservatórios de hidrelétricas. Oecol. Bras., 12 (1):116-129., 2008.

[107] W. H. Schlesinger. Biogeochemistry. Academic Press, New York., 1997.

[108] R. Segers. Methane production and methane consumption: a review of processes underlying wetland methane fluxes. Biogeochemistry, 41:23-51, 1998.

[109] W. L. Shew and J. F. Pinton. Viscoelastic effects on the dynamics of a rising bubble. Journal of Statistical Mechanics: Theory and Experiment, 1:1-17, 2006.

[110] D. Sikorski, H. Tabuteau, and J. R. Bruyn. Motion and shape of bubbles rising through a yield-stress fluid. Journal of Non-Newtonian Fluid Mechanics, 159:10-16, 2009.

[111] B. C. P. Silva, D. M. Vidal, and P. I. B. Queiroz. Efeito da sorção no transporte de contaminantes orgânicos em solos argilosos. In X ENCITA - Encontro de Iniciação Científica e Pós-Graduação do ITA, 2004.

[112] M. B. Silva. Aspectos do Comportamento de Gás Metano Dissolvido na Água de Reservatórios Brasileiros. PhD thesis, Escola de Engenharia de São Carlos, 2004.

[113] L. E. Sissom and D. R. Pitss. Fenômeno de Transporte. Guanabara Dois S. A. Rio de Janeiro - RJ, 1979.

[114] G. D. Smith. Numerical Solution of Partial Differential Equations: finite difference methods 3rd ed. Oxford applied mathematics and computing science series, 1990. 
[115] F. S. Sousa. Simulação de Escoamentos multifásicos em Malhas não Estruturadas. PhD thesis, Instituto de Ciências Matemáticas e de Computação - ICMC/USP, 2006.

[116] F. S. Sousa, N. Mangiavacchi, L. G. Nonato, A. Castelo, M. F. Tomé, V. G. Ferreira, L. A. Cuminato, and S. McKee. A front-tracking/front-capturing method for the simulation of $3 \mathrm{~d}$ multi-fluid flows with free surfaces. Journal of Computational Physics, 198:469-499, 2004.

[117] R. F. Strayer and J. M. Tiedje. In situ methane production in a small, hypereutrophic, hardwater lake: Loss of methane from sediments by vertical diffusion and ebullition. Limnol. Oceanogr., 23(6):1201-1206, 1978.

[118] V. L. Streeter. Fluid Mechanics. International Student Edition. Tokio-Japão, 1966.

[119] K. Suguio. Mudanças Ambientais da Terra. São Paulo: Instituto Geológico, 2008.

[120] K. Symon. Mechanics - second edition. Addison Wesley, Massachusetts, 1964.

[121] M. A. R. Talaia. Terminal velocity of a bubble rise in a liquid column. Proceedings of World Academy of Science, Engineering and Technology, 22:264-268., 2007.

[122] R. Taylor and the co authors. Assessment of the ghg status of freshwater reservoirs. Technical report, International Hydropower Association, 2008.

[123] R. V. Thomann and J. A. Mueller. Principles of Surface Water Quality Modeling and Control. Harper \& Row, Publishers, New York, 1987.

[124] M. F. Tome, A. Castelo, J. Murakami, J. A. Cuminato, R. Minghim, M. C. F. Oliveira, N. Mangiavacchi, and S. McKee. Numerical simulation of axisymmetric free surface flows. Journal of Computational Physics, 157:441-472, 2000.

[125] M. F. Tomé, M. S. B. Araujo, M. A. Alves, and F. T. Pinho. Numerical simulation of viscoelastic flows using integral constitutive equations: A finite difference approach. Journal of Computational Physics, 227:4207-4243, 2008.

[126] M. F. Tomé, J. L. Doricio, A. Castelo, J. A. Cuminato, and S. McKee. Solving viscoelastic free surface flows of a second-order fluid using a marker-and-cell approach. Int. J. Numer. Meth. Fluids, 53:599-627, 2007. 
[127] M. F. Tomé, L. Grossi, A. Castelo, J. A. Cuminato, N. Mangiavacchi, V. G. Ferreira, F. S. Sousa, and S. McKee. A numerical method for solving three-dimensional generalized newtonian free surface flows. Journal Non-Newtonian Fluid Mechanics, 123:85-103, 2004.

[128] M. F. Tomé, L. Grossi, A. Castelo, J. A. Cuminato, N. Mangiavacchia, V. G. Ferreira, F. S. Sousa, and S. McKee. A numerical method for solving three-dimensional generalized newtonian free surface flows. J. Non-Newtonian Fluid Mech, 123:85-103, 2004.

[129] M. F. Tomé, L. Grossi, A. Castelo, J. A. Cuminato, S. McKee, and K. Walters. Die-swell, splashing drop and a numerical technique for solving the oldroyd b model for axisymmetric free surface flows. J. Non-Newtonian Fluid Mech., 141:148-166, 2007.

[130] M. F. Tomé and S. Mckee. Gensmac: A computational marker and cell method for free surface flows in general domains. Journal of Computational Physics, 110:171-186, 1994.

[131] J. T. C. L. Toneli, F. E. X. Murr, and K. J. Park. Estudo da reologia de polissacarídeos utilizados na indústria de alimentos. Revista Brasileira de Produtos Agroindustriais, 7(2):181-204, 2005.

[132] C. E. M. Tucci. Modelos Hidrológicos. Porto Alegre: Ed. Universidade/UFRGS/Associação Brasileira de Recursos Hídricos, 1998.

[133] S. O. Unverdi and G. Tryggvason. A front-tracking method for viscous, incompressible, multifluid flows. Journal of Computational Physics, 100:25-37, 1992.

[134] R. F. Vazoller. Avaliação do ecossistema microbiano de um biodigestor anaeróbio de fluxo ascendente e manta de lodo, operado com vinhaça sob condições termofílicas. $\mathrm{PhD}$ thesis, Escola de Engenharia de São Carlos/USP, 1995.

[135] R. E. Vermillion. A look at some rising bubbles. American Journal of Physics, 43:177-179, 1975.

[136] M. M. Villar. Análise Numérica Detalhada de Escoamentos Multifásicos Bidimensionais. PhD thesis, Programa de Pós-Graduação em Engenharia Mecânica da Universidade Federal de Uberlândia, 2007.

[137] B. P. Walter, M. Heimann, and E. Matthews. Modeling modern methane emissions from natural wetlands. Journal of Geophysical Research, 106:34189-34206, 2001.

[138] X. Wang, H. Dong, X. Zhang, L. Yu, S. Zhang, and Y. Xu. Numerical simulation of single bubble motion in ionic liquids. Chemical Engineering Science, 65:6036-6047, 2010. 
[139] R. T. Watson and the co authors. Climate change 2001: Synthesis report. Technical report, Intergovernmental Panel on Climate Change, 2001.

[140] M. Wu and M. Gharib. Experimental studies on the shape and path of small air bubbles rising in clean water. Physics of Fluids, 14(7):49-52., 2002.

[141] H. Xu and C. Guetari. Numerical simulations of a train of air bubbles rising through stagnant water. In International ANSYS Conference, Pittsburgh, 2004.

[142] X. Yang and C. C. Church. Nonlinear dynamics of gas bubbles in viscoelastic media. Acoustical Society of America, 6(3):151-156, 2005.

[143] L. Zhang, C. Yang, and Z. Mao. Numerical simulation of a bubble rising in shear-thinning fluids. Journal of Non-Newtonian Fluid Mechanics, 165:555-567, 2010. 
APÊNDICE $\mathcal{A}$

\section{Teoremas}

Segue logo abaixo, alguns teoremas básicos necessários ao desenvolvimento das passagens matemáticas nas equações.

Teorema A.0.1 (Teorema de Green) Seja C uma curva plana simples, fechada, contínua por trechos, orientada positivamente, e seja $D$ a região delimitada por $C$. Se $P$ e $Q$ têm derivadas parciais de primeira ordem contínuas sobre uma região aberta que contenha $D$, então

$$
\int_{C} P d x+Q d y=\int_{D}\left(\frac{\partial Q}{\partial x}-\frac{\partial P}{\partial y}\right) d A
$$

Teorema A.0.2 (Teorema de Gauss) Seja E uma região sólida simples e seja S a superfície fronteira de E, orientada positivamente (para fora). Seja $\boldsymbol{F}$ um campo vetorial cujas funções componentes têm derivadas parciais contínuas em uma região aberta que contenha E. Então

$$
\int_{S} \boldsymbol{F} . \boldsymbol{n} d S=\int_{E} \operatorname{div} \boldsymbol{F} d V=\int_{E} \frac{\partial}{x_{j}} F_{j} d V
$$




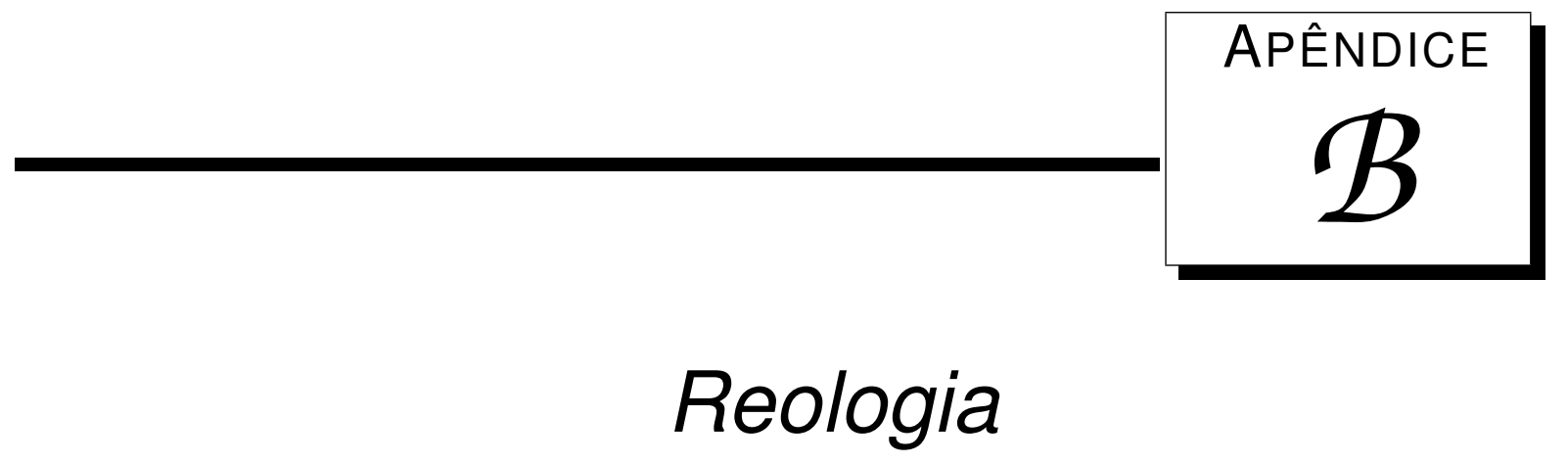

A Reologia é a ciência da deformação e escoamento, que vem sendo disseminado o seu conhecimento e sua importância rapidamente. Valiosas informações na variedade de campos da reologia tem sido feito por reuniões de seus grupos nas conferências internacionais Reológicas, bem como também, por monografias. A investigação dos diferentes tipos de deformação em relação a tensão é o objetivo da reologia [34]. Basicamente os modelos reológicos podem ser divididos e classificados conforme o diagrama apresentado na figura B.1

Um fluido Viscoelástico (exemplos: fluidos poliméricos, massa de farinha de trigo, gelatinas, manteiga de amendoim e marshmallow) é aquele que possui característica de líquido viscoso com propriedades elásticas e de um sólido com propriedades viscosas, ou seja, possui propriedades elásticas e viscosas acopladas. Esta substância quando submetida à tensão de cisalhamento sofre deformação e quando esta cessa, ocorre uma certa recuperação da deformação sofrida. Um modelo que descreve este tipo de comportamento é o modelo de maxwell. Por exemplo, os pesquisadores Xinmai Yang e Charles C. Church em seu artigo propuseram um modelo viscoelástico para o caso da dinâmica de microbolha [142].

Os fluidos que apresentam o comportamento de variar as suas propriedades com o tempo de aplicação da tensão, para uma velocidade de cisalhamento constante são os Tixotrópicos (exemplos: suspensões concentradas, emulsões, soluções protéicas, petróleo cru, tintas, ketchup), este tipo de fluido tem sua viscosidade diminuída com o passar do tempo de aplicação da tensão de cisalhamento, voltando a ficar mais viscosos quando a mesma cessa de atuar. Reopéticos (exemplo: argila bentonita) 
são fluidos que apresentam comportamento inverso aos tixotrópicos, assim a viscosidade deste fluido aumenta com o passar do tempo da aplicação da tensão, retornando à viscosidade inicial quando esta força cessa de atuar. No processamento mineral, esse tipo de comportamento, nas suspensões, é bastante inconveniente, devido às constantes mudanças na viscosidade [38].

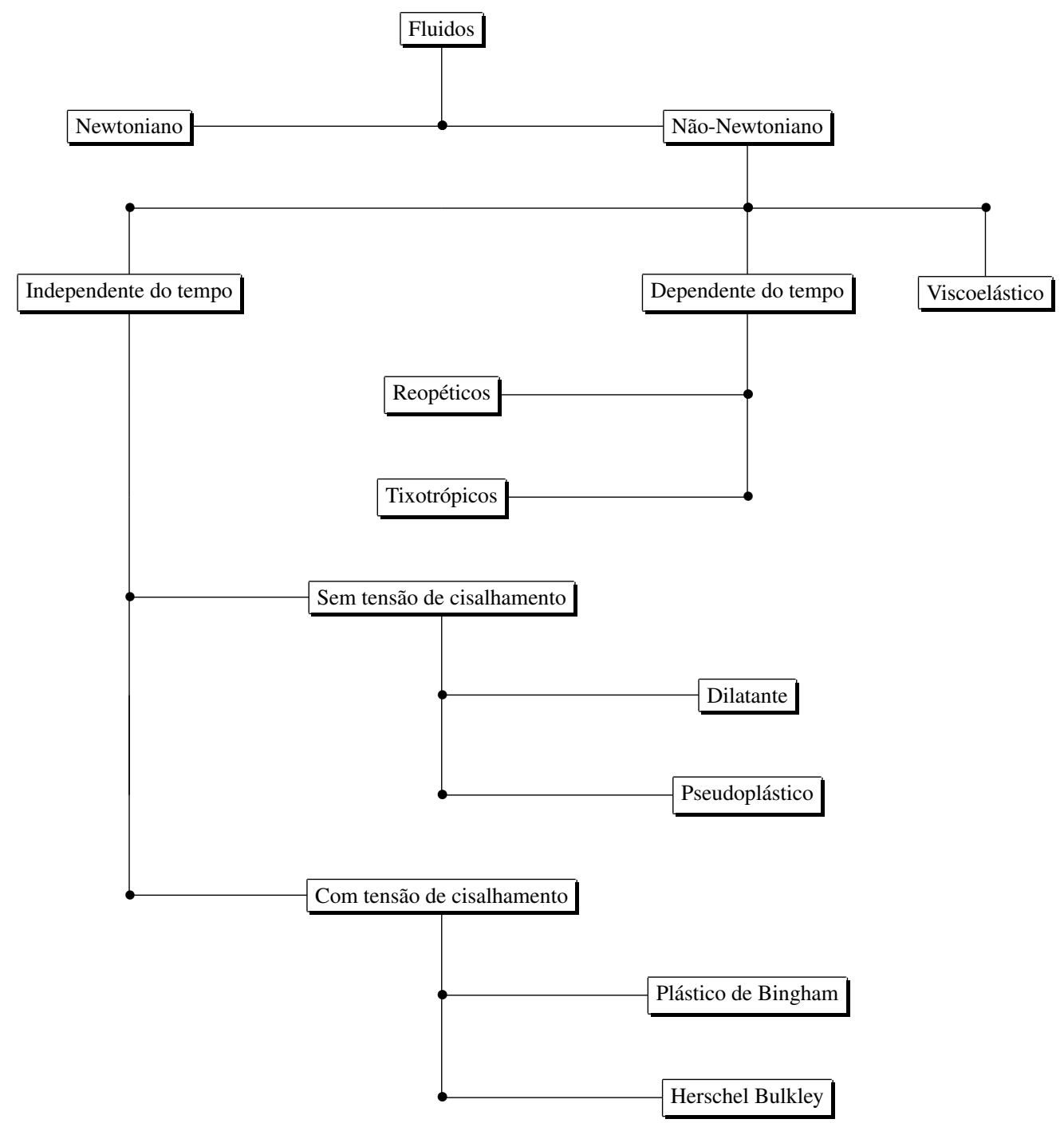

Figura B.1: Diagrama de classificação reológico, adaptado de [14].

Os fluidos ditos Dilatantes (exemplos: suspensões de amido, soluções de farinha de milho e açúcar, lama, silicato de potássio e areia) são aqueles que apresentam um aumento da viscosidade aparente em função da tensão de cisalhamento, ou seja a viscosidade aumenta com aumento da taxa de cisalhamento [38]. Os fluidos deste tipo podem ser modelados pelo modelo Power Law.

Já os fluidos tipo Pseudoplásticos (exemplos: polpa de frutas, caldos de fermentação, melaço de cana e sangue) são substâncias que, em repouso, apresentam suas moléculas em um estado desordenado, e quando submetidas a uma tensão de cisalhamento, suas moléculas tendem a se orientar na 
direção da força aplicada. E quanto maior esta força, maior será a ordenação e, consequentemente, menor será a viscosidade aparente [38]. Dentro da categoria dos escoametos não-newtonianos, os pseudoplásticos podem ser considerados como os mais abundantes na natureza. Caracterizam-se por apresentar uma relação decrescente entre a viscosidade aparente e a taxa de deformação, podendo exibir viscosidade constante quando o fluido encontra-se submetido a baixas ou altas taxas de deformação. Este fluido pode ser modelado pelo modelo de Ostwald-de-Waele ou modelo Power Law, Sisko e o modelo de Carreau [14]. Os modelos de Prandtl-Eyringe, Ellis, Reiner-Philippoff também podem ser utilizados para modelar este tipo de fluido.

O fluido tipo Plástico de Bingham (exemplos: fluidos de perfuração de poços de petróleo, algumas suspensões de sólidos granulares) apresenta uma relação linear entre a tensão de cisalhamento e a taxa de deformação e o tipo Herschel-Bulkley (exemplo: iogurte, purê de tomate e mel de flora silvestre), também denominado Bingham generalizado, é aquele cuja relação funcional entre a tensão de cisalhamento e a taxa de deformação é do tipo não linear. Eles são tipos de fluidos que necessitam de uma tensão de cisalhamento inicial para que o escoamento ocorra. Esse comportamento é característico de suspensões pseudo-homogêneas de partículas finas ou ultrafinas [38]. O pesquisador Alexandre J. de M. Queiroz et al. pesquisaram o mel de flora silvestre obtendo resultados significativos no ajuste do modelo via Herschel-Bulkley [96]. Em [105] os autores caracterizaram uma mistura sólido-líquido (água-argila caulinítica) via o modelo reológico Herschel-Bulkley. Lá, em condições controladas, eles obtiveram leis de evolução para os parâmetros em função da concentração em volume. Os resultados ficaram de acordo com o que é apontado na literatura. O modelo de Casson pode ser utilizado para descrever o comportamento do fluido tipo Herschel-Bulkley. Mattiusi et al., estudando o escoamento laminar em tubos de seção transversal elíptica, utilizou o modelo para fluido Herschel-Bulkley porquê o mesmo possuia características de dois outros fluidos também viscoplásticos, o fluido de Bingham e o Power-Law. Os resultados por eles obtidos mostraram significativa concordância com a solução analítica para o perfil de velocidade [75].

Para finalizar, a título de exemplo, uma das áreas do conhecimento que mais vem utilizando as informações reológicas das substâncias é a Ciencia dos Alimentos, a pesquisadora Juliana Tófano de Campos Leite Toneli et al. objetivaram ressaltar a importância do conhecimento das propriedades reológicas dos polissacarídeos, face à grande variedade de produtos passíveis de aplicação na indústria de alimentos e à riqueza das pesquisas desenvolvidas nesta área. Eles dissertaram em seu artigo a influência da temperatura que permitiu a substância comportamento newtoniano e pseudoplástico. Observaram também a apresentação de comportamento Herschel-Bulkley para um tipo especial de goma que mediante a influência na taxa de concentração a temperatura de $20^{\circ} \mathrm{C}$ propiciava compor- 
tamento pseudoplástico. Em seu trabalho eles concluiram que os polissacarídeos são ingredientes importantes para a formulação de alimentos, cujas propriedades físicas e químicas têm influência nas condições de processo. E o conhecimento do comportamento reológico dos polissacarídeos é essencial na formulação de alimentos [131].

Muitos tipos de relações no termo da viscosidade foram propostos, entre eles destacamos:

1. Ostwald-de-Waele, também conhecido como Power Law:

$$
\mu(\dot{\gamma})=k[\dot{\gamma}]^{\alpha-1}
$$

neste caso existem as constantes $k$ (índice de consistência) e $\alpha$ (índice de comportamento do escoamento), que podem ser ajustadas a partir de dados experimentais [94]. O modelo é utilizado para fluidos pseudoplásticos quando $\alpha<1$ e dilatantes se $\alpha>1$. Note que $\alpha=1$ o modelo newtoniano é recuperado.

\section{Cross:}

$$
\mu(\dot{\gamma})=\frac{\mu_{0}-\mu_{\infty}}{\left[1+[k \dot{\gamma}]^{\alpha}\right]}+\mu_{\infty}
$$

$k$ é uma constante com dimensões de tempo e $\alpha$ uma constante adimensional [92]. Os termos $\mu_{0}$ e $\mu_{\infty}$ são os valores assintóticos da viscosidade aparente para regiões de baixa e alta taxas de deformação respectivamente.

\section{Carraeu:}

$$
\mu(\dot{\gamma})=\frac{\mu_{0}-\mu_{\infty}}{\left[1+[k \dot{\gamma}]^{2}\right]^{\frac{\alpha}{2}}}+\mu_{\infty}
$$

também tomado como uma ponderação entre os valores assintóticos da viscosidade aparente para regiões de baixa e alta taxas de deformação [65]

\section{First-Order:}

$$
\mu(\dot{\gamma}, T)=\mu_{0}[\dot{\gamma}]^{\alpha-1} \exp (-b T)
$$

com $b$ e $\alpha$ constantes e $T$ a temperatura

\section{Barus/Cross:}

$$
\mu(\dot{\gamma}, p)=\left\{\mu_{\infty}+\frac{\mu_{0}-\mu_{\infty}}{\left(1+(k \dot{\gamma})^{\alpha}\right)}\right\} \times \exp (\alpha p)
$$

que consiste da combinação entre a lei de Barus (que modela o efeito da pressão sobre a viscosidade) e o modelo Cross. Sendo que $k=\exp (\bar{\alpha} p+E), \operatorname{com} \mu_{0}, \mu_{\infty}, \alpha, \bar{\alpha}$ e $E$ estimados via dados experimentais. O parâmetro $\alpha$ controla a dependência do platô de baixa taxa cisalhante sobre a pressão, enquanto que $\bar{\alpha}$ controla o cisalhamento fino sobre a pressão [92]. 


\section{Herschel-Bulkley:}

$$
\tau=\tau_{0}+K \dot{\gamma}^{n}
$$

onde $\tau$ é a tensão de cisalhamento, $\tau_{0}$ é a tensão crítica (rigidez inicial), $K$ é a viscosidade plástica, $\dot{\gamma}$ é a taxa de deformação por cisalhamento e $n$ o índice de escoamento [40] [110]. Conforme a tabela B.1 temos variações no comportamento reológico do fluido estudado.

\begin{tabular}{c|c|c|c}
$K$ & $n$ & $\tau_{0}$ & Comportamento \\
\hline$>0$ & $(0, \infty)$ & $>0$ & Herschel-Bulkley \\
$>0$ & $(0, \infty)$ & 0 & Power-Law \\
$>0$ & 1 & 0 & Newtoniano \\
$>0$ & $(0,1)$ & 0 & Pseudoplástico \\
$>0$ & $(0, \infty)$ & 0 & Dilatante \\
$>0$ & $(1, \infty)$ & $>0$ & Plástico de Bingham
\end{tabular}

Tabela B.1: Tabela de comportamento reológico em função dos parâmetros.

Os modelos acima (no contexto do modelo newtoniano generalizado) podem dar excelentes resultados para escoamentos cisalhantes, mas o mesmo não poderia ser verdade para outros tipos de escoamentos, onde a elasticidade pode ser importante [92]. Desta forma outros tipos de relações funcionais deram origem a vários modelos, por exemplo para fluidos viscoelásticos alguns deles são:

\section{Oldroyd B:}

$$
\mathbf{T}+\lambda_{1} \stackrel{\nabla}{\mathbf{T}}=\mu_{0}\left(\mathbf{D}+\lambda_{2} \stackrel{\nabla}{\mathbf{D}}\right)
$$

onde $\mathbf{T}$ é o tensor tensão-extra, $\stackrel{\nabla}{\mathbf{T}}=\frac{\partial \mathbf{T}}{\partial t}+(\mathbf{u} . \nabla) \mathbf{T}-(\nabla \mathbf{u})^{T} \mathbf{T}-\mathbf{T}(\nabla \mathbf{u}), \lambda_{1}$ e $\lambda_{2}$ são os tempos de relaxação e retardo característicos para o fluido, $\mu_{0}$ a viscosidade e $\mathbf{D}$ o tensor taxa de deformação [129].

\section{PTT:}

$$
f(t r(\mathbf{T})) \mathbf{T}+\lambda \stackrel{\nabla}{\mathbf{T}}=\mu \mathbf{D}
$$

T é o tensor tensão-extra, $\lambda$ é o tempo de relaxação, $\mu$ a viscosidade e $\mathbf{D}$ o tensor taxa de deformação [4].

\section{Maxwell:}

$$
\mathbf{T}+\lambda_{1} \stackrel{\nabla}{\mathbf{T}}=\mu_{0} \mathbf{D}
$$

note que este modelo é o Oldroyd B, equação B.7, $\operatorname{com} \lambda_{2}=0$. 
Para detalhes sobre mais informações de modelos reológicos o leitor pode reportar-se a bibliografia [34] e [49] que tratam de problemas e modelos viscoplásticos, suspensões coloidais e da birefrigerância. Já na bibliografia [98] existe uma ampla quantidade de informações sobre a teoria de escoamentos plásticos, a lei geral do escoamento da matéria, teoria matemática da dilatância entre outros. 